\title{
THE DIRECT JOINT PROBABILITY METHOD FOR ESTIMATING EXTREME SEA LEVELS
}

\author{
by \\ JOAN C. H. LIU \\ B. A. Sc., The University of British Columbia, 2002 \\ A THESIS SUBMITTED IN A PARTIAL COMPLETION OF THE \\ REQUIREMENTS FOR THE DEGREE OF THE \\ MASTERS OF APPLIED SCIENCE \\ in \\ THE FACULTY OF GRADUATE STUDIES \\ (Department of Civil Engineering) \\ We accepted this thesis as conforming to the required standard
}

\author{
THE UNIVERSITY OF BRITISH COLUMBIA \\ August 2004 \\ CJoan C. H. Liu, 2004
}


THE UNIVERSITY OF BRITISH COLUMBIA

FACULTY OF GRADUATE STUDIES

Library Authorization

In presenting this thesis in partial fulfillment of the requirements for an advanced degree at the University of British Columbia, 1 agree that the Library shall make it freely available for reference and study. I further agree that permission for extensive copying of this thesis for scholarly purposes may be granted by the head of my department or by his or her representatives. It is understood that copying or publication of this thesis for financial gain shall not be allowed without my written permission.

JOAN C.H. LU

Name of Author (please print)



Title of Thesis: The Direct Joint Probability Method for Estimating
Extreme sea Levels.

Degree:

m. A. Sc.

Year: 2004

Department of Civil Engineering

The University of British Columbia Vancouver, BC Canada

grad.ubc.calforms/?formiD= THS

page 1 of 1

last updated.20=1intod 


\section{ABSTRACT}

The design of coastal structures includes the key element of estimating crest elevation. A crest height designed to protect against specified return periods avoids damages due to overflowing and overtopping. In order to avoid overflowing, the design sea levels should be at least at the design flood level, also referred to as the extreme flood level, which is usually composed of tides and storm surges. The extreme flood level can be determined by several approaches, such as the Annual Maxima, Simple Addition, Joint Probability, and Revised Joint Probability Methods. These methods have various limitations in terms of the required amount of data, the representation of contributing factors in sea level fluctuations, the ability to assess the joint probability of these factors, and the degree of independence required of the data. To minimize overtopping, in addition to considering tides and storm surges, the design sea levels should also include wave run-up. The design sea level, also referred to as the extreme sea level, includes the effects of tides, storm surges, and wave run-up. Wave run-up estimates are generally based on the design flood level and design wave climate, data for which are often dependent. This thesis develops the Direct Joint Probability Method for estimating extreme sea levels which simultaneously considers tides, storm surges, and wave run-up. This method has fewer limitations than the previously mentioned methods in terms of the assumption of independent variables and the required amount of data. Data for the City of Richmond, British Columbia, 'Canada, are used to demonstrate the Direct Joint Probability Method, and results show that the method provides a reasonable estimate of extreme sea levels, that is, the resulting estimates are within the same range as other traditionally applied methods. The results also indicate a large difference between design sea levels required for preventing overflowing and those for preventing overtopping. The sea levels at Richmond are also increasing due to the 
climatic and geologic effects. A hybrid of the Direct Joint Probability and the Simple Addition Methods is also applied in this thesis and is used to estimate extreme sea levels for regions facing long-term increases in sea levels. The results of the hybrid approach indicate that the contribution to extreme sea level due to wave run-up increases with long-term increases in sea levels. This can dramatically affect estimates of extreme sea levels. 


\section{TABLE OF CONTENTS}







LIST OF FIGURES …................................................................................................. vii

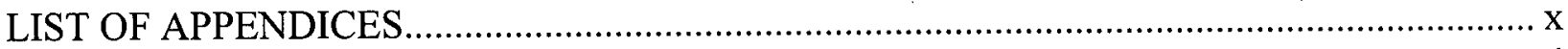



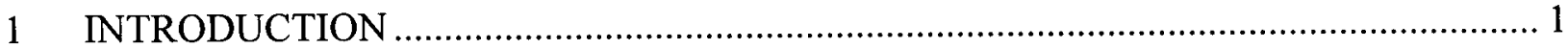

2 COASTAL STRUCTURES AND FLUCTUATIONS IN SEA LEVELS............................. 6

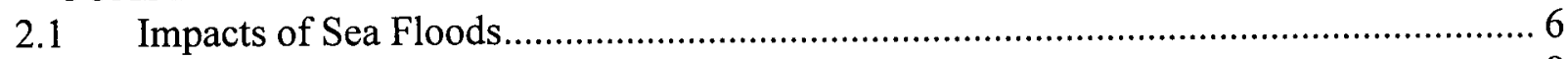



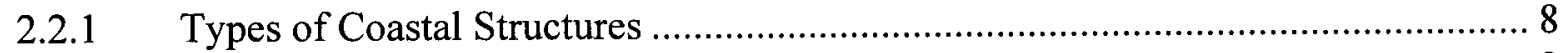







2.2.2 Modes and Consequences of Failures ................................................................ 11



2.2.2.2 Instability of Outer Slope ............................................................................. 13

2.2.2.3 Instability of Inner Slope ………............................................................ 13



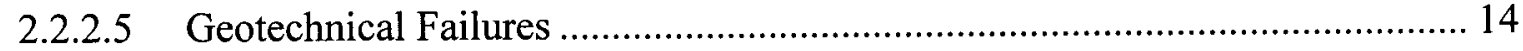

2.2.3 Design of Coastal Structures ........................................................................... 15

2.2.3.1 Crest Elevation.................................................................................. 17



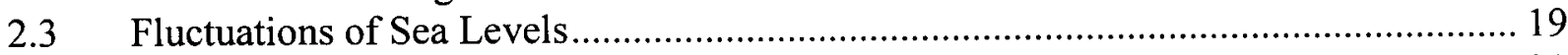



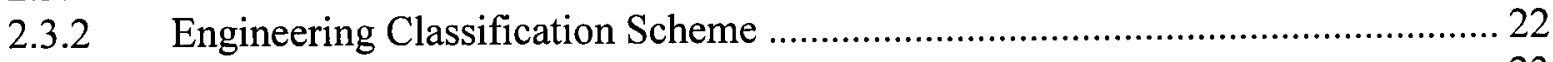





2.3.3.2 Statistical Analysis of Waves ........................................................................ 24

2.3.3.2.1 Statistical Analysis of Wave Height and Period....................................... 25

2.3.3.2.2 Wave Spectrum Analysis of Wave Height and Period............................... 26





2.3.4.1 Generation of Storm Surges............................................................................. 29

2.3.4.2 Characteristics of Storm Surges.................................................................... 30

2.3.4.3 Estimation of Storm Surges ........................................................................ 30

2.3.4.3.1 Indirect Measurement of Storm Surges ....................................................... 30

2.3.4.3.2 Numerical Models of Storm Surges ………............................................. 31





2.3.5.2 Characteristics of Tides ......................................................................................... 33

2.3.5.3 Measurements of Tides and Establishment of Datum ....................................... 34

2.3.5.4 Prediction of Astronomical Tides ......................................................................... 35

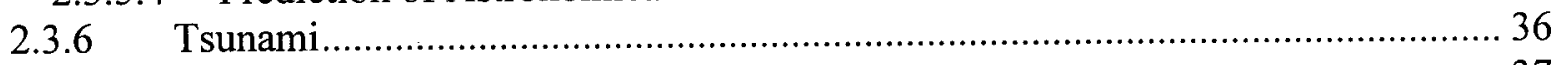



2.3.6.2 Characteristics of Tsunami ......................................................................... 38 


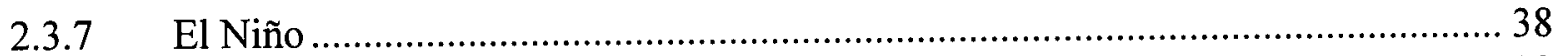

2.3.8 Climatologic and Geologic Effects ………........................................................ 39

3 QUANTITATIVE METHODS FOR ESTIMATING EXTREME CONDITIONS............. 50

3.1 Methods for Estimating Flood Levels ……………..................................................... 50

3.1.1 Probability of Exceedance and Return Period ..................................................... 51

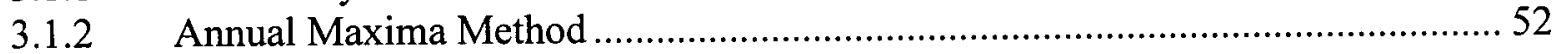

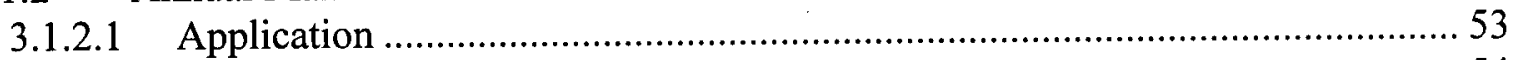

3.1.2.2 Data Requirements................................................................................. 54

3.1.2.3 Assumptions ......................................................................................... 55

3.1.2.4 Advantages and Disadvantages .................................................................. 56

3.1.3 $R$-Largest Maxima Method ................................................................................... 56

3.1.3.1 Advantages and Disadvantages ………….................................................. 58

3.1.4 Simple Addition Method...................................................................................... 58

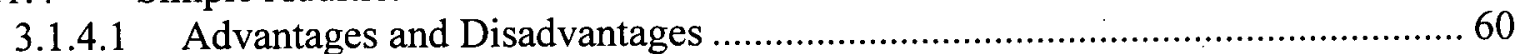

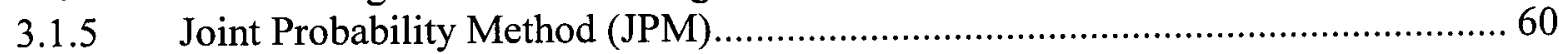

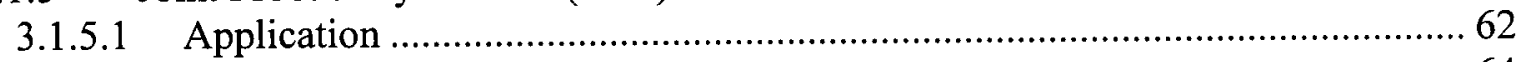

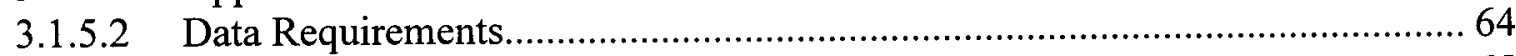

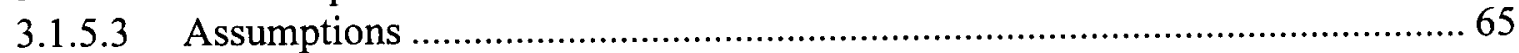



3.1.6 Revised Joint Probability Method (RJPM) ..........................................................6 67

3.1.6.1 Advantages and Disadvantages .......................................................................6 68



3.2.1 Long-Term Distribution of Sea States ................................................................ 70

3.2.2 Long-Term Distribution of Individual Wave Height ................................................ 70

3.3 Joint Probability of Flood Levels and Extreme Wave Conditions ............................... 71

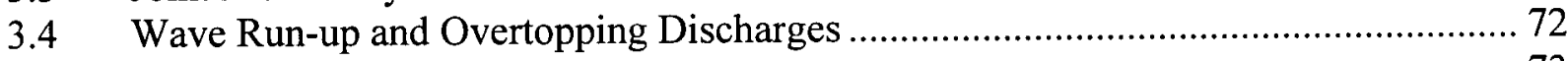

3.4.1 Wave Transition in Shallow Water................................................................... 73

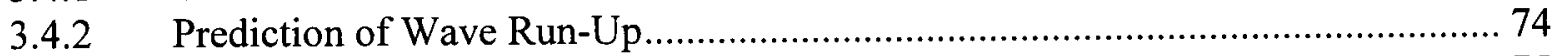

3.4.2.1 Shore Protection Manual (SPM) Method ……………………....................... 75

3.4.2.2 Van Der Meer-Janssen (VDMJ) Method......................................................... 77

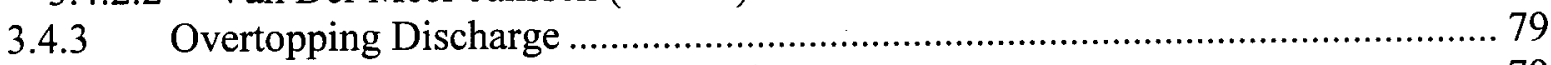

3.4.3.1 Estimation of Overtopping Discharges......................................................... 79

3.4.3.1.1 Shore Protection Manual (SPM) Method .................................................. 80

3.4.3.1.2 Van Der Meer (VDM) Method .............................................................. 81

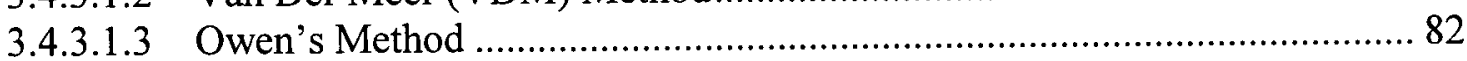

3.4.3.1.4 Comparison of Methods for Predicting Overtopping Discharges .............. 83

3.4.3.2 Allowable Overtopping Discharge .................................................................. 84

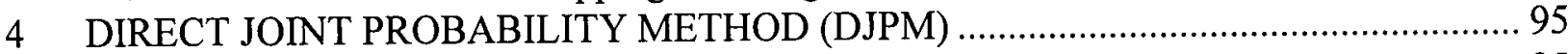

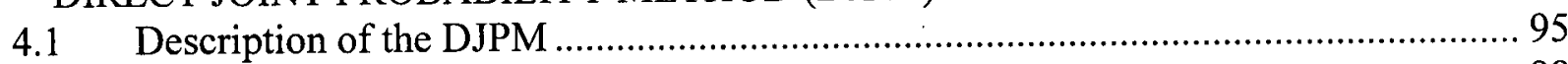

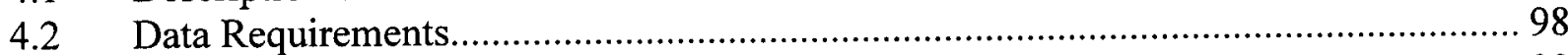

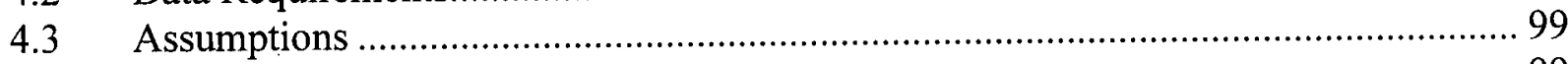

4.4 Advantages and Disadvantages .............................................................................. 99

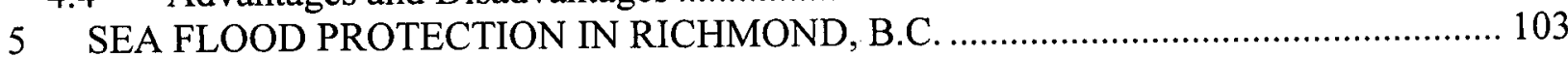

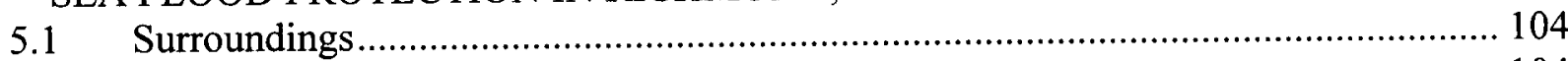

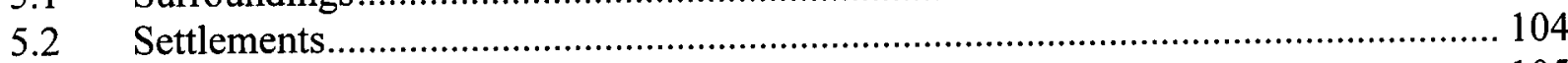

5.3 Flood Concerns............................................................................................... 105

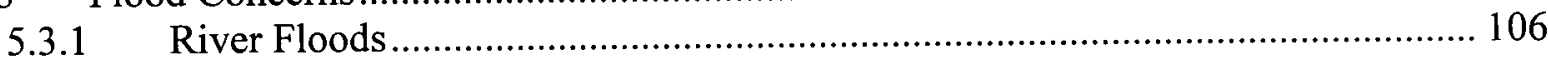

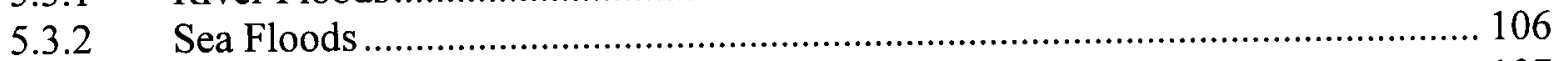

5.3.3 Excessive Amount of Rain............................................................................... 107 


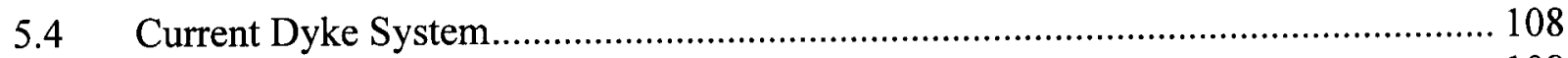

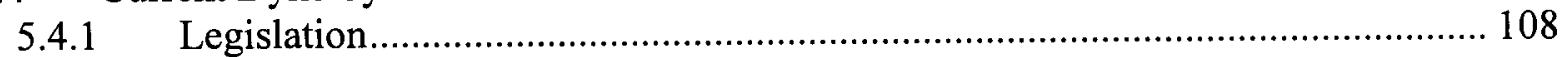

5.4.2 Description of the Dyke System ...................................................................... 109

5.4.3 Dyke Maintenance Program.............................................................................. 110

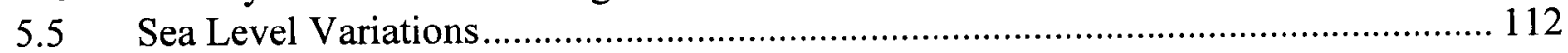

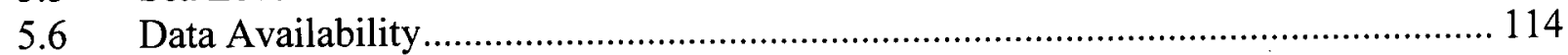

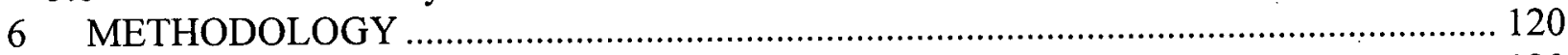

6.1 Input Parameters ................................................................................................. 120

6.2 Assessment of the DJPM for Estimating Extreme Flood Levels ............................... 123

6.2.1 Application of the DJPM for Estimating Extreme Flood Levels........................ 123

6.2.2 Application of the Annual Maxima Method for Estimating Extreme

Flood Levels........................................................................................................ 124

6.2.3 Application of the Simple Addition Method for Estimating Extreme

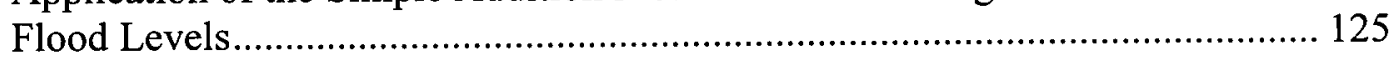

6.3 Estimating Extreme Sea Levels for Richmond.......................................................... 126

6.3.1 Application of the DJPM for Estimating Extreme Sea Levels ........................... 126

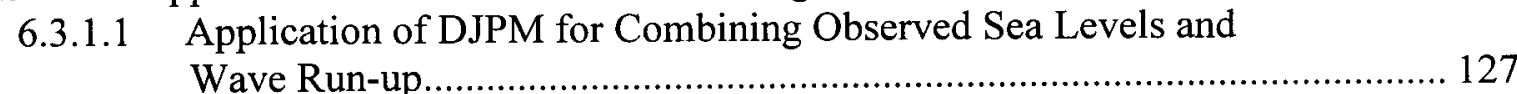

6.3.1.2 Application of DJPM for Combining Tides, Storm surges, and Wave run-up .............................................................................................. 129

6.3.2 Application of the Hybrid of the DJPM and Simple Addition Method for Combining Tides, Storm surges, Wave Run-up, and Long-term Sea

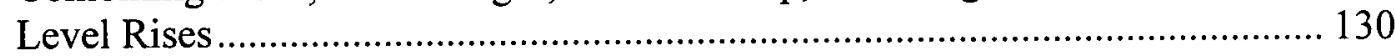

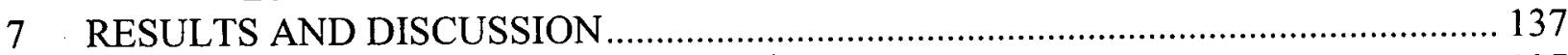

7.1 Assessment of the Direct Joint Probability Method .................................................... 137

7.1.1 Estimation of Extreme Flood Levels Using the Direct Joint

Probability Method ............................................................................................ 137

7.1.2 Estimation of Extreme Flood Levels Using the Annual Maxima Method .......... 138

7.1.3 Estimation of Extreme Flood Levels Using the Simple Addition Method .......... 139

7.1.4 Assessment of the Direct Joint Probability Method for Estimating Extreme

Flood Levels................................................................................................ 139

7.2 Estimation of Extreme Sea Levels using the DJPM and Hybrid DJP-Simple

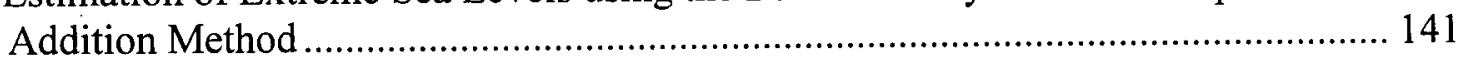

7.2.1 Estimations of Extreme Sea Levels Using the Direct Joint

Probability Method ............................................................................................... 141

7.2.1.1 DJPM Application to Observed Sea Levels and Wave Run-up ...................... 141

7.2.1.2 DJPM Application to Tides, Storm Surges, and Wave Run-up ..................... 142

7.2.2 Hybrid DJP-Simple Addition Method Application to Tides, Storm Surges, Wave Run-up, and Long-term Sea Level Changes ....................................................... 143

7.2.3 Discussion of the Estimations of Extreme Sea Levels for Richmond ................. 143

7.3 Sources of Error for Estimates of Extreme Flood and Sea Levels ............................... 145

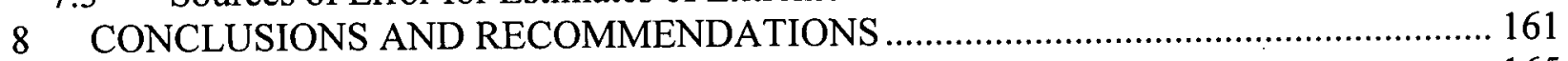

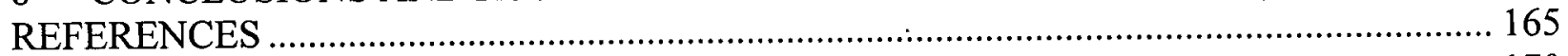

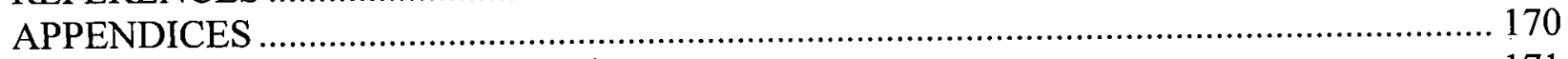

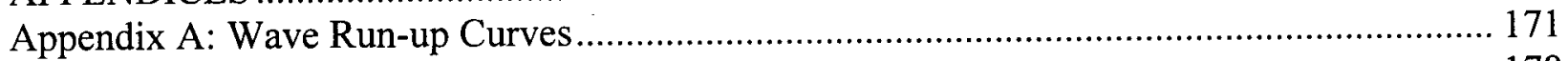

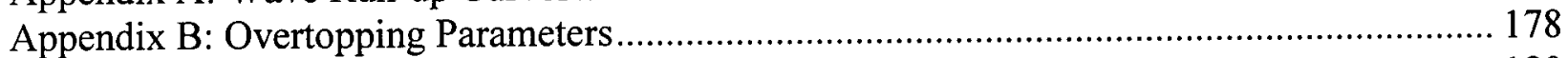

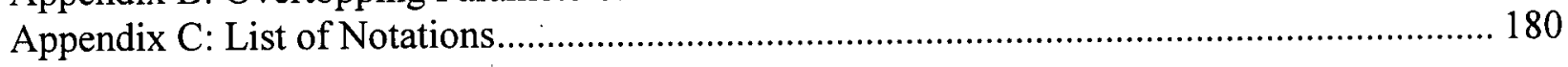




\section{LIST OF TABLES}

Table 2.1 Sea Flood Historical Events

Table 2.2 Design Considerations and Critical Modes of Failure of Revetments from

Pilarczyk (2000)

Table 2.3 Characteristics of Waves from Thomson (1981) and Sorensen (1997)........................ 44

Table 2.4 Saffir-Simpson Hurricane Damage Potential Scale from Abbott (1999) ..................... 44

Table 2.5 Storm Surge Models Developed for Use in the Public Domain from Reid (1990)...... 44

Table 3.1 Plotting Position Formulas from Watt et al. (1989), and Rao and Hamed (2000) ....... 85

Table 3.2 Value of $\gamma_{\mathrm{f}}$ for Various Slope Surface Characteristics from CERC (1984) .................. 85

Table 3.3 Reduction Factor $\gamma_{\mathrm{f}}$ for Rough Slope from Besley and Allsop (2000).........................8 86

Table 3.4 Reduction Factor $\gamma_{\mathrm{f}}$ for Rough Slope from Pilarczyk (2000) .....................................86

Table 3.5 Reduction Factor $\gamma_{\mathrm{f}}$ for Rough Slope from Headland et al. (2000)............................. 86

Table 3.6 Empirical Coefficients for Smooth Impermeable Simple Sloping Coastal

Structures from Besley and Allsop (2000) .................................................................... 86

Table 3.7 Tolerable Mean Discharge ( $\mathrm{m}^{3} / \mathrm{s}$ per meter run) from Besley and Allsop (2000) ....... 87

Table 5.1 Data Availability.............................................................................................. 116

Table 6.1 Description of the Quality Codes from Marine Environment Data Service

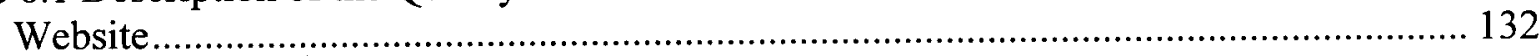

Table 7.1 Two-Dimensional Histogram of Tides and Storm Surges.......................................... 149

Table 7.2 Screened Annual Maxima Series of Observed Sea Levels.......................................... 150

Table 7.3 Summary of Estimates of Extreme Flood Levels ....................................................... 151

Table 7.4 Summary of Estimates of Extreme Sea levels........................................................... 151

Table 7.5 Summary of Estimates of Extreme Sea Levels under Different Propagation

Angles.

Table 7.6 Summary of the Estimates of Extreme Sea Levels Projected for Different Years

based on Long-Term Sea Level Changes. 152 


\section{LIST OF FIGURES}

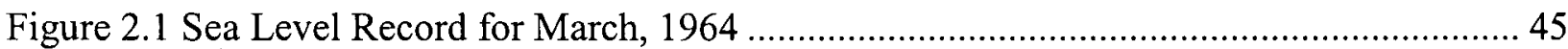

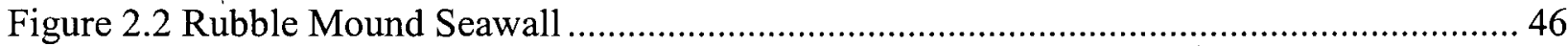

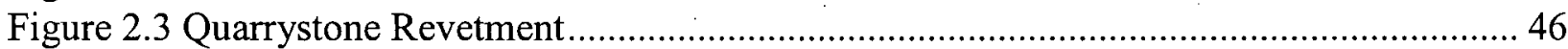

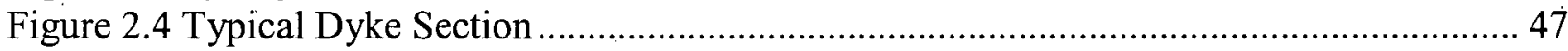

Figure 2.5 Flowchart of Design Process for Revetments ......................................................... 47

Figure 2.6 Scientific Classification of Factors Affecting Sea Level Fluctuations ....................... 48

Figure 2.7 Engineering Classification of Factors Affecting Sea Level Fluctuations ................... 48

Figure 2.8 Deep-water Significant Wave Height and Period Monogram ................................. 49

Figure 3.1 Example of Two-Dimensional Histogram for the JPM ............................................. 88

Figure 3.2 Waves in Deep Water and Waves in Shallow Water ................................................ 88

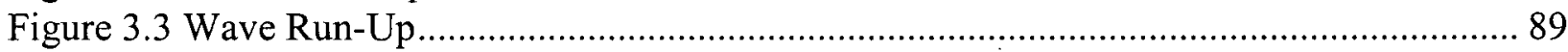

Figure 3.4 Wave Run-Up on Smooth, Impermeable Slopes on a 1:10 Bottom

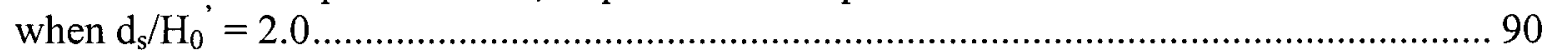

Figure 3.5 Wave Run-Up Correction for Scale Factor ............................................................. 91

Figure 3.6 Definition of the Angle of the Wave Attack ............................................................. 92

Figure 3.7 Overtopping Parameters $\alpha$ and $\mathrm{Q}_{0}{ }^{*}$ for Riprapped and 1:1.5 Structure Slope ........... 93

Figure 3.8 Suggested Limits for Overtopping Discharges ....................................................... 94

Figure 4.1 Example of Two-Dimensional Histogram ....................................................... 100

Figure 4.2 Example of Three-Dimensional Histogram ............................................................ 100

Figure 4.3 Flow Diagram of DJPM for Combining of Tides, Surges, and Wave Run-up ......... 101

Figure 4.4 Example of the Result of the Direct Joint Probability Method for Two

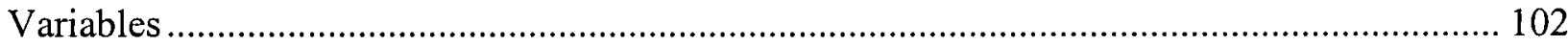

Figure 4.5 Example of the Result of the Direct Joint Probability Method for Three Variables. 102

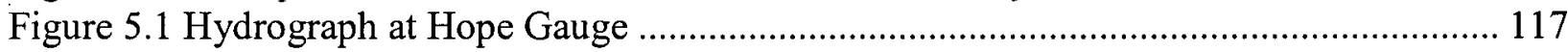

Figure 5.2 Standard Cross Section of the Dyke System............................................................ 117

Figure 5.3 Flood Protection Features in Richmond................................................................. 118

Figure 5.4 Sea Dyke of Richmond a) Looking North b) Looking toward West ........................ 118

Figure 5.5 Map of Gauge Stations near Richmond .............................................................. 119

Figure 6.1 Long-term Trend of Sea Levels at Point Atkinson ................................................... 133

Figure 6.2 Construction Drawing at West End of Blundell Road in 1974 ............................... 133

Figure 6.3 Flow Diagram of the DJPM for Combining Observed Sea Levels and

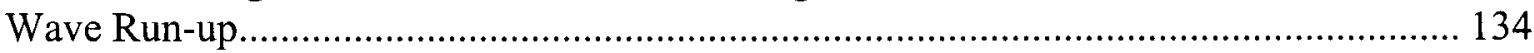

Figure 6.4 Flow Diagram of the DJPM for Combining Tides, Storm Surges, and

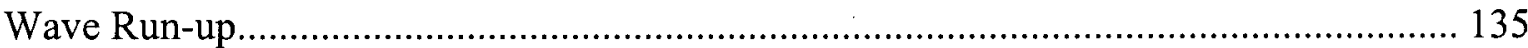

Figure 6.5 Flow Diagram of the Hybrid of the DJPM and Simple Addition Method ................. 136

Figure 7.1 Estimates of Extreme Flood Levels using the DJPM for Tides and Storm Surges... 153

Figure 7.2 Estimates of Extreme Flood Levels using the Annual Maxima Method ................... 154

Figure 7.3 Estimates of Extreme Flood Levels using the Simple Addition Method for

Tides and Storm Surge.

Figure 7.4 Estimates of Extreme Sea Levels Using the DJPM for Observed Sea Levels and

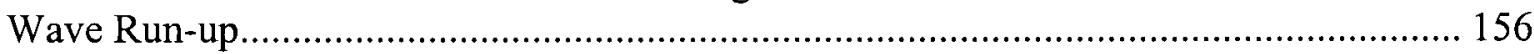

Figure 7.5 Estimates of Extreme Sea Levels Using the DJPM for Tides, Storm Surges, and

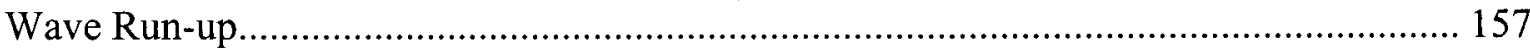

Figure 7.6 Estimates of Extreme Sea Levels using DJPM for Tides, Storm Surges, and

Wave Run-up with Angle Reduction Factor .............................................................. 158

Figure 7.7. Estimates of Extreme Sea Levels Using the Hybrid DJP-Simple Addition 
Method...

159

Figure 7.8 Estimates of Extreme Flood and Sea Levels using Different Methods..................... 160 


\section{LIST OF APPENDICES}

\section{Appendix A}

A 1. Wave Run-up Curve for $d_{s} / H_{0}^{\prime}=0$ on a 1:10 Bottom Slope from CERC (1984)........... 171

A 2. Wave Run-up Curve for $d_{s} / H_{0}^{\prime} \approx 0.45$ on a 1:10 Bottom Slope from CERC (1984)...... 172

A 3. Wave Run-up Curve for $d_{s} / H_{0}^{\prime} \approx 0.8$ on a 1:10 Bottom Slope from CERC (1984)....... 173

A 4. Wave Run-up Curve for and $d_{s} / H_{0}^{\prime} \geq 3.0$ on a 1:10 Bottom Slope from CERC (1984).. 174

A 5: Wave Run-up Curve for $d_{s} / H_{0}^{\prime}=3$ on a Horizontal Bottom from CERC (1984) ........... 175

A 6. Wave Run-up Curve of $d_{s} / H_{0}^{\prime}=5$ on a Horizontal Bottom from CERC (1984) ............ 176

A 7. Wave Run-up Curve for $d_{s} / H_{0}^{\prime}=8$ on a Horizontal Bottom from CERC (1984) ............ 177

\section{Appendix B}

B 1. Overtopping Parameters for a Smooth Vertical Wall on a 1:10 Bottom Slope from CERC (1984).

B 2. Overtopping Parameters for a 1:10 Structure Slope on a 1:10 Bottom Slope from CERC (1984). 


\section{ACKNOWLEDGEMENTS}

I would like to express my gratitude to those who made this master thesis possible.

- NSERC and UBC Flood Fund, for providing the financial support to complete this degree.

- Dr. Barbara Lence of the Department of Civil Engineering at UBC, supervisor, for providing valuable comments and constant reviewing of my thesis, and spending all those weekends to work with me.

- Dr. Michael Isaacson of the Department of Civil Engineering at UBC, supervisor, for providing his expertise in coastal engineering, and providing stimulating suggestions and encouragement.

- Yaroslav Shumuk of UMA Engineering, Dr. Sheng Li of the Department of Civil Engineering at UBC, and Scott Thomlinson of MEDS, for their technical assistance which is vital for the research.

- David Brownlee and Terry Crowe of the City of Richmond, for giving me permission to use the Richmond data in my thesis and giving me an opportunity to work on this interesting subject.

- Family members, Yin-Yen Liu, Grace Liu, Christina Liu, Thomas Liu, and Joseph Liu, for their supports and encouragement in difficult times.

- Friends, especially Wayne Lo and David Roche, for all their help, support, interest, and valuable hints.

- Finally, Kevin Chen, for his patient love which enables me to complete my thesis. 


\section{INTRODUCTION}

While coastal areas provide the convenience of transportation and abundance of natural resources, ocean water may threaten the safety of coastal residents because natural beaches may be too narrow and too rapidly eroded to provide adequate protection from extreme waves and water levels. Numerous natural disasters related to sea floods in the maritime areas have been recorded worldwide. The impacts of sea floods are usually significant as such events have relatively short warning periods. The devastating loss of lives and damage to property resulting from sea floods have led maritime countries to build coastal protection structures including seawalls, revetments, and dykes along the shoreline as the primary defence against sea floods.

One of the key design considerations of such systems is the crest elevation. Engineers and scientists have sought to better understand causes of extreme sea conditions in coastal areas and to better estimate these for setting appropriate standards for crest elevation of coastal structures. To date, many lessons have been learned from European practices as countries such as the Netherlands are considered the leaders in coastal engineering. This thesis develops a modification of the Joint Probability Method (JPM), the Direct Joint Probability Method (DJPM), to estimate extreme sea levels. The DJPM requires fewer assumptions and enables a broader range of applications than existing methods for estimating flood and sea levels. An example application of the method, based on the City of Richmond, British Columbia (B.C.), locating in western Canada, is also provided.

Initially, coastal protection systems were designed based on previous extreme events, such as the highest storm surge observed. However, the growing importance of these coastal systems, due to the increasing number of communities and facilities in coastal areas, has led to improvements in the design of coastal structures based on more robust estimates of extreme sea 
conditions that have a given likelihood of occurrence. Instead of using historical events directly, extreme sea conditions are predicted in order to select a crest elevation that is able to protect against potential future events. The estimation of extreme sea conditions involves three major steps: 1) identification of the critical factors of extreme sea conditions, 2) investigation of various approaches for assessing and combining these factors, and 3) estimations of design sea levels including extreme flood and sea levels.

Oceanographers have studied the characteristics of sea level fluctuations and have identified components of extreme conditions. These components include extreme flood levels and extreme wave conditions. The components of extreme flood levels include storm surges, astronomical tides, and tsunami; however, extreme flood level estimates exclude the influence of waves on sea levels. In addition to flood levels, wave conditions can also cause various degrees of damage to coastal structures, and thus extreme wave conditions are integrated in estimates of extreme sea levels. Nevertheless, controversy exists regarding the inclusion of the wave climate because the damage caused by waves may be small. While most design manuals suggest the use of wave run-up to represent the impact of waves on coastal structures, several recent studies focus on the identification of allowable overtopping discharges in assessing extreme sea levels. In those studies, the identified allowable overtopping discharges are used as a basis for selecting design extreme sea levels.

After selecting the critical components of extreme flood and sea levels and assessing the available data, the extreme flood and sea levels may be estimated with various methods. Traditionally, the Annual Maxima Method is applied to estimate the extreme flood levels. However, this method requires a data set collected over a long period of time, and cannot distinguish among the different components of extreme flood levels. Although the $R$-Largest Maxima Method improves upon the Annual Maxima Method, it cannot treat the extreme flood levels as a function of a number of distinct components. The Simple Addition Method allows 
for the representation of the different components of extreme flood and sea levels, but it cannot associate the estimates with an actual joint probability of these components. Two additional methods developed to estimate extreme flood levels are the JPM and the Revised Joint Probability Method (RJPM). These two methods estimate the extreme flood levels as a function of various components with distinct probabilities of occurrence. They are based on the assumptions that tides and storm surges are independent, and that the probability density function for storm surges over a limited time period represents the probability density function for the population of all possible storm surges. The first assumption of having independent components limits the applications of these approaches, because the factors causing the fluctuations of water levels are rarely independent of each other. The DJPM is developed in this research to overcome this limitation. The DJPM finds the extreme flood and sea levels with associated probabilities of exceedance by evaluating the function of the joint probabilities of the various components of the extreme flood and sea levels, respectively. The joint probabilities of the various components are obtained by constructing a multi-dimensional histogram for the discrete ranges of the data for each component, where the dimensions of the histogram correspond to the number of components considered. This method is applied in the case of Richmond, B. C., Canada.

The City of Richmond, B. C., Canada is a part of the delta region located along the Pacific Coast and faces potential threats of sea floods due to its low elevation relative to sea levels. The City has perimeter dyke systems for both Lulu and Sea Islands. The current crest elevation of dykes and revetments used in these systems has been constructed to meet design flood level standards plus freeboard. A lack of data available for predicting extreme conditions has lead to the use of historical extreme events to define the design flood level. Whether or not an increase in the crest elevation is necessary is a question that has been raised during the recent strategic flood planning for the City. To respond to this question, a reassessment of the extreme flood and 
sea levels is required. The estimation of the extreme sea levels for Richmond requires the identification of the critical components contributing to sea level fluctuations and an assessment of the available data. The critical components include tides, storm surges, wave run-up, and long-term sea level increases, and various types of data related to these are available at nearby locations. The DJPM is an ideal approach for estimating extreme sea levels of a complex situation such as the Richmond case, because it is able to estimate the extreme sea levels composed of tides, storm surges, and wave run-up. Although the Annual Maxima Method and Simple Addition Method can only estimate the extreme flood levels composed of tides and storm surges, they are also applied herein in order to assess the representativeness of the DJPM. Resulting sea level fluctuations due to increases in long-term sea levels are also assessed using a hybrid of the DJPM and the Simple Addition Method.

The objectives of this thesis are to:

1. investigate the various causes of variations in sea levels,

2. explore options for estimating extreme sea conditions including extreme flood levels and wave conditions,

3. develop and demonstrate the DJPM, a methodology for determining extreme sea levels, and

4. estimate the extreme sea levels for Richmond, B.C., in order to set the standard for this particular dyke system.

The first objective of investigating the fluctuations in sea levels is addressed in Chapter 2 with a discussion of the impacts of sea floods and the designs of coastal structures. The second objective of identifying and evaluating quantitative methods for estimating extreme conditions is addressed in Chapter 3. The DJPM is then developed in Chapter 4. Chapter 5 describes the case of Richmond, B.C. and discusses the background, variations in sea levels, and data availability. Chapter 6 presents the methodology used to estimate extreme sea levels for Richmond, and 
Chapter 7 presents the resulting design crest elevation for the Richmond case, addressing the fourth and final objective. Chapter 8 provides a summary of the thesis findings and a discussion of the recommendations based on these findings. 


\section{COASTAL STRUCTURES AND FLUCTUATIONS IN SEA LEVELS}

The first part of this chapter stresses the importance of coastal structures by reviewing a list of historical catastrophic events caused by sea floods in Section 2.1. Section 2.2 presents the types of structures used to provide a higher level of protection in coastal areas, focusing on the design processes and in particular the design crest elevation of the coastal structures. To better design the coastal structures, including the determination of the crest elevations, the understanding of ocean processes is necessary. Therefore, Section 2.3 investigates the factors that contribute to sea level fluctuations.

\section{$2.1 \quad$ Impacts of Sea Floods}

Coastal areas often attract the gathering of settlements and civilizations due to the ease of finding means of transportation and sources of food, but the dangers due to flooding increases with proximity to oceans. The records of events of sea floods and resulting damages are tangible evidence of such dangers. The impacts of sea floods can be estimated for historical events and a list of such events is presented in Table 2.1. As shown in Table 2.1, sea floods occurring at different times and locations stem from different causes and result in different degrees of damage due to differences in geological location, oceanographic characteristics, and climate systems.

Maritime countries, such as the Netherlands, India, Japan, Canada, and the United States of American (USA), have experienced the continued threats of sea floods. Among these countries, the Netherlands is the first country to develop an ongoing log of events and also one of the first countries to implement dyke systems. The earliest recorded events are in 1228 in Friesland and 1282 in Zuyder Zee, both in the Netherlands. As the elevation of the Netherlands is lower than 
the sea level, the country is more susceptible to sea floods. Although the Netherlands already implemented dykes after 1228 , storm surges in 1282 still managed to sweep the protected area. Learning gradually from such historical events, the Netherlands has built and improved the dyke systems minimizing the potential impacts of sea floods.

In addition, the historical events indicate that the common sources of major floods are storms, tsunami, and a combination of high tides and wind. For example, storms are the cause of sea floods in the events of the 1954 flood in Rhode Island, USA and the 1970 flood in Pakistan. Tsunami are among the sources that cause sea floods resulting in the greatest level of damages, and the cause of several events, for example the 1896 flood in Saniku, Japan, the 1946 and 1960 floods in British Columbia, Canada. An example of a sea flood originating by a combination of high tide and wind is the 1953 flood in Northwest Europe.

Historical events also suggest that sea levels are localized during extreme events. The 1964 event which occurred in British Columbia, Canada is of particular interest, and was caused by an earthquake in Alaska. Figure 2.1 presents the sea level records from four locations in British Columbia, including Tofino, Port Alberni, Victoria, and Point Atkinson during this event. The tsunami generated an average peak wave height of $3 \mathrm{~m}$ at Tofino and an average peak wave amplitude of $6 \mathrm{~m}$ at Port Alberni, simultaneously. Other locations also experienced higher wave run-up. Although the distance between Tofino and Port Alberni is only about $125 \mathrm{~km}$, the severity of sea floods at these sites varies to a great extent. Therefore, estimates of extreme sea levels should consider local conditions. 


\subsection{Coastal Structures}

To avoid potential damages from sea floods, coastal structures are constructed, particularly when a natural beach cannot provide adequate protection. Coastal structures are positioned relative to the shoreline according to their functions, and classified based on their relative position to the shoreline as shore-parallel and shore-perpendicular. Focusing on shore-parallel structures, Section 2.2.1 introduces different types of coastal structures. Although coastal structures serve to increase the level of protection of near shore areas from wave attacks, erosion, and sea floods, these structures are not able to completely eliminate potential damage. When a coastal structure is unable to accomplish its function, failure occurs. Section 2.2 .2 describes various failure modes, as understanding failure modes is essential to successful design of the coastal structures. Section 2.2.3 describes the design of the coastal structures.

\subsubsection{Types of Coastal Structures}

Shore-perpendicular structures, such as T-groins, offshore breakwaters, and artificial headlands, are usually used to reduce sediment transport (Headland et al., 2000). By reducing sediment transport, the shore-perpendicular structures indirectly decrease the risk of flooding, because sediment transport to the near-shore area can increase the elevation of the ocean beds, and thus increase sea levels. For example, the experience in the Netherlands suggests a trend in rising sea levels due to the increase of sediments in the ocean beds. Shore-parallel structures, such as seawalls, revetments, and dykes, are used to prevent the cross-shore movement of sand that occurs during storms and the inundation of near shore areas (Headland et al., 2000). Although both structures provide protection to the coastal areas, this section focuses on the 
shore-parallel structures, in particular sea walls, revetments, and dykes. Sea walls, revetments, and dykes possess certain similarities and are usually classified by their relative distance to the natural beach profile. Revetments and dykes are located closer to the land, whereas seawalls are located somewhat seaward of a typical dyke or revetment location (Headland et al., 2000).

\subsubsection{Seawalls}

Seawalls are massive structures built along the coastline to protect near shore areas from wave impact, erosion damage, and flooding. They are the most widely used option for coastal defence (Besley, 1999; USACE, 1995). Since seawalls are constructed closer to the sea than dykes and revetments, they are exposed to stronger waves on a near-continuous basis, such as storm waves. Thus, they are designed to be relatively massive and have higher crest elevations in order to resist the full force of storm waves. In general, seawalls are composed of an armour, base layer, filter, toe protection, filter layer, and backslope armour, as shown in Figure 2.2. The armour is used to protect the seawall from overtopping and to resist wave action without significant displacement of armour material (Besley, 1999). Two common materials for the base layer of seawalls are rubble mound, i.e., rock, and monolithic material, i.e., steel or concrete sheet pile (Headland et al., 2000). A filter is a transitional layer of gravel, small stone, or fabric placed between the underlying soil and structure to prevent the migration of fine soil particles through the voids, distribute the weight of the armour units, and permit relief of pressures within the soils (CERC, 1995). In addition, seawalls normally require extensive toe protection to prevent the occurrence of scour. According to their functions, seawalls have various face shapes including vertical, near vertical, sloping faces, stepped walls, and curved faces. 


\subsubsection{Revetments}

A revetment may be a coastal structure or a facing of erosion resistant material. This section refers to revetments as coastal structures, but they are commonly used as a facing when combined with other coastal structures. The revetment system serves a number of different functions, including the provision of protection for exposed faces of coastal flood embankments, reduction of overtopping discharges, limiting of damage to crests and rear faces, provision of erosion protection at cliff bases and around new reclamations, and provision of protection for windward faces of reservoir dams and embankments (Allsop and McConnell, 2000). Although there are cases where it is difficult to make a clear distinction between a seawall and a revetment, a revetment is generally located closer to the land than a seawall. Thus, a revetment is exposed to a lower level of wave attack than a seawall, it does not feature back slope armour. A revetment system has a number of key components including a cover or armour layer, filter, toe protection, and crest protection (Allsop and McConnell, 2000). The armour layer provides basic protection against wave action, and the main types of material likely to be used are rock armour or riprap (narrow or wide graded), stone or concrete blocks (loose or grouted), concrete blocks (loose, cable-tied, solid, cellular interlocking, or articulated), concrete slabs (usually cast in situ), fabric-formed concrete mattresses, and asphaltic materials (open stone asphalt, bitumen grouting, or asphaltic concrete) (CERC, 1995; Allsop and McConnell, 2000). Figure 2.3 is an example of a revetment with rock armour. Rigid armours, such as concrete slabs, are more massive but are unable to accommodate settlement of the underlying material, whereas flexible armours, such as riprap, are lighter and can tolerate varying amounts of displacement (CERC, 1995). The filter functions similarly as for seawalls. The toe protection for a revetment has a similar function as the toe protection for a seawall in terms of its prevention of scour. 


\subsubsection{Dykes}

Similar to seawalls and revetments, dykes are barriers constructed to prevent flooding during storms. They generally feature a large and sometimes relatively impermeable core. The key components of a dyke include an armour layer, toe protection, and filter as shown in Figure 2.4. The armour layer serves to protect the dyke with the armour often replaced by revetments as a facing of erosion resistant material. The filter functions similarly to that for seawalls and revetments, and toe protection is essential when scour becomes a problem. Dykes can be applied with other coastal protection structures, such as revetments. The dyke system in Richmond, B.C., Canada is an example of the dyke with a revetment.

\subsubsection{Modes and Consequences of Failures}

Although coastal structures have been constructed in most maritime countries, damages still occur due to failures in extreme conditions as discussed in Section 2.1. Various factors have caused coastal structures to be more vulnerable in extreme conditions. This section investigates various failure modes, which include overtopping and overflowing, instability of outer slope, instability of inner slope, scour, and geotechnical failure.

\subsubsection{Overtopping and Overflowing}

Overtopping and overflowing are two modes of failure occurring at the crest of coastal structures. Overtopping refers to when wave overtopping or wave run-up exceeds an acceptable threshold (an acceptable threshold could be less than or equal to the crest elevation), whereas 
overflowing refers to when a flood level exceeds the crest elevation. Overflowing can obviously cause damage to coastal structures and coastal areas due to the involvement of a greater amount of water on a continuous basis, but there is controversy surrounding whether a single wave or wave run-up can cause the failure of a coastal structure due to its instantaneous nature. Allsop and McConnell (2000) suggest that "overtopping does not itself constitute structural failure, but heavy overtopping may constitute a functional failure of the defence, which may in turn endanger the stability of the crest or other elements of the structure." Pilarczyk (2000) suggests that "if a structure is overtopped, even by minor splash, the stability can be affected by eroding the area above or behind the structure, removing soil supporting the top of the structure leading to the unravelling of the structure from the top down, or increasing the volume of water in the soil beneath the structure, contributing to drainage problems." Most design guides permit an acceptable threshold of overtopping discharge depending on the types of usage of areas behind the coastal structures, but they also require the determination of the potential wave run-up to set the crest elevation. The design guidance regarding the crest elevation is further discussed in Section 2.2.3.1. In the case where some overtopping is allowed, the crest elevation is reduced. For a small amount of overtopping, a grass mat over clay on the dyke surface is sufficient (Pilarczyk, 2000). Nevertheless, for heavy overtopping, the crest should be increased until an acceptable overtopping discharge is achieved (Allsop and McConnell, 2000). Figure 2.2 shows an example of a wave wall incorporated in the design of a seawall, which may also be implemented in the case of heavy overtopping. 


\subsubsection{Instability of Outer Slope}

Instability of the outer slope is a type of failure occurring on the seaward slopes usually composed of armour or revetments, when wave impact pressures from wave attacks are greater than the strength of the armour or revetments. Wave impact pressures are induced by localized breaking waves, and they generally occur close to the water level (Allsop and McConnell, 2000). This type of wave attack may lead to erosion and loss of stability of the outer slope (Pilarczyk, 2000). Examples of this type of failure include local deformations and loss of individual cover layer elements (Allsop and McConnell, 2000). Damage from wave pressures can be minimized if coastal structures possess sufficient size and thickness of armour material, particularly in the region of the structure exposed to the still water level (Allsop and McConnell, 2000).

\subsubsection{Instability of Inner Slope}

Similarly, instability of the inner slope is also a type of failure in armour units or revetments, when uplift pressures from wave attacks are greater than the strength of the armour or revetments. Wave uplift pressures are created on the underside of the armour layer or revetments during wave draw-down, when the armour layer is low in permeability (Allsop and McConnell, 2000). An example of instability of the inner slope is piping. To avoid instability of the inner slope, armour material or revetments should be of a sufficient size and thickness (Allsop and McConnell, 2000). 


\subsubsection{Scour}

Scour often occurs at the toe of coastal structures. This may cause instability at the toe and eventually lead to failure throughout the entire structure (Allsop and McConnell, 2000; Pilarczyk, 2000). Factors that affect the severity of toe scour include wave break, wave run-up, backwash, wave reflection, and the grain size distribution of the beach or bottom materials (Pilarczyk, 2000). For example, the possibility of scour increases when a wave breaks near the toe of a coastal structure. Wave breaking is a phenomenon particular to shallow water, where the water depth is less than twice the height of the wave. Thus, one approach for avoiding scour is to locate the toe below at least twice the design wave height. In addition, scour can be avoided by constructing toe protection using sheet piles, which extend down to below the maximum predicted scour depth (Allsop and McConnell, 2000). As mentioned in Section 2.2.1, toe protection is a key component of most coastal structures.

\subsubsection{Geotechnical Failures}

Geotechnical failure often occurs at the foundations of coastal structures. Causes of geotechnical failure include seismic effects and the slumping of poorly compacted sub-soil. This may lead to a significant deformation of the armour layer and settlement of the whole structure. Settlement is a common problem for seawalls because of their heavy weight. Construction may allow for some settlement, but significant differential settlement along a section of the structure is likely to lead to local failure and to decrease the overall height of the structure. Adequate compaction before the construction and a full seismic investigation could minimize this type of failure. 


\subsubsection{Design of Coastal Structures}

A complete design of coastal structures involves four interconnected aspects: the function of the structure, the physical environment, the construction method, and the operation and maintenance (Allsop and McConnell, 2000; Pilarczyk, 2000). Figure 2.5 presents a flowchart of the design process for revetments, but could be effectively applied with minor adjustments to most shore-parallel coastal structures. In the process of defining the function of a structure, the objectives and criteria are established. Criteria are used to measure the objectives including technical feasibility, economic feasibility, and social and political feasibility (Pilarczyk, 2000). An example of criteria constraining the technical feasibility is a sufficient crest height to avoid overtopping or overflowing. The criteria for economic feasibility and social and political feasibility are also used when selecting alternative designs of coastal structures. As described in Figure 2.5, optimization is often applied in the selection process. For instance, when a structure is designed to protect against overtopping, the cost of construction increases due to the higher standard of crest elevation. In addition, the construction method and operation and maintenance are important considerations. The remainder of this section focuses on the function of the structure and its physical environment in the context of technical feasibility.

In general, the main objective of coastal structures is to provide an increased level of protection in coastal areas while minimizing all modes of failure without excessive maintenance. However, because of the stochastic nature of wave conditions and water levels, it is impossible to design a coastal structure with zero probability of failure. Thus, the design objectives should include the design life of the coastal structure and an acceptable risk level during the design life. The design life $\left(N_{D}\right)$ of the coastal structure is typically 50 to 100 years (Allsop and McConnell, 
2000). The structures are designed to withstand a design event (or events), which is (are) usually defined by a particular combination of wave condition and water level. Each design event will have a selected return period $\left(T_{R}\right)$ which indicates the average likelihood of the event being exceeded in a given time period. The design return period should normally be significantly longer than the design life. The probability of exceedance of the design event during the life of the structure is the encounter probability $\left(p_{e}\right)$ as described by (Allsop and McConnell, 2000; Pilarczyk, 2000; Headland et al., 2000):

$p_{e}=1-\left(1-1 / T_{R}\right)^{N_{D}}$

While the function of the structure sets the overview of the design, "shore protection works cannot be designed without an adequate understanding of local environmental site condition" (Headland et al., 2000). Thus, an investigation of the physical environment is conducted. The physical environment related to the technical design of coastal structures is described statistically by the following variables: topography, bathymetry, climate, water levels, wave climate, current system, coastal processes, and geotechnical features (Pilarczyk, 2000; Headland et al., 2000). The topography and fronting bathymetry of the area of interest are essential to the functional and structural design of coastal protection works, because the design of a coastal protection scheme is often dictated by water depth (Headland et al., 2000). Structural requirements for resisting the wave force may be reduced result when the fronting bathymetry is shallow as shallow near-shore bathymetry acts to break waves before they reach the structure (Headland et al., 2000). Coastal processes, such as regional geomorphology, long-term shoreline changes, and sediment transport, should also be considered in the long-term planning of coastal protection. Hydraulic conditions, such as water level and wave climate, are investigated further in Section 2.3. All variables serve as the input into the design of components of coastal structures. While the choice of crest elevation is the focus of this research and is discussed in detail in Section 2.2.3.1, other 
design components are briefly reviewed in Section 2.2.3.2. Detailed guidelines can be found in the Shore Protection Manual by the Coastal Engineering Research Center (CERC) of U.S. Army Corp. of Engineering (USACE) (1984). Although the coastal structures can be determined with a higher level of accuracy using the guidelines for coastal protection compared with experiencebased designs in the past, Pilarczyk still cautions that "the solution being considered should still be tested with a scaled model, since no generally accepted design rules exist for all possible solutions and circumstances" (Pilarczyk, 2000).

\subsubsection{Crest Elevation}

In the past, the crest elevation was selected based on the highest observed storm surge level and an estimate of wave characteristics from historical records. The study of the failure modes of coastal structures led to a systematic approach for estimating crest elevation, where the crest elevation is selected to avoid overflowing, overtopping, and geotechnical failures. Components to be considered when selecting the crest height include flood level, wave run-up, allowable overtopping discharge, and anticipated structure settlement (CERC, 1995). The crest elevation should be at least at flood level. The flood level is a common basis for the design of coastal structures, because failure of such structures typically causes floods in low-lying areas and amplifies the impact of waves. In general, a flood level is primarily affected by tides, being responsible for $97 \%$ of the impacts, and storm surges, being responsible for $3 \%$ of the impacts (Pugh and Vassie, 1980). Both factors are discussed in Section 2.3, and the methods of estimating extreme flood levels are discussed in Section 3.1.

To minimize overtopping, the extreme sea levels should include both flood levels and wave run-up. Two issues arising from estimating extreme sea levels composed of flood levels 
and wave run-up are the 1) estimation of the joint probability of water level and wave conditions, and 2) estimation of the damage caused by overtopping. The first issue is addressed in Section 3.3, and the second issue is discussed here. To prevent overtopping, some suggest the use of wave run-up to set the crest height as a conservative approach, under the assumption that only a significant wave run-up will cause considerable damage to coastal structures (CERC, 1995). Assuming this is correct, two methods are commonly used to determine conservative damage estimation: 1) using a smaller value of wave run-up and 2) using allowable overtopping discharges. An example of using a smaller value of wave run-up can be found in Dutch practice for designing dykes. The crest elevation in the Dutch practice is defined by a combination of a static water level with a $0.01 \%$ probability of exceedance while wave run-up is derived for wave conditions with a $2 \%$ probability of exceedance (Pilarczyk, 2000). A larger probability of exceedance means the occurrence of such an event is more frequent, and thus, the value of the event is smaller. The extreme sea level or crest elevation value is then reduced due to the possibility of an increased wave run-up occurring. The alternate method involves determining an allowable volume of water that would result in overtopping or an allowable overtopping discharge. While recent research in Europe has focussed on determining the allowable overtopping discharge, there is no consensus regarding the amount of overtopping discharge allowed. The estimation of wave run-up and overtopping is discussed in Section 3.4.

\subsubsection{Other Design Considerations}

Other design components of coastal structures include slope, slope protection (i.e., armour unit or revetment), toe, and filter selection. The slope of a coastal structure influences the distribution of wave forces, and thus also influences the choice of materials suitable for slope 
protection and the height of the structure (Pilarczyk, 2000). Shallower slopes lead to a distributed reduced wave force and reduced wave run-up on the seaward slope. Thus, the design slope is usually $1: 2$ to $1: 6$, depending on the differences in water levels and the wave conditions (Allsop and McConnell, 2000). Slope protection provides stability, and the design includes the selection of materials and the determination of the thickness of the materials. Each type of cover layer for revetments has its own critical failure mode, wave loading, and strength, as shown in Table 2.2. The thickness or size of the protection layer is determined by a stability criterion for wave attack, as discussed in Sections 2.2.2.2 and 2.2.2.3. The design of toe components includes the determination of elevation of toe and types of toe protection. As mentioned in Section 2.2.2.4, when scour is a concern for the design area, the toe should be constructed to a depth greater than the predicted scour, and should include toe protection (Allsop and McConnell, 2000). A filter is a transitional layer of stones ranging with a weight ranging from 6 to $10 \%$ of the armour weight in order to distribute the weight of the armour units (CERC, 1984).

\subsection{Fluctuations of Sea Levels}

One of the earliest studies describing the factors influencing sea-level is by Nomitsu and Okamoto (1927). They suggest two principal classes of contributing factors, the internal and external causes. The internal causes refer to the factors affecting changes in the properties of sea water, such as temperature, salinity, and precipitation. Examples of external causes are atmospheric pressure, wind and the consequences of the Coriolis Effect upon the moving water mass. Helna (1944) cites river discharge as an additional external cause. Galerkin (1960) proposes three classes of factors: those related to the variations of the physical properties of sea water, those related to the fluctuations in the quantity of water, and those affecting the uneven 
distribution of sea-level heights within a basin. For example, river discharge is one of the factors causing changes in the quantity of water. More recently, Hilmi et al. (2000) suggest that changes in sea levels are influenced by various factors, such as "tidal motions, wind effects, atmospheric pressure, variation of sea water density, river runoff, and (ocean) current system." Although an ocean current characterized by regularity as a continuous stream flowing along a definable path could be tidal or non-tidal, permanent or seasonal, horizontal or vertical, some individuals argue that the ocean current system is associated with water motion rather than vertical variations in sea levels (Thomson, 1981). In general, the current system yields local fluctuations of sea levels, except under the more extreme scenario of El Niño. Therefore, El Niño is considered as a critical factor in the estimation of extreme sea levels and is discussed later in this section.

Recognizing the importance of the changes of physical properties and the quantity of sea water, this section focuses on the generating mechanisms affecting the uneven distribution of sea-level heights within a basin, because these are often the causes of extreme conditions and thus are related to the estimation of extreme sea levels. Sections 2.3 .1 and 2.3 .2 first compare the differences in the common terms used in the scientific and engineering classification schemes concerning the generation mechanisms causing sea fluctuations. The generating mechanisms described in Sections 2.3 .3 to 2.3 .8 include wind waves, storm surges, tsunami, tides, El Niño, and climatologic and geologic effects. As waves approach the shores, the forward momentum carries the waves up the coastal structures resulting in wave run-up, which is described in Section 3.4. 


\subsubsection{Scientific Classification Scheme}

In the scientific context, sea levels are described as the superimposition of different types of waves and seasonal and long-term fluctuations in sea levels. Thus, the factors contributing to sea fluctuations can be classified into waves and non-waves. As summarized in Figure 2.6, wave components include wind waves, storm surges, tsunami, and tides. Among all wave components in the scientific context, the most significant one affecting the degree of variation in sea level is the wave component generated by wind as wind-induced waves are accountable for approximately $90 \%$ of the maximum wave heights achieved (Myers, 1969; Ochi, 1998). In addition, the non-wave components include El Niño, and climatologic and geologic effects.

Waves are defined as an oscillatory movement of water on or near the surface of standing water. They initiate the oscillatory movement by a disturbance applied to water, with a restoring mechanism forcing the water toward equilibrium and forming a distortion in the opposite direction. The type of disturbance and the type of restoring mechanism define the type of waves, as summarized in Table 2.3. Table 2.3 presents the characteristics of each mechanism: wave period $(T)$, wave length $(L)$, wave height $(H)$, and generating and restoring forces. A wave period is the time that it takes two successive crests to pass a fixed point, and a wave length is the distance between two successive crests. A wave height is the difference in surface elevation from wave crest to trough. Waves can be further classified into deep-water waves, intermediatewater waves, and shallow-water waves, depending on the ratio of water depth and wavelength. If the total water depth $(d)$ exceeds $25 \%$ of the wavelength, the waves are deep-water waves or short waves, such as wind waves. Deep-water or short waves are unaffected by the bottom, so wave motions are identical to those in infinitely deep water. If the water depth is between $25 \%$ and $5 \%$ of the wavelength, the waves are intermediate-water waves. Intermediate-water waves are partly affected by the bottom topography. If the water depth is less than $5 \%$ of the wave 
length, the waves are considered to be shallow-water waves or long waves, such as tides and tsunami. Their characteristics are strongly influenced by variations in water depth and wave period.

\subsubsection{Engineering Classification Scheme}

In the engineering context, the effects on sea levels are composed of waves and water level factors (see Figure 2.7). Here, waves have short wave periods on the order of seconds. Water levels affect the mean elevation of the water when averaged over a short period of time, about one minute (CERC, 1984). Here, water levels have a low frequency of occurrence, and are composed of waves with longer wave periods (i.e., minutes, hours, and days) and long-term sea level changes (i.e., seasonal and annual). The category of "water level" includes storm surges, tsunami, tides, El Niño, and climatologic and geologic effects.

Water levels are commonly measured by a stilling-well type of gauge, which is composed of a float and an orifice. The float inside the still well moves upward or downward with the water surface elevation, with the movement recorded on a chart to provide a time series of the observed water levels. The orifice at the bottom of the well serves to filter out oscillations having a period smaller than one minute. As discussed earlier, flood levels are primarily composed of tides and storm surges, and do not include wave factors. Therefore flood levels coincide with the definition of "water level," and thus, the engineering classification approach is more relevant for the design process. 


\subsubsection{Wind Waves}

Although waves may be generated by various mechanisms, the most random fluctuation of the sea surface is generally attributed to wind waves. The generation of wind-induced waves is initiated by the transfer of energy from the wind to the water. Ripples on a calm water surface are the first sign of such energy transfer, and develop when wind reaches a threshold velocity. Ripples or small wind waves are known as capillary waves, because the restoring mechanism is the water tension. As wind with increasing strength blows over an undisturbed distance for a period of time, the waves grow higher and longer, and begin to move at greater speeds until reaching a "fully developed sea." A "fully developed sea" is a condition in which the rate of energy input to the waves from the wind is balanced by the rate of energy dissipation due to wave breaking and surface water turbulence (Sorensen, 1997). Wave breaking is a function of water depth for a given wind condition, wave heights are smaller and wave periods are shorter if generation takes place in shallower water (CERC, 1984). However, the condition of "fully developed sea" is not commonly reached even in large storms. This maximum limit depends on three factors: wind speed, wind duration, and fetch (Thomson, 1981; Sorensen, 1997). The wind duration is the length of time the wind has been blowing at a particular speed, and the fetch is an unobstructed distance over which the wind has been blowing in the same direction at the same speed. The wind fetch is important in wind generation, because it limits the length of time a group of traveling waves will directly receive energy from a particular wind system. As the waves grow, the restoring mechanism evolves from water tension to gravity; thus, the larger wind waves are called gravity waves. 


\subsubsection{Characteristics of Wind Waves}

The characteristics of wind waves, which may be types of capillary waves or gravity waves, can be found in Table 2.3. The wave periods are in the range of 0.1 to $30 \mathrm{sec}$, and their lengths are in the range of 0.02 to $1000 \mathrm{~m}$. In addition, wind waves in the ocean can reach wave heights of up to typically nearly $3 \mathrm{~m}$ (Sorensen, 1997). Wind waves are also a type of deepwater wave, where the bottom of ocean does not affect the wave. The wide range of periods, wavelengths, and heights contribute to the complexity of oceans.

\subsubsection{Statistical Analysis of Waves}

Analysis of recorded or predicted data is used to describe and forecast wind waves or sea state. A sea state describes the force of progressively higher seas by wave height, and is composed of waves with varying height and period. Wind is an essential element in storm generation, thus wave statistics are also used to describe the severity of storm waves and extreme wave conditions. Wave data may be predicted or measured. Procedures for predicting waves are provided in Section 2.3.3.3. Waves can be measured by visual observation, wave-rider buoys, ship-borne accelerometers mounted in the hull, bottom-mounted pressure sensors, and more recently, satellite laser altimeters and over-the horizon radar (Thomson, 1981). Visually observed wave data are routinely obtained from ships or fishing boats, but the data collected are typically not very accurate. Instruments used to measure waves have higher accuracy in general, but they fail occasionally during major storms. Radar systems can also collect directional information. Waves are commonly measured every three hours. Analysis of wave records can be performed in two ways: using a statistical approach or a wave spectrum analysis. The most 
common statistical indices, or parameters of a sea state, are the significant wave height and peak wave period, and these may be derived from either approach. The significant wave height, denoted as $H_{s}$, is the average height of the highest one-third of the observed or measured waves, and the peak wave period, denoted as $T_{p}$, is the wave period that corresponds to the maximum wave energy level in the wave spectrum (Sorensen, 1997; Ochi, 1998).

\subsection{Statistical Analysis of Wave Height and Period}

The statistical approach identifies the individual waves in the history of record and analyzes the statistical properties of the height and periods of the individual waves. The identification of waves from gauged wave record is commonly conducted by the zero upcrossing method, which is a standard method used to divide a time series record of waves into individual components. The primary goal is to find the appropriate distribution type for the probability density function of the wave height, $p(H)$. Longuet-Higgins (1952) state that the density function of waves is best defined by a Rayleigh Probability Distribution (Sorensen, 1997; Ochi, 1998). The Rayleigh Probability Distribution can be written as:

$$
p(H)=\frac{2 H}{H_{r m s}^{2}} e^{-\left(\frac{H}{H_{m i s}}\right)^{2}}
$$

where $H_{r m s}$, the root mean square height, is a parameter of the Rayleigh Probability Distribution. The root mean square height is defined as: 
$H_{r m s}=\sqrt{\sum_{i=1}^{N} \frac{H_{i}^{2}}{N}}$

where $H_{i}$ are the individual wave heights in a record containing $N$ waves (Sorensen, 1997; Ochi, 1998). Combining the Rayleigh Probability Distribution and the definition of the significant wave height leads to the following representation of significant wave height (CERC, 1984; Ochi, 1998):

$$
H_{s}=1.416 H_{r m s} \approx \sqrt{2} H_{r m s}
$$

The height of the most probable maximum wave in this particular sea state, $H_{\max }$, can also be derived by the significant wave height and the total number of waves encountered, $N$, as described by Equation 2.5 (Isaacson and Foschi, 2000).

$$
H_{\max }=H_{s} \sqrt{\frac{\ln N}{2}} \approx 1.8 \sim 2.0 H_{s}
$$

$N$ can be estimated by the following equation:

$$
N=3600 \frac{D}{T}
$$

where $D$ is the duration in hours, and $T$ is the average wave period in seconds. If the most probable maximum wave height within a storm is of interest, $D$ can represent the duration of a storm in hours. For other cases, $D$ represents the recording interval in hours.

\subsection{Wave Spectrum Analysis of Wave Height and Period}

An alternate and more recent approach utilizes the wave spectrum of the wave record based on a Fournier Analysis of the record (Sorensen, 1997). This approach is different from the 
statistical approach, because the sea state is described in terms of a spectrum of wave energy. A spectrum of wave energy is a plot of the observed wave energy at each possible wave frequency against the wave energy, which is equal to the square of wave amplitude. The total area under the spectral curve can be used to describe the degree of sea severity and the total area is proportional to the total energy in the wave field. The definition of significant wave height using the spectrum approach is (CERC, 1984; Ochi, 1998):

$H_{s}=4.01 \sqrt{m_{0}}$

where $m_{0}$ is the area under the spectral density function, and is defined as (CERC, 1984; Ochi, 1998):

$m_{0}=\sum_{i=1}^{N} \frac{a_{i}^{2}}{2}$

where $a_{i}$ is the amplitude of wave $i$. Equation 2.7 can be used with Equations 2.5 and 2.6 to estimate the most probably maximum wave height.

\subsubsection{Wave Prediction}

There are two types of wave prediction: hindcasting and forecasting. In hindcasting the prediction is based on past meteorological conditions, whereas in forecasting the prediction is based on predicted conditions. Although the same procedures are used for both types of wave prediction, the sources of meteorological data are different. Several numerical models and parametric models for hindcasting and forecasting exist each with various computational and data requirements, and validity considerations. 
The prediction of wind waves can be accomplished by employing numerical models. These numerical models are developed to solve the equations described in the Miles-PhillipsHasselmann Theory (MPH Theory). The MPH Theory developed by Miles (1957) and Phillips (1957), and modified by Hasselmann et al. (1973) describes the mechanism of wind wave generation with differential equations. To solve these equations, the numerical methods require enormous computational time and meteorological data.

Simplification of the differential equations led to the development of the simplified models, such as parametric models, to predict a small number of parameters, such as wave height, wave period, and wave direction. Although the parametric models do not require a great deal of computation time, they are valid only under certain conditions, such as fetch-limited or duration-limited cases. The Sverdrup-Munk-Bretschneider (SMB) Method, developed by Sverdrup and Munk (1947) and modified by Bretschneider (1952), uses a set of empirical monograms, such as that shown in Figure 2.8, to provide a first order approximation of the significant wave heights and periods based on the fetch length and duration of wind. These empirical monograms are developed through field observations and analyses. For example, using Figure 2.8, the intersection of the value of a known fetch length located on the $\mathrm{x}$-axis, and the value of a known duration of wind located on the $y$-axis is determined and used to approximate the significant wave height and period. However, most monograms are restricted to deep water regions, because the SMB Method assumes that waves are generated under constant wind in deep or constant depth waters. This method remained the most widely used approach until the JONSWAP experiment (Sorensen, 1997). The JONSWAP-based curves include results from more recent tests and observations, and appear to be more accepted in the scientific community. However, neither results should be considered definitive. Although the SMB curves have a long history of use, the JONSWAP-based curves have the advantage in that the effects of atmospheric stability may be included in the calculation (Vincent and Resio, 1990). 


\subsubsection{Storm Surges}

Storm surges are another wave component which cause fluctuating sea levels and possess a close relationship with wind. Section 2.3.4.1 discusses the generation of storm surges, Section 2.3.4.2 presents the characteristics of storm surges, and Section 2.3.4.3 investigates the numerical models of storm surges.

\subsection{4:1 Generation of Storm Surges}

Storm surges, the super-elevation of the water surface, result from the barometric pressure differential and storm wind stress, which are the two conditions for a storm. Storm surges are a type of infragravity wave. When storm surges approach the shore, the change in momentum associated with the breaking of waves results in a force that raises water levels at the shoreline. The extent to which water levels can rise depends on the initial water depth, the characteristics and behaviour of the storm, the hydrography of the basin, and the initial state of the system (CERC, 1984). For example, since wave breaking is a phenomenon occurring when the water depth decreases, the effect of storm surges is considerable in shallower areas. Therefore, in low-lying areas, such as Holland, or the delta of the Ganges River in Bangladesh, there is extensive flooding caused by storm surges, particularly those that occur during periods of high astronomical tides (Thomson, 1981). 


\subsubsection{Characteristics of Storm Surges}

Although the frequency of occurrence of surge events is less than that of wind-induced waves, the impact of a storm surge is typically greater than wind-induced waves particularly for low-lying countries. As indicated in Table 2.3, for storm surges the wave periods are in the range of minutes, and the wavelengths are in the range of hundreds of meters to hundreds of kilometres. The heights of storm surges vary with the pressure and wind speed. The SaffirSimpson Hurricane Damage Potential Scale relates variations in pressure and wind speed to wave heights and potential damage (see Table 2.4). A hurricane is a storm emanating in the subtropics. In general, the wave heights are less than $3 \mathrm{~m}$ in deep water, but they can reach as high as $6 \mathrm{~m}$ while propagating into shallow areas.

\subsubsection{Estimation of Storm Surges}

Estimation of the height of a storm surge can be conducted in several ways, using indirect measurement or numerical and empirical models. The empirical models are developed and valid for regions near the. North Sea only. The method of indirect measurement requires both data of observed sea levels and tides, whereas the numerical models require the use of wind and pressure fields.

\subsection{Indirect Measurement of Storm Surges}

Values of observed sea levels, as mentioned earlier, are the average of the water levels after filtering out oscillations with a period smaller than a minute. Although observed sea levels 
may be composed of storm surges, tsunami, and tides, tsunami usually destroy gauge stations and thus are rarely captured through measurement. Thus, the observed sea level generally refers to tides and storm surges. Therefore, the time series of storm surges can be estimated by the difference between observed water levels and predicted astronomical tides, where the differences between water levels and astronomical tides are called residuals or residual water levels. Given the time series of residuals, design storm surges can be estimated from statistical analyses, such as the Annual Maxima Method. Unfortunately, the instruments used to measure observed sea levels may not provide a reliable measurement due to operational difficulties during storms. Nonetheless, measured water levels are often used in combination with numerical models to estimate design storm tides (Headland et al., 2000).

There is a problem with this approach when applied to data in semi-enclosed basins, such as bays and inlets, because semi-enclosed basins possess rapid and small sea-level changes, called seiches. Seiches are generated by tides and local winds. The effect of seiches on sea levels is captured in the measured observed sea levels. Thus, the difference between observed sea levels and tides in such situations includes both storm surges and seiches.

\subsection{Numerical Models of Storm Surges}

Storm surges can also be estimated by numerical models which simulate a hypothetical design storm. Use of numerical models often requires the knowledge of the spatial and temporal distribution of surface wind speed and direction, the surface air pressure, the forward path, and the speed of the design storm (Sorensen, 1997). The models involve hydrodynamic continuity and motion equations, which describe the storm surge generation process (CERC, 1984). In general, the equations are approximated using a two-dimensional finite difference method. The 
finite difference method first requires the construction of a grid system that covers the area to be modeled. Employing known input data and properly specified boundary conditions, the two horizontal flow components and the water surface elevation at successive time intervals are calculated at each grid point. Several numerical models have been developed to analyze storm surges for different boundary conditions, such as along the open coast, and in bays and estuaries. Some examples of two-dimensional storm-surge models are listed in Table 2.5. Each model has its strengths and weaknesses, and the overall credibility of the model depends on the following elements: the consistency of boundary constraints, the adequacy of the resolution provided, and the verification of the model by the calibration process (Reid, 1990).

\subsubsection{Astronomical Tides}

Astronomical tides are the alternate rise and fall of the surface of the sea due to the gravitational attraction between the sun, moon, and the earth. High tide is the highest point reached by the sea, while low tide is the lowest point that the water reaches as the sea surface falls. The tidal range is the difference between the height of water at high and low tide in any given place. Astronomical tides are important in estimating the extreme sea level for the following reasons: 1) the range of tides influences the mechanism of water breaking at the nearshore area, and 2) the potential impact of a storm or tsunami may be very dependent on whether it arrives at high or low tide (Sorensen, 1997). A discussion of the generation of tides is provided in Section 2.3.5.1, characteristics of tides in Section 2.3.5.2, measurement of tides in Section 2.3.5.3, and finally prediction of tides in Section 2.3.5.4. 


\subsubsection{Generation of Tides}

Astronomical tides are waves generated by the gravitational attraction of the sun, moon, and other astronomical bodies acting on the oceans. The strength of the gravitational force is inversely related to the square of the distance between two objects. Thus, the variations in distances between the sun and earth, and the moon and earth from the rotation of the earth-sunmoon system yield the difference in the strength of the gravitational force and the heights of tidal waves. There are over 390 active tidal components based on the different combinations of gravitational forces between the sun and earth, and the moon and earth (Sorensen, 1997). For example, a lunar component is when a point on the earth completes the full rotation to the same position relative to the moon, where the time for the rotation or the period for a lunar cycle is 24 hours and 50 minutes. The various components combine in different ways at each coastal location. The resultant tidal waves repeat themselves based on the different combinations. Their regularity makes tidal wave prediction straight-forward.

\subsubsection{Characteristics of Tides}

The characteristics of tides are closely related to the active tidal components, as each of the 390 active tidal components has a period, phase angle, and amplitude. The variations in components yield tidal waves having periods ranging from 8 hours to 18.61 years. In general, the periods are typically 12 hours, or 24 hours and 50 minutes which correspond to the principal periods of the solar and lunar cycles, respectively (Thomson, 1981; Sorensen, 1997). The wavelengths can be thousands of kilometres. The wave heights are usually low as shown in Table 2.3. However, at some locations, the wave heights can be as high as $6 \mathrm{~m}$, because long 
waves are strongly affected by variations in sea depth. Tidal waves can also be categorized by the number of cycles of the tidal wave per day. When a tidal wave has one cycle or one crest and one trough per day it is called diurnal, while a tidal wave having two cycles per day is called semidiurnal.

\subsubsection{Measurements of Tides and Establishment of Datum}

The purpose of measuring tidal levels is to establish datum levels and to predict magnitudes of tides. Tides are commonly measured by tidal gauges (Thomson, 1981). In Canada, the Canadian Hydrographic Service (CHS) is responsible for tide data collection. The CHS chooses the coastal locations for gauge stations, collects tidal data, and produces the Canadian Tide and Current Table. An ideal gauge station should experience the full tidal range, should not be exposed to strong currents or waves, and should also be strategically located to aid marine navigation.

Tides are measured by tidal gauges. The types of gauges include the stilling well, pressure gauge, and satellite altimetry. These instruments are also used to measure observed sea levels. The stilling well is the traditional method of measurement described in Section 2.3.2. Stilling wells are robust and relatively simple to operate, but have some disadvantages, which include 1) high costs, 2) the need for a vertical structure for mounting the still well over deep water (i.e., adjacent to a cliff), and 3) the susceptibility to erroneous readings (Pugh, 1987). The errors involved in using stilling wells are due to swell waves and partial plugging by debris and living organisms, limiting accuracy to approximately $0.02 \mathrm{~m}$ for water levels and two minutes for time (Thomson, 1981; Pugh, 1987). Thus, pressure gauges have been developed to measure tidal levels by measuring the pressure at some fixed point below the sea surface and converting 
the pressure to water level. The advantages of pressure gauges include the ability to be placed at offshore locations, the lack of susceptibility of records to be affected by wind waves, the ease of handling and the comparatively good accuracy (Thomson, 1981). The main disadvantages of pressure gauges are 1) their susceptibility to undesired dynamic pressure effects due to currents that flow past the orifice, and 2) their limitations due to the accuracy of the pressure sensing transducer (Pugh, 1987). Satellite altimetry can cover a large area very rapidly, but the results are difficult to interpret in terms of tide levels (Pugh, 1987).

A datum is used as the reference level for depths plotted on nautical charts and for describing sea levels. Various types of datum exist, such as the chart (CHAR) datum and geodetic (GSC) datum. The CHAR datum is the reference for measuring the height of the tides and is the lowest water level during normal tides. Consequently, the CHAR datum is subject to change if the lowest water level is changed. The GSC datum is a fixed datum chosen by local authorities.

\subsubsection{Prediction of Astronomical Tides}

Due to the regularity in the rotation of the sun, moon, and earth system, the astronomical tides can be predicted with a high accuracy. Prediction of astronomical tides first requires continuous observations for a year or more in order to accurately estimate the times and heights of high and low tides. The observed record of sea level is then analyzed and decomposed into constituents by harmonic analysis. The basis of harmonic analysis is the assumption that the tidal variations can be represented by a finite number of harmonic terms or constituents. Each constituent or component has a specified amplitude, cyclic period, angular speed, and phase lag. 
Upon the determination of these parameters, the overall equation of the height of tides can be expressed, as in Equation 2.9 (Tawn and Vassie, 1989):

$$
X(t)=\sum_{i=1}^{M} f_{i} A_{i} \cos \left(\sigma_{i} t+V_{i}+u_{i}-g_{i}\right)
$$

where $A_{i}$ is the amplitude of constituent $i, \sigma_{i}$ is the angular speed of constituent $i, V_{i}$ is the equilibrium tidal phase at $t=0$ for constituent $i, g_{i}$ is the phase lag of constituents, and $f_{i}$ and $u_{i}$ are the corresponding nodal corrections of constituent $i$. The summation in Equation 2.9 is over the number of constituents, $M$, that can be resolved within the length of data collected (Tawn, 1992; Tsimplis and Blackman, 1997). The values of $V_{i}, \sigma_{i}, u_{i}$, and $f_{i}$ are usually known, and $A_{i}$ and $g_{i}$ are estimated using at least one year of sea level data (Pugh and Vassie, 1980). Once the

parameters have been estimated, hourly tidal levels can be generated for the full nodal cycle of 18.61 years, because the tidal sequence is a deterministic periodic function (Tawn and Vassie, 1989; Tawn, 1992).

\subsubsection{Tsunami}

Tsunami is a Japanese word for harbour wave. Although the frequency of occurrence of tsunami is very small, tsunami have the potential for causing great destruction as discussed in Section 2.1 (Impact of Sea Floods). Therefore, tsunami are generally not considered in the design of coastal protection systems, unless the coastal systems are designated for critical facilities, such as bridges or power plants (Headland et al., 2000). Section 2.3.6.1 discusses the generation of tsunami, and Section 2.3.6.2 presents the characteristics of tsunami. 


\subsubsection{Generation of Tsunami}

Tsunami are generated by underwater disturbances, such as fault earthquakes, landslides, and volcanic eruptions. Tsunami generated by landslides and volcanic eruptions only affect the areas near the source, whereas tsunami generated by earthquakes can travel across an ocean basin (Camfield, 1990). The most common cause of tsunami is earthquakes, but not all earthquakes result in tsunami. The conditions under which earthquakes generate tsunami include: 1) the earthquake is generated beneath the sea floor and has a magnitude of greater than 6.5 on the Richter scale, 2) the center of the earthquake is not deeper than approximately $100 \mathrm{~km}$ below the seabed, and 3) the earthquake causes an upward or downward displacement (Thomson, 1981; Sorensen, 1997). The third condition is essential, because only an upward or downward displacement can cause distortion of the ocean surface. The majority of earthquakes in the Pacific Ocean cause a sideways slipping of the sea floor rather than an upward or downward displacement, so most earthquakes in the Pacific Ocean do not result in tsunami. Having said this, $62 \%$ of all tsunami occur in the Pacific Ocean (Thomson, 1981). Waves generated by tsunami are similar to the waves generated by dropping a rock in a pond, in which

the waves move outward from the source region. In general, wave heights generated by tsunami decrease, but the number of waves increase with distance from the source region, because the energy level decreases as the distance from the source region increases (CERC, 1984). The energy level is lost to the friction caused by "rubbing against the bottom" or natural obstacles, such as straits, passages, islands, and shoals. 


\subsubsection{Characteristics of Tsunami}

The characteristics of tsunami are discussed from the point of view of two scenarios: originating in conditions of deep water, and propagation near the shore. When a tsunami is generated in the ocean or deep water, it consists of a series of waves that spread rapidly away from their source where speeds can be over $900 \mathrm{~km} / \mathrm{h}$ (Thomson, 1980). The height of a tsunami at sea is always small, rarely exceeding $1 \mathrm{~m}$, having a wave length of typically in the range of 100 to $400 \mathrm{~km}$ (Thomson, 1980). Due to the characteristics of long waves, the tsunami decelerates as it approaches shallow areas, while the speed of the tsunami is directionally proportional to the depth of water. Tsunami arrive as a series of waves having periods ranging from 10 to 60 minutes (Abbott, 1999). Some waves may cause nothing more than a series of gentle rises and falls. The height of tsunami can increase to as high as $10 \mathrm{~m}$ while approaching shallow areas due to shoaling, refraction, and resonance. The wave can be amplified dramatically, particularly when the natural resonant frequency matches that of the tsunami. Before a large tsunami is generated near the shore, the withdrawal of water from the beach is usually observed. This phenomenon is caused by the large wave length. As it typically takes 10 to $50 \mathrm{~min}$ for a successive crest to pass a given point with the given speed and wave length, often a trough reaches the shore first, thus, creating the withdrawal of water.

\subsubsection{El Niño}

El Niño is an inter-annual event of an ocean current carrying an irregular flow of unusually warm surface water. Upwelling along the Pacific Coast, where the cold water from the subsurface moves upward to the surface, occurs throughout the year serving to cool the ocean 
water, cool the air, moderate the coastal temperatures and humidity, and bring deep, nutrient-rich water upward (Thomson, 1984). However, during an El Niño event, upwelling ceases near northern Peru and causes "a tongue of the warm eastward-flowing equatorial current to push southward about $6^{\circ} \mathrm{S}$ (Thomson, 1984). Because this occurs during the Christmas season, this event is called El Niño meaning "Christ Child." An El Niño event leads to a breakdown of the trade winds system over the equatorial Pacific Ocean and causes an abnormally high rainfall. The climatic effects of large-scale E1 Niño disturbances also cause flooding (mainly due to excessive rainfall) and drought conditions over a wide area, sometimes extending as far as the Southern Pacific Ocean, Europe, Africa, and Asia. The warm and nutrient-poor waters cause great ecological damage. Such disturbances have taken place in 1953, 1957-58, 1972-73, 1976, 1982-83, and 1992 (Thomson, 1984; North American Lake Management Society Website). It is believed that El Niño events enhance the sea level variability for various durations depending on the location relative to the equator (Subbotina et al., 1994). Although the impact of El Niño on the sea levels is still subject to ongoing research, it is not generally considered in the design of coastal protection systems.

\subsubsection{Climatologic and Geologic Effects}

While other components provide an explanation for short-term changes in sea levels, on a global level, the mean sea level is observed to be changing relative to land levels over a long period of time. Sea level rise is important in the design of coastal structures, because it increases the risks of overflowing and overtopping (Pilarczyk, 2000). Furthermore, the sea level rise can also impact the shore through erosion which leads to an instability of coastlines. Thus, there is an increased need to include the effect of the long-term sea level rise in the design of coastal 
structures, such as in the estimation of extreme sea levels. Two causes of long-term sea level changes are climatologic and geologic effects. The climatologic effects are mainly caused by global warming that results in expansion of sea water and melting of glaciers. The trend of sealevel rise is well documented in the United States, with research showing that the sea level rise during the latest decades ranges from 1 to $4 \mathrm{~mm}$ per year depending on the location (Bruun, 1989). For example, the East Coast of the USA has an average rate of sea level rise of 2 to 3.5 mm per year, whereas the Gulf Coast has an average rise of 2 to $3 \mathrm{~mm}$ per year (Bruun, 1989). Other studies also indicate that the sea level rise on the Pacific Ocean during the $20^{\text {th }}$ Century is estimated to be at the rate of $2 \mathrm{~mm}$ per year (Bruun, 1989; Church, 2002). Geological effects are due to possible tectonic uplift or subsidence of the coast, where an uplift motion will increase the relative sea level, and a subsidence motion will decrease the sea level. The geological effects on sea level thus depend on the location of the coast and the possible coastal movements. 
Table 2.1 Sea Flood Historical Events

\begin{tabular}{|c|c|c|c|}
\hline Date & Place & Description & Damage \\
\hline 1228 & $\begin{array}{l}\text { Friesland, the } \\
\text { Netherlands }\end{array}$ & Sea flood in Friesland & 100,000 lives lost \\
\hline 1282 & $\begin{array}{l}\text { Zuyder Zee, the } \\
\text { Netherlands }\end{array}$ & $\begin{array}{l}\text { A great storm broke through the } \\
\text { natural dykes, and the North Sea } \\
\text { flooded into the area in one day. }\end{array}$ & $\mathrm{N} / \mathrm{A}$ \\
\hline $\begin{array}{l}\text { Oct. } 11 \\
1634\end{array}$ & $\begin{array}{l}\text { Northsea Coast, the } \\
\text { Netherlands }\end{array}$ & $\begin{array}{l}\text { A storm destroyed the coastline of } \\
\text { North Friesland, and the flood } \\
\text { accompanying this storm swept away } \\
\text { complete villages. }\end{array}$ & 15,000 lives lost \\
\hline $\begin{array}{l}\text { Oct. } 31 \\
1876\end{array}$ & Backergunge, India & $\begin{array}{l}\text { Tidal waves caused by a cyclone } \\
\text { flooded the river delta, and some } \\
\text { areas were covered by } 40 \mathrm{ft} \text { of water. }\end{array}$ & 100,000 lives lost \\
\hline $\begin{array}{l}\text { June 15, } \\
1896\end{array}$ & Sanriku, Japan & $\begin{array}{l}\text { An undersea earthquake about } 100 \\
\text { miles offshore triggered a tidal wave } \\
80 \mathrm{ft} \text { high (Abbott, 1999). }\end{array}$ & 27,000 lives lost \\
\hline $\begin{array}{l}\text { Sept. 8, } \\
1900\end{array}$ & $\begin{array}{l}\text { Galveston, Texas, } \\
\text { USA }\end{array}$ & $\begin{array}{l}\text { A hurricane with a wind speed of } 120 \\
\text { mph raised the water level along the } \\
\text { shore of the Gulf of Mexico } 15 \mathrm{ft} \\
\text { above the usual } 2 \mathrm{ft} \text { of the tidal range } \\
\text { (Abbott, 1999). }\end{array}$ & 7,200 lives lost \\
\hline $\begin{array}{l}\text { June 23, } \\
1946\end{array}$ & $\begin{array}{l}\text { Vancouver Island, } \\
\text { British Columbia, } \\
\text { Canada }\end{array}$ & $\begin{array}{l}\text { An earthquake on the east coast of } \\
\text { Vancouver Island caused the water } \\
\text { level at Franklin River in Alberni } \\
\text { Inlet to rise } 6.1 \text { to } 9.1 \mathrm{~m} \text { above } \\
\text { average. }\end{array}$ & $\mathrm{N} / \mathrm{A}$ \\
\hline $\begin{array}{l}\text { Jan. } 31- \\
\text { Feb. } 5 \\
1953\end{array}$ & Northwest Europe & $\begin{array}{l}\text { A hurricane and high tides followed } \\
\text { by floods led to dyke failure and } \\
\text { devastated North Sea coastal areas. } \\
\text { The storm surge rose } 3 \text { to } 3.5 \mathrm{~m} \\
\text { above the normal high water; the } \\
\text { waves topped over the dykes } \\
\text { (Pilarczyk, 2000). }\end{array}$ & $\begin{array}{l}1,850 \text { people lives } \\
\text { lost and over } \\
\$ 250 \text { million of } \\
\text { damages }\end{array}$ \\
\hline Aug., 1954 & $\begin{array}{l}\text { Providence, Rhode } \\
\text { Island, USA }\end{array}$ & $\begin{array}{l}\text { Hurricane Carol raised the water } \\
\text { level to } 16 \mathrm{ft} \text { above normal level. }\end{array}$ & $\begin{array}{l}\text { Property damages } \\
\text { of } \$ 41 \text { million }\end{array}$ \\
\hline 1960 & $\begin{array}{l}\text { Tofino (Vancouver } \\
\text { Island), } \\
\text { British Columbia, } \\
\text { Canada }\end{array}$ & $\begin{array}{l}\text { An earthquake of magnitude of } 9.5 \text { in } \\
\text { Chile caused a } 1.2-\mathrm{m} \text { wave at Tofino. } \\
\text { Wave run-up was higher in many } \\
\text { areas. }\end{array}$ & N/A \\
\hline $\begin{array}{l}\text { Oct. } 31 \\
1960\end{array}$ & Chittagong, Pakistan & $\begin{array}{l}\text { A cyclone and storm surge caused } \\
\text { much damage. }\end{array}$ & $\begin{array}{l}\text { Thousands of } \\
\text { lives and houses } \\
\text { were lost }\end{array}$ \\
\hline $\begin{array}{l}\text { Feb. 16, } \\
1962\end{array}$ & $\begin{array}{l}\text { Hamburg and western } \\
\text { coastal areas, } \\
\text { Germany }\end{array}$ & $\begin{array}{l}\text { High tide and strong wind conditions } \\
\text { led to the failure of the levee system. }\end{array}$ & 315 lives lost \\
\hline $\begin{array}{l}\text { Mar. 27, } \\
1964\end{array}$ & $\begin{array}{l}\text { British Columbia, } \\
\text { Canada }\end{array}$ & $\begin{array}{l}\text { An earthquake of magnitude } 8.5 \text { in } \\
\text { Alaska caused a } 2.4-\mathrm{m} \text { wave at }\end{array}$ & $\begin{array}{l}\text { Property damages } \\
\text { of } \$ 8.4 \text { million }\end{array}$ \\
\hline
\end{tabular}




\begin{tabular}{|c|c|c|c|}
\hline & & $\begin{array}{l}\text { Tofino. Wave run-up was higher in } \\
\text { many areas. Wave amplitude in Port } \\
\text { Alberni was over } 6 \mathrm{~m} \text { (Thomson, } \\
\text { 1981). }\end{array}$ & \\
\hline Aug.,,1969 & Mississippi, USA & $\begin{array}{l}\text { Hurricane Camille caused the storm } \\
\text { surge that reached a maximum of } 6.9 \\
\text { m above mean sea level (Sorensen, } \\
\text { 1997; Abbott, 1999). }\end{array}$ & $\begin{array}{l}256 \text { lives lost; } \\
\text { property damage } \\
\text { of } \$ 1 \text { billion }\end{array}$ \\
\hline $\begin{array}{l}\text { Nov. } 13 \\
1970\end{array}$ & East Pakistan & $\begin{array}{l}\text { A cyclone-driven tidal wave from the } \\
\text { Bay of Bengal led to flooding. }\end{array}$ & $\begin{array}{l}200,000 \text { killed; } \\
\text { over } 100,000 \\
\text { missing }\end{array}$ \\
\hline Sept., 1972 & Atlantic Seaboard & $\begin{array}{l}\text { Remnants of Hurricane Agnes caused } \\
\text { flash flooding. }\end{array}$ & $\begin{array}{l}134 \text { lives lost; } \\
\text { property damage } \\
\text { of } \$ 3 \text { million }\end{array}$ \\
\hline$F e b ., 1976$ & $\begin{array}{l}\text { Bay of Fundy, NS } \\
\text { and NB, Canada }\end{array}$ & $\begin{array}{l}\text { Hurricane force winds accompanied } \\
\text { the Groundhog Day storm. }\end{array}$ & $\begin{array}{l}\text { Tens of millions } \\
\text { of damages }\end{array}$ \\
\hline $\begin{array}{l}\text { Feb. } 27- \\
\text { March } 5 \\
1983\end{array}$ & California, USA & $\begin{array}{l}\text { Pacific storms caused severe flooding } \\
\text { along the California coast. }\end{array}$ & $\begin{array}{l}13 \text { lives lost; } \\
\text { property damage } \\
\text { estimated at } \$ 200 \\
\text { million }\end{array}$ \\
\hline $\begin{array}{l}\text { Sept. } 17- \\
21,1989\end{array}$ & $\begin{array}{l}\text { Caribbean Sea and } \\
\text { the USA East Coast }\end{array}$ & $\begin{array}{l}\text { Hurricane Hugo brought a storm } \\
\text { surge of } 5.2 \mathrm{~m} \text { in height and caused } \\
\text { flash flooding (Abbott, 1999). }\end{array}$ & $\begin{array}{l}11 \text { lives lost; } \\
\text { property damage } \\
\text { about } \$ 7 \text { billions } \\
\text { of dollars }\end{array}$ \\
\hline $\begin{array}{l}\text { April 30, } \\
1991\end{array}$ & Bangladesh, India & $\begin{array}{l}145 \mathrm{mph} \text { cyclone struck coastal areas } \\
\text { and offshore islands causing } 6 \text {-meter } \\
\text { waves. }\end{array}$ & $\begin{array}{l}150,000 \text { killed; } \\
\text { property damage } \\
\text { about } \$ 1 \text { billion }\end{array}$ \\
\hline $\begin{array}{l}\text { Nov. } 5-7 \\
1992\end{array}$ & The Philippines & $\begin{array}{l}\text { Tropical storm Thelma caused 3-m } \\
\text { floodwaters on Leytes, Samar, and } \\
\text { Negros Islands. }\end{array}$ & $\begin{array}{l}\text { About } 3,400 \\
\text { killed; } 50,000 \\
\text { homeless } \\
\end{array}$ \\
\hline $\begin{array}{l}\text { Jul. } 17 \\
1998\end{array}$ & Papua New Guinea & $\begin{array}{l}\text { Three tsunami, possibly spurred by } \\
\text { an undersea landslide following an } \\
\text { earthquake, destroyed entire villages } \\
\text { in the northwest province of Sepik. }\end{array}$ & $\begin{array}{l}\text { At least } 2,000 \\
\text { found or } \\
\text { presumed dead }\end{array}$ \\
\hline $\begin{array}{l}\text { September, } \\
1999\end{array}$ & $\begin{array}{l}\text { Maritime Provinces, } \\
\text { Canada }\end{array}$ & $\begin{array}{l}\text { Tropical storm Harvey and Hurricane } \\
\text { Gert flooded Oxford, Nova Scotia. }\end{array}$ & $\begin{array}{l}\text { Property damage } \\
\text { of } 12 \text { million. }\end{array}$ \\
\hline Jan., 2000 & $\begin{array}{l}\text { Maritime Provinces, } \\
\text { Canada }\end{array}$ & $\begin{array}{l}\text { An intense winter storm occurred in } \\
\text { the Maritimes during a run of very } \\
\text { high tides. The storm surge caused } \\
\text { coastal flooding in the Gulf of St. } \\
\text { Lawrence affecting PEI, NB, and NS. }\end{array}$ & $\begin{array}{l}\text { \$20 million of } \\
\text { damages }\end{array}$ \\
\hline $\begin{array}{l}\text { March, } \\
2000\end{array}$ & $\begin{array}{l}\text { Prince Edward Island } \\
\text { and the Gulf of St. } \\
\text { Lawrence coast of } \\
\text { New Brunswick, } \\
\text { Canada }\end{array}$ & $\begin{array}{l}\text { The remains of a tropical storm hit } \\
\text { the Gulf of the St. Lawrence with } \\
\text { wind gusts of } 120 \mathrm{~km} / \mathrm{h} \text { causing ocean } \\
\text { waves of } 7 \text { to } 11 \mathrm{~m} \text { and massive } \\
\text { damage to coastal infrastructure. }\end{array}$ & $\mathrm{N} / \mathrm{A}$ \\
\hline
\end{tabular}


Table 2.2 Design Considerations and Critical Modes of Failure of Revetments from Pilarczyk (2000)

\begin{tabular}{|c|c|c|c|}
\hline $\begin{array}{c}\text { Type of cover } \\
\text { layer }\end{array}$ & Critical failure mode & $\begin{array}{c}\text { Determinant wave } \\
\text { loading }\end{array}$ & Strength \\
\hline Sand/gravel & $\begin{array}{l}\text { Initiation of motion } \\
\text { Transportation of material } \\
\text { Profile formation }\end{array}$ & Velocity field in waves & $\begin{array}{l}\text { Weight, friction } \\
\text { Dynamic "statlibty" }\end{array}$ \\
\hline Clay/grass & $\begin{array}{l}\text { Erosion } \\
\text { Deformation }\end{array}$ & $\begin{array}{l}\text { Maximum velocity } \\
\text { Wave impact }\end{array}$ & $\begin{array}{l}\text { Cohesion } \\
\text { Grass roots } \\
\text { Quality of clay }\end{array}$ \\
\hline Riprap & $\begin{array}{l}\text { Initiation of motion } \\
\text { Deformation }\end{array}$ & $\begin{array}{l}\text { Maximum velocity } \\
\text { Seepage }\end{array}$ & $\begin{array}{l}\text { Weight } \\
\text { Friction } \\
\text { Permeability of sub- } \\
\quad \text { layer/core }\end{array}$ \\
\hline $\begin{array}{l}\text { Gabions and } \\
\text { sand, or } \\
\text { cement } \\
\text { mattresses, } \\
\text { including } \\
\text { geotextiles } \\
\end{array}$ & $\begin{array}{l}\text { Initiation of motion } \\
\text { Deformation } \\
\text { Rocking } \\
\text { Abrasion/corrosion of } \\
\quad \text { wires } \\
\text { U.V. light }\end{array}$ & $\begin{array}{l}\text { Maximum velocity } \\
\text { Wave impact } \\
\text { Climate } \\
\text { Vandalism }\end{array}$ & $\begin{array}{l}\text { Weight } \\
\text { Blocking } \\
\text { Wires } \\
\text { Large unit } \\
\text { Permeability including } \\
\quad \text { sub-layer } \\
\end{array}$ \\
\hline $\begin{array}{l}\text { Placed blocks, } \\
\text { including } \\
\text { block mats }\end{array}$ & $\begin{array}{l}\text { Lifting } \\
\text { Bending } \\
\text { Deformation } \\
\text { Sliding }\end{array}$ & $\begin{array}{l}\text { Overpressure } \\
\text { Wave impact }\end{array}$ & $\begin{array}{l}\text { Thickness, friction, } \\
\text { interlocking } \\
\text { Permeability, including } \\
\text { sub-layer/ geotextile } \\
\text { Cabling/pins }\end{array}$ \\
\hline Asphalt & $\begin{array}{l}\text { Erosion } \\
\text { Deformation } \\
\text { Lifting }\end{array}$ & $\begin{array}{l}\text { Maximum velocity } \\
\text { Wave impact } \\
\text { Overpressure }\end{array}$ & $\begin{array}{l}\text { Mechanical strength } \\
\text { Weight }\end{array}$ \\
\hline
\end{tabular}


Table 2.3 Characteristics of Waves from Thomson (1981) and Sorensen (1997)

\begin{tabular}{|c|l|l|l|l|l|}
\hline Type & \multicolumn{1}{|c|}{ Period } & Wavelengths & \multicolumn{1}{|c|}{ Wave Heights } & \multicolumn{1}{c|}{$\begin{array}{c}\text { Generating } \\
\text { Mechanisms }\end{array}$} & $\begin{array}{c}\text { Restoring } \\
\text { Mechanisms }\end{array}$ \\
\hline $\begin{array}{c}\text { Capillary Waves } \\
\text { (ripples, wavelets) }\end{array}$ & Less than $0.1 \mathrm{~s}$ & Less than $2 \mathrm{~cm}$ & Less than $10 \mathrm{~cm}$ & $\begin{array}{l}\text { Wind, pressure } \\
\text { fluctuations }\end{array}$ & $\begin{array}{l}\text { Surface } \\
\text { tension }\end{array}$ \\
\hline $\begin{array}{c}\text { Gravity waves } \\
\text { (chop, sea, swell) }\end{array}$ & $0.5 \mathrm{~s}$ to $30 \mathrm{~s}$ & $10 \mathrm{~cm}$ to $1000 \mathrm{~m}$ & $\begin{array}{l}\text { Over } 10 \mathrm{~cm} \text { and less } \\
\text { than } 3 \mathrm{~m}\end{array}$ & Wind & Gravity \\
\hline Infragravity waves & $\begin{array}{l}\text { On the order } \\
\text { of minutes }\end{array}$ & $\begin{array}{l}\text { Hundreds of } \\
\text { meters to } \\
\text { hundreds of } \\
\text { kilometers }\end{array}$ & $\begin{array}{l}\text { Typically less than 3 } \\
\text { m but can exceed 6 } \\
\text { m during significant } \\
\text { storms }\end{array}$ & $\begin{array}{l}\text { Storm system } \\
\text { (winds and } \\
\text { atmospheric } \\
\text { pressure } \\
\text { gradients) }\end{array}$ & Gravity \\
\hline Tsunami & $\begin{array}{l}5 \text { min to more } \\
\text { than } 1 \mathrm{~h}\end{array}$ & $\begin{array}{l}\text { Hundreds of } \\
\text { kilometers }\end{array}$ & $\begin{array}{l}\text { Less than } 1 \mathrm{~m} \text { at sea, } \\
\text { but can increase to } \\
\text { as high as } 10 \mathrm{~m} \\
\text { when approaching } \\
\text { shallow areas }\end{array}$ & $\begin{array}{l}\text { Volcanic activity, } \\
\text { landslides, and } \\
\text { tectonic uplifting }\end{array}$ & Gravity \\
\hline Tides & $\begin{array}{l}\text { Mainly } 12 \mathrm{1} / 2 \\
\text { h and } 25 \mathrm{~h}\end{array}$ & $\begin{array}{l}\text { Thousands of } \\
\text { kilometers }\end{array}$ & $\begin{array}{l}\text { Low height in deep } \\
\text { ocean, but up to } 6 \mathrm{~m} \\
\text { in some locations }\end{array}$ & $\begin{array}{l}\text { Gravitational } \\
\text { attraction of sun } \\
\text { and moon }\end{array}$ & $\begin{array}{l}\text { Gravity and } \\
\text { Coriolis force }\end{array}$ \\
\hline
\end{tabular}

Table 2.4 Saffir-Simpson Hurricane Damage Potential Scale from Abbott (1999)

\begin{tabular}{|l|c|c|c|c|}
\hline & $\begin{array}{c}\text { Barometric } \\
\text { Pressure }\end{array}$ & $\begin{array}{c}\text { Wind Speed } \\
(\mathbf{m p h})\end{array}$ & $\begin{array}{c}\text { Storm Surges } \\
(\mathbf{m})\end{array}$ & Damages \\
\hline Category 1 & Over 28.94 in & $74-95$ & $1.22-1.52$ & Minimal \\
\hline Category 2 & $28.50-28.93$ & $96-110$ & $1.83-2.44$ & Moderate \\
\hline Category 3 & $27.91-28.49$ & $111-130$ & $2.74-3.66$ & Extensive \\
\hline Category 4 & $27.17-27.90$ & $131-155$ & $3.97-5.47$ & Extreme \\
\hline Category 5 & Less than 27.17 & Over 155 & Over 5.47 & Catastrophic \\
\hline
\end{tabular}

Table 2.5 Storm Surge Models Developed for Use in the Public Domain from Reid (1990)

\begin{tabular}{|l|l|l|}
\hline Code Name & Originator & Agency User \\
\hline SPLASH & Jelesnianski & National Weather Service \\
\hline SLOSH & Jelesenianski and Chen & National Weather Service \\
\hline SURGE II & Reid et al. & Coastal Engineering Research Center \\
\hline SSURGE & Wanstrath & Waterways Experiment Station \\
\hline CESSM & Tetra Tech & Federal Emergency Management Agency \\
\hline WIFM & Butler & Waterways Experiment Station \\
\hline
\end{tabular}




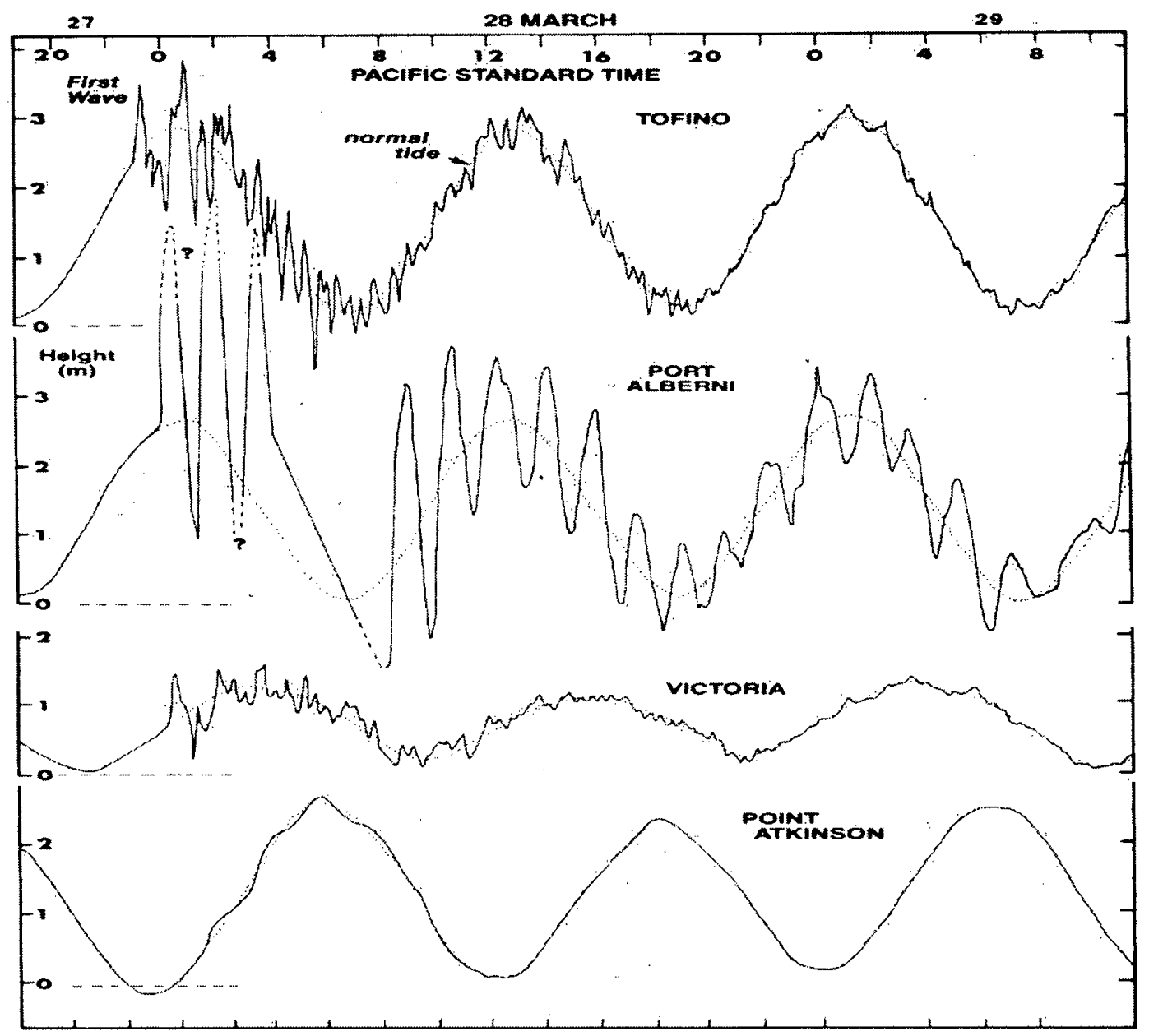

Figure 2.1 Sea Level Record for March, 1964

From Thomson (1981) 


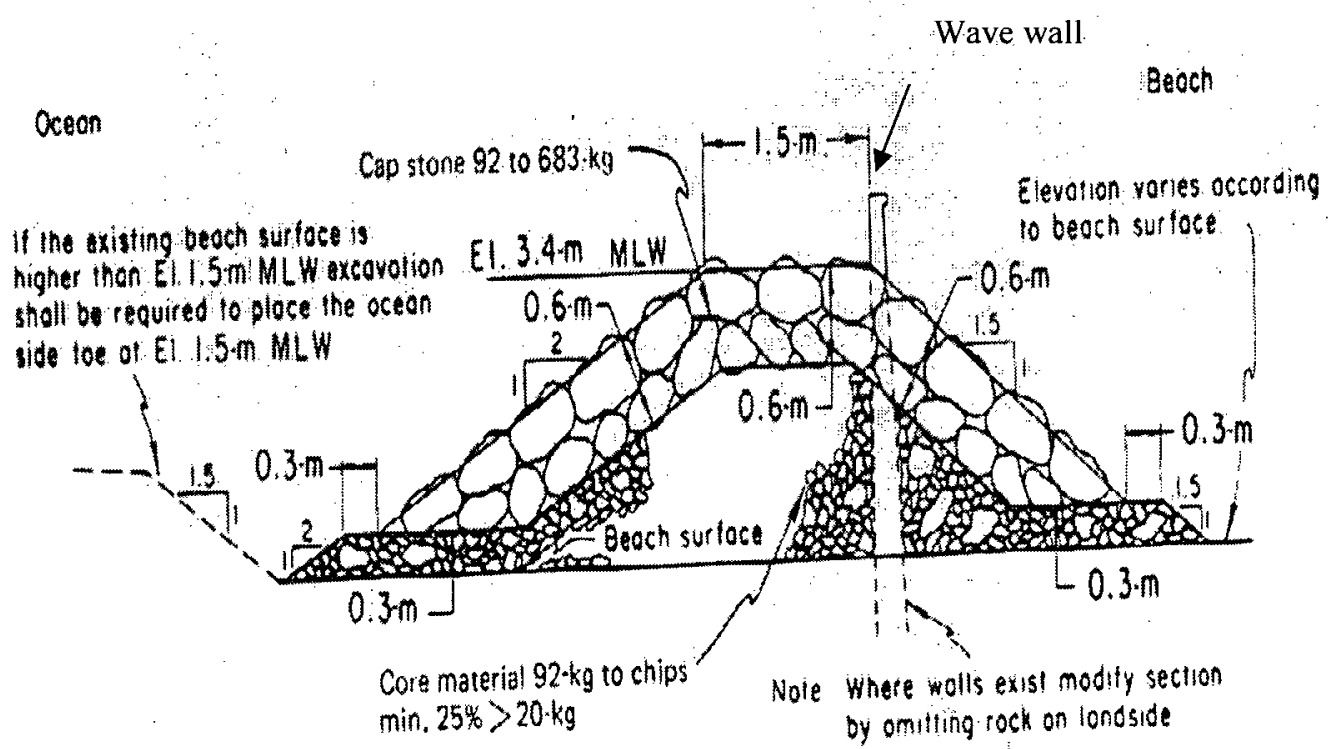

Figure 2.2 Rubble Mound Seawall

From CERC (1984)

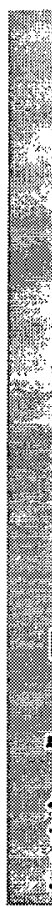

Topsoil and Seed

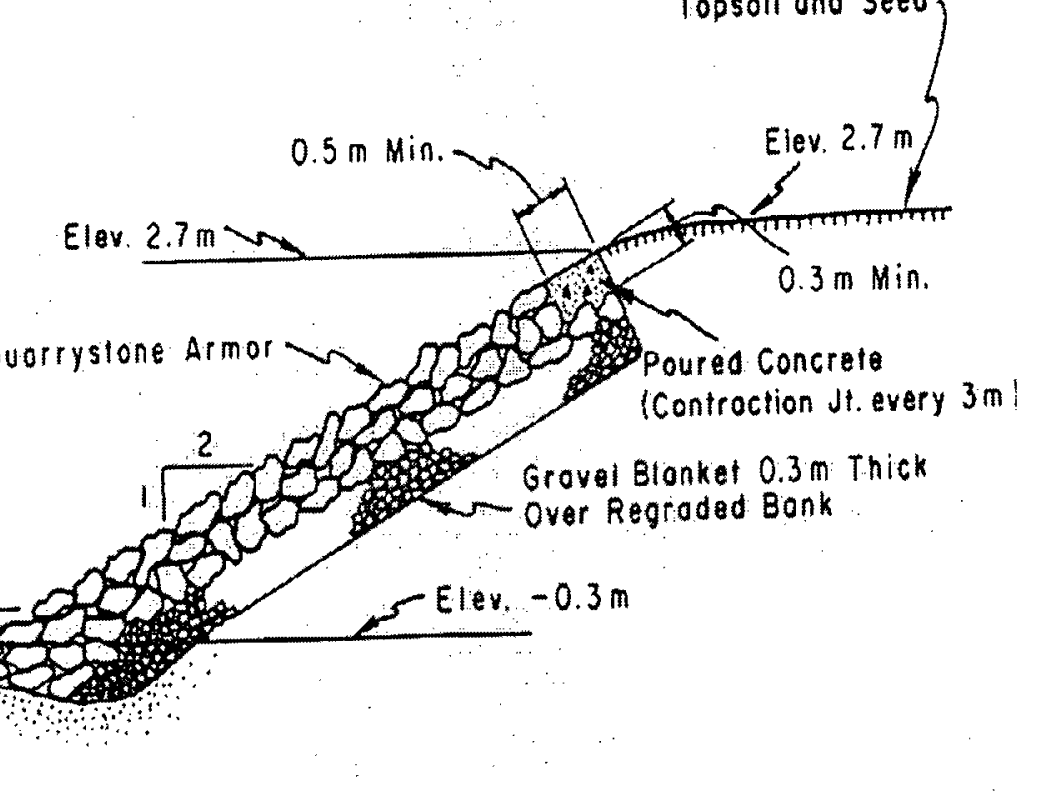

Figure 2.3 Quarrystone Revetment

From CERC (1984) 


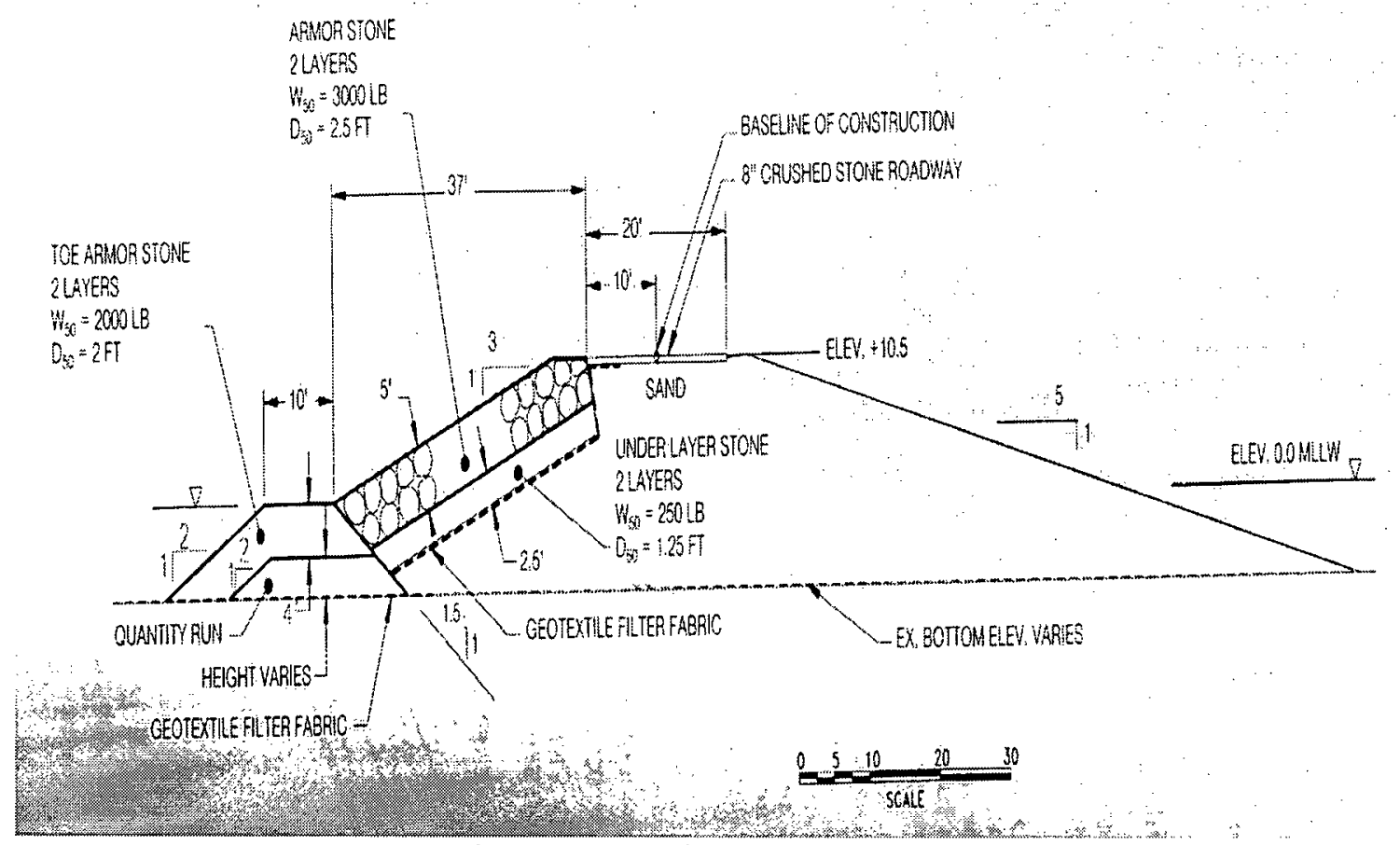

Figure 2.4 Typical Dyke Section

From Headland et al. (2000)

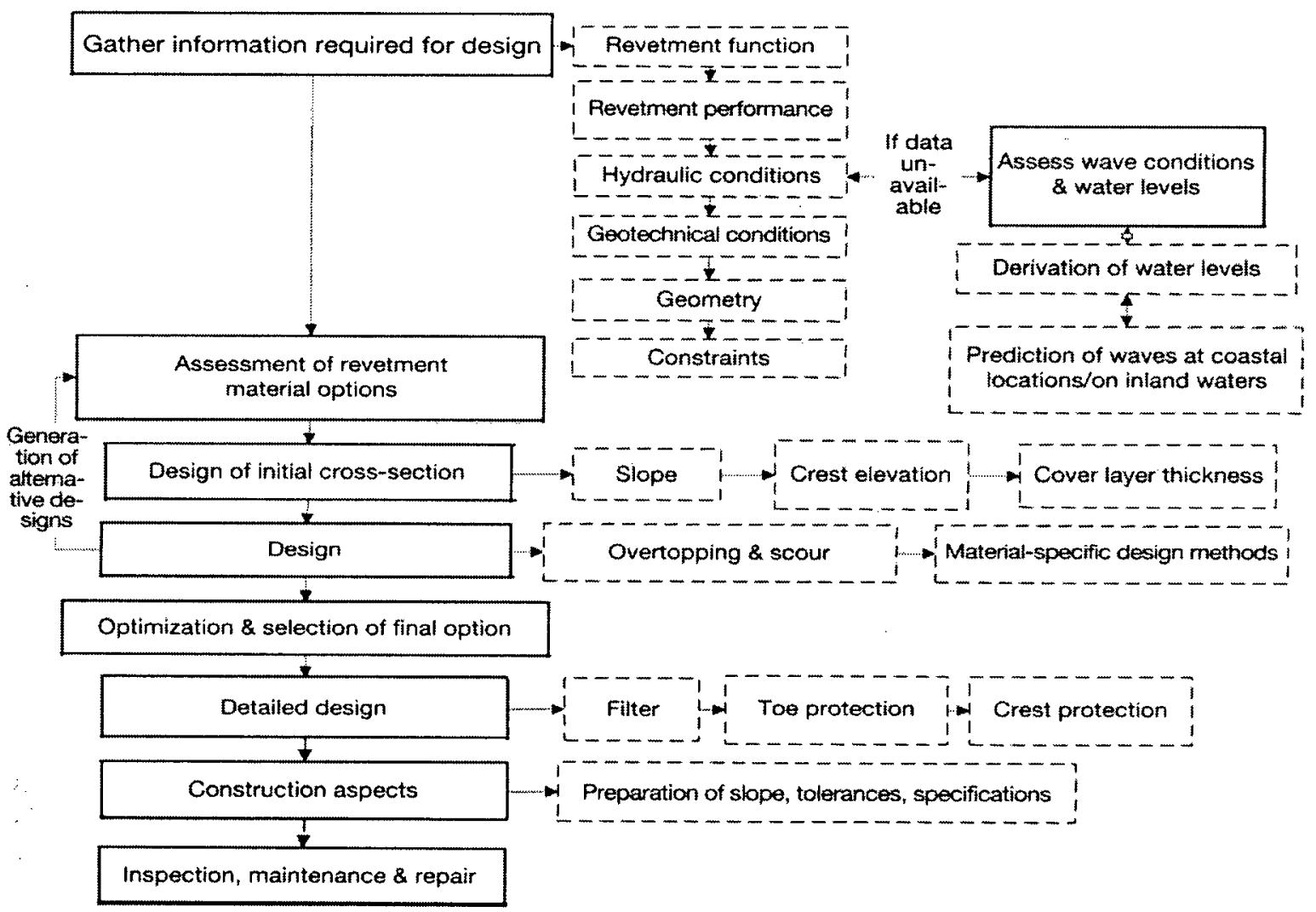

Figure 2.5 Flowchart of Design Process for Revetments

From Allsop and McConnell (2000) 


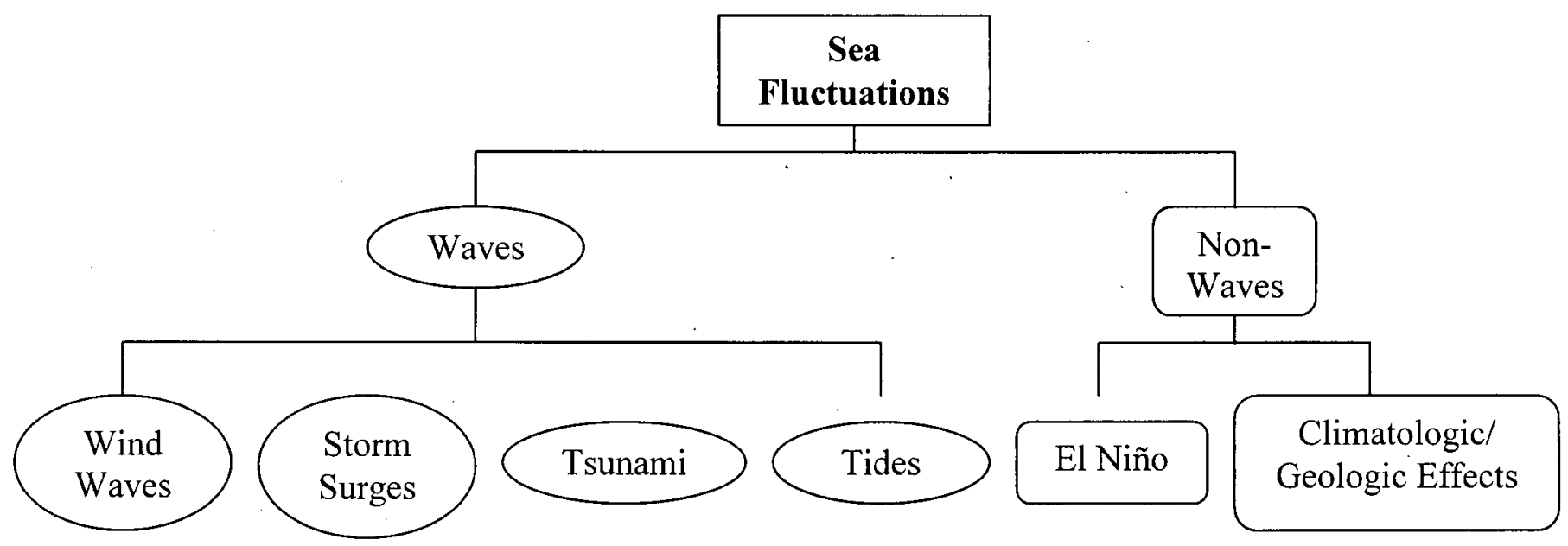

Figure 2.6 Scientific Classification of Factors Affecting Sea Level Fluctuations

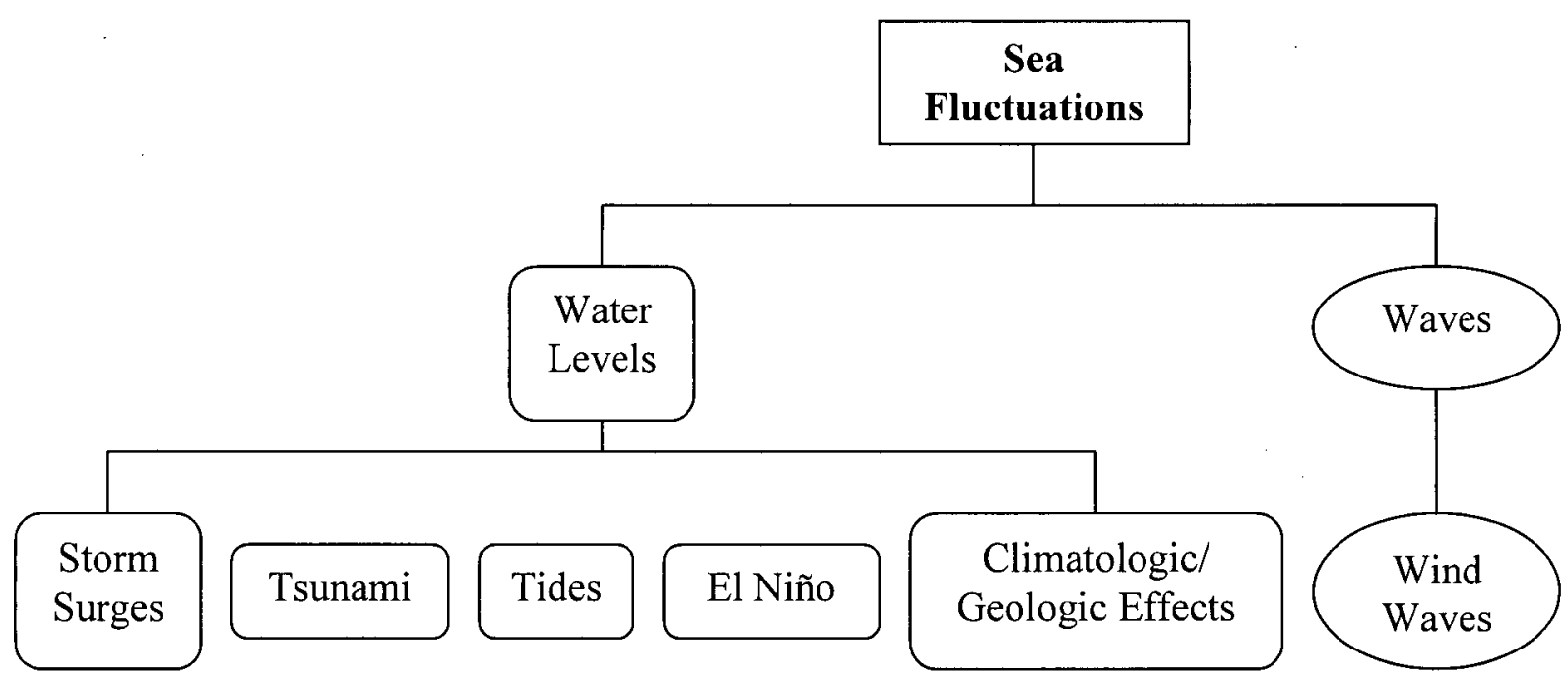

Figure 2.7 Engineering Classification of Factors Affecting Sea Level Fluctuations 


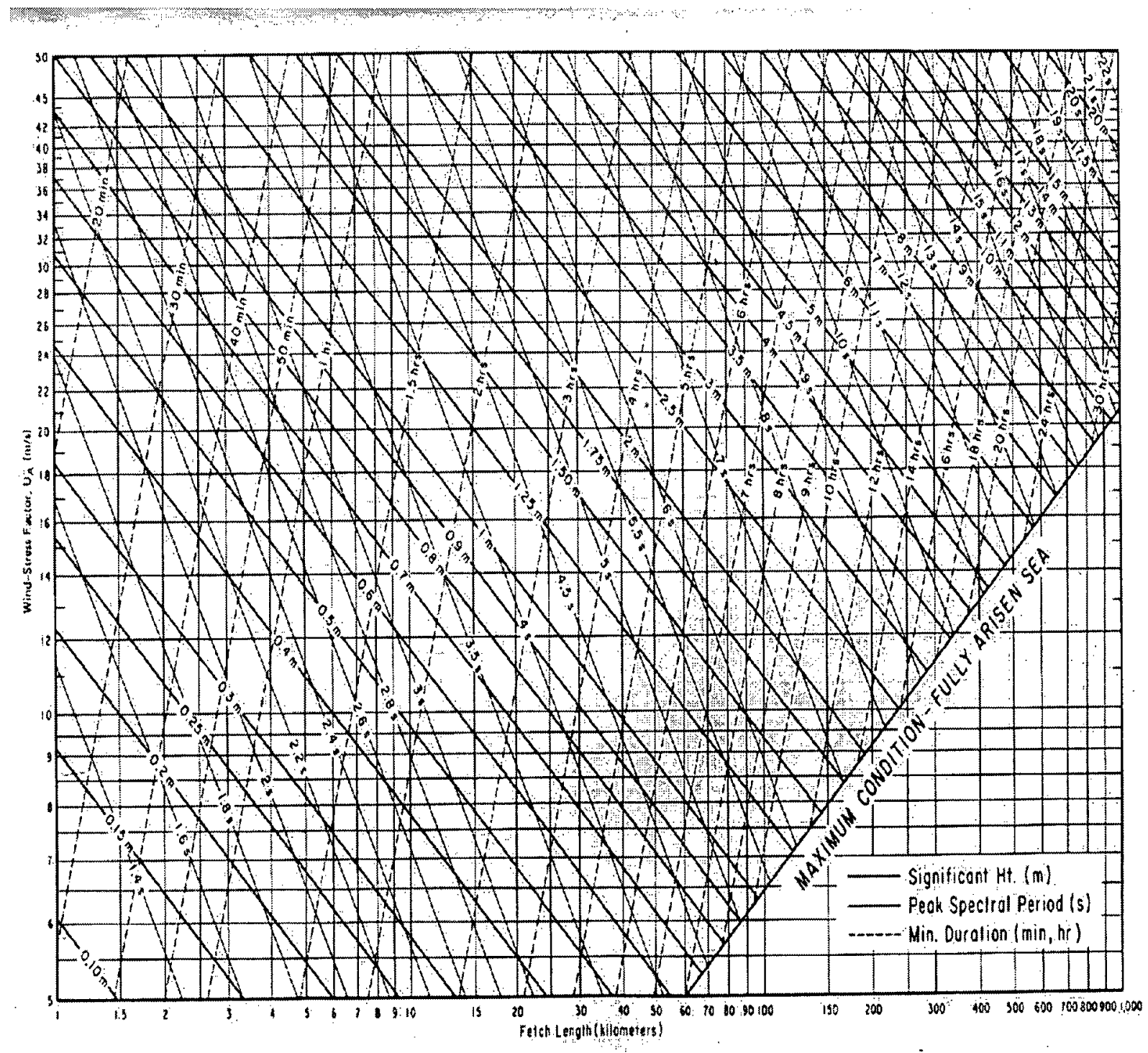

Figure 2.8 Deep-water Significant Wave Height and Period Monogram From CERC (1984) 


\section{QUANTITATIVE METHODS FOR ESTIMATING EXTREME CONDITIONS}

Estimates of extreme conditions used in the design of coastal structures require quantification of the extreme flood levels and wave conditions associated with a design probability and determination of wave run-up and overtopping conditions. This Chapter discusses the quantitative methods for estimating extreme conditions. Sections 3.1 and 3.2 discuss the methods for estimating extreme sea floods and extreme wave conditions, respectively. Section 3.3 describes the joint probability of flood levels and extreme wave conditions that occur in nature, which is essential for estimating extreme sea levels that include wave effects. Finally, Section 3.4 provides the methods for estimating wave run-up and overtopping conditions.

\subsection{Methods for Estimating Flood Levels}

Methods for estimating flood levels range from statistical to deterministic approaches. Statistical analysis is the conventional method for determining an extreme flood level; however, due to the assumptions used in the statistical methods, such an approach is usually limited by the availability of long-term data. The statistical methods include the Annual Maxima Method and Annual $R$-largest Maxima Method, which are described in Sections 3.1.2 and 3.1.3, respectively. These statistical approaches require long-term data, and a common problem encountered by coastal engineers is the lack of such data, particularly for sea levels and waves. In addition, the statistical approaches consider flood levels as a single independent variable, but flood levels are 
actually influenced by a range of factors, such as tides and storm surges. The deterministic approaches incorporate simplified representations of sea conditions that are composed of only the critical components that contribute to sea level fluctuations. These approaches require data collected for a relatively short period of time, but the complexities of flood levels may not be fully characterized. The Simple Addition Method introduced in Section 3.1.4 is a deterministic approach that does not consider the probability associated with each component. The Joint Probability Method (JPM) introduced in Section 3.1.5 incorporates the components that affect sea level fluctuations, and the probability associated with the various components. The most successful applications of the JPM have been for tidally dominant sites. The Revised Joint Probability Method (RJPM) presented in Section 3.1.6 was developed to overcome the restrictions of the JPM. Before presenting these methods, the concept of a probability of exceedance and return period associated with an extreme condition is introduced in Section 3.1.1.

\subsubsection{Probability of Exceedance and Return Period}

The main objective of the extreme analysis of flood levels or wave conditions is to determine the future probability of the occurrence of an event. The future probability of occurrence of an event can be characterized by the probability of exceedance $(p)$, which is the probability of a flood level being exceeded in any one time period, or the return period $\left(T_{R}\right)$, which is the average number of time periods between occurrence of events equal to or greater than a given flood level. $T_{R}$ is then the reciprocal of $p$. 
To obtain $p$ and $T_{R}$, allow $f(x)$ to be the probability density function for the variable of interest $(x)$. Then $F(x)$ is the cumulative distribution function for this variable. The probability that $x$ will not exceed an extreme event $(z)$ in any one time period as defined by:

$$
F(z)=\int_{-\infty}^{z} f(x) d x
$$

The probability of $z$ being exceeded in any given year, or the probability of exceedance $(p(z))$ is described as:

$$
p(z)=1-F(z)=\int_{z}^{\infty} f(x) d x
$$

In addition, the return period of $z$, which is denoted as $T_{R}(z)$, is the reciprocal of $p(z)$ (Pugh and Vassie, 1980, Watt et al., 1989):

$$
T_{R}(z)=\frac{1}{p(z)}=\frac{1}{1-F(z)}
$$

In this thesis, the variable of interest, $x$, could represent either sea level or wave height. The value $z$ therefore represents the extreme flood level or extreme wave height. The magnitude of the extreme flood or extreme wave condition, $z$, corresponds to a particular exceedance probability $(p(z))$ and return period $\left(T_{R}(z)\right)$.

\subsubsection{Annual Maxima Method}

The Annual Maxima Method is a frequency analysis of the historical flood levels. This section presents the application, data requirements, assumptions, and advantages and disadvantages of this method. It is important to keep in mind the possibility that the basic flood 
data being processed may contain substantial errors resulting from human failings and the difficulty of measuring high floods particularly during extreme conditions (Watt et al., 1989).

\subsubsection{Application}

The application of the Annual Maxima Method involves the following steps: selecting a sample in the form of an available data series, fitting a theoretical probability distribution to the sample, and determining the extreme flood levels based on the theoretical probability distribution.

In the analysis of historical flood levels, the maximum value of hourly sea levels for each year is first identified and extracted from the original set of sea level data to form the maximum annual series. The maximum annual series is then screened for missing data and outliers. Missing data series are categorized into broken records and incomplete records. A broken record is generally due to financial or manpower constraints, and is not related to the occurrence of an event, thus "the different record segments should normally be combined and treated as continuous record" (Watt et al., 1989). An incomplete record may result from extreme events, and may indicate an inaccurate recording of an extreme event. Therefore, missing data should be estimated in a manner consistent with the data collection agency (Watt et al., 1989). The annual maxima series should also be screened for outliers, which refer to observations in a data set which depart significantly from the main trend of the data. An outlier could be the result of an error in measurement, in which case it will distort the interpretation of the data. Environment Canada recommends that "no special measures be adopted to identify and treat outliers unless one or more very unusual event of a special nature are known to have occurred" (Watt et al., 1989). 
The screened annual maxima series is ranked in descending order according to observed sea levels. The probability of exceedance is estimated for each data point by applying plotting position formula. Examples of the plotting position formula are shown in Table 3.1, and the most commonly used formula are the Weibull and Cunnane. As indicated in Table 3.1, the empirical probability of exceedance or plotting position, $p_{m}$, is a function of the number of data points $(N)$ and the rank of the data value $\left(m_{n}\right)$. Each data value represents an extreme water level with an empirical probability of exceedance which is then used to fit a distribution type. Two approaches for defining the theoretical distribution are used for annual maxima series. The traditional approach plots data points on different types of distribution paper, where the return period is plotted on the $\mathrm{x}$-axis and the water level is plotted on the $\mathrm{y}$-axis. A linear trend is determined among the data points and the distribution that is most appropriate is selected based on the best-fit linear function. Theoretical distributions can also be determined using the parameters of the distribution types, and examples of the distribution types commonly used are

the Log-Normal (LN), and Extreme Value (EV) Distributions including the Generalized Extreme Value (GEV), Extreme Value Type I or Gumbel (EV I), and Extreme Value Type III or Weibull (EV III) Distributions.

\subsubsection{Data Requirements}

The Annual Maxima Method requires a long record of observed sea levels. While there is no standard for the minimum length of data set for a reasonable estimation, two sources of literature provide some guidance on this matter. Pugh and Vassie (1980) suggest that "the number of years of data required is not explicit, but estimates based on fewer than 25 years of data are unlikely to be reliable." Viessman, and Lewis (1996) also suggest that the required 
length of the data set depends on the projected quantile, where the "extrapolation using any of the graphical aids is not recommended beyond two times the period of record" (Viessman, and Lewis, 1996). Therefore, given the general practice of coastal engineering that requires the estimation of extreme flood levels having a minimum return period of 200 years, using the latter rule, the data collection required for the return period should be at least 100 years duration.

\subsubsection{Assumptions}

The application of the Annual Maxima Method requires several assumptions regarding the statistical characteristics of the data, the length of the data set, and the theoretical distribution. The statistical characteristics include randomness, independence, non-homogeneity and stationarity (Watt et al., 1989). For randomness to hold the fluctuations of the variable must arise from natural causes. Independence refers to the requirement that there should be no relationship between two consecutive events. For example, the dependence between successive hourly sea levels is strong due to tides, while the dependence between annual maximum values is generally weak. Non-homogeneity implies that all the elements of the data series originate from different populations or are caused by different storms. Stationarity requires that the mean and variance of the data are invariant with respect to time. There are statistical tests for the latter three criteria (e.g., the Mann-Whitney test can be used to test stationarity and homogeneity). The use of a large set of data is also required because it provides a fair size of sample to represent the actual condition (Watt et al., 1989), and it is necessary to justify the asymptotic arguments when the GEV Distribution is applied to the annual maxima series (Tawn, 1992). In addition, the Annual Maxima Method requires the assumption that all data share the same theoretical distribution type (i.e., they are identically distributed). Failures to meet these 
assumptions do not necessary imply the complete invalidity of the method, but the users should be cautious when extrapolating or interpolating from the theoretical distribution.

\subsubsection{Advantages and Disadvantages}

The Annual Maxima Method is the most commonly used method of estimating extreme flood levels. However, there are several disadvantages of utilizing this method. The method does not specify the physical properties of the flood levels, which are comprised of tides and storm surges. The largest meteorological surge in a particular year is unlikely to be considered unless it happens to coincide with high tide (Pugh and Vassie, 1980). However, storm surges are commonly the governing factor in an extreme condition, so a distribution of storm surges imbues a more meaningful insight into the estimation of actual extreme conditions. Therefore, the Annual Maxima Method, which is incapable of representing sea levels as a function of various factors, cannot portray the impact of storm surges. Another disadvantage of this method is the requirement for a long-term data collection, though only one value from each year is utilized for the annual maxima series. The data extraction process may exclude some of the extreme events, since only one event in a year is used. For example, one year may have lower values of water level in general, but the maximum value from this year is still considered an extreme.

\subsubsection{R-Largest Maxima Method}

The Annual Maxima Method is improved by the $R$-Largest Maxima Method, which is the same as the Annual Maxima Method except that the $R$-Largest Maxima Method extracts $R$ number of maximum values from each year instead of only one value from each year. This 
method was first applied to estimate extreme sea levels by Pirazzoli (1983) in a study of sea levels in Venice. The sea level in Venice is steadily rising, so it is important to examine $R$ extreme values per year to identify the trend (Tsimplis and Blackman, 1997). The $R$-largest Maxima Method shares the same assumptions as the Annual Maxima Method but while the assumptions regarding the statistical criteria for the data set, the long-term data set, and the distribution type may be met, the assumptions regarding independence and non-homogeneity criteria may not. Because the same storm can continue for hours and yield a number of extreme sea levels for a particular year, extreme sea levels from the same storm are clearly dependent or homogeneous. Therefore, there should be a screening process to ensure that the $R$-largest values for each year are from different storms. An example of such a screening process involves selecting a storm length, $\tau$, in hours, such that the $R$-largest values from the same year are chosen to be at least $\tau$ hours apart (Tsimplis and Blackman, 1997). Because more than one maximum value is selected from one year, this method requires only just over ten years of data for a reliable estimation (Tawn and Vassie, 1989).

Similar to the Annual Maxima Method, the $R$-largest values from each year are fit to a suitable extreme value distribution, and the theoretical distribution is used to estimate the extreme flood levels. The suggested distribution type for this method is the GEV Distribution. Assuming that each individual extreme value belongs to the same GEV Distribution, the density function of the $R$-largest values $\left(Z_{1}, Z_{2}, \ldots, Z_{R}\right)$ for each year is shown to be (Smith, 1986; Tsimplis and Blackman, 1997):

$$
f\left(Z_{1}, Z_{2}, \cdots, Z_{R}\right)=\varsigma^{-R} \exp \left\{-\left[1-k\left(\frac{Z_{R}-\mu}{\varsigma}\right)\right]^{\frac{1}{k}}+\left(\frac{1}{k}-1\right) \sum_{j=1}^{R} \log \left[1-k\left(\frac{Z_{j}-\mu}{\varsigma}\right)\right]\right\}
$$

where $Z_{1, \ldots, R}$ denotes the $R$ extreme values for the year, $\mu$ is the mean of $Z_{1}, Z_{2}, \ldots, Z_{R}, \varsigma$ is the standard deviation of $Z_{1}, Z_{2}, \ldots, Z_{R}$, and $k$ is the parameter of the distribution. Equation 3.4 is 
valid under the following conditions: 1) $Z_{l}>Z_{2}>$.. $>Z_{R}$, and 2) $1-k\left(\frac{Z_{1}-\mu}{\varsigma}\right)>0$. If $Z_{l, l}, Z_{2, l}, \ldots$, $Z_{(R-I), n}, Z_{R, n}$, are the largest values for each year, $n$, Equation 3.4 approximates the joint density of the $R$-larger values for each year through $\mu_{n}, \varsigma_{n}$ and $k_{n}$, where $\mu_{n}, \varsigma_{n}$ and $k_{n}$ are the mean, standard deviation, and distribution parameter of the $R$-largest values for $n$ years. Finally, the extreme sea levels can be interpolated or extrapolated with a selected probability of exceedance and return period by employing the theoretical distribution.

\subsubsection{Advantages and Disadvantages}

By extending the use of the data set, this method renders considerably more precise estimates of the extreme levels than the Annual Maxima Method, because more than one high water value is taken from one year. Furthermore, the use of $R$ number of maximum values from each year allows for a connection to regional climate variability, which in effect requires a shorter data set to ensure the reliability of this method (Tsimplis and Blackman, 1997). However, the method does not overcome the fundamental problems observed for applications of the Annual Maxima Method, that is, the lack of accounting for sea-level data that characterize the various components of sea level fluctuations.

\subsubsection{Simple Addition Method}

The Simple Addition Method estimates extreme sea levels by simply adding extreme values of all factors which are considered significant to sea level variations. The value for each factor is estimated in one of two ways: either it is the probable maximum value of the data in the 
history of record or it is the quantile obtained using the Annual Maxima Method or the R-Largest Method.

Ker, Priestman \& Associates Engineering Ltd. (KPA) describes another procedure for selecting appropriate values for tides and storm surges. The two data sets, used for the purpose of comparison, are the monthly maxima of the observed water levels (i.e., tides plus storm surges) and residuals (i.e., storm surges) occurring at the time of the monthly peak water level. Sea levels are estimated in different combinations in this work, such as monthly maxima or median tidal waves plus residuals. In addition, the probability of extreme values is also extracted by two methods: selecting the highest annual values and selecting the highest values in the entire data set (KPA, 1992). Although the study indicates that the results of extreme sea levels using different data sets and probabilities are similar, it shows the degree of variety in choosing data sets and methods. Due to the conservative nature of the Simple Addition Method, adjustments may be made. KPA (1994) demonstrates such adjustments in which the final estimation of extreme sea level is determined by subtracting $0.44 \mathrm{~m}$ from the sum of the extreme water level components.

An example of the second approach to estimate values for the critical factors is presented in SeaConsult Marine Research Ltd. (1985). Here, the extreme sea level is calculated by adding the 200-year storm surge and maximum tides (Hodgins, 1985). In general, the factors involved in the estimation include tides, storm surges, and allowance for errors and other factors. For example, the study conducted by KPA (1990) estimates the extreme sea level by adding the high tides, maximum storm surges, additional allowance for concurrent local wind setup, numerical errors in data, wind chop, El Niño effects, and freeboard. Freeboard is considered in order to account for factors such as wave run-up, seiches, rise in sea level, and settlements. The value of freeboard is generally regulated by local authorities. In this study, the values for each item are estimated as the probable maximum values based on historical data. 


\subsubsection{Advantages and Disadvantages}

The Simple Addition Method offers the advantages of being simple and involving minimal computation time. However, this method is also very conservative, because all factors are assumed to occur at the same time. In fact, the probability of the maximum effects from all factors occurring at the same time is very low. There is also the difficulty in determining a reasonable value for each factor. There is a great variety in the methods of estimating the value and the probability associated with any estimation is subjective, because no actual joint probability is calculated.

\subsubsection{Joint Probability Method (JPM)}

The importance of obtaining accurate estimates of extreme sea levels enhanced the need for improvements in the precision of the resulting estimates and in the ability to use shorter data series (Tawn and Vassie, 1990). The JPM was developed by Pugh and Vassie (1980) to fulfill these two objectives. The major difference between this method and the aforementioned methods is that it recognizes the various components causing sea level variations that are considered in the engineering context as discussed in Section 2.3.

The three main components of sea level variations considered in the JPM are the mean sea level $\left(Z_{0}(t)\right)$, tidal level $(X(t))$, and meteorologically induced level $(Y(t))$. The mean sea level refers to the long-term variations caused by climatologic and geologic effects and can be identified by standard regression of the long-term record of the observed sea level. However, this term is usually assigned a constant value or a value of zero, because it generally is small 
compared with tidal and meteorologically induced levels (Tsimplis and Blackman, 1997). The tidal levels are generally predicted based on measured tide data as described in Section 2.3.5.4. The meteorologically induced sea level is in general the effect of storm surges and in some cases is due to a combination of storm surges. Thus, the sea level, $\zeta(t)$, is defined as follows (Pugh and Vassie, 1980):

$$
\zeta(t)=Z_{o}(t)+X(t)+Y(t)
$$

With the availability of observed sea level data $(\zeta(t))$ and tide data $(X(t))$, and an assumption of $Z_{0}(t)=0$, the storm surge can be expressed as:

$$
Y(t)=\zeta(t)-X(t)
$$

If the probability density function of storm surges is $f_{T}(y)$, the probability density function of tides can be represented by $f_{T}(\zeta-y)$. The JPM assumes that tides and storm surges are independent, thus the probability density function of the total sea level can be expressed as (Pugh and Vassie, 1980):

$$
f(\zeta)=\int_{-\infty}^{\infty} f_{T}(\zeta-y) f_{S}(y) d y
$$

The cumulative density function, $F(\zeta)$, for a given extreme sea level, $z$, is:

$$
F(z)=\int_{-\infty}^{z} f(\zeta) d \zeta
$$

Given the cumulative density function of the sea level, any probability of exceedance and return period can be obtained by applying Equations 3.2 and 3.3 .

The following sections describe the detailed application of the JPM, the data requirements and assumptions for the method, and its advantages and disadvantages. 


\subsubsection{Application}

Throughout this description of the JPM, it is assumed that hourly data are available for the factors that contribute to sea level fluctuations, although the JPM may be applied for data collected at any short time interval. In the case of hourly data, the JPM is used to estimate the sample probability density functions for each contributing factor in Equation 3.7, to estimate the hourly joint probability of exceedance based on these, and to use the hourly joint probability of exceedance to estimate the annual joint probability of exceedance. The corresponding return period may also be determined based on Equation 3.3. Because the JPM can be applied for data collected for short time intervals, it can be used in cases with short data records, on the order of years, providing that there are sufficient and accurate data records within those years.

For example, assuming availability of hourly tides and observed sea levels, the process of estimating the hourly joint probability of exceedance begins with compiling the time series of hourly tides and storm surges. The time series of hourly tides are in general provided by local hydrographic services, and the hourly storm surges may be determined by indirect measurements (i.e., subtracting the tides from the observed sea levels) or numerical models. Then, the time series of tides $(X(t))$ and storm surges $(Y(t))$ are used to construct histograms for the tides and storm surges. With reference to Figure 3.1, for $N$ data points, $n$ intervals for tides $(X)$ and $m$ intervals for storm surges $(Y)$, the relative frequencies, $f$, in the highlighted cells represent the probabilities of occurrence of tides and storm surges for the given intervals. For example, $f\left(X_{m}\right)$ is the relative frequency of tides in the interval of $X_{m-l}$ to $X_{m}$, and, if the interval size is sufficiently small, is an estimate of the probability of occurrence for $X=\frac{X_{m-1}+X_{m}}{2}$. The series of probabilities of occurrence for each variable may be used to construct its sample probability 
density function. Applying Equation 3.7, the product of the sample probability density functions of tides and storm surges yields the sample joint probability density function of tides and storm surges. The sample joint probability density function of tides and storm surges are used in Equation 3.8 to determine the sample joint cumulative density function and the sample joint probability of exceedance based on Equation 3.2. Denoting the sample joint probability of exceedance as $p_{N}(z)$, the joint hourly probability of exceedance, $p_{1}(z)$, is determined based on:

$p_{N}(z)=1-\left[1-p_{1}(z)\right]^{N}$

where $z$ is the sea level composed of tides and storm surges. For large values of $N$, Equation 3.9 can be approximated as:

$p_{N}(z) \approx 1-\exp \left[-N p_{1}(z)\right]$

If the values of sea levels exhibit persistence (i.e., dependence between values in adjacent time periods) the hourly probability of exceedance may be adjusted. The JPM has been adapted based on the assumption of one-dependence, which implies that the probability density function of each sea level depends only on the value of the previous sea level (Pugh and Vassie, 1980). Here, the hourly joint probability of exceedance in a set of $N$ samples can be determined by solving the following equation (Pugh and Vassie, 1980):

$$
p_{N}(z)=1-\exp \left[-N p_{1}(z)\left(1-\frac{p_{2}(z)}{p_{1}(z)}\right)\right]
$$

where $p_{2}(z)$ is the probability of exceeding $z$ in two successive time periods and can be determined by constructing the histograms based on two-hour intervals. Pugh and Vassie (1980) indicate that "the adjustment for correlation (i.e., $\left.1-\frac{p_{2}(z)}{p_{1}(z)}\right)$ is so small compared with the uncertainties from other causes that, in view of the accuracy. required, in practice it is not 
required." The ultimate goal of the JPM is to determine the annual joint probability of exceedance and return period in years. Thus, the relationship between the annual joint probability of exceedance and the hourly joint probability of exceedance needs to be established. If $p_{Y}(z)$ is defined as the annual joint probability of exceedance, $p_{Y}(z)$ can be described as a function of $p_{l}(z)$ (Pugh and Vassie, 1980):

$p_{Y}(z)=1-\exp \left[-8766 p_{1}(z) \alpha\right]$

where $\alpha=1$ for independent hourly sea levels, and $\alpha=1-\frac{p_{2}(z)}{p_{1}(z)}$ for dependent hourly sea levels. The argument of the exponential described in Equation 3.12 is very small in the case of extreme values due to the low probability of exceedance; thus, Equation 3.12 can thus be modified to (Pugh and Vassie, 1980):

$p_{Y}(z)=8766 p_{1}(z) \alpha$

The annual joint probability of exceedance may be used to determine the corresponding return period by applying Equation 3.3.

\subsubsection{Data Requirements}

The JPM requires two types of data, the hourly tide and hourly observed sea level at the same location. As suggested by Pugh and Vassie (1980), two years of data will provide a reliable estimation. Because short-term data are used in this method, the JPM requires "a better observational accuracy and greater diligence in data processing (than the Annual Maxima Method)" (Pugh and Vassie, 1980). In particular, the process of obtaining the time series of storm surge levels requires careful consideration because timing errors may occur when different 
time scales are used for the time series of tides and observed sea levels. Timing errors can distort the probability distribution of storm surges, which is a governing factor for extreme flood levels. Thus, the timing should be corrected to within one or two minutes (Pugh, 1989). It is also important to choose the data having no bias regarding a particular season, because the amplitude and frequency of storm surges vary seasonally. Nevertheless, when accurate data are not available, Tawn and Vassie (1990) suggest that the JPM is applicable if at least ten years of data are available.

\subsubsection{Assumptions}

The application of the JPM is valid under a few assumptions. While hourly sea levels must be independent, the independent assumption for sea levels is weak for two possible reasons, due to the tidal and storm surge influences. Tidal influences are the usual cause of dependent sea levels at tide-dominant sites, whereas storm surges, which can last for hours, are the common cause of dependent sea levels at storm-dominant sites. Therefore, the assumption must be relaxed so that the probability density function of each sample depends only on the value of the previous sample (i.e., the assumption of one-dependence). In addition, tides and storm surges are assumed to be independent for Equation 3.7 to be valid, and adherence to this assumption is site specific. The assumption of the independent relationship between tides and storm surges is usually true except in shallow water where there is significant tide and storm surge interaction (Tawn and Vassie, 1989). Tides and storm surges interact in shallow water areas in that the largest storm surges are restricted from occurring at high tide (Tawn, 1992). In order to satisfy

this assumption, Pugh and Vassie (1980) suggest finding the storm surge distributions for each interval of tides. This increases the computation time, and is not applicable in the cases with 
more than two dependent variables. Another assumption is that the density function of storm surges over a given period should represent the probability density function for the population of all storm surges. This assumption is the key to the stability of the JPM and must hold if the tidal and storm surge probabilities are to be combined to compute the probabilities of total sea levels as described by Equation 3.7 (Pugh and Vassie, 1980). Using data in Aberdeen and Newlyn, Britain, Pugh and Vassie (1980) conclude that "the surge activity is a stationary process and that a few years of data gives a representative sample of the surge population."

\subsubsection{Advantages and Disadvantages}

The advantages of this approach include: 1) the physical factors affecting sea levels are identified and incorporated, 2) stable values are obtained from a relatively short period of data, 3) the associated probabilities are not based on extrapolation, 4) less restrictive physical assumptions are required, and 5) separation of the deterministic tidal signal from the sea level should, in principle, provide a better way of estimating the stochastic storm surge signal (Pugh, 1987; Tawn, 1992; Tsimplis and Blackman, 1997). The first advantage is significant, because the extreme values caused by high storm surges with low tides can be identified by separating the observed sea levels into components of tide and storm surge levels. The JPM provides for a more explicit identification of the actual extreme conditions. The second advantage is practical for coastal engineers, because short-term data collection is a routine problem for coastal engineering projects. However, one of the primary disadvantages is that this method cannot be applied to the estimation of extreme sea levels composed of any number of dependent variables

due to the utilization of Equation 3.7 for obtaining the joint probability density function of factors contributing to extreme sea levels. Thus far, the JPM has only been applied to the 
estimation of extreme sea levels composed of tides and storm surges. In addition, the assumption of one-dependence in sea levels in the application could lead to significant bias in estimates of extreme sea level. This is a weak assumption in storm-dominant areas, where storms could last for several hours. The assumption that the empirical storm surge distribution represents the true population may not hold except for tide-dominant sites. For surge-dominant sites, this assumption is valid only if the number of samples is sufficiently large to represent the true distribution. Another disadvantage is that the JPM will not produce a probability of sea levels greater than the sum of the largest observed storm surge combined with the highest recorded astronomical tide, when in fact there is a possibility of a higher sea level occurring (Tawn and Vassie, 1989).

\subsubsection{Revised Joint Probability Method (RJPM)}

The Revised Joint Probability Method (RJPM) derived by Tawn and Vassie (1989) attempts to account for some deficiencies of the JPM caused by the assumptions requiring onedependence in sea levels and representative distributions of storm surges within a given period. The RJPM is applicable for both tide-dominant and surge-dominant sites, requiring only one year of the tide and observed sea level data. The underlying concept, assumptions, and procedures of the RJPM are similar to the JMP. The RJPM introduces the extremal index, $\delta$, to relax the assumption of one-dependence of sea levels and replace $\alpha$ in Equation 3.13:

$$
p_{N}(z)=N \delta_{n}(z) p_{1}(z)
$$

where $p_{N}(z)$ is the joint probability function, and $N$ is the number of observations in one year. The term, $N \delta_{n}(z)$, can be thought of as the effective number of independent observations in $N$ observations. The extremal index ranges from zero to one and can be explained in the inverse 
form, $\delta_{n}^{-1}(z)$, which is the mean overtopping time of sea level $z$ for each independent excursion. It is determined for different values of $z$ using the original time series of hourly sea levels. For example, if a storm lasts for only one hour in a storm-dominant site, the extremal index would be $1-\frac{p_{2}(z)}{p_{1}(z)}$ as assumed in the JPM.

The RJPM also introduces a modification to the determination of the probability density function for storm surges to account for insufficient data of storm surges for representing the true population. Instead of finding the probability density function for storm surges using the histogram, maximum values of storm surges are extracted from each independent event to generate a probability density function, which is represented by any EV Distribution.

This method can be coupled with a procedure of spatial transfer, if the site of interest has less than one year of data available. The extreme information is transferred from a site with an extensive sea level record to a neighbouring site which has only a limited data series (Tawn and Vassie, 1990). The distributions of tides and storm surges from the site of interest, which has fewer data, can be represented as a function of the distribution of tides and storm surges of the reference site where the data are adjusted with a time lag between the two locations and correlation coefficients. The extreme sea levels can be estimated with less than a year of data using this approach.

\subsubsection{Advantages and Disadvantages}

Although the RJPM requires the computation of the extremal index, $\delta_{n}(z)$, it provides a more statistically sound approach, and provides a higher level of confidence. The introduction of $\delta_{n}(z)$ is not only capable of addressing the dependence of sea levels but also guards against the effect of a small number of observations on the estimation of probability of exceedance and 
return period. In addition, the use of the extreme value function for storm surges can better represent the true population of storm surges. When the records of data collection are relatively short, the RJPM may provide an improved estimation of the extreme sea levels. However, the RJPM have the same deficiency as the JPM in terms of being incapable of finding the joint probability of extreme sea levels composed of a number of dependent variables.

\subsection{Estimation of Extreme Wave Conditions}

Due to the stochastic nature of waves, extreme wave conditions including both wave heights and periods are ideally obtained from long-term data of 15 to 20 years (Herbich, 1990). There is no established procedure for the selection of the design wave period. The general practice is to use a scatter diagram of the wave heights and associated periods based on the actual wave data, each point of which has a joint probability of occurrence, and to select a wave height and period combination based on structural design objectives. This section focuses on determining the design wave heights directly. The two approaches for selecting a design wave height take into consideration the long-term distribution of sea states and the long-term distribution of individual waves. Isaacson and Foschi (2000) determine the difference in the estimations of extreme wave heights using different approaches. They show that the maximum wave height in a sea state with a specified return period may be significantly different than the maximum individual wave height. They demonstrate that the return period of an individual wave height may be lower than the return period of a sea state (Isaacson and Foschi, 2000). Most guidelines suggest the use of the long-term distribution of sea states to estimate design wave conditions, but one should keep in mind that the maximum wave heights derived by the long-term distribution of sea states may occur more often than expected. This section discusses 
both approaches: the long-term distribution of sea states and the long-term distribution of individual waves.

\subsubsection{Long-Term Distribution of Sea States}

The parameters of sea states, including significant wave height, can be derived from measured or predicted wave data, and measured or predicted sea state values are then used to estimate extreme wave heights. When long-term data for sea states are available, the recommended procedure is similar to the Annual Maxima Method. The procedure involves 1) extracting the maximum value of significant wave heights or individual wave heights for each year, 2) fitting the annual maxima series to a theoretical distribution type, and 3) interpolating and extrapolating the design sea state or significant wave height with a selected probability of exceedance or return period. The commonly used distribution types for extreme wave conditions are the Gumbel, Frechet, Weibull, and Log-Normal Distributions (Isaacson and Foschi, 2000). Although no single distribution function is preferred for extreme wave statistics, the Gumbel Distribution and Log-Normal Distribution are most widely used (Goda, 1990). Given the estimated significant wave height of a specified return period, employing Equation 2.5 allows the estimation of maximum individual wave height within the design sea state.

\subsubsection{Long-Term Distribution of Individual Wave Height}

The use of the long-term distribution of individual wave heights to estimate the extreme wave condition is developed by Battjes (1970). Assumptions involved in this approach include

1) the sea state must remain unchanged between two successive observation hours, and 2) the 
individual wave height can be described by the Rayleigh Distribution (Goda, 1990). The cumulative probability function of individual wave heights $(H)$ is described as a function of significant wave heights and periods (Goda, 1990; Isaacson and Foschi, 2000):

$P(H)=\frac{\iint p\left(H \mid H_{s}\right) T^{-1} p\left(H_{s}, T\right) d H_{s} d T}{\iint T^{-1} p\left(H_{s}, T\right) d H_{s} d T}$

where $p\left(H \mid H_{s}\right)$ is the conditional probability function of individual wave heights under a given sea state, and $p\left(H_{s}, T\right)$ denotes the joint probability of the significant wave height and wave period. The probability of exceedance and return period can be obtained by applying Equations 3.2 and 3.3 .

\subsection{Joint Probability of Flood Levels and Extreme Wave Conditions}

Both flood levels and wave conditions are components of extreme sea levels. Sections 3.1 and 3.2 discuss methods for estimating flood levels and extreme wave conditions, respectively, but the joint probability of flood levels and extreme wave conditions is important when estimating extreme sea levels. However, the difficulties of incorporating wave statistics in a joint probability approach are as follows: 1) there is an interaction between wave probability and water levels, due to coastal refraction changing as sea levels change, and 2) conditions which produce maximum storm surges are also likely to produce high waves from a particular direction (Pugh and Vassie, 1980). Coastal refraction creates a dependence between waves and water levels and the degree of dependence between waves and water levels varies from site to site. Higher degrees of dependence between storms surges and waves exist because of the relationship between maximum storm surges and waves. However, in order to apply the JPM for multi-variables from observational data, the variables must be either completely independent or 
completely dependent (Hawkes et al., 2002). Thus, the JPM is generally simplified in order to estimate extreme sea levels. The simplification approaches involve: 1) calculating the design wave height with an assumed water level, 2) calculating the design water level with an assumed wave height, or 3) calculating extreme wave heights and water levels and applying the Simple Addition Method (Besley, 1999). These three approaches have different applications. For example, one of the applications of the first method is in situations where wave heights are limited by the depth of the water, because wave heights pose more randomness under this condition. Hawkes and Hague (1994), and Simm (1996) apply the JPM by deriving the time series of waves and water levels and analyzing correlation and joint probability. Hawkes et al. (2002) apply a Monte Carlo Simulation approach to find the joint probability of three variables. The three variables used in this study are water level, significant wave height, and mean wave period, where the distribution for each variable is used to simulate a synthetic set of data. The synthetic set of data is used to determine the joint probability, and the dependence issue is dealt with by a statistical model for dependence. The principal advantage of applying Monte Carlo Simulation with the JPM is that the higher extreme sea levels, which are not observed or measured within the period of data collection, may be replicated by the Monte Carlo Simulation. However, these approaches ignore different components of extreme flood levels in order to compromise the inclusion of extreme wave conditions in the estimation of extreme sea levels.

\subsection{Wave Run-up and Overtopping Discharges}

Wave run-up and overtopping discharges are two important factors influencing the crest height of a coastal structure, because they determine the amount of freeboard required to prevent or minimize overtopping. As waves propagate into shallow water, some waves start to break. 
After waves break, the momentum keeps the water moving up the face of a beach or shore structure. Wave run-up, $R_{w}$, is defined as the maximum vertical height above the still water level. When the wave run-up exceeds the crest height of a coastal structure, overtopping occurs. This section discusses overtopping as a volume, and as an allowable overtopping discharge. Wave run-up and overtopping discharges depend on a large number of variables, such as geometric variables and wave conditions. The transition of waves entering shallow water is discussed in Section 3.4.1, two approaches for predicting wave run-up are described in Section 3.4.2, and approaches for predicting the overtopping discharges are discussed in Section 3.4.3.

\subsubsection{Wave Transition in Shallow Water}

The transition from deep to shallow water changes the wave characteristics. As waves propagate from deep water to shallow water, wave heights initially decrease slightly, and then the wave heights rapidly increase until break-point is reached. Unlike the wave height, the wavelengths shorten as the depth decreases, and the decrease proceeds at a rate proportional to the decrease in the wave speed. The increase of wave heights and decrease of wavelengths yields an increase in the steepness of the waves, that is, an increase in the ratio of the wave heights to the wave lengths. Conversely, the ratio of water depth to wavelengths decreases and reaches a lower limit for shallow-water waves. Once waves fall into the category of shallowwater waves, the waves are affected by the sea bottom. In addition, an asymmetrical wave profile starts to develop in shallow water. The asymmetry develops around the horizontal axis as the wave crest steepens and the wave trough flattens. A comparison of waves in deep and shallow water is shown in Figure 3.2. Figure 3.2 indicates that the positive and negative sides of the wave profile in deep water are similar, whereas the peaks of the wave profile are much 
sharper than the troughs in shallow water (Ochi, 1998). The asymmetrical waves are unstable and eventually break, when the wave steepness reaches about $1 / 7$ (Abbott, 1999). A wave breaks for two basic reasons: 1) the wave becomes so steep that it can no longer support its own weight and the crest collapses, or 2) the speed of the water that moves with the crest of the wave exceeds the speed of the wave, allowing the water in the crest to overtake the wave form, and causing it to fall and break (Thomson, 1980). After breaking, waves have smaller amplitudes, and they may continue to break if the condition stated above is reached or they may not break. The breaking or non-breaking waves finally advance onto the shore and run up the coastal structures. The maximum distance above the mean sea level that the wave runs up a coastal structure is defined as the wave run-up. The volume of wave run-up overtopping the coastal structures is the overtopping discharge.

\subsubsection{Prediction of Wave Run-Up}

Wave run-up is the maximum vertical height above the still water level to which the water from an incident wave will rise on the beach or structure, denoted as $R_{w}$ in Figure 3.3 (Sorensen, 1997; CERC, 1984). Wave run-up is a function of various factors, such as wave characteristics, geometric variables, and fluid properties. The wave characteristics include the wave heights, period, length, celerity, and energy. The geometric variables include water depth, slope of the beach, slope of the structure, shape of the structure, slope relative roughness, and angle of wave approach. The fluid properties include mass density and dynamic viscosity. However, the prediction of wave run-up is made possible by simplifying the parameters, and by ignoring some variables. The following two sections introduce two methods to predict wave run-up: the Shore Protection Manual (SPM) Method and the Van der Meer and Janssen (VDMJ) 
Method. The two approaches use empirical relationships derived from experimental results, and the different experiments performed distinguish the two methods. For instance, the SPM Method uses deep-water wave characteristics to predict the wave run-up, whereas the VDMJ Method requires the shallow-water wave characteristics. Futhermore, the SPM Method predicts the wave run-up in general, whereas the VDMJ Method estimates the wave run-up associated with the 50-year wave. The appliability of the approaches mainly depends on the data availability. The Federal Emergency Management Agency (FEMA) suggests that the SPM Method provides the mean wave run-up instead of the extreme value of wave run-up when coastal structures are comprised of composite slopes (Headland et al., 2000).

\subsubsection{Shore Protection Manual (SPM) Method}

The Shore Protection Manual (SPM) Method for estimating wave run-up was developed by Stoa (1979), who re-analyzed the results from several experimental investigations by Brunn, et al. (1984). The SPM Method recognizes the following variables as parameters of wave runup: water depth at structure toe $\left(d_{s}\right)$, bottom slope in front of a structure $(\theta)$, incident deep-water wave height $\left(H_{0}\right)$, incident deep-water wave period $(T)$, structure shape and roughness, and scale effects, as shown in Figure 3.3(CERC, 1984). The first four parameters are included in the empirical relationship:

$$
\frac{R_{\text {smooth }, l a b}}{H_{0}^{\prime}}=f\left(\theta, \frac{d_{s}}{H_{0}^{\prime}}, \frac{H_{0}^{\prime}}{g T^{2}}\right)
$$

Equation 3.16 defines the relative wave run-up or the ratio of wave run-up on smooth and impermeable slopes in small-scaled physical models $\left(R_{\text {smooth }, l a b}\right)$ to incident deep water wave height $\left(H_{0}^{\prime}\right)$. The relative wave run-up, $R_{\text {smooth,lab }} / H_{0}^{\prime}$, is a function of the bottom slope $(\theta)$, 
relative depth or ratio of water depth to incident deep water wave height $\left(d_{s} / H_{0}^{\prime}\right)$, and relative steepness $\left(H_{0}^{\prime} / g T^{2}\right)$. The empirical relationship can be illustrated by a set of wave run-up curves. Figure 3.4 contains a set of such curves for wave run-up on smooth and impermeable slopes on a $1: 10$ bottom slope when $d_{s} / H_{0}^{\prime} \approx 2.0$. Similar graphs have been developed for $d_{s} / H_{0}^{\prime}=0, d_{s} / H_{0}^{\prime} \approx 0.45, d_{s} / \dot{H_{0}^{\prime}} \approx 0.8$, and $d_{s} / H_{0}^{\prime} \geq 3.0$ on $1: 10$ bottom slope, and $d_{s} / H_{0}^{\prime}=3, d_{s} / H_{0}^{\prime}=5$, and $d_{s} / H_{0}^{\prime}=8$ on a horizontal bottom, and these curves are included in Appendix A. The other parameters that affect the wave run-up are structure roughness and scale effect, and the prediction of the actual wave run-up is adjusted for these by:

$R_{w}=\frac{R_{\text {smooth }, l a b}^{\prime}}{H_{0}^{\prime}} H_{0}^{\prime} \gamma_{f} \gamma_{s}$

where $\gamma_{f}$ is the reduction factor for slope roughness and porosity, and $\gamma_{s}$ is the adjustment factor for scale effects. The concept of a reduction factor for slope roughness is introduced by Battjes, et al. (1984), who recognize the effect of roughness and porosity on wave run-up and suggest the use of a roughness and porosity correction factor to allow for wave run-up calculations for a range of structure slope characteristics. This roughness reduction factor, $\gamma_{f}$, is the ratio of wave run-up or relative wave run-up on rough permeable or other non-smooth slope to the wave runup on a smooth impermeable slope. That is:

$r_{f}=\frac{R_{\text {rough }}}{R_{\text {smooth }}}=\frac{R_{\text {rough }} / H_{0}^{\prime}}{R_{\text {smooth }} / H_{0}^{\prime}}$

The values of $\gamma_{f}$ for various types of surfaces are listed in Table 3.2. Similarly, the correction factor for scale effects, $\gamma_{s}$, represents the ratio of wave run-up derived for scaled physical models or other non-smooth slopes to the wave run-up under the actual physical setting. The value of $\gamma_{s}$ is a function of wave heights and slope and is summarized in the curves shown in Figure 3.5. 
In conclusion, the prediction of wave run-up begins with identifying all parameters, including water depth at structure toe $\left(d_{s}\right)$, bottom slope in front of a structure $(\theta)$, incident deepwater wave height $\left(H_{0}\right)^{\prime}$, incident deep-water wave period $(T)$, and surface materials. Then, two ratios are calculated, the wave steepness ratio $\left(H_{0}^{\prime} / g T^{2}\right)$ and relative depth ratio $\left(d_{s} / H_{0}^{\prime}\right)$. The relative depth ratio is used to identify an appropriate set of wave run-up curves. According to the wave run-up curves, the relative wave run-up is obtained with the slope and the wave steepness ratio. The actual wave run-up is estimated according to Equation 3.18, which adjusts wave run-up for a range of roughness and porosity, and scale effects.

\subsubsection{Van Der Meer-Janssen (VDMJ) Method}

In European practice, wave run-up is often indicated by $R_{u, 2} \%$, representing the wave runup level above the still water level which exceeds $2 \%$ of the incoming waves, or the 50 -year waves. According to a series of tests under various factors, Van der Meer and Janssen (1994) expressed the average value of the wave run-up for a smooth straight slope as:

$\frac{R_{u, 2 \%}}{H_{s}}=1.5 \gamma_{h} \gamma_{f} \gamma_{\beta} \xi_{e q}$

where $H_{s}$ is the significant wave height near the toe of the structure, $\gamma_{h}$ is the reduction factor for a shallow foreshore, $\gamma_{f}$ is the reduction factor for slope roughness, $\gamma_{\beta}$ is the reduction factor for an oblique wave attack, and $\xi_{e q}$ is the equivalent breaker parameter for a slope with a berm.

The reduction factor for a shallow foreshore $\left(y_{h}\right)$ is included when the relative depth ratio is between 1 and 4 , in which waves start to break. Thus, $\gamma_{h}$ can be estimated as: 
$\gamma_{h}=1-0.03\left(4-\frac{d_{s}}{H_{s}}\right)^{2}$

The reduction factor for slope roughness is listed in Table 3.3, Table 3.4, and Table 3.5. They list alternative slope roughness reduction factors for a range of armour and construction materials.

The angle of the wave attack can also influence the wave run-up. Van der Meer and de Wall (1993) describe wave run-up as a function of obliquely incoming waves and directional spreading. This investigation suggests that $\gamma_{\beta}$ for the $2 \%$ wave run-up is estimated by:

$\gamma_{\beta}=1-0.0022 \beta$

where $\beta$ is the angle of the propagation direction with respect to the normal alignment axis of coastal structures. Equation 3.21 requires $\beta$ to be measured in degrees, and the definition of $\beta$ is shown in Figure 3.6.

Since the VDMJ Method uses the shallow-water waves in the prediction of wave run-up, wave breaking is a phenomenon necessary to be taken into consideration during the calculation of wave run-up. The equivalent breaker parameter for a slope with a berm can be estimated by (Pilarczyk, 2000):

$\xi_{e q}=\gamma_{b} \xi_{o p}$

where $\gamma_{b}$ represents the reduction factor for a berm, and $\xi_{o p}$ represents the breaker parameter. In addition, the breaker parameter is obtained by (Pilarczyk, 2000; Besley and Allsop, 2000):

$$
\xi_{o p}=\frac{\tan \theta}{\sqrt{2 \pi H_{s} /\left(g T_{p}^{2}\right)}}
$$

where $\theta$ denotes the bottom slope in front of a structure, and $T_{p}$ denotes the peak period of the wave spectrum. The reduction factor, $r_{b}$, can be estimated by (Headland et al., 2000): 
$r_{b}=1-\frac{B_{w}}{L_{b e r m}}\left[1-0.5\left(\frac{d_{h}}{H_{s}}\right)\right]$

where $B_{w}$ denotes berm width, $L_{\text {berm }}$ denotes berm length, and $d_{h}$ is the wave depth over the berm. Equation 3.24 only applies to cases where the product of $\gamma_{h} \gamma_{f} \gamma_{\beta} \leq 3.0$.

\subsubsection{Overtopping Discharge}

When wave run-up exceeds the crest height of coastal structures, overtopping occurs. Although overtopping is considered one of the failure modes of coastal structures, there is extensive debate over the allowable level of overtopping discharge that minimizes the structural damage and reduces costs by allowing for lowering crest elevation. This section presents methods for estimating overtopping discharge in Section 3.4.3.1, and discusses the amount of the allowable overtopping discharge in Section 3.4.3.2

\subsubsection{Estimation of Overtopping Discharges}

Since overtopping occurs due to a large wave run-up, the overtopping discharge is a function of parameters similar to those affecting the wave run-up. Overtopping discharges are commonly described as the peak or the mean overtopping discharge during a design event. Three methods for predicting mean overtopping discharge are the Shoreline Protection Manual (SPM), Van Der Meer (VDM), and Owen's Method. While the SPM Method is commonly used in North America, the VDM Method and Owen's Method are used in Europe. 


\subsection{Shore Protection Manual (SPM) Method}

The SPM Method, recommended by the U.S. Army Corps. of Engineers (1984), describes the volume rate of wave overtopping as a function of the structure height, water depth at the structure toe, structure slope, and structure shape. The empirical relationship was first derived by Saville and Caldwell (1955), who investigated overtopping rates and wave run-up heights on small-scaled laboratory models. Saville (1958) used a larger scaled model to tests the results obtained in earlier research. The latter research indicates that the overtopping rate per unit length of structure can be expressed by Equation 3.25 or Equation 3.26, where both equations are valid under the condition of $0 \leq H-d_{s} \prec R$ and $0 \leq \frac{h-d_{s}}{R} \prec 1.0$ (CERC, 1984):

$$
\begin{aligned}
& Q=\left(g Q_{0}^{*} H_{0}^{\prime 3}\right)^{1 / 2} e^{-\left[\frac{0.214}{\alpha^{*}} \operatorname{tabh}^{-1}\left(\frac{h-d_{s}}{R}\right)\right]} \\
& Q=\left(g Q_{0}^{*} H_{0}^{\prime 3}\right)^{1 / 2} e^{-\left[\frac{0.1085}{\alpha^{*}} \log _{e}\left(\frac{R+h-d_{s}}{R-h+d_{s}}\right)\right]}
\end{aligned}
$$

where $Q$ is the overtopping rate having the units of volume per unit time per unit structure length, $H_{0}{ }^{\prime}$ is the equivalent deep-water wave height, $h$ is the height of the structure crest above the bottom, $d_{s}$ is the depth at the structure toe, $R_{w}$ is the wave run-up on the structure that would occur if the structure were high enough to prevent overtopping, and $\alpha^{*}$ and $Q_{0}{ }^{*}$ are empirically determined coefficients that depend on incident wave characteristics and structure geometry. Values of $\alpha^{*}$ and $Q_{0}{ }^{*}$ are functions of wave steepness $\left(H_{0}^{\prime} / g T^{2}\right)$ and relative depth $\left(d_{s} / H_{0}^{\prime}\right)$, and the approximation of both values for various slope and structure types are summarized as empirical relationships in graphical format. Figure 3.7 provides the empirical relationship for structures having rip-rap and 1:1.5 slope. Values of $\alpha^{*}$ and $Q_{0}{ }^{*}$ are estimated by first identifying whether waves are breaking or non-breaking. The breaking of waves can be determined using 
Equation 3.23, where waves are breaking when $\xi_{o p}<2$, and waves are not breaking when $\xi_{o p}>2$. Empirical curves for other types of structures are provided in Appendix 2.

\subsection{Van Der Meer (VDM) Method}

Van der Meer and de Wall (1993) present the most recent approach for estimating the overtopping discharge, $Q$, which has the units of $\mathrm{m}^{3} / \mathrm{s}$ per $\mathrm{m}$ or $\mathrm{L} / \mathrm{s}$ per $\mathrm{m}$. They suggest a method of determining the average overtopping discharge for breaking waves and non-breaking waves separately. Thus, the method requires the identification of the status of breaking for the design conditions, and the wave breaking can be determined by the breaker parameter as described in Equation 3.23.

Under the condition of breaking waves $\left(\xi_{o p}<2\right)$, the average overtopping discharge is expressed as a function of a dimensionless parameter of overtopping discharge $\left(Q_{b}\right)$ (Pilarczyk, 2000):

$Q_{b}=\frac{Q}{\sqrt{g H_{s}^{3}}} \sqrt{\frac{2 \pi H_{s} /\left(g T_{p}^{2}\right)}{\tan \theta}}$

The dimensionless overtopping discharge parameter is estimated using a dimensionless crest height $\left(R_{b}\right)$. The relationship between the two parameters is as described (Pilarczyk, 2000; Besley and Allsop, 2000):

$Q_{b}=0.06 \exp \left(-5.2 R_{b}\right)$

In addition, $R_{b}$ is estimated by the following relationship, which is valid under the condition of $0.3<R_{b}<2$ (Pilarczyk, 2000; Besley and Allsop, 2000): 
$R_{b}=\frac{R_{c}}{H_{s}} \frac{\sqrt{2 \pi H_{s} /\left(g T_{p}^{2}\right)}}{\tan \theta} \frac{1}{\gamma_{b} \gamma_{h} \gamma_{f} \gamma_{\beta}}$

where $R_{c}$ is the crest height relative to still water level. By obtaining the value of $R_{b}$ and employing Equations 3.27 and 3.28, $Q$ can be estimated.

Similarly, for non-breaking waves $\left(\xi_{\mathrm{op}}<2\right)$, the dimensionless overtopping discharge $\left(Q_{n}\right)$ is given by (Pilarczyk, 2000):

$Q_{n}=\frac{Q}{\sqrt{g H_{s}^{3}}}$

The relationship of the dimensionless overtopping discharge and dimensionless crest height is:

$$
Q_{n}=0.2 \exp \left(-2.6 R_{n}\right)
$$

where $R_{n}$ is the dimensionless crest height. The prediction of overtopping discharges can be achieved by first obtaining the value $R_{n}$. The dimensionless crest height is estimated as:

$$
R_{n}=\frac{R_{c}}{H_{s}} \frac{1}{\gamma_{b} \gamma_{h} \gamma_{f} \gamma_{\beta}}
$$

Upon the determination of $R_{n}, Q$ can be estimated by employing Equations 3.30 and 3.31 .

\subsection{Owen's Method}

Owen's Method (Owen, 1980) predicts overtopping discharge, $Q$, and involves the estimation of two dimensionless parameters: the dimensionless overtopping discharge parameter $\left(Q^{*}\right)$ and the dimensionless crest height parameter $\left(R^{*}\right)$. The overtopping discharge $(Q)$ is estimated: 


$$
Q^{*}=Q /\left(g T_{m} H_{s}\right)
$$

The dimensionless parameters, $Q^{*}$ and $R^{*}$, are functions of the roughness coefficient $\left(r_{f}\right)$ and coefficients for all slope angles (Allsop and McConnell, 2000; Besley and Allsop; 2000):

$$
Q^{*}=A \exp \left(-B R^{*} / r_{f}\right)
$$

$$
R^{*}=R_{c} / T_{m}\left(g H_{s}\right)^{0.5}
$$

where $A$ and $B$ are empirical coefficients that depend on the profile of coastal structures. Owen derived values of $A$ and $B$ for simple coastal structures with slopes of 1:1 to 1:5. They are summarized in Table 3.6.

\subsection{Comparison of Methods for Predicting Overtopping Discharges}

The comparison of the VDM Method and Owen's Method shows the following advantages and disadvantages for each method. The equation used in Owen's Method is simple to apply, but requires different empirical coefficients for different wall profiles. On the other hand, the VDM Method is more complicated to use, but does not require different coefficients for different types of coastal structures. However, the reduced number of empirical coefficients in the VDM Method can also reduce the sensitivity of the response to different conditions. Besley and Allsop (2002) suggest that Owen's Method is still the most appropriate means of estimating overtopping discharges for smooth, simple sloping and bermed coastal structures for the wider range of conditions around the U.K. coastline. 


\subsubsection{Allowable Overtopping Discharge}

There is no general recommendation for acceptable levels for overtopping for coastal structures, because allowable overtopping discharges depend on location, use of the structure, and type of structure. However, some guidelines currently exist. A simple guideline is found in standard Dutch practice, for which a safe value of overtopping discharge is approximately 0.002 $\mathrm{m}^{3} / \mathrm{s}$ for a grassed crest (Pilarczyk, 2000). To be more conservative, recent Dutch practice indicates that this value can be increased to $0.005 \mathrm{~m}^{3} / \mathrm{s}$ or even to $0.001 \mathrm{~m}^{3} / \mathrm{s}$ for a "good" quality grass mat on a clay sub-layer (Pilarczyk, 2000). This guideline is not general for other types of coastal structures. Owen (1980) suggests a number of limiting discharges for more general purposes, as shown in Figure 3.8. The allowable overtopping discharges are suggested for functional and structural safety. Another example of guidelines for allowable overtopping discharge is given by Simm (1991), as shown in Table 3.7. Table 3.7 presents different limits for embankments (with back slopes) and revetments (without back slopes), but this guideline is for structural safety only. 
Table 3.1 Plotting Position Formulas from Watt et al. (1989), and Rao and Hamed (2000)

\begin{tabular}{|c|c|l|}
\hline Method & Equation & \multicolumn{1}{|c|}{ Comments } \\
\hline California & $p_{m}=m_{n} / N$ & Used in part of Canada. \\
\hline Hazen & $p_{m}=\frac{m_{n}-0.5}{N}$ & Not in general use. \\
\hline Weibull & $p_{m}=\frac{m_{n}}{N+1}$ & $\begin{array}{l}\text { Recommended in Bulletin 17B (U.S. Interagency } \\
\text { Advisory Committee on Water Data 1982). }\end{array}$ \\
\hline Chegodayev & $p_{m}=\frac{m_{n}-0.3}{N+0.4}$ & Not in general use. \\
\hline Cunnane & $p_{m}=\frac{m_{n}-0.4}{N+0.2}$ & $\begin{array}{l}\text { Used by the Water Resources Branch of } \\
\text { Environment Canada (Pilon et al. 1985) }\end{array}$ \\
\hline Gringorton & $p_{m}=\frac{m^{2}-0.44}{N_{m}+0.12}$ & \\
\hline Blom & $p_{m}=\frac{m_{n}-0.375}{N+0.25}$ & \\
\hline Adamowski & $p_{m}=\frac{m_{n}-0.24}{N+0.5}$ & \\
\hline
\end{tabular}

Table 3.2 Value of $\gamma_{\mathrm{f}}$ for Various Slope Surface Characteristics from CERC (1984)

\begin{tabular}{|l|c|c|}
\hline Slope Surface Characteristic & Placement & $\gamma_{\mathbf{f}}$ \\
\hline Smooth, impermeable & ---- & 1.0 \\
\hline Concrete blocks & Fitted & 0.90 \\
\hline Basalt blocks & Fitted & $0.85-0.90$ \\
\hline Gobi blocks & Fitted & $0.85-0.90$ \\
\hline Grass & --- & $0.85-0.90$ \\
\hline One layer of quarrystone (impermeable foundation) & Random & 0.80 \\
\hline Quarrystone & Fitted & $0.75-0.80$ \\
\hline Round quarrystone & Random & $0.60-0.65$ \\
\hline Three layers of quarrystone (impermeable foundation) & Random & $0.60-0.65$ \\
\hline Quarrystone & Random & $0.50-0.55$ \\
\hline Concrete armour unit & Random & $0.45-0.50$ \\
\hline
\end{tabular}


Table 3.3 Reduction Factor $\gamma_{f}$ for Rough Slope from Besley and Allsop (2000)

\begin{tabular}{|l|c|}
\hline Armour type & $\gamma_{\mathrm{f}}$ \\
\hline Smooth, impermeable & 1.0 \\
\hline Rough concrete & 0.85 \\
\hline Pitched stone in mrtar & $0.75-0.8$ \\
\hline Rock armour, 2 layer & $0.5-0.6$ \\
\hline Hollow cube armour units, one layer & 0.5 \\
\hline Dolos armor units & 0.4 \\
\hline Stabit armor units & $0.35-0.4$ \\
\hline Tetrapods, two layers & 0.3 \\
\hline
\end{tabular}

Table 3.4 Reduction Factor $\gamma_{f}$ for Rough Slope from Pilarczyk (2000)

\begin{tabular}{|l|c|}
\hline Type of slope & $\gamma_{\mathrm{f}}$ \\
\hline Smooth, concrete, asphalt & 1.0 \\
\hline Closed, smooth, block revetment & 1.0 \\
\hline Grass $(3 \mathrm{~cm})$ & $0.9-1.0$ \\
\hline 1 rubble layer $\left(H_{s} / D=1.5-3\right)$ & $0.55-0.6$ \\
\hline 2 or more rubble layers $\left(H_{s} / D=1.5-6\right)$ & $0.50-0.55$ \\
\hline
\end{tabular}

Table 3.5 Reduction Factor $\gamma_{f}$ for Rough Slope from Headland et al. (2000)

\begin{tabular}{|l|c|}
\hline Type of slope & $\gamma_{\mathrm{f}}$ \\
\hline One layer of rock & $0.55-0.60$ \\
\hline Two or more rock layers & $0.50-0.55$ \\
\hline
\end{tabular}

Table 3.6 Empirical Coefficients for Smooth Impermeable Simple Sloping Coastal Structures from Besley and Allsop (2000)

\begin{tabular}{|c|c|c|}
\hline Slope & A & B \\
\hline $1: 1$ & $7.94 \times 10^{-3}$ & 20.1 \\
\hline $1: 1.5$ & $8.84 \times 10^{-3}$ & 19.9 \\
\hline $1: 2$ & $9.39 \times 10^{-3}$ & 21.6 \\
\hline $1: 2.5$ & $1.03 \times 10^{-3}$ & 24.5 \\
\hline $1: 3$ & $1.09 \times 10^{-3}$ & 28.7 \\
\hline $1: 3.5$ & $1.12 \times 10^{-3}$ & 34.1 \\
\hline $1: 4$ & $1.16 \times 10^{-3}$ & 41.0 \\
\hline $1: 4.5$ & $1.20 \times 10^{-3}$ & 47.7 \\
\hline 1.5 & $1.31 \times 10^{-3}$ & 55.6 \\
\hline
\end{tabular}


Table 3.7 Tolerable Mean Discharge $\left(\mathrm{m}^{3} / \mathrm{s}\right.$ per meter run) from Besley and Allsop (2000)

\begin{tabular}{|l|l|}
\hline Buildings & No damage \\
\hline$Q<1 \times 10^{-6}$ & Minor damage to fittings, etc. \\
\hline$Q<3 \times 10^{-5}$ & Structural damage \\
\hline$Q>3 \times 10^{-5}$ & No damage \\
\hline Embankment sea walls \\
\hline$Q<0.002$ & Damage if crest not protected \\
\hline$Q<0.02$ & Damage if back slope not protected \\
\hline$Q<0.05$ & Damage even if fully protected \\
\hline$Q>0.05$ & No damage \\
\hline Revetment sea walls & Damage if promenade not paved \\
\hline$Q<0.05$ & Damage even if promenade paved \\
\hline$Q<0.2$ &
\end{tabular}




\begin{tabular}{|c|c|c|c|c|}
\hline \multicolumn{5}{|c|}{ Tides, $i=1, \ldots, m$} \\
\hline Intervals & $X_{1}$ & $X_{2}$ & $\ldots \ldots \ldots \ldots \ldots \ldots \ldots$ & $X_{m}$ \\
\hline $\begin{array}{c}\text { Relative } \\
\text { Frequencies }\end{array}$ & $f\left(X_{1}\right)$ & $f\left(X_{2}\right)$ & $\ldots \ldots \ldots \ldots \ldots \ldots \ldots$ & $f\left(X_{m}\right)$ \\
\hline
\end{tabular}

\begin{tabular}{|c|c|c|c|c|}
\hline \multicolumn{7}{|c|}{ Storm Surges, $j=1, \ldots, n$} \\
\hline Intervals & $Y_{I}$ & $Y_{2}$ & $\ldots \ldots \ldots \ldots \ldots \ldots \ldots$ & $Y_{n}$ \\
\hline $\begin{array}{c}\text { Relative } \\
\text { Frequencies }\end{array}$ & $f\left(Y_{1}\right)$ & $f\left(Y_{2}\right)$ & $\ldots \ldots \ldots \ldots \ldots \ldots \ldots$ & $f\left(Y_{n}\right)$ \\
\hline
\end{tabular}

Figure 3.1 Example of Two-Dimensional Histogram for the JPM

Deep Water

Shallow Water

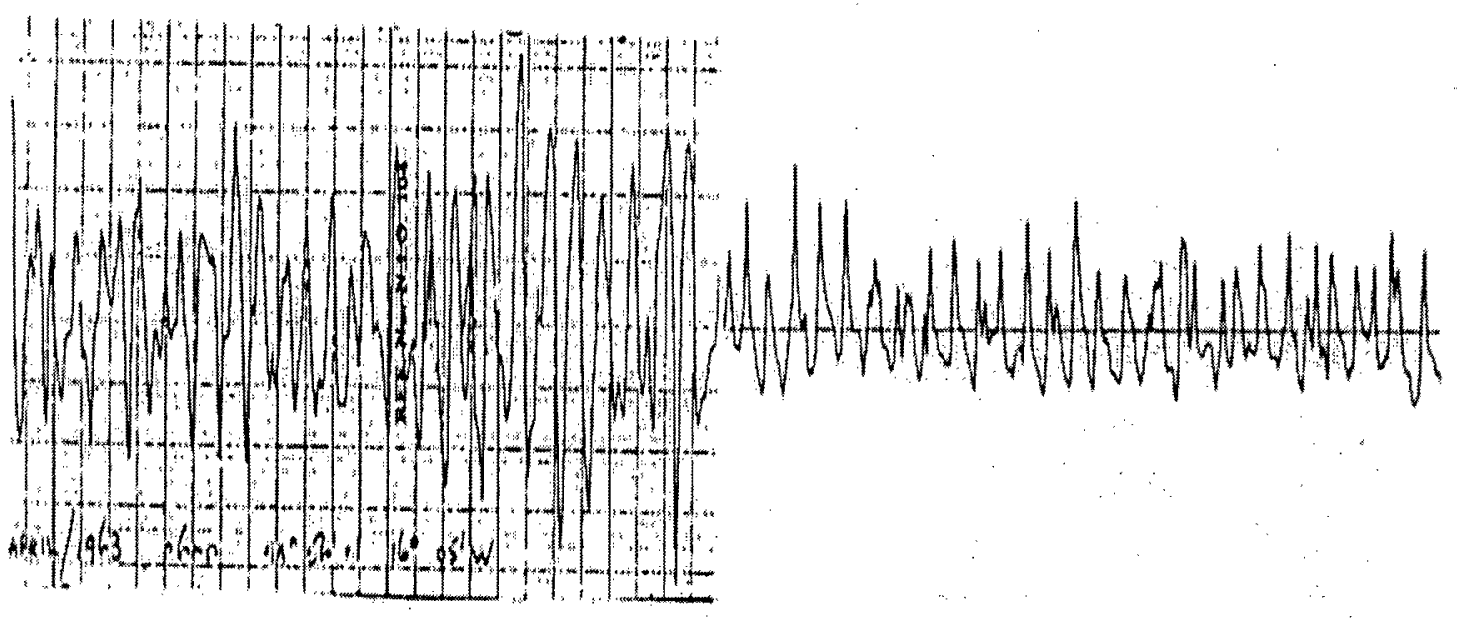

Figure 3.2 Waves in Deep Water and Waves in Shallow Water From Ochi (1998) 


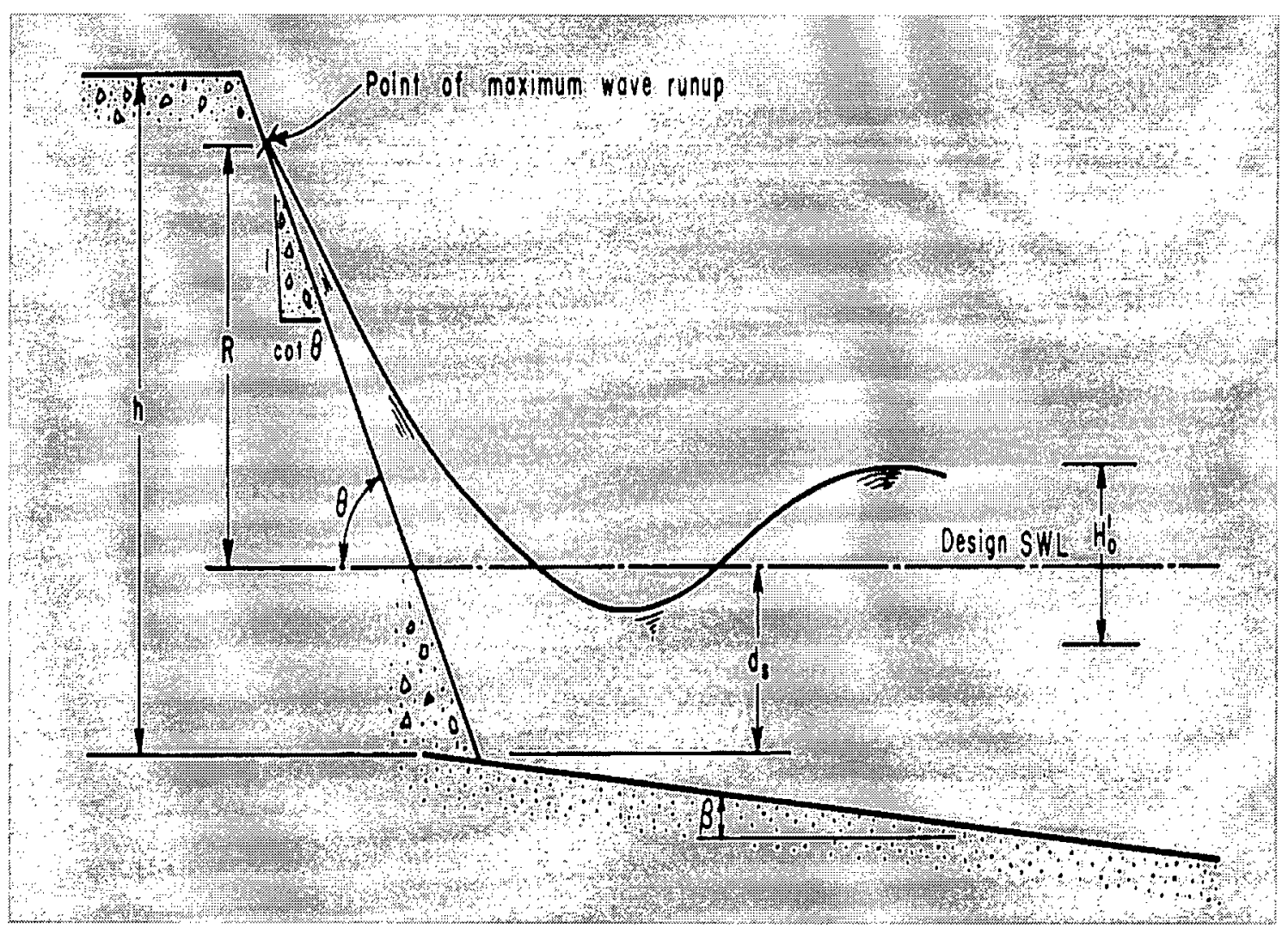

Figure 3.3 Wave Run-Up

From CERC (1984) 


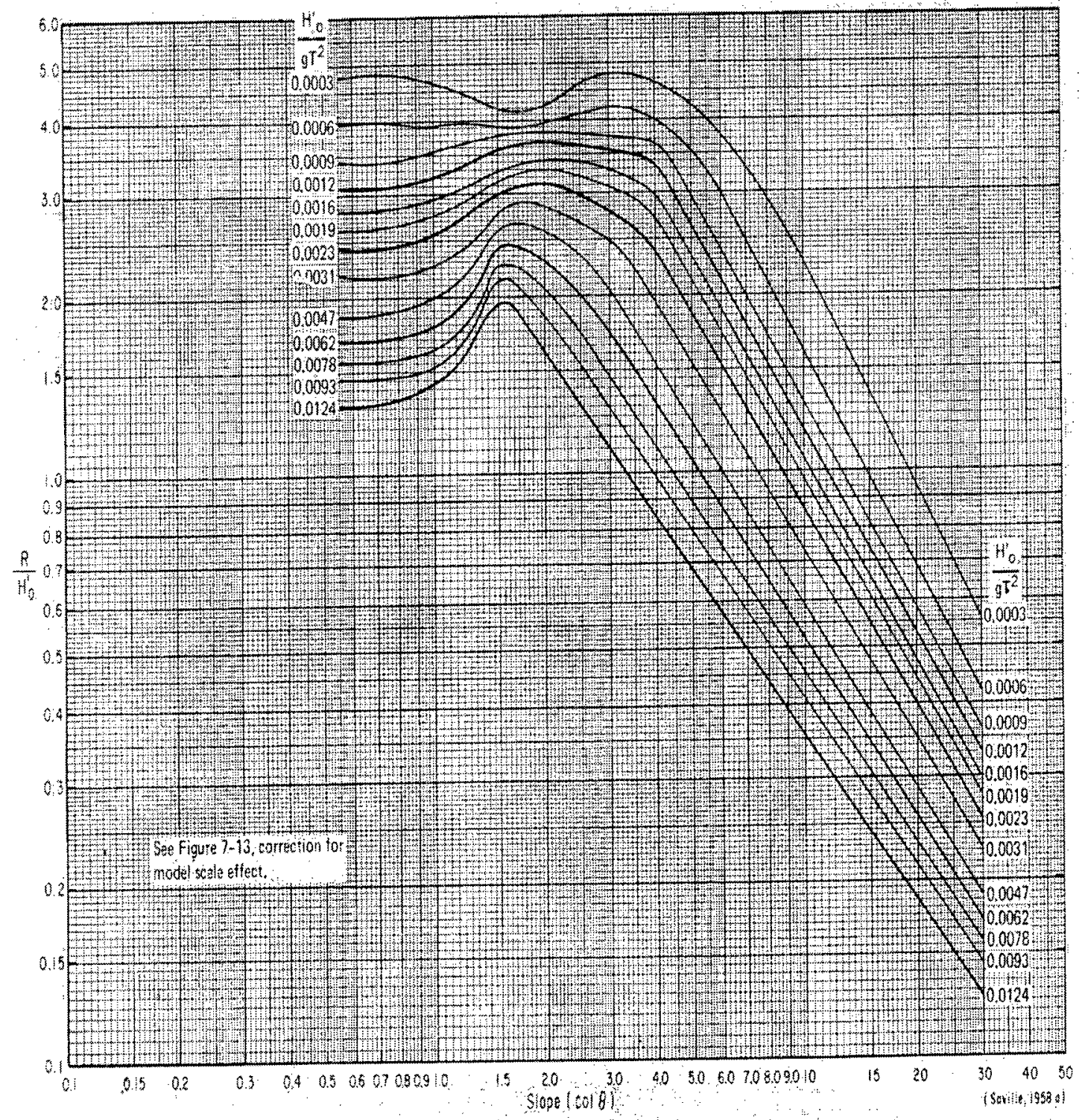

Figure 3.4 Wave Run-Up on Smooth, Impermeable Slopes on a 1:10 Bottom when $\mathrm{d}_{\mathrm{s}} / \mathrm{H}_{0}{ }^{\circ}=2.0$

From CERC (1984) 


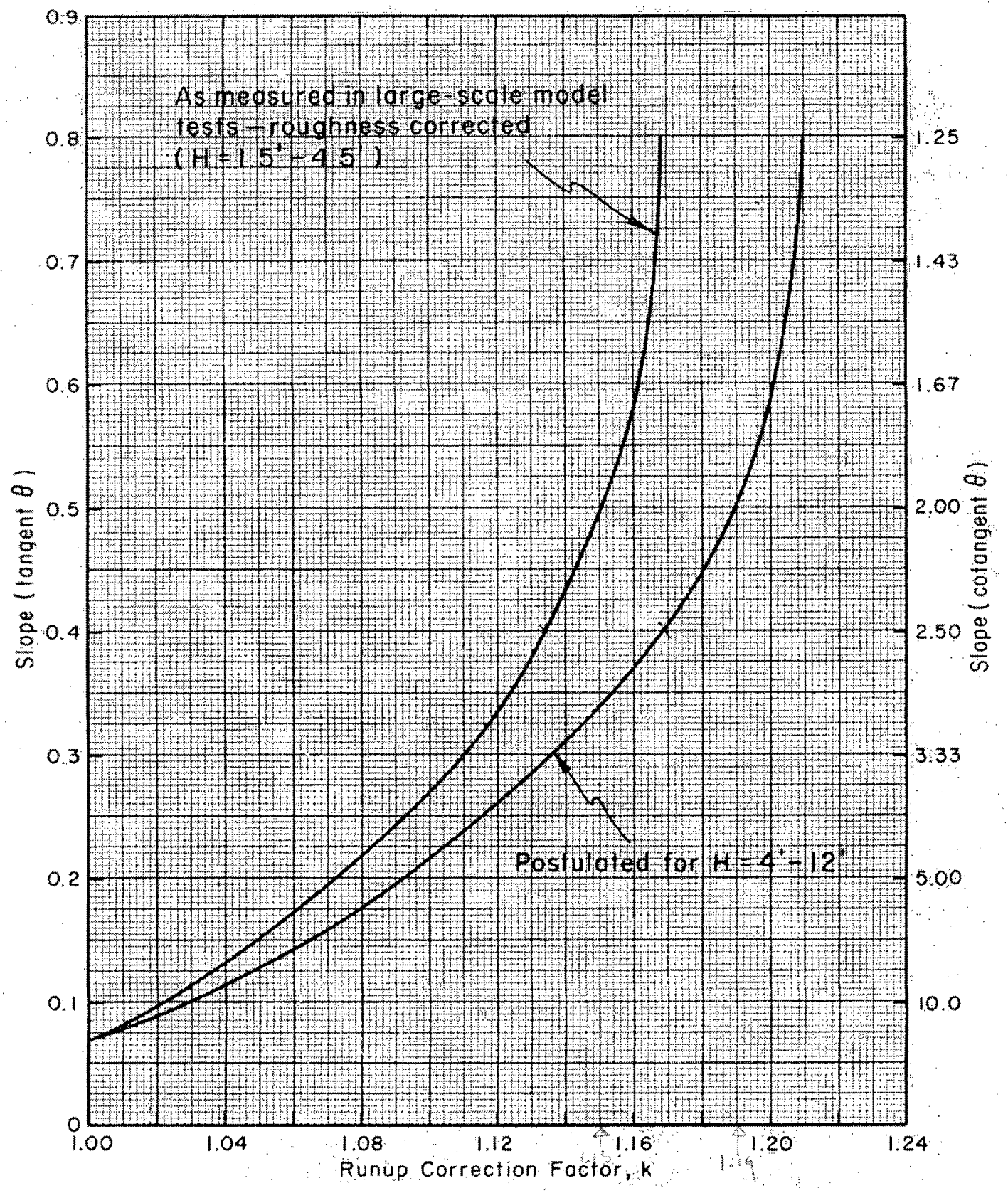

Figure 3.5 Wave Run-Up Correction for Scale Factor

From CERC (1984) 


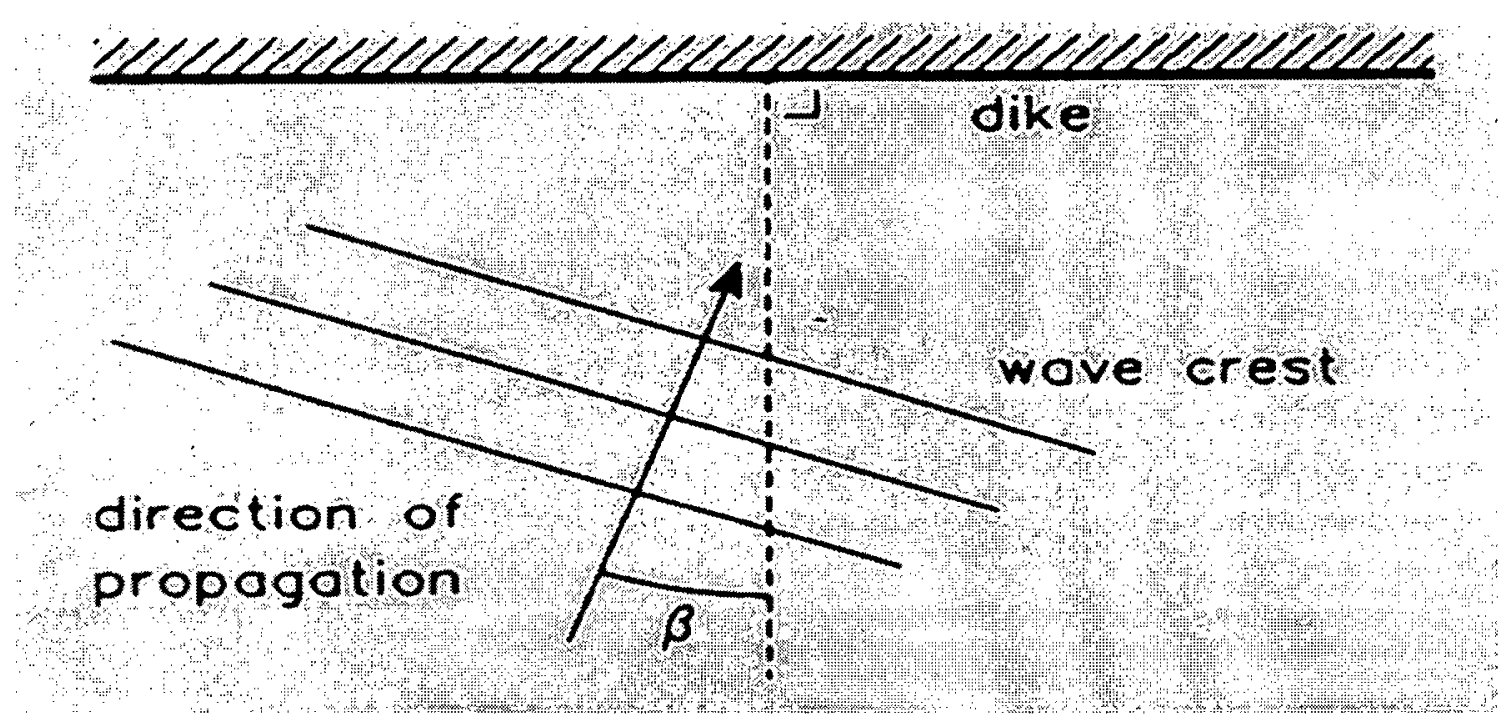

Figure 3.6 Definition of the Angle of the Wave Attack

From Pilarczyk (2000) 


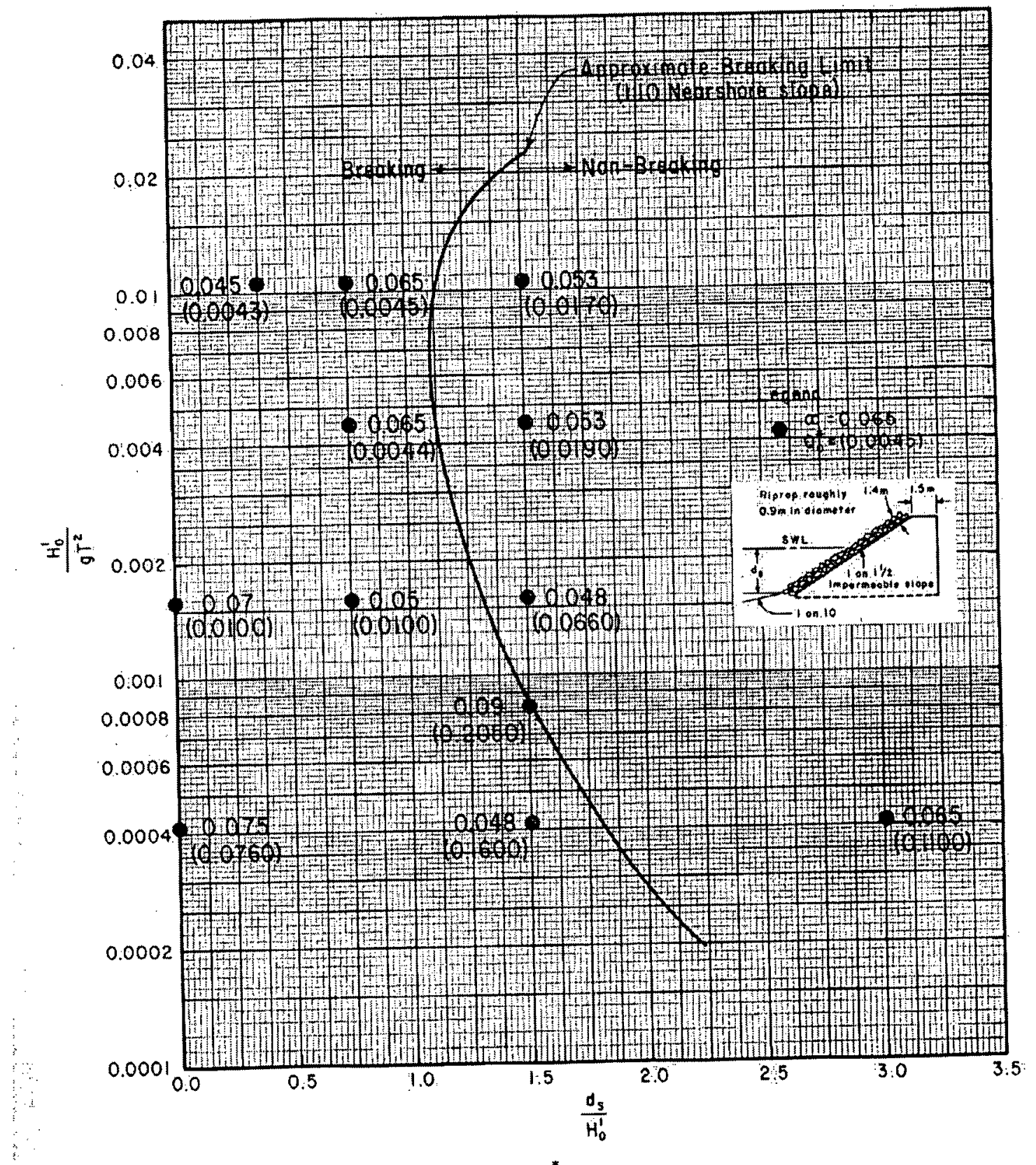

Figure 3.7 Overtopping Parameters $\alpha$ and $\mathrm{Q}_{0}{ }^{*}$ for Riprapped and 1:1.5 Structure Slope From CERC (1984) 


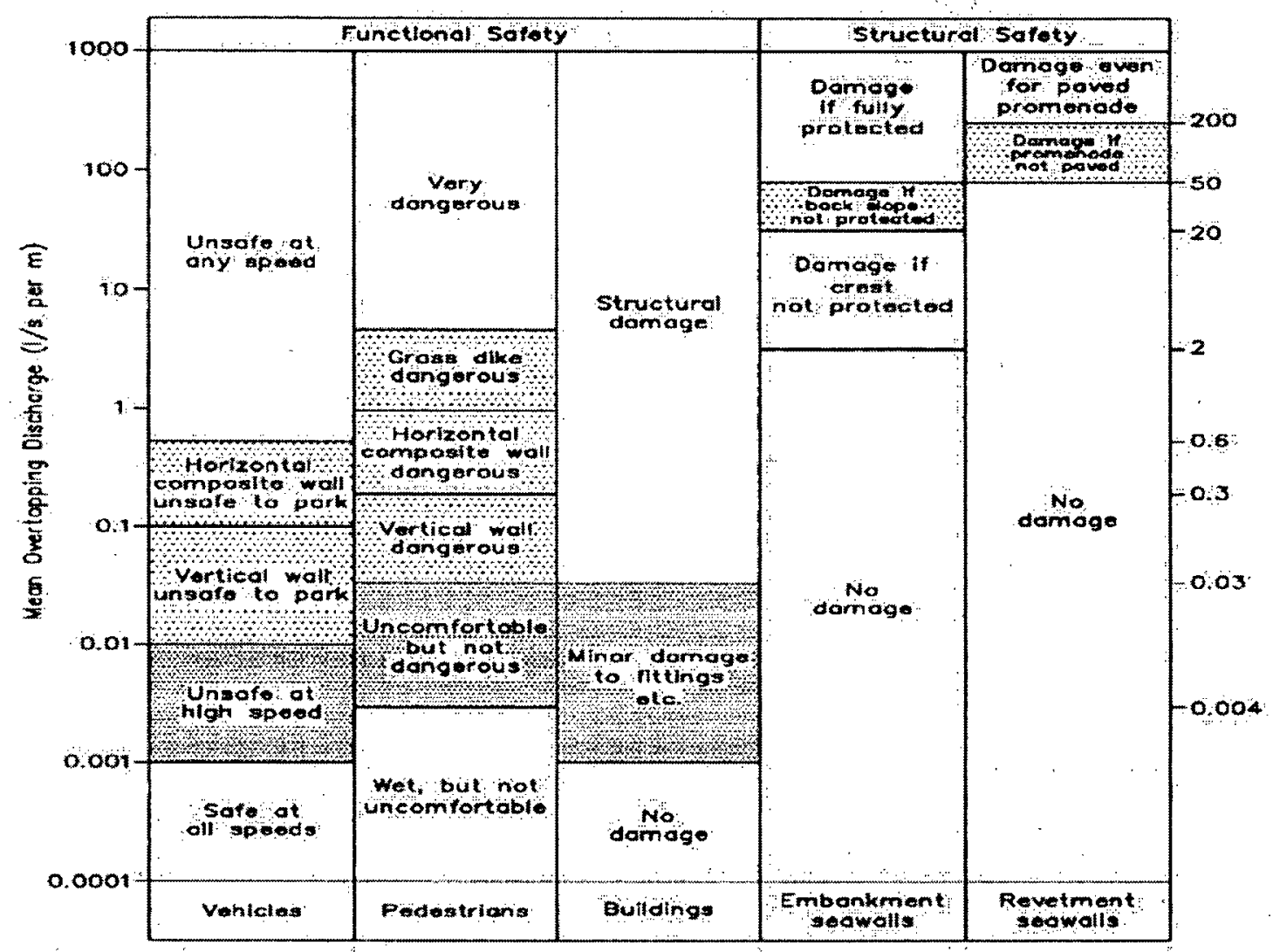

Figure 3.8 Suggested Limits for Overtopping Discharges

From Allsop and McConnell (2000) 


\section{DIRECT JOINT PROBABILITY METHOD (DJPM)}

The limitations under in the JPM or RJPM, imposed by the requirement of an independent relationship between variables, such as for tides and storm surges, or for sea levels and wave run-up, inspired the development of the Direct Joint Probability Method (DJPM). The major difference between the DJPM and JPM or RJPM is that in the former the sample cumulative density function for a given sea level is determined directly based on the collection of joint relative frequency values for combinations of contributing factors that result in this sea level and all sea levels of smaller magnitude. The sample cumulative density function is then used along with Equation 3.2 to determine the sample joint probability of exceedance. Finally, the instantaneous (or hourly, etc., depending on the recording frequency of the data) and annual joint probabilities of exceedance are determined based on the sample joint probability of exceedance. While the assumptions and data requirements of the DJPM are similar to those of the JPM or RJPM, the direct determination of the sample cumulative density function values for a range of sea levels without application of Equation 3.7, allows for the accommodation of two or more contributing factors and of dependence among these factors. This chapter provides a description of the DJPM in Section 4.1, and discussions of the data requirements and assumptions of the method in Sections 4.2, and 4.3, respectively.

\subsection{Description of the DJPM}

Assuming the availability of hourly data, application of the DJPM involves two steps: obtaining the sample cumulative density function values for a range of sea levels using multivariate histograms that compile the joint relative frequency of combinations of contributing 
factors, and determining the sample, hourly, and annual joint probabilities of exceedance for the range of sea levels based on these values. The corresponding return period can then be determined using Equation 3.3. The process of obtaining the sample cumulative density function values is the major difference between the DJPM and the JPM or RJPM, and is the feature that provides the additional advantage relative to the JPM or RJPM of facilitating the inclusion of multiple dependent variables.

The number of components that affect the extreme sea levels dictates the number of dimensions required for the histograms that are used to determine the joint relative frequency of combinations of contributing factors, and thereby the sample cumulative density values for sea levels based on these. Figure 4.1 and Figure 4.2 are examples of two- and three-dimensional histograms, that represent cases where two and three factors contribute to resulting sea levels, respectively. Each element of the histogram represents the joint relative frequency, $f\left(z_{i j}\right)$ or $f\left(z_{i j, k}\right)$, for the specified intervals of a set of conditions, $X_{i}, Y_{j}, W_{k}$, where $i=1, \ldots m$, and $j=1$, $\ldots n$, and $k=1, \ldots o$ that affect the sea level, $z_{i, j}$ or $z_{i, j, k}$. In any case, each element of the multidimensional histogram represents the joint relative frequencies of the contributing factors and these are used to determine the sample cumulative density function for sea levels directly (i.e., Equation 3.7 and 3.8 are not applied). For a given sea level, all elements of the histogram that result in sea levels of smaller magnitude are identified and the sum of the joint relative frequencies in these elements comprise the sample cumulative density function value for the specified sea level. Thereafter, Equation 3.2 can be applied to determine the sample joint probability of exceedance using the sample cumulative density function value for a given threshold sea level, and Equations 3.10, 3.13, and 3.3 can be applied to.determine the hourly and annual joint probabilities of exceedance, and return period as described in Sections 3.1.1 and 3.1.5. 
An example application of the DJPM, where the three major contributing factors are tides, storm surges, and wave run-up, is described here with reference to the flow chart shown in Figure 4.3. The required data, equations employed to convert the data into tides, storm surges, and wave run-up, and the overall equation that integrates these factors for producing an extreme sea level are represented in the flow chart. Storm surge may be simply estimated as the difference between observed sea levels and tide levels or simulated using numerical models. Wave run-up may be estimated using a range of methods described in Section 3.4.2. If the SPM Method is selected, Equations 3.16 and 3.17 are applied to estimate wave run-up with the requirement of data regarding wave heights and periods, data recording intervals, and deep-water wave height, as well as structural design information such as the slope of the dyke, depth of the fronting slope, and roughness and porosity of the dyke materials.

The histogram of joint relative frequencies of this multivariate problem is three dimensional with elements representing three-dimensional joint intervals of the data, and the joint relative frequency in each element is the likelihood of each of the contributing factors being in these joint intervals. Here, combinations of values for tides, storm surges, and wave run-up (based on wave height data) that occur simultaneously over the history of record are used to evaluate the joint relative frequency associated with a given joint data interval. The joint relative frequencies are the number of data points in each joint data interval divided by the total number of data points.

The sum of given tidal level, storm surge value, and wave run-up define the sea level, and therefore, each combination of different values of these contributing factors and the joint relative frequency of the combination is associated with a given sea level. For a given sea level, the sum of the joint relative frequencies associated with all sea levels of equal or lower magnitude is the estimate of the sample cumulative density function value for that sea level. 
The sample joint probability of exceedance is found using Equation 3.2 and the determination of the hourly and annual joint probabilities of exceedance proceed as described above for the general application of the DJPM. The relationship between sea levels and annual probabilities of exceedance may be obtained by examining a range of sea level-probability of exceedance pairs and fitting.an appropriate function to these results. Figure 4.4 and Figure 4.5 show examples such functions. Figure 4.4 demonstrates the shape of the curve generated by two variables, whereas Figure 4.5 demonstrates the shape of the curve generated by three variables. In both cases, the data for these curves are obtained from the Point Atkinson station near Richmond, B.C., where the data are tides and storm surges for Figure 4.4, and tides, storm surges, and wave run-up for Figure 4.5. Further details regarding these examples and others are provided in Chapter 6 and 7. The curve in Figure 4.5 exhibits lumpiness; thus, it would be difficult to find an appropriate function to represent these results.

\subsection{Data Requirements}

The data required in the application of the DJPM depend on the number of variables considered as critical in the estimate of extreme sea levels. For extreme sea level estimates based on a number of variables, the length of data required for a reasonable estimate increases with the number of variables. The range of sea levels estimated may depend on the length and quality of data collected as well as the intensity of collection. The availability of more data may help to capture greater extremes, but this outcome does not necessarily occur. Nonetheless the availability of more data should increase the accuracy of estimation. As the number of contributing factors increases, the irregularity in the results (e.g., lumpiness) may increase, because of the larger amount of data required to adequately characterize the system. The 
efficacy of the DJPM for estimating extreme sea levels for the City of Richmond, B.C. is evaluated in Chapter 7. The timing of each data series should be as accurate as possible.

\section{3 $\quad$ Assumptions}

While the DJPM does not require the assumption of independent variables, it still requires that hourly sea levels be independent from one time step to the next, and that the data are representative of the system being analyzed. The DJPM does not require the independence between the data for the various contributing factors, because the estimated probability of a given sea level is not obtained through the production of the individual distribution functions for each of the variables as in the JPM and RJPM. Instead, the DJPM determines the joint probability of the variables directly and uses this information to estimate the probability of exceedance and return period of the corresponding extreme sea level.

\subsection{Advantages and Disadvantages}

The DJPM can be applied broadly in the case of finding extreme sea levels based on different combinations, such as tides, storm surges, and wave run-up, or observed sea levels and wave run-up, because it does not require the assumption of independent variables. The extreme sea levels are composed of several factors, and such factors are rarely independent of each other. Thus, the DJPM may be very practical especially in regions where sea levels are a function of more than two variables. 


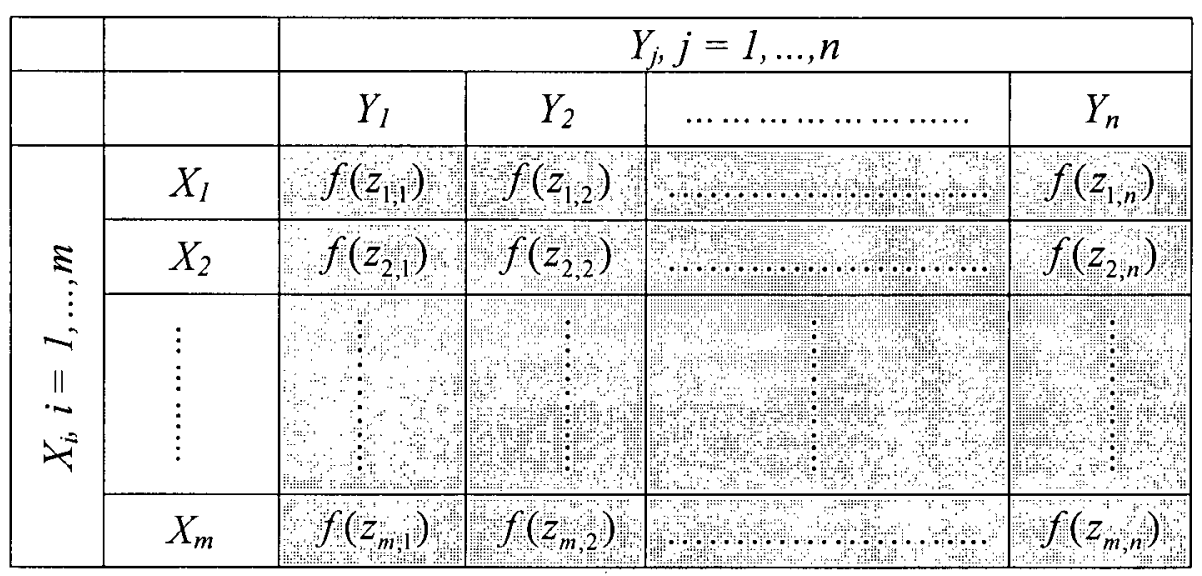

Figure 4.1 Example of Two-Dimensional Histogram

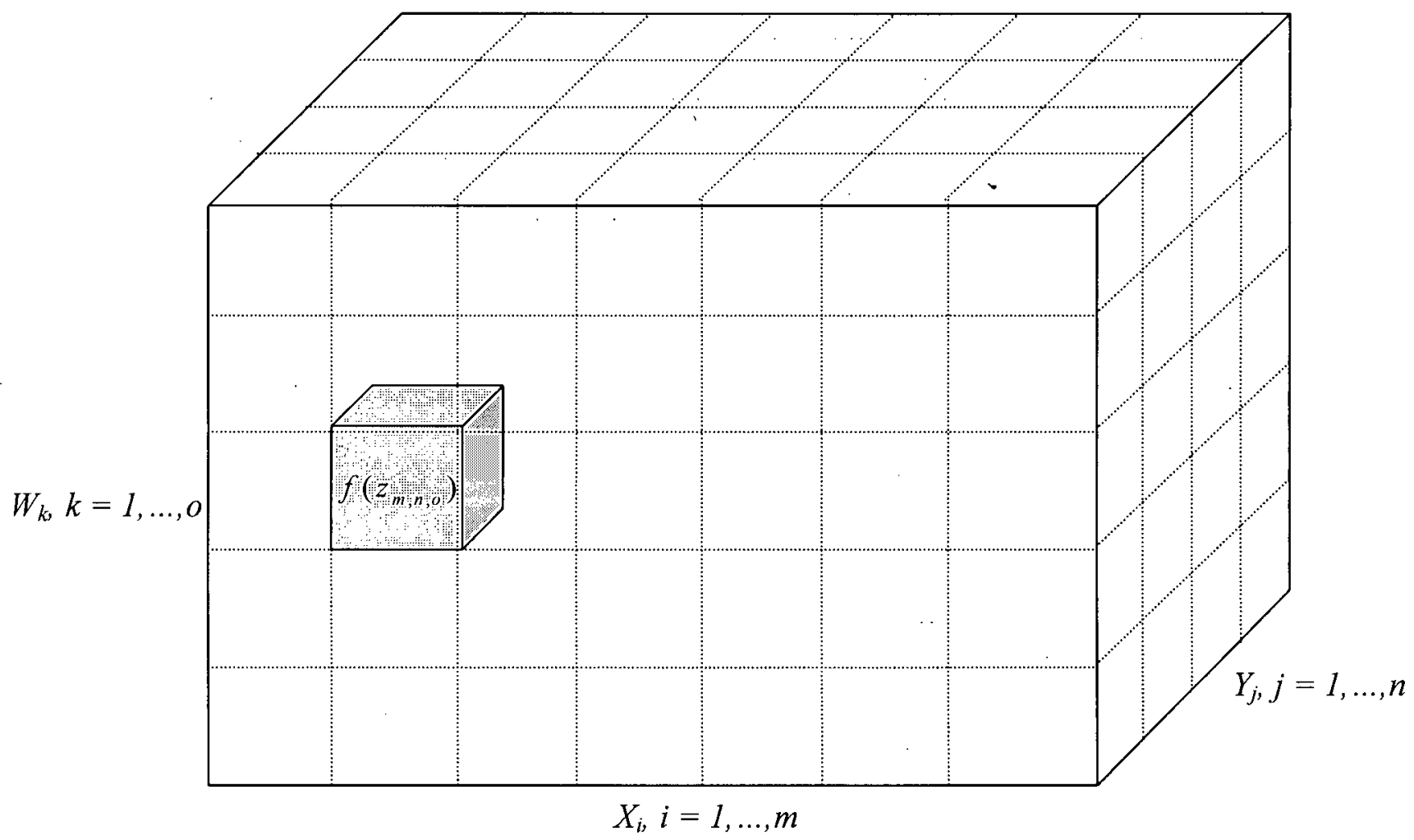

Figure 4.2 Example of Three-Dimensional Histogram 


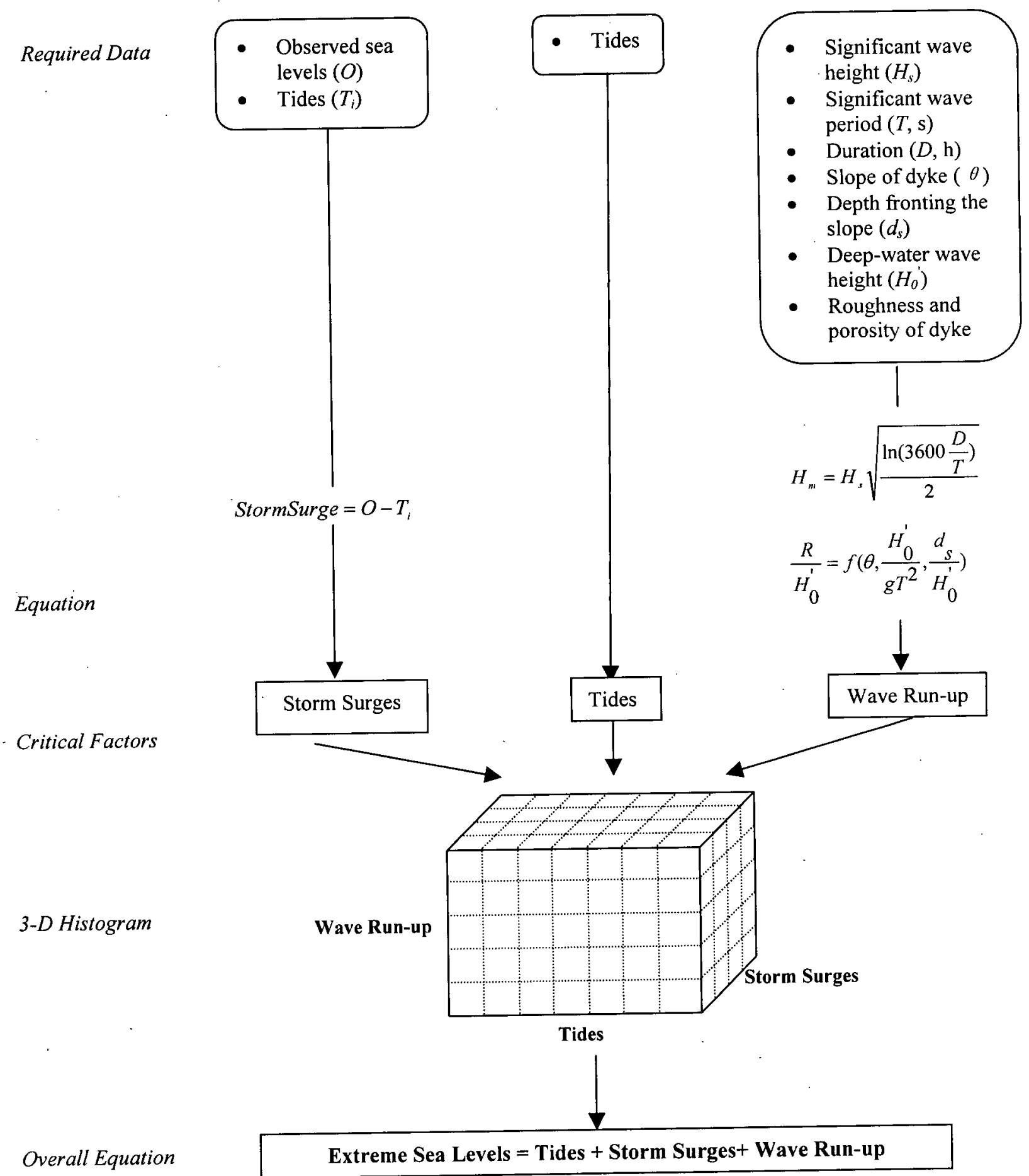

Figure 4.3 Flow Diagram of DJPM for Combining of Tides, Surges, and Wave Run-up 


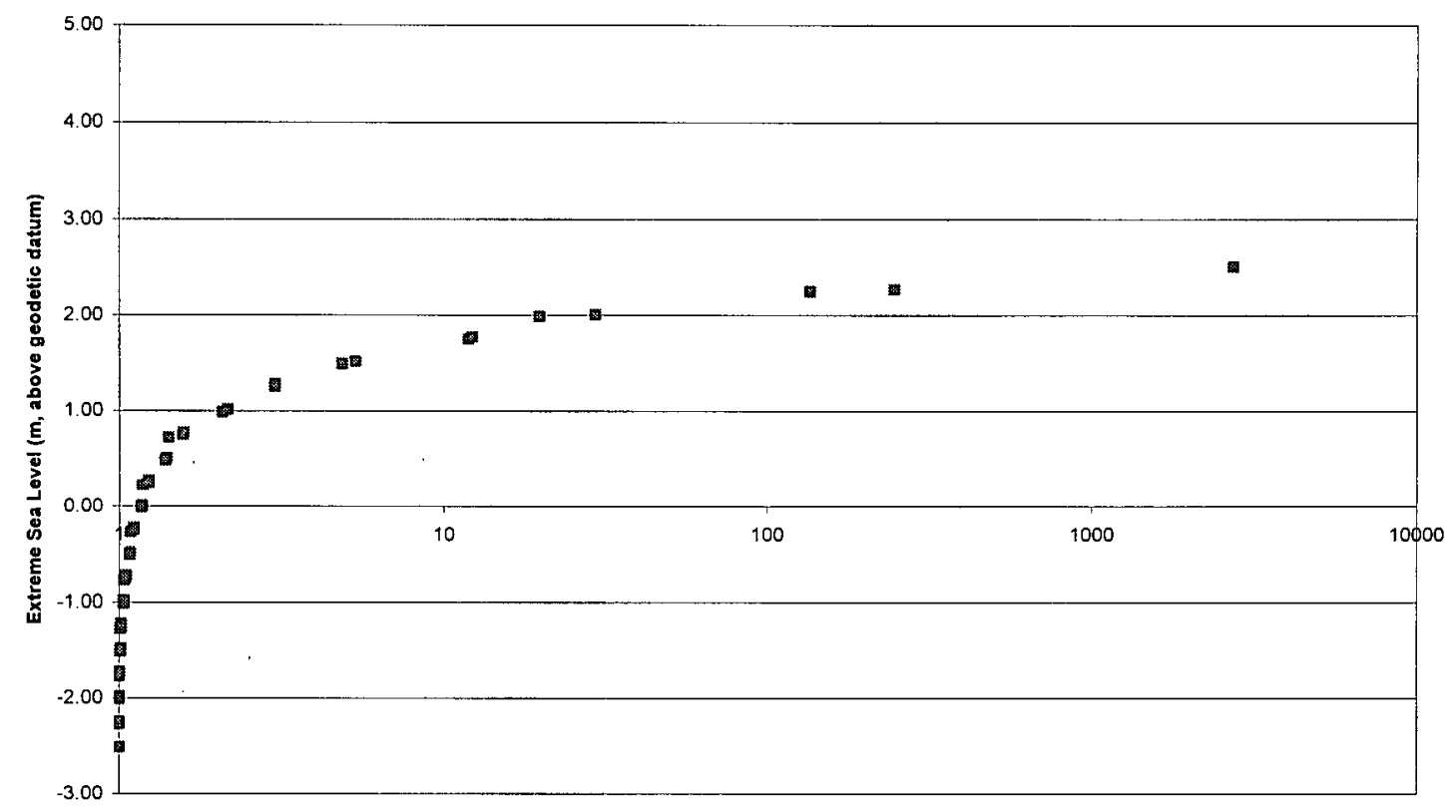

Return Period (year)

Figure 4.4 Example of the Result of the Direct Joint Probability Method for Two Variables

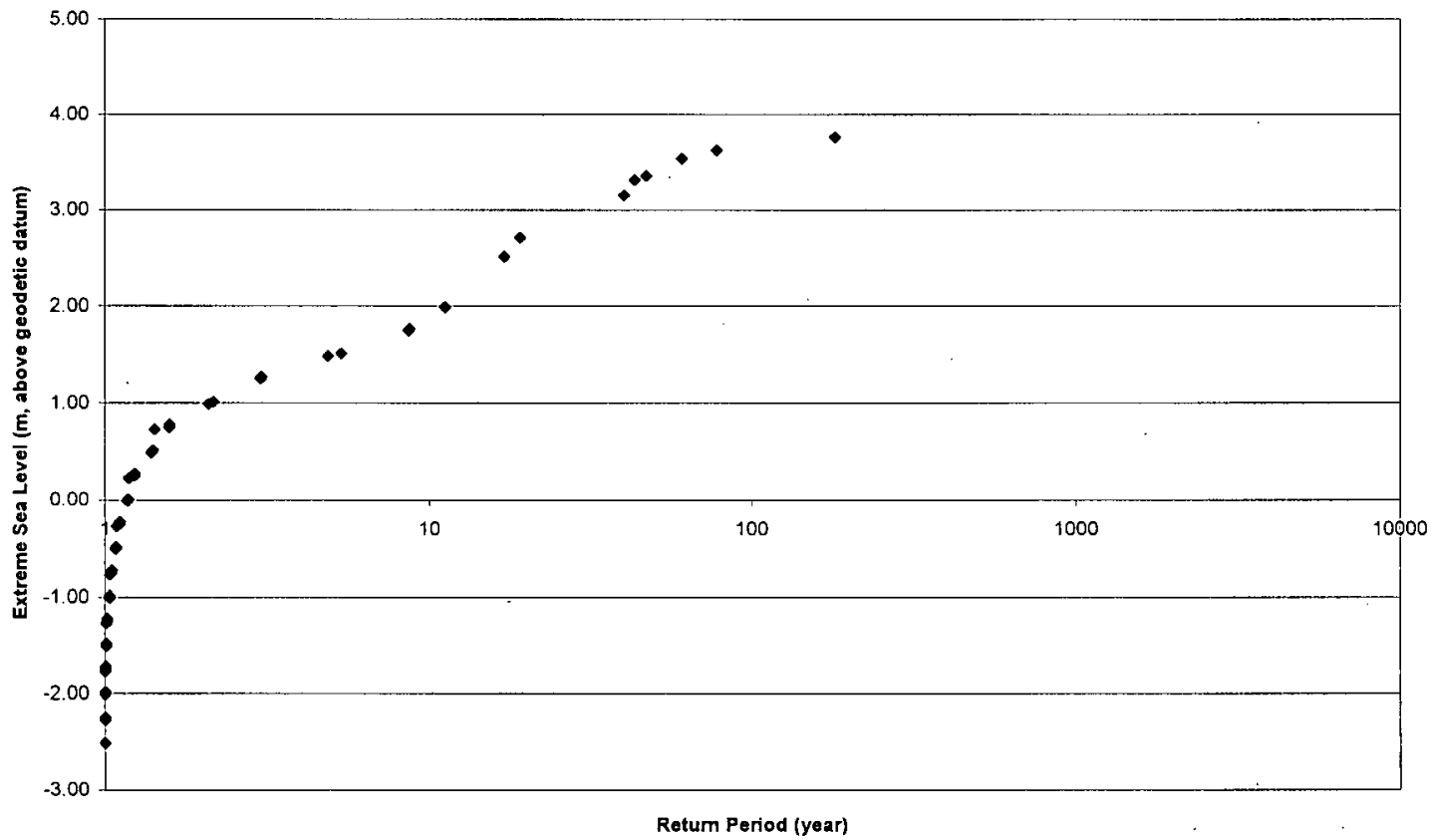

Figure 4.5 Example of the Result of the Direct Joint Probability Method for Three Variables 


\section{SEA FLOOD PROTECTION IN RICHMOND, B.C.}

The City of Richmond, located in the southeast of the Province of British Columbia, is comprised of a series of islands, including most of Lulu Island, Sea Island, and fifteen other small islands. The islands are surrounded by the Fraser River, but are also adjacent to the Strait of Georgia in the Pacific Ocean. The formation, diverse industries, rich cultures, and flood issues of this unique island city are all related to its location. The growing population and developments in Richmond have motivated the government to implement a long-term strategic citywide plan for flood protection and management. The 2021 Flood Protection Strategy is a long-term comprehensive strategy including planning of flood-proofing designs and techniques, land use planning, flood protection works, emergency preparedness, and disaster financial assistance. The strategy is implemented in two phases: the analysis and strategy development in 2002 - 2003, and the flood strategy implementation in the subsequent years (Manager, Policy Planning, 2002). In 2002, the City of Richmond engaged the services of UMA Engineering Ltd. to assist in the first phase of the Richmond Flood Protection and Management Strategy. One of the objectives of the plan is to maintain and upgrade the perimeter dyke system on Lulu and Sea Islands (Richmond, 2002). UMA Engineering Ltd. raised the concern of adequacy of the current crest height of the sea dyke. While most attention is paid to the river dykes and river floods, UMA chose to also examine the current sea dyke elevation level. A primary goal of this thesis is to determine more accurate, updated design extreme sea levels and to conclude whether the crest elevation is adequate to withstand these conditions. This chapter discusses the critical factors contributing to sea level variations and the data that are necessary for determining the extreme sea levels for Richmond. Sections 5.1 and 5.2 introduce the surroundings and the background of Richmond, respectively. Section 5.3 discusses the flood concerns, Section 5.4 describes the 
current dyke system, Section 5.5 discusses the variations in sea levels, and Section 5.6 describes the data availability.

\subsection{Surroundings}

The City of Richmond is surrounded by the Strait of Georgia on the west and the Fraser River on the north and south. The formation of the Strait of Georgia began around 150 million years ago by a depression of the Earth crust along the Pacific Coast. The depression is accompanied by an uplift of the adjoining land, which forms the Vancouver Island Range and Olympic Mountains to the west, and the Coast.Mountains and Cascade Mountains to the east. Although the Strait of Georgia has the maximum depth of $3940 \mathrm{~m}$, water depths inside this protected coastal domain vary considerably over short distances. Around 10,000 years ago, an ice sheet with a thickness of $1200 \mathrm{~m}$ at the present Fraser River delta started melting, and the decreased load on the Earth caused an 80 to $140 \mathrm{~m}$ upward heave (Thomson, 1981). A postglacial uplift of approximately $15 \mathrm{~m}$ in the Lower Fraser River Valley also diverted the Fraser River to its present course into the Strait of Georgia. Since the diversion of the Fraser River, large sediments and deposits have been carried to the ocean. The river deposits have gradually built the Fraser River Delta including Lulu Island and Sea Island. The delta extends to the near shore zone of the coast, making the near shore areas shallow due to sedimentation.

\subsection{Settlements}

The large quantities of fresh water from the Fraser River in the coastal basin have created an estuary which acts as a nutrient trap allowing river-borne organic and inorganic materials to 
collect in concentrated amounts. Lulu Island's association with estuaries formed the nuclei for settlement and industrialization. The rich soils in the delta area create the opportunity for agriculture. Europeans are among the first pioneers to settle here for agricultural purposes, and the diversity of agriculture included dairying and berry growing which remain important to this day. In addition, the Pacific Ocean coast along the west side of the City provides abundant fisheries, which have become another major industry. Agriculture and fisheries have been the basis of the economy and industrial development. Since Richmond was incorporated as a municipality on November 10, 1879, and designated as a city on December 3, 1990, the community has seen continued growth, gradually expanding into a multi-industrial area boasting agriculture, fisheries, transportation services, manufacturing, and technologies. Growth of the

City is also apparent in an ever increasing population, with a steady annual population growth of $2 \%$ it has become a dynamic urban center offering a unique mix of residential and commercial properties, agricultural lands, industrial parks, waterways, and natural areas.

\subsection{Flood Concerns}

Unfortunately, the topographic and climatic characteristics indicate that Richmond currently faces potential threats of flooding. The sources of flooding include river floods, sea floods, and an excessive amount of rain. The following three sections discuss the background, historical data, and magnitude of hazards for each of these sources. 


\subsubsection{River Floods}

The potential river floods in Richmond are the result of runoff into the Fraser River from the melting snow on the Rocky Mountains during early spring and late summer. The amount of runoff varies each year and depends on the precipitation in the previous winter, temperature change from winter to spring, and tidal variation. When the snowfall in the previous winter is heavy and the temperature changes suddenly from cold to warm, the amount of runoff for that year is increased and the possibility of flooding is high. The high variation of water level is closely monitored. Richmond relies on records at a gauge at Hope, BC. According to the flood data collected at this station, two of the largest recorded floods in the Fraser River occurred in 1894 and 1948 . It is estimated that the flood reached a peak of $17,000 \mathrm{~m}^{3} / \mathrm{s}$ in 1894 , the largest flood of record. Figure 5.1 shows an example of flow data at the Hope gauge of $15,000 \mathrm{~m}^{3} / \mathrm{s}$ in 1948. The 200-year river flood has a flow rate of $17,000 \mathrm{~m}^{3} / \mathrm{s}$, and is adopted as the design flow. Among all the three sources of floods, HAYCO (1989) identifies the river floods as the worst source of flooding, because the possible water levels are highest and the flood duration is longest. The river water levels can remain high for 12 to 18 days during a major flood. Thus, the prevention of river floods has been the historical focus of flood planning in Richmond.

\subsubsection{Sea Floods}

Richmond is also confronted with possible flood threats from the sea, because it has a low elevation relative to the sea level. HAYCO (1989) identifies the three major components contributing to changes in sea level as astronomical tides, storm surges, and long-term sea level rise due to climatologic and geologic effects. At Richmond, storm surges occur during winter, 
with the largest storm surge recorded at $0.9 \mathrm{~m}$ above the GSC datum. Storm surges in the area can typically last for three consecutive days. When storm surges coincide with high tides, the maximum sea level of $1 \mathrm{~m}$ could be added to the storm surges and cause potential sea floods. The sea level in Richmond is monitored by the tide gauges at Point Atkinson, B.C (HAYCO, 1989). The highest observed sea level at this station since 1914 is $5.6 \mathrm{~m}$ above the CHAR datum or $2.56 \mathrm{~m}$ above the GSC datum on December 16, 1982. Based on this value, the 200-year design sea flood level estimated by the Fraser River Flood Control Program is $2.8 \mathrm{~m}$ above the GSC datum. The influence of sea floods is not as strong as river floods, but Richmond has a low elevation relative to sea level. The average elevation of Richmond is $1 \mathrm{~m}$ above the GSC datum, but the high tide at Point Atkinson is $1.4 \mathrm{~m}$ above the GSC datum. Due to tectonic movements and greenhouse effects, the rising of global sea levels can effectively result in localized flooding in portions of the City. It is estimated that the global average rate of sea level rising during the $20^{\text {th }}$ Century is near $2 \mathrm{~mm}$ per year (Church, 2002). HAYCO (1989) suggests that the sea level rise will range from 0.2 to $1.17 \mathrm{~m}$ by the year 2050 and from 0.5 to $3.68 \mathrm{~m}$ by 2100 . Although the change is invariably slow and gradual this needs to be taken into consideration when determining the design sea flood level.

\section{5:3.3 Excessive Amount of Rain}

Flooding by rainfall in Richmond has received less attention than river or sea floods in most flood management plans for the City. Although rain may not always cause flooding, a certain strength and duration of rain can effectively flood the City. A heavy rainfall persisting for several days with intensities reaching from 6 to $7 \mathrm{~mm} /$ hour per 24 hours will cause flooding in the lower areas of Richmond. A common problem with the perimeter dyke system is that the 
dyke blocks the normal passage of rainfall into rivers and seas. For example, being surrounded by a dyke, Lulu Island requires an extensive drainage system in order to prevent floods due to excessive rain. The current drainage system includes 32 pump stations and canals around the City perimeter (City of Richmond Website). The pump stations serve as the primary system of drainage, whereas the canals operate as a secondary system when the pump stations are at full capacity.

\subsection{Current Dyke System}

Sea and river floods can be mitigated with a dyke system. The construction of the dyke system was initiated by residents who realized that a normal life was impossible without the dykes. The residents of Richmond, mainly farmers, continued building their own dykes until 1905. In 1905, a local petition called for the formation of a commission to adequately maintain the dyke and drainage system in Richmond. Since then the dyke system has been gradually constructed around Richmond. The current dyke system in Richmond surrounds Lulu and Sea Islands. The following section presents the legislation for the dyke system. The current dyke system is then described in Section 5.4.2, and the maintenance program executed by Richmond is presented in Section 5.4.3.

\subsubsection{Legislation}

Dyke systems in B.C. are built, maintained, and operated by local authorities under common law and in accordance with pertinent legislation and agreements. The Fraser River Flood Control Agreement (1973) provides the means to improve the dyke system and 
rehabilitate the internal drainage system within Richmond. In addition, the Dyke Maintenance Act (1995) is the legislative basis for operation and maintenance of public dykes in B. C. Legislation relevant to the formation and operation of dyke authorities includes the Drainage Ditch and Dyke Act (1996) and the Local Government Act (1996). The Local Government Act provides guidance for new dyke authorities. Other pertinent provincial legislation includes the Emergency Management Act (1996), Water Act (1996), and Environmental Assessment Act (1996). Relevant federal legislation includes the Canada Fisheries Act (1985) and the Navigable Waters Protection Act (1985).

\subsubsection{Description of the Dyke System}

The dyke system in Richmond includes the Sea Dyke at the west end of Lulu Island, River Dykes at the north and south of Lulu Island, the dyke surrounding Mitchell Island, and the dyke surrounding Sea Island. The Sea Island dyke is under the jurisdiction of the Vancouver Airport. Under the Dyke Act, the design and construction of the dyke system in Richmond is regulated by the Dyke Design and Construction Guide of the Ministry of Water, Land, and Air Protection. The standard design of the cross section of the dyke system is shown in Figure 5.2. Richmond adopts the revetment pavements on the outer slope, where the slope is 1:2. The crest elevation of the dyke system is set to prevent the 200-year flood with a minimum freeboard of $0.6 \mathrm{~m}$ (GA and $\mathrm{AE}, 2003)$.

The River Dyke and Sea Dyke surround Lulu Island and create the perimeter dyke system for the Island, as shown in Figure 5.3. The perimeter dyke system includes 10 pumps and 17 flood boxes, which provide protection for over 34,000 buildings. The River Dyke includes two segments, the North Arm and South Arm. Both segments are used to prevent the 
river flood caused by spring freshets. The current River Dyke elevation is on average at $3.5 \mathrm{~m}$ above the GSC datum, although the elevations of the River Dyke vary from west to east with elevations at the east end of Lulu Island being greater than elevations at the west end (Brownlee, Personal Communication, September 23, 2004). This value was obtained by converting the flood rate into the water level and adding a freeboard of $0.6 \mathrm{~m}$. The Sea Dyke or West Dyke is the main defence system against sea floods. The current Sea Dyke elevation is at $3.35 \mathrm{~m}$ above the GSC datum, that is, the 200-year sea level, with a freeboard of $0.6 \mathrm{~m}$. The total length of the Sea Dyke is $6 \mathrm{~km}$ from No. 1 Road to Garry Point, overlooking the tidal flats, which extend 1.6 $\mathrm{km}$ westward into the Georgia Strait. Although Figure 5.2 shows the standard design for the dyke systems adopted in Richmond, the standard design is only implemented at two locations of the Sea Dyke, Terra Nova and Garry Point. Figure 5:4 shows the actual condition of the majority of the sea dyke. The majority of the Sea Dyke has grass mat on the slope. An interesting observation is the vegetal growth on the tidal flats. Some areas have very dense vegetation to the degree that water cannot be visibly identified beneath this vegetation (Figure 5.4 (a)), while other areas exhibit less vegetation, making the water visible (Figure 5.4 (b)). The Sea Dyke has become the popular West Dyke Trail for the residents of Richmond.

\subsubsection{Dyke Maintenance Program}

Richmond undertakes the operation and maintenance of the dyke system under the Dyke Maintenance Act. Under the authority of the Dike Maintenance Act, the Ministry of Water, Land and Air Protection (formerly the Ministry of Environment, Land, and Park or MELP) regulates the operation and maintenance of flood protection structures. Thus, Richmond implements the maintenance program described in the MELP Dyke Operation and Maintenance 
Manual. Richmond performs the regular inspection and maintenance of the dyke. Regular inspection is essential for identification of areas requiring maintenance before major problems develop. The dyke system requires annual inspection, which is completed prior to the high flow season and sufficiently early to allow for adequate time for any required work to be completed prior to possible flood events. The inspection of the dyke system includes the following (MELP, 2001):

1) Check crest, slopes, and toe for settlement, depressions, sinkholes, cracking, slides, sloughing, erosion, seepage, piping, boils, loss of freeboard, and low spots;

2) Look for unauthorized activity, such as construction, excavation, etc.;

3) Check for areas where vegetation hampers inspection and may weaken the dyke;

4) Look for rodent activity;

5) Check for unauthorized excavation or construction on or adjacent to dyke;

6) Check river flow pattern for changes, deposition, scour, debris jams, etc.; and

7) Check conditions exhibiting scour or erosion around bridges or other structures in the vicinity.

If there are obvious problems and damages, repair work is initiated immediately. The Maintenance Program is carried out by the City's Public Work Department. According to the foreman for the dyke system, the inspection is performed every three months to include seasons of high and low tides (Minns, Personal Communication, December 23, 2003). It is important to have inspection during low tides in order that inspection of the toe and repair, if necessary, can be executed. The sections from No. 1 Road to Blundell Road and Garry Point are often attacked by stronger waves. The section from No. 1 Road and Blundell Road is subject to both river discharges and ocean waves, and the currents from both systems can cause the waves to overtop the dyke. An incident of overtopping was noticed on December, 2002, but there was no apparent damage, only concerned phone calls from the local residents (Minns, Personal Communication, 
December 23, 2003). Garry Point is another trouble spot, where wave attacks are generated by boats travelling through this area. But to date there has been no damage reported. The main reason for dyke failure in Richmond is generally due to rodent activity, which has usually led to piping (Gilfillan, Personal Communication, February, 2003).

\subsection{Sea Level Variations}

The generations of wind waves are a function of wind speed, wind duration, and fetch length as previously stated. Nevertheless, wind waves at Richmond are mainly limited by the wind strength and fetch length, because the Strait of Georgia is located to the east of Vancouver Island. The Island restricts the wind activity by reducing the wind speed and the fetch length, making the maximum wave heights in this area $0.6 \mathrm{~m}$ on average and approximately $2.7 \mathrm{~m}$ during the winter. The maximum waves occurring during winter are usually from the northwest and southwest direction (Thomson, 1981). The wind waves do not directly impact the coastal structures in Richmond, however wave run-up is an important factor to be considered as a wave approaches the shore. Because the west coast of Richmond has a flat and long shoreline, wave run-up occurring at the near shore area is significant (Isaacson, Personal Communication, April 11, 2003). The long extent of sedimentation deposits on the west coast of Richmond also implies that the maximum wave may break before the wave reaches the dykes, so the extreme sea conditions can be caused by smaller waves. The calculation of wave run-up will determine the maximum impact of waves.

Even though storms are generally not a problem on the Pacific Coast, the low elevation of Richmond requires consideration of storm events. The time series of storm surges can be estimated by subtracting the tide signal from the observed sea levels. Storm surges can also be 
predicted using a numerical model. A numerical model for the area of the Juan de Fuca Strait and the northern end of Johnston Strait, both near Richmond, the GF7 model, was developed by the Institute of Ocean Sciences (Hodgins, 1985).

Another essential factor contributing to sea level variations for Richmond is variations in astronomical tides, because the west coast of B.C. has a large tidal range. The coast of B.C. usually experiences high tides twice a year, and the tidal range for the area is from 3 to $5 \mathrm{~m}$ (Thomson, 1981). The B.C. coast usually experiences the highest tides on June 21 and December 22, and experiences the lowest tides on September 22 and March 21. It should be noted that the storm surges also occur in winter, with the extreme conditions at this location likely to constitute high tides and storm surges.

Fortunately, the probability that a large tsunami from the ocean will propagate far into the Strait of Georgia is very low. It is also unlikely that the occurrence of a major earthquake off the coast will generate a tsunami because faulting in this geographical location is mostly of the sideway slip type. Two historical events of tsunami affected Vancouver Island and caused damages (see Table 2.1). Both events suggest that Richmond is shielded by Vancouver Island and is unlikely to be affected by tsunami even if tsunami occur in close proximity. Therefore, tsunami are not a concern for Richmond.

Finally, the long-term sea level change is also an important factor for Richmond. A longterm sea level rise is attributed to the global warming and the movement of tectonic plates, with the climate factor dominating the rate of rising sea levels. As stated earlier, the sea level rise is predicted to range from 0.2 to $1.17 \mathrm{~m}$ by 2050 and 0.5 to $3.68 \mathrm{~m}$ by 2100 (HAYCO, 1989). The average rate of sea level rising is predicted to be $2 \mathrm{~mm}$ per year (Church, 2002). For a low-lying area such as Richmond, the gradual increase in sea level has to be considered in long-term planning. 
In conclusion, the critical factors contributing to extreme sea levels in Richmond are tides, storm surges, wave run-up, and long-term sea level changes.

\subsection{Data Availability}

The three types of data necessary to identify the tides, storm surges, wave run-up, and long-term sea level changes are tide, wave, and water level data. Richmond currently has no gauge station of its own to collect any data. Therefore, estimating extreme sea levels for Richmond requires a search among existing data at nearby stations. The three locations closest to Richmond are Point Atkinson, Halibut Bank, and Roberts Bank, and the relative locations of the stations are shown in Figure 5.5. The Point Atkinson Station has been used historically to estimate sea flood for Richmond as previously mentioned. This location also has a complete set of data including tide, wave, and water level data. Since it is a permanent gauge station, hourly tide and water level data have been continuously monitored. Unfortunately, among the three stations, the location of Point Atkinson is furthest from Richmond and does not share similar geological conditions as Richmond. The wave data collected at Point Atkinson are only for a short period of time from December 19, 1972 to May 18, 1974 and are simple point measurements which do not include directional information. The instrument involved in the data collection is the non-directional Waverider by Datawell: Although it nominally consists of hourly data, there are several missing data, and therefore the actual sampling frequency is only 2.3 hours per data point.

The Halibut Bank Station is located close to the Point Atkinson Station. Although it does not have a record of tide and sea level data, the wave data collected at this station are recent and 
are collected over a relatively long period of time from March 13, 1992 to June 25, 2003. In addition, the wind direction is collected here while measuring waves.

Roberts Bank is often used for estimates related to Richmond due to its similar oceanographic characteristics. The Roberts Bank Station is the only location that has similar geological characteristics to Richmond, because it is also in the delta region. With the absence of data at Richmond, this location provides an ideal condition for a complementary data set. However, there are only two sets of data available here, that of tide and significant wave data. The information regarding the data availability at the three stations is summarized in Table 5.1 with their station numbers, coordinates, and summary remarks. 
Table 5.1 Data Availability

\begin{tabular}{|c|c|c|c|c|}
\hline Location & Tide Data & Significant Wave Data & Water Level & Remarks \\
\hline $\begin{array}{l}\text { Point } \\
\text { Atkinson } \\
49.35 \mathrm{~N} \\
123.74 \mathrm{~W}\end{array}$ & $\begin{array}{l}\text { Yes } \\
\text { - Station\#7795 }\end{array}$ & $\begin{array}{l}\text { Yes } \\
\text { - MEDS106, } \\
\text { - Without direction, } \\
\text { - } 19 / 12 / 1972- \\
\text { 18/05/1974 }\end{array}$ & \begin{tabular}{ll}
\multicolumn{2}{l}{ Yes } \\
- & Station\#7795 \\
- & $01 / 05 / 1914-$ \\
& $06 / 08 / 0997$
\end{tabular} & $\begin{array}{l}\text { historically used } \\
\text { to estimate sea } \\
\text { flood level for } \\
\text { Richmond } \\
\text { - most complete } \\
\text { set of data } \\
\text { collection }\end{array}$ \\
\hline $\begin{array}{l}\text { Halibut } \\
\text { Bank } \\
49.34 \mathrm{~N} \\
123.74 \mathrm{~W}\end{array}$ & No & $\begin{array}{l}\text { Yes } \\
\text { - } \quad \text { C46146 } \\
\text { With wind } \\
\text { direction } \\
\text { - } 13 / 03 / 1992- \\
25 / 06 / 2003\end{array}$ & No & $\begin{array}{l}\text { most recent and } \\
\text { longest wave } \\
\text { data } \\
\text { station is very } \\
\text { close to Point } \\
\text { Atkinson }\end{array}$ \\
\hline $\begin{array}{l}\text { Roberts } \\
\text { Bank } \\
49.02 \mathrm{~N} \\
123.27 \mathrm{~W}\end{array}$ & $\begin{array}{l}\text { Yes } \\
\text { - Station\#7592 }\end{array}$ & $\begin{array}{l}\text { Yes } \\
\text { - } \quad \text { MEDS108/ } \\
\text { - Without direction } \\
\text { - } 07 / 02 / 1974- \\
03 / 04 / 1976\end{array}$ & No & $\begin{array}{ll}\text { - } & \text { delta area } \\
\text { similar } \\
\text { geological } \\
\text { characteristics } \\
\text { to Sturgeon } \\
\text { Bank } \\
\end{array}$ \\
\hline
\end{tabular}


Hydrograph - Fraser River at Hope

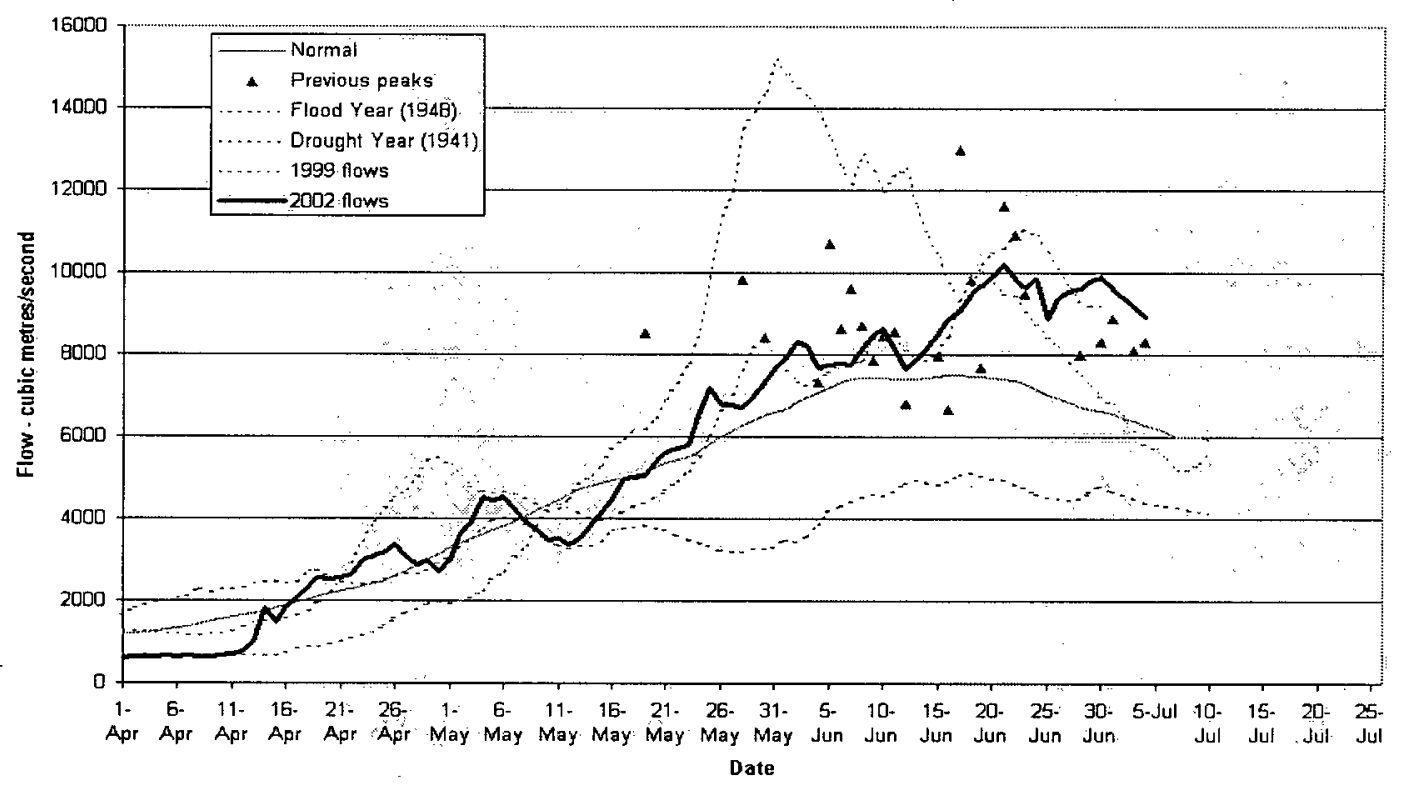

Figure 5.1 Hydrograph at Hope Gauge

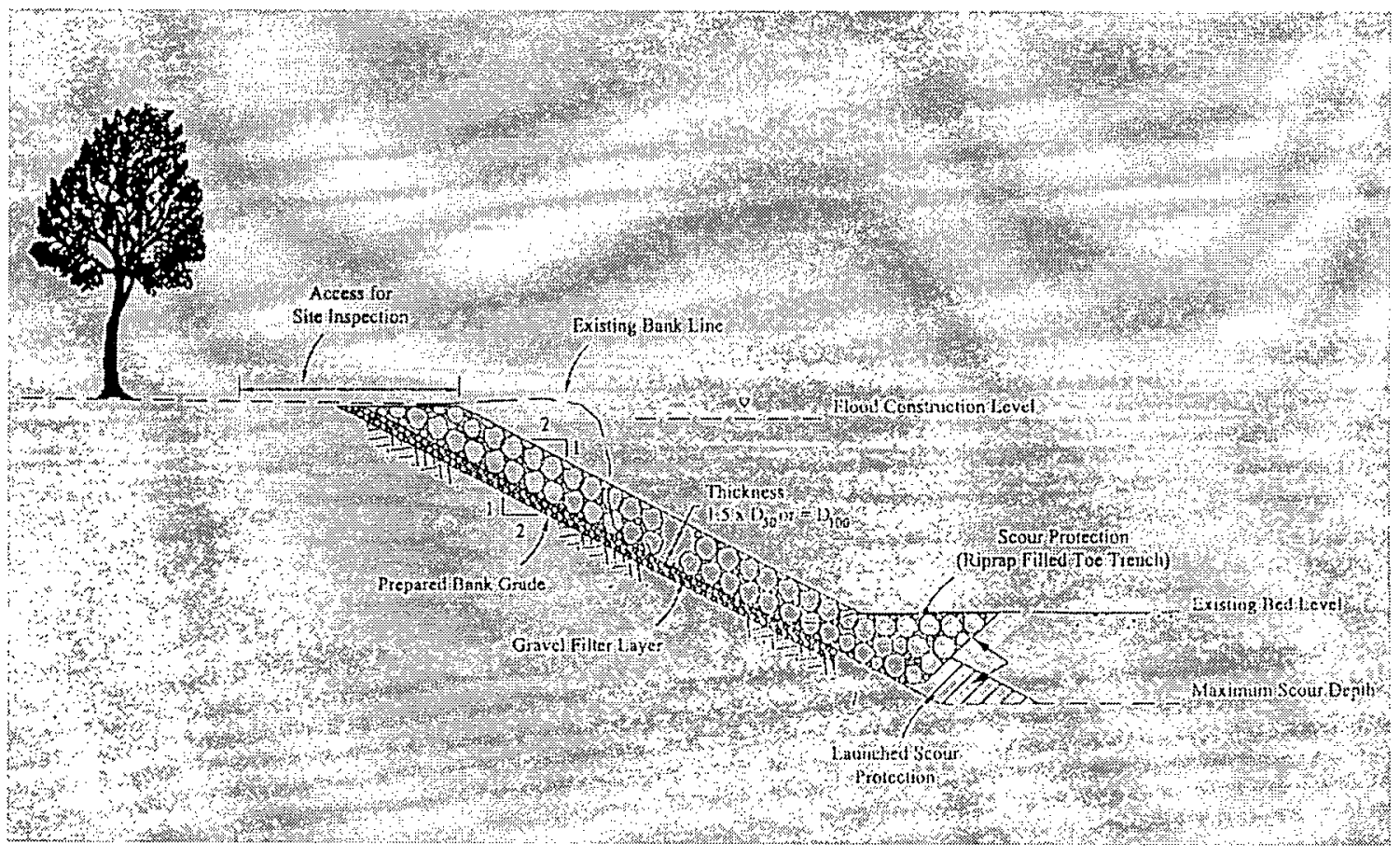

Figure 5.2 Standard Cross Section of the Dyke System 


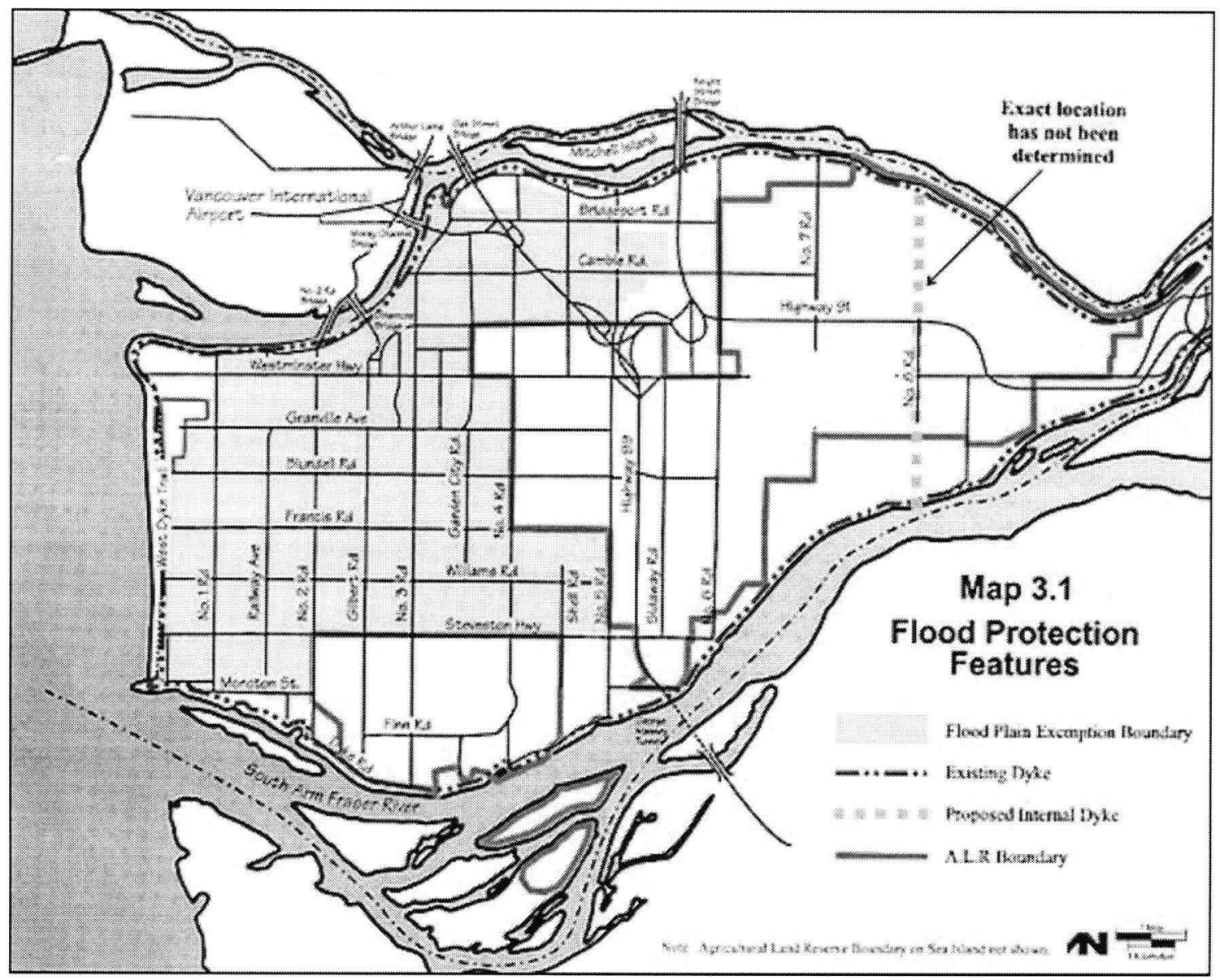

Figure 5.3 Flood Protection Features in Richmond

From City of Richmond Website
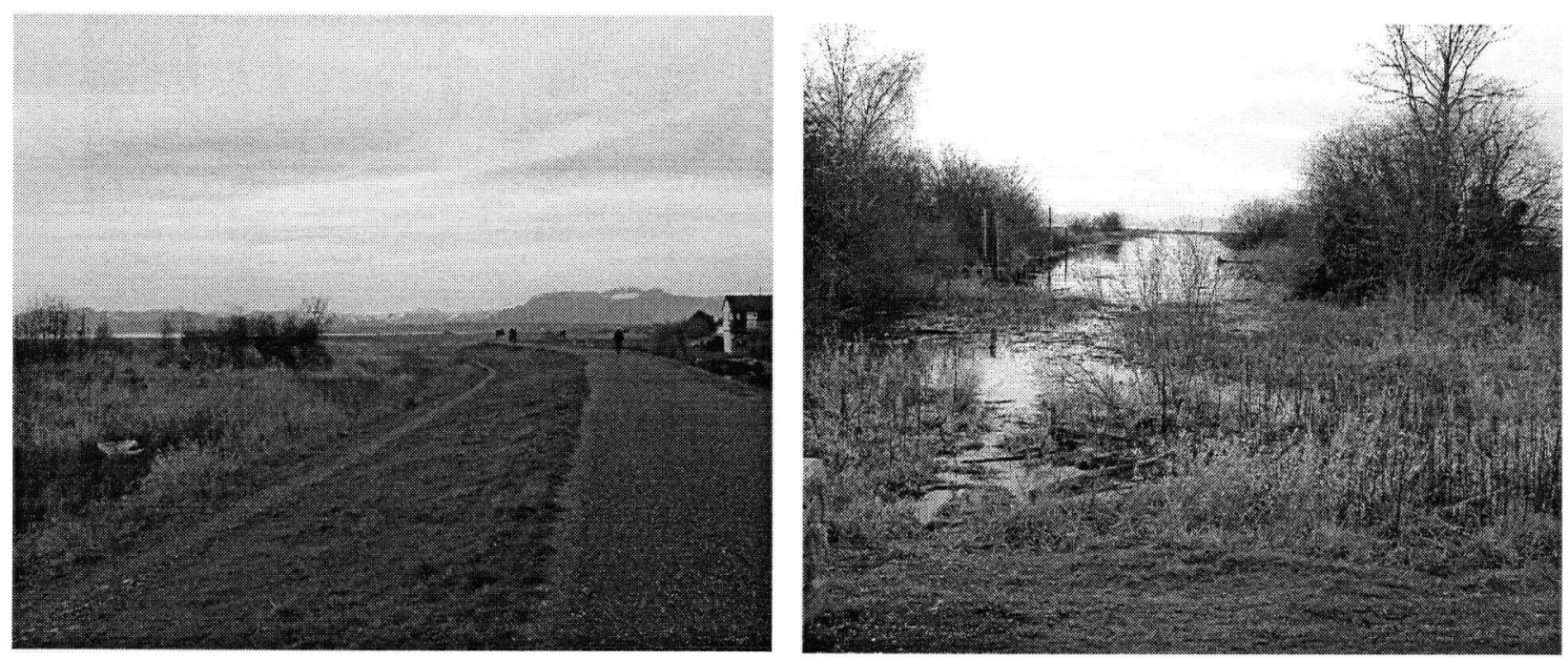

Figure 5.4 Sea Dyke of Richmond a) Looking North b) Looking toward West 


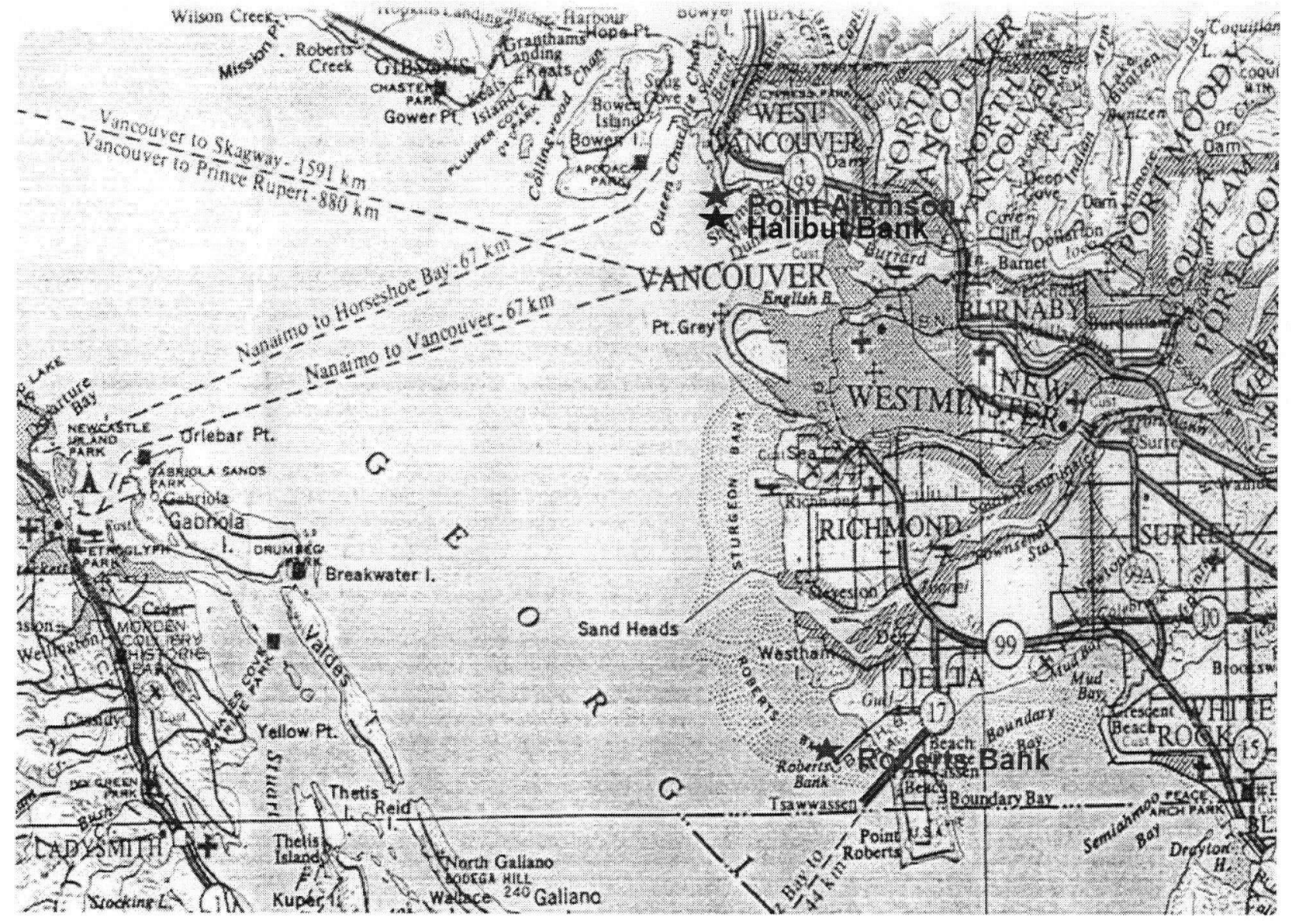

Figure 5.5 Map of Gauge Stations near Richmond 


\section{METHODOLOGY}

The DJPM is demonstrated herein for estimating extreme flood and sea levels for Richmond, B.C. As a preliminary assessment of the effectiveness of the method, flood levels estimated with the Annual Maxima and Simple Addition Method are compared with those estimated with the DJPM. Due to the geologic conditions in the Richmond area, the data for tides and storm surges are partially-dependent, and therefore application of the JPM to this case is not possible. Then, the estimation of extreme sea levels is undertaken with an approach that accounts for the critical factors affecting sea levels at Richmond and accommodates the limited available data. As identified in Section 5.5, the important factors contributing to the fluctuations in sea levels at Richmond include storm surges, tides, wave run-up, and long-term sea level variations. An application of the DJPM is used to identify extreme sea level estimations affected by combinations of storm surges, tides, and wave run-up (as in the example described with Figure 4.3), and of a hybrid of the Direct Joint Probability Method and the Simple Addition Method to account for these three factors plus long-term sea level variations. Because the 200year extreme sea level is the standard regulated under the B.C. Dyke Act, and the 1250-year extreme sea level is an alternative design standard that the City of Richmond is currently considering, the 200- and 1250-year extreme sea levels are estimated.

\subsection{Input Parameters}

Since there are no data collected in Richmond as indicated in Section 5.6, the analyses undertaken are based on the data collected at Point Atkinson. The two reasons for selecting the data collected at this station are that the data are complete and comprised of observed sea levels, 
tides, and waves, and that the data are historically used to determine design flood levels in Richmond and therefore provide consistency with respect to the present design approach for the dyke. The input parameters necessary for the estimation of the extreme flood levels include the tides and storm surges, whereas the input parameters used to predict extreme sea levels include the observed sea levels, tides, storm surges, waves, and dyke characteristics. As described in Section 3.4.2, the wave data and dyke characteristics are employed in the computation of wave run-up.

The observed sea level data are provided by the Marine Environment Data Service (MEDS), which is a branch of the Canadian Department of Fisheries and Oceans (DFO). The observed sea levels are collected hourly from 1:00 on May 1, 1914 to 23:00 on December 1, 1997. The hourly sea levels measured in meters above the CHAR datum are taken directly from the digital readings without interpolation. The water levels, in meters above the CHAR datum, can be converted to the water levels above the GSC datum by:

$G S C=C H A R-3.04$

The observed data undergo two levels of quality control and are adjusted if there is a change in reference datum at the station (MEDS Website). The quality control is performed by confirming that the time series of the observed sea and tide levels follow the same pattern (Thomlinson, Personal Communication, October 21, 2003). Observed sea levels can also be used to obtain a long-term trend of sea levels by performing a linear regression, as shown in Figure 6.1. Although the length of observed sea level data is insufficient to facilitate a definite conclusion regarding the long-term trend, which requires at least 100 years of data, Figure 6.1 indicates an increase in sea levels at the average rate of $1.3 \mathrm{~mm}$ per year based on the existing data.

The tide data provided by MEDS are predicted from 0:00 on May 1, 1914 to 23:00 on August 6, 1997. The tide data are predicted hourly applying the procedure described in Section 
2.3.5.4 with the constituents established by the Institute of Ocean Science dated June 4, 1997. The level of accuracy for predicted tide data is high.

Given the hourly observed sea levels and predicted tides at Point Atkinson, the hourly storm surges can be estimated by the Indirect Measurement Method, which involves a simple subtraction to obtain the difference between the observed sea levels and the corresponding tide levels, and the maximum wave heights are calculated based on the significant wave heights and peak wave periods using Equation 2.5. Given that the observed sea levels undergo a quality check, the level of accuracy for the estimated storm surges is also high.

The wave data obtained from the MEDS website are collected hourly from 17:00 on December 19, 1972 to $18: 00$ May 18,1974, although there are some missing data from time to time. The average sampling frequency is two hours. Each data point contains the following items: Date, QC_Flag, Latitude, Longitude, Depth, VCAR, and VTPK. QC_Flag is the quality code assigned subjectively to individual spectral records based on the shape of the spectral curve, and the descriptions of quality codes are summarized in Table 6.1 (MEDS Website). The depth for collecting the wave data is $40 \mathrm{~m}$, so the waves collected here are considered as deepwater waves. As defined in Section 2.3.1, for deep-water waves, water depth is greater than $25 \%$ of the wavelength. Wavelengths can be expressed as a function of wave periods, and described as:

$L=\frac{g T^{2}}{2 \pi}$

where $T$ is the wave period in seconds. Wave periods are measured and denoted as VTPK. The waves have an average wave period of $4.112 \mathrm{sec}$, and this can be represented as a ratio of water depth to wavelength of 1.52 , which is greater than 0.25 . VCAR denotes the characteristic significant wave height in metres, and it is calculated by employing Equation 2.7 (Tomlinson, email, July 16, 2003). 
The characteristics of the Sea Dyke at Richmond are also essential to the estimation of wave run-up, and the characteristics required are the slope of the dyke, the material of the dyke surface, and the elevation at the toe of the dyke. The Sea Dyke in Richmond as described in Section 5.4 has the slope of $1: 2$. While some sections have rip-rap slopes, most sections have grass mat on the slope. The elevation at the toe of the dyke is estimated based on a field survey conducted in 1974 by the City of Richmond as shown in Figure 6.2. The survey, performed for the purpose of improving the dyke system in 1974, is the only construction drawing available for the area west end of the Blundell Road in Richmond. The elevation at the toe of the dyke here is $5.0 \mathrm{ft}$ or $1.52 \mathrm{~m}$ above the GSC datum.

\subsection{Assessment of the DJPM for Estimating Extreme Flood Levels}

The efficacy of the DJPM is evaluated by comparison with the Annual Maxima and Simple Addition Methods. The latter two methods can only be used to determine the extreme flood levels, which are composed of tides and storm surges, and thus the comparison is based on estimated extreme flood levels.

\subsubsection{Application of the DJPM for Estimating Extreme Flood Levels}

The 200- and 1250-year estimates of the flood level based on tides and storm surges is determined. The data used in applying the DJPM include data for tides and observed sea levels collected at Point Atkinson. Since the wave data collected at Point Atkinson are only for the years from 1972 to 1974 and these data are used in the estimation of extreme sea levels as well, the tide and observed sea level data for the matching period of time are used to estimate extreme 
flood levels. Storm surges are estimated by subtracting tides from the corresponding observed sea levels. The time series of tides and storm surges are first divided into equal intervals, and the time series are used to construct the two-dimensional histogram of relative frequencies for the determination of hourly and annual probability of exceedance for extreme flood levels based on the selected intervals. The number of equal intervals for all data was selected to minimize the sensitivity of the results; results for $5,10,15,20$, and 25 equal intervals were examined, and 20 equal intervals were selected. A functional form of the relationship between the annual probabilities of exceedance and the corresponding extreme flood levels is then determined, and the 200-year and 1250-year flood levels are estimated using this function. It should be noted here that the adjustment factor of $1-\frac{p_{1}(z)}{p_{x}(z)}$ in Equation 3.12 or $\delta_{n}^{-1}(z)$ in Equation 3.14 is not used because the dependency of sea levels in this case study cannot be determined due to the inconsistent sampling frequency for wave measurements.

\subsubsection{Application of the Annual Maxima Method for Estimating Extreme Flood Levels}

The Annual Maxima Method is used to estimate the 200-year and 1250-year flood levels. The data required for this method are the long-term data of observed sea levels, and the record of observed sea levels at Point Atkinson from 1914 to 1997 is used. The following steps are undertaken:

1. The maximum value of the observed sea levels is determined for each year, and these values comprise the annual maxima series.

2. The annual maxima series is screened for missing data and outliers.

3. The annual maxima series is fit to various distribution types. Two software packages are used in this step to determine the parameters of distributions, and they are the 
Consolidated Frequency Analysis Package (CFA) and Reliability Analysis Package (RELAN). CFA is developed by the Surveys and Information Systems Branch, Environment Canada (1994), and RELAN is developed by Dr. R. Foschi at the University of British Columbia (1994).

4. Goodness-of-fit tests, standard error estimates, and engineering judgement are used to determine the performance of the distribution types.

5. The distribution types which best represent the data series are plotted in the form of a peak water level versus return period plot. The plots also show the data series used to conduct the analysis, the $95 \%$ Confidence Interval, and the estimations of the 200 -year and 1250-year flood levels.

As suggested by Tsimplis and Blackman (1997), an appropriate distribution type is important, so this approach includes several trials of various types of distributions.

\subsubsection{Application of the Simple Addition Method for Estimating Extreme Flood Levels}

Results of this approach can provide a conservative benchmark of the extreme flood level. This method estimates the 200-year and 1250-year flood levels by adding estimates of the corresponding quantiles of two components, the tides and storm surges. The quantiles of the tides and storm surges are estimated by the Annual Maxima Method, and the procedure involved in the Annual Maxima Method is presented in Section 6.2.2. Applying the Annual Maxima Method precludes the use of wave data, because the record of wave data at Point Atkinson, collected for less than two years, is too short to provide reliable estimates of the quantiles. Thus, the data used in the method include the long-term data of observed sea levels and tides at the Point Atkinson station from 1914 to 1997 . As previously stated, the series of storm surges is 
estimated by subtracting the tidal signals from the observed sea levels. The estimation of flood levels is obtained by simply adding the tides and storm surges with the same return period together after applying the Annual Maxima Method.

\subsection{Estimating Extreme Sea Levels for Richmond}

The critical factors contributing to the fluctuations in sea levels at Richmond include storm surges, tides, wave run-up, and long-term sea level variations. The Annual Maxima Method cannot consider the effect of wave run-up and long-term change in sea levels, and the Simple Addition Method cannot evaluate the actual joint probability of all the factors. The JPM and RJPM cannot consider the wave component in the estimation of extreme sea levels, because the waves and sea levels in shallow regions, such as that at Richmond, are generally dependent. The DJPM is the most appropriate method to estimate extreme sea levels in this case and allows for the incorporation of wave run-up. Finally, a hybrid of the DJPM and Simple Addition Method may be used to estimate the extreme sea levels with the long-term sea level variations. These approaches are described in Sections 6.3.1 and 6.3.2.

\subsubsection{Application of the DJPM for Estimating Extreme Sea Levels}

The DJPM is first applied to estimate the extreme sea level composed of tides, storm surges, and wave run-up, as described with respect to Figure 4.3. The data used in applying the DJPM include data for tides, storm surges, and waves collected at Point Atkinson. Since the wave data collected at Point Atkinson are only from 1972 to 1974, the tide and storm surge data 
for the matching period of time are used. As stated earlier, the adjustment factor of $1-\frac{p_{1}(z)}{p_{x}(z)}$ in Equation 3.12 or $\delta_{n}^{-1}(z)$ in Equation 3.14 is not used in the estimation of the hourly probability of exceedance. The DJPM is applied first to obtain the extreme flood levels composed of observed sea levels and wave run-up as described in Section 6.3.1.1, and then it is applied to determine the extreme sea levels composed of the tides, storm surges, and wave run-up as described in Section 6.3 .1 .2

\subsubsection{Application of DJPM for Combining Observed Sea Levels and Wave Run-up}

The data for this case includes the observed sea levels and waves from 1972 to 1974. The flow diagram for this application is shown in Figure 6.3, which follows the same logic as Figure 4.3. As shown in Figure 6.3, the extreme sea level is estimated by the adding observed sea levels and the wave run-up, and joint relative frequencies of these data are the elements of the two-dimensional histogram for these information. While the observed sea levels are provided, the wave run-up is calculated according to the SPM Method introduced in Section 3.4.2.1. The SPM Method is chosen because the waves at this location are deep-water waves. Data required for estimation of wave run-up using the SPM Method include the observed water levels, wave information, and dyke characteristics. Recall from Equation 3.16, wave run-up on smooth and impermeable surfaces is a function of bottom slope $(\theta)$, relative depth $\left(d_{s} / H_{0}^{\prime}\right)$, and relative steepness $\left(H_{0}^{\prime} / g T^{2}\right)$. Before computing the value of wave run-up on smooth and impermeable surfaces using Equation $3.16, \theta, d_{s} / H_{0}^{\prime}$, and $H_{0}^{\prime} / g T^{2}$ are estimated. The slope of $1: 2$, given by the standard design of the dyke system, identifies $\cot \theta$ as 2 . The value of $d_{s} / H_{0}^{\prime}$ is determined by first identifying the water depth fronting the toe $\left(d_{s}\right)$ and the wave heights $\left(H_{0}\right)$. 
While $d_{s}$ is obtained by finding the difference between the observed sea levels and the elevation at the toe of the dyke, $H_{0}{ }^{\prime}$ can be interpreted as the maximum wave height calculated using Equation 2.5 and the significant wave height and peak wave period from the wave data. With the maximum wave height and corresponding wave period, $H_{0}^{\prime} / g T^{2}$ can also be calculated. The value of $d_{s} / H_{0}^{\prime}$ first identifies the appropriate wave run-up curve(s) from the range of wave runup curves for a bottom slope of 1:10 in Appendix 1. The computation carried out in this work utilizes the wave run-up curves for a bottom slope of $1: 10$, rather than those for a horizontal bottom slope, because the wave run-up curves for a bottom slope of $1: 10$ are for the $d_{s} / H_{0}^{\prime}$ ranging from zero to three, which is a more suitable range of $d_{s} / H_{0}^{\prime}$ for Richmond. The wave run-up estimated from the curves are for smooth and impermeable surfaces in experimental conditions, thus adjustments are then made for different slope material and scale factor with the roughness $\left(\gamma_{f}\right)$ and scale $\left(\gamma_{s}\right)$ reduction factors. The material used on the seaward surface of the dyke is the governing factor for $\gamma_{f}$, and $y_{f}$ is 0.8 for fitted quarrystone or grass according to Table 3.2. In addition, $\gamma_{s}$ is 1.13 for $H_{0}$ ' ranging from 0.45 to $1.37 \mathrm{~m}$ and 1.19 for $H_{0}$ 'ranging from 3.66 to $1.22 \mathrm{~m}$ as indicated in Figure 3.5. Given the wave run-up on smooth and impermeable surfaces, $\gamma_{f}$, and $\gamma_{s}$, the actual wave run-up is estimated employing Equation 3.17. The joint probabilities of exceedance associated the observed sea levels and wave run-up are represented by the joint relative frequencies of the observed sea levels and waves, and are estimated using the DJPM. 


\subsubsection{Application of DJPM for Combining Tides, Storm surges, and Wave run-up}

The DJPM is also applied for the three dimensional input conditions, tides, storm surges, and wave run-up. The data required include the observed sea levels, tides, and waves. As shown in Figure 6.4 (which is identical to Figure 4.3), the extreme sea levels are estimated by adding the tides, storm surges, and wave run-up, and the corresponding joint probability of exceedance is based on the joint relative frequencies of three events. Storm surges are estimated by subtracting the tidal signals from the observed sea levels. Wave run-up is predicted using the SPM method with a similar procedure as that described in Section 6.3.1.1. The associated probability of exceedance is obtained by constructing a three-dimensional histogram of joint relative frequencies.

Since there is no directional information for the wave data, the approach taken is to find the range for wave run-up by assuming that waves are attacking the dykes within the angle of propagation of between $0^{\circ}$ and $30^{\circ}$. In order to include the angle of propagation in the prediction of wave run-up, Equation 3.17.in the SPM method is modified as:

$R_{w}=\frac{R_{s m o o t h, l a b}}{H_{0}^{\prime}} H_{0}^{\prime} \gamma_{f} \gamma_{s} \gamma_{\beta}$

where $\gamma_{\beta}$ is the reduction factor for angle of propagation and the value of $\gamma_{\beta}$ is estimated by Equation 3.21. 


\subsubsection{Application of the Hybrid of the DJPM and Simple Addition Method for Combining Tides, Storm surges, Wave Run-up, and Long-term Sea Level Rises}

The long-term rate of sea level rise for Richmond is considered to be a constant, so the Hybrid of the DJPM and the Simple Addition Method, the Hybrid DJP-Simple Addition Method, is designed for the inclusion of a constant long-term trend in sea levels. Although the component of long-term sea level change is incorporated in the estimation of extreme sea levels, the effect of using old data to project the future changes is not analyzed. This work not only estimates the extreme sea level including the long-term sea level changes, but also demonstrates the timing issues that must be addressed when old data are used to project future changes.

As shown in Figure 6.5, the goal is to estimate the extreme sea level by adding tides, storm surges, wave run-up, and long-term sea level rises. Two major steps involved in this approach are the estimate of extreme sea levels composed of tides, storm surges, and wave runup using the DJPM as discussed in Section 6.3.1.2, and the addition of the long-term sea level increases and these extreme sea level estimates. The rate of long-term sea level change adopted herein in this approach is $1.3 \mathrm{~mm}$ per year, which is the rate experienced in Richmond as discussed in Section 6.1. The rate of the long-term sea level changes suggests that the cumulative effect of rising sea levels from 1972 to 2010 is approximately $0.05 \mathrm{~m}$. This means that when data collected in 1972 are used to estimate extreme sea levels, the estimations are under-estimated by $0.05 \mathrm{~m}$ due to long-term sea level rises. Although $0.05 \mathrm{~m}$ is a small value, it may make a big difference in the estimation of extreme sea levels. This approach demonstrates the effect of the long-term sea level increases on the estimation of extreme sea levels by projecting the extreme sea levels for 2000 and 2010 (recall that the existing data are for the years 1972 to 1974). In each scenario, a constant value of sea level increase is added to the estimation 
of extreme sea level based on the DJPM, and the constant value is obtained by multiplying the difference between the projected and data year by the constant rate of $1.3 \mathrm{~mm}$ per year. 
Table 6.1 Description of the Quality Codes from Marine Environment Data Service Website

\begin{tabular}{|c|l|}
\hline QC_Flag & \multicolumn{1}{|c|}{ Description } \\
\hline 0 & Blank - No quality control (QC) has been performed \\
\hline 1 & Good - QC has been performed: record appears correct \\
\hline 2 & Doubtful - QC has been performed: record appears doubtful \\
\hline 3 & Erroneous - QC has been performed: record appears erroneous \\
\hline 4 & Changes - The record has been changed as a result of QC \\
\hline 5 & Acceptable - QC has been performed: record seems inconsistent with other record \\
\hline 6 & $\begin{array}{l}\text { Off Position - There is a problem with the buoy position or mooring. Data may still } \\
\text { be useful }\end{array}$ \\
\hline 7 & Reserved \\
\hline 8 & Reserved - indicates missing elements \\
\hline
\end{tabular}




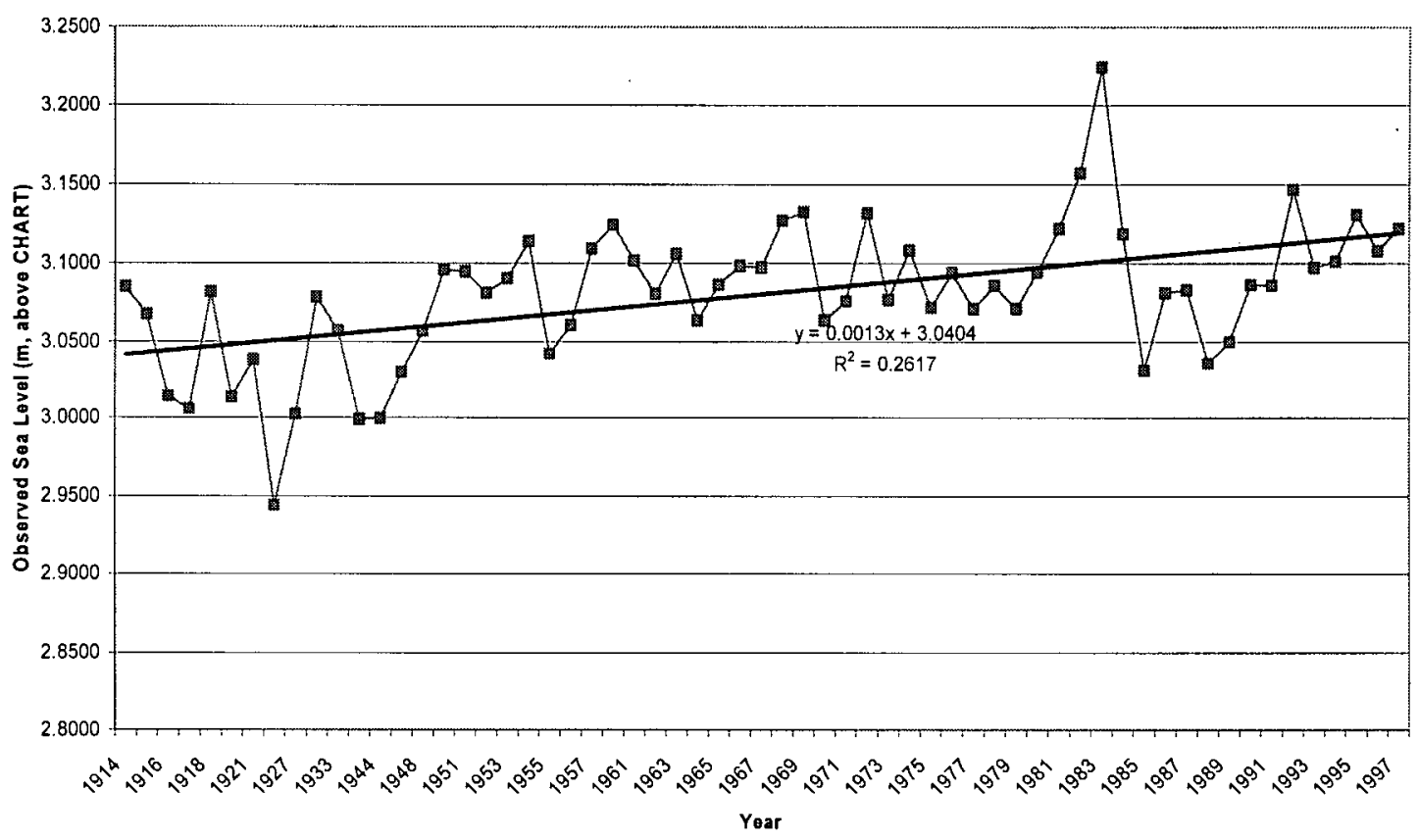

Figure 6.1 Long-term Trend of Sea Levels at Point Atkinson
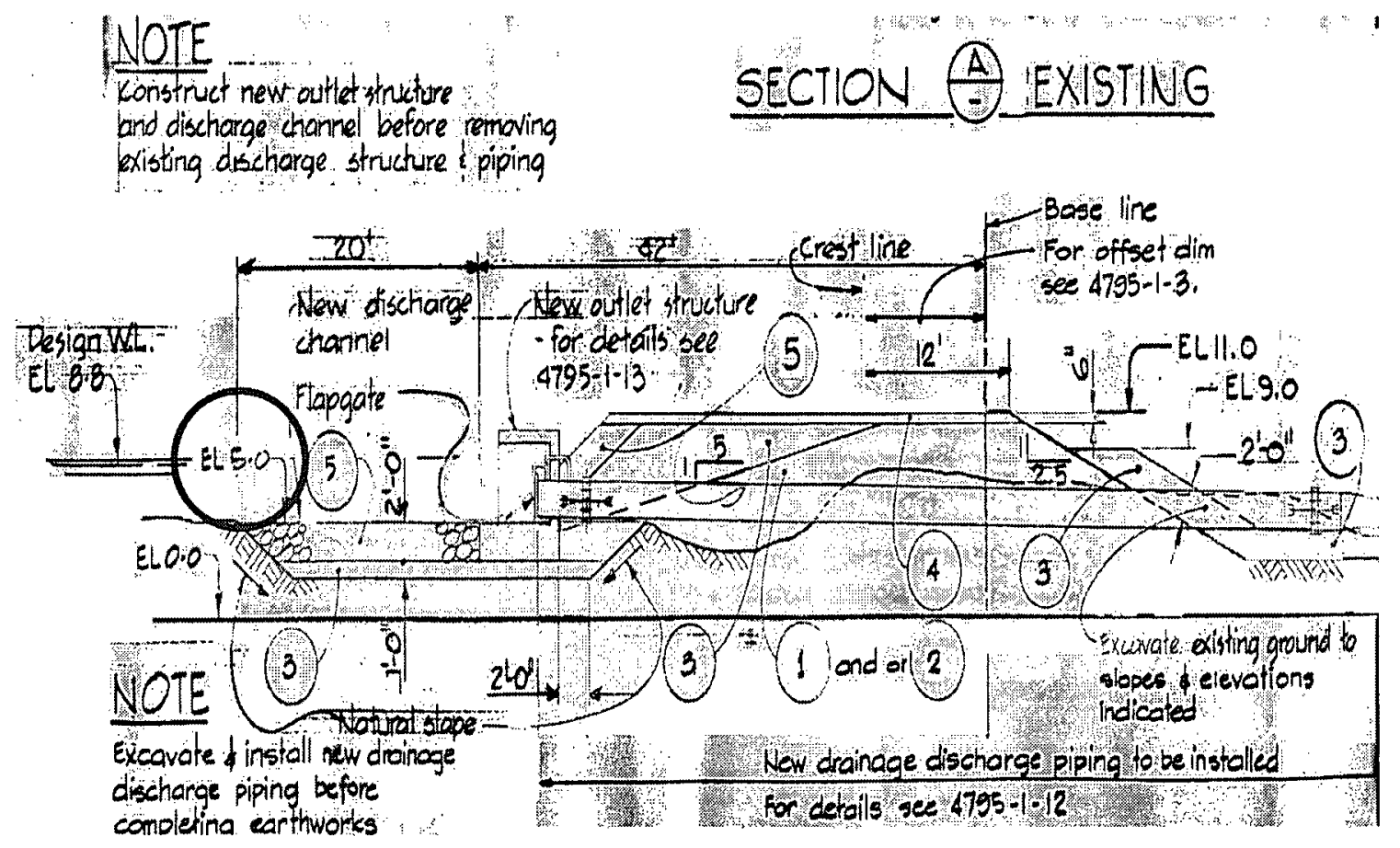

Figure 6.2 Construction Drawing at West End of Blundell Road in 1974 
Required Data

Equation

Critical Factors

3-D Histogram

Overall Equation

Overall Equation

Figure 6.3 Flow Diagram of the DJPM for Combining Observed Sea Levels and Wave Run-up

- Observed sea levels

- Significant wave height $\left(H_{s}\right)$

- $\quad$ Significant wave period $(T, \mathrm{~s})$

- Duration $(D, \mathrm{~h})$

- Slope of dyke ( $\theta$ )

- Depth fronting the slope $\left(d_{s}\right)$

- Deep-water wave height $\left(H_{0}\right)$

- Roughness and porosity of dyke

$$
H_{m}=H_{s} \sqrt{\frac{\ln \left(3600 \frac{D}{T}\right)}{2}}
$$

$$
\frac{R}{H_{0}^{\prime}}=f c r\left(\theta, \frac{H_{0}^{\prime}}{g T^{2}}, \frac{d_{s}}{H_{0}^{\prime}}\right)
$$

\section{Observed Sea Levels}

Wave Run-up

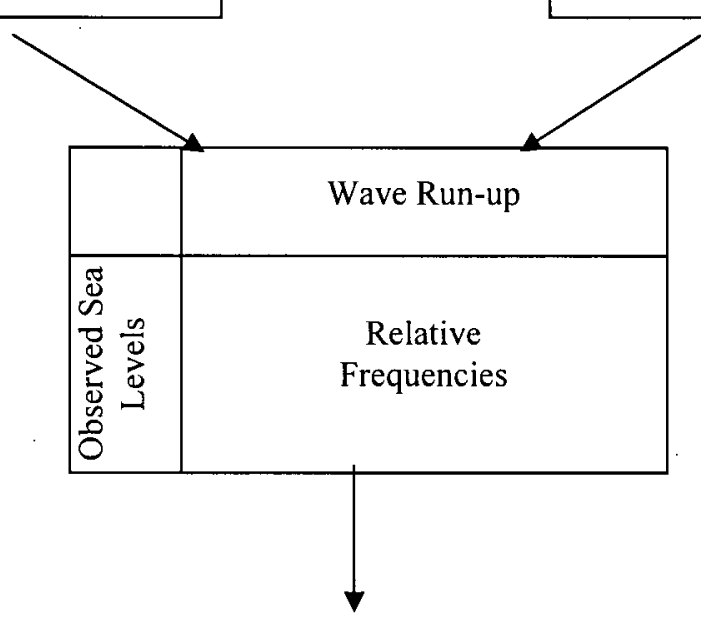

Extreme Sea Levels = Observed Sea Levels+ Wave Run-up 


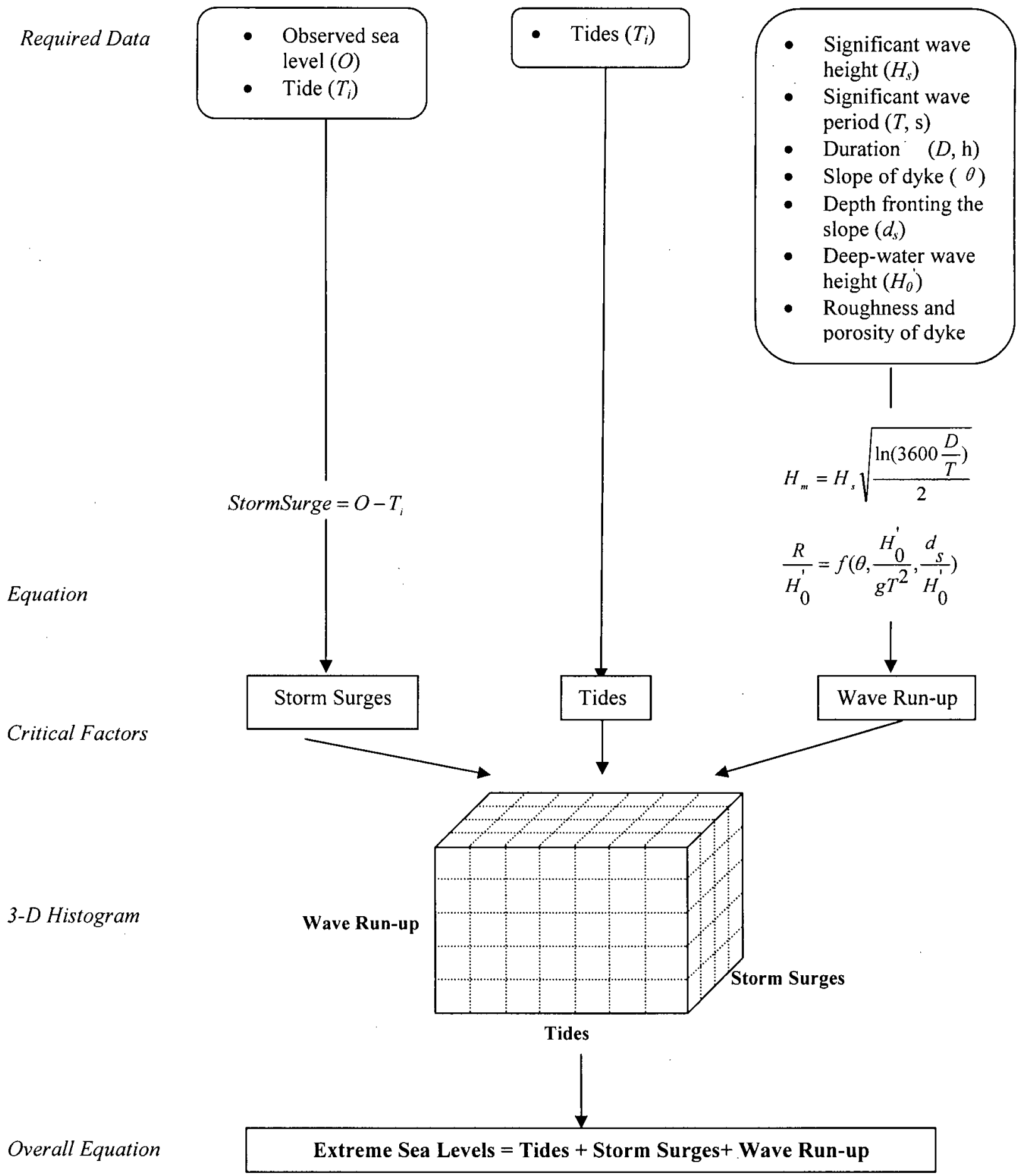

Figure 6.4 Flow Diagram of the DJPM for Combining Tides, Storm Surges, and Wave Run-up 
Required Data

Critical Factors

3-D Histogram

Overall

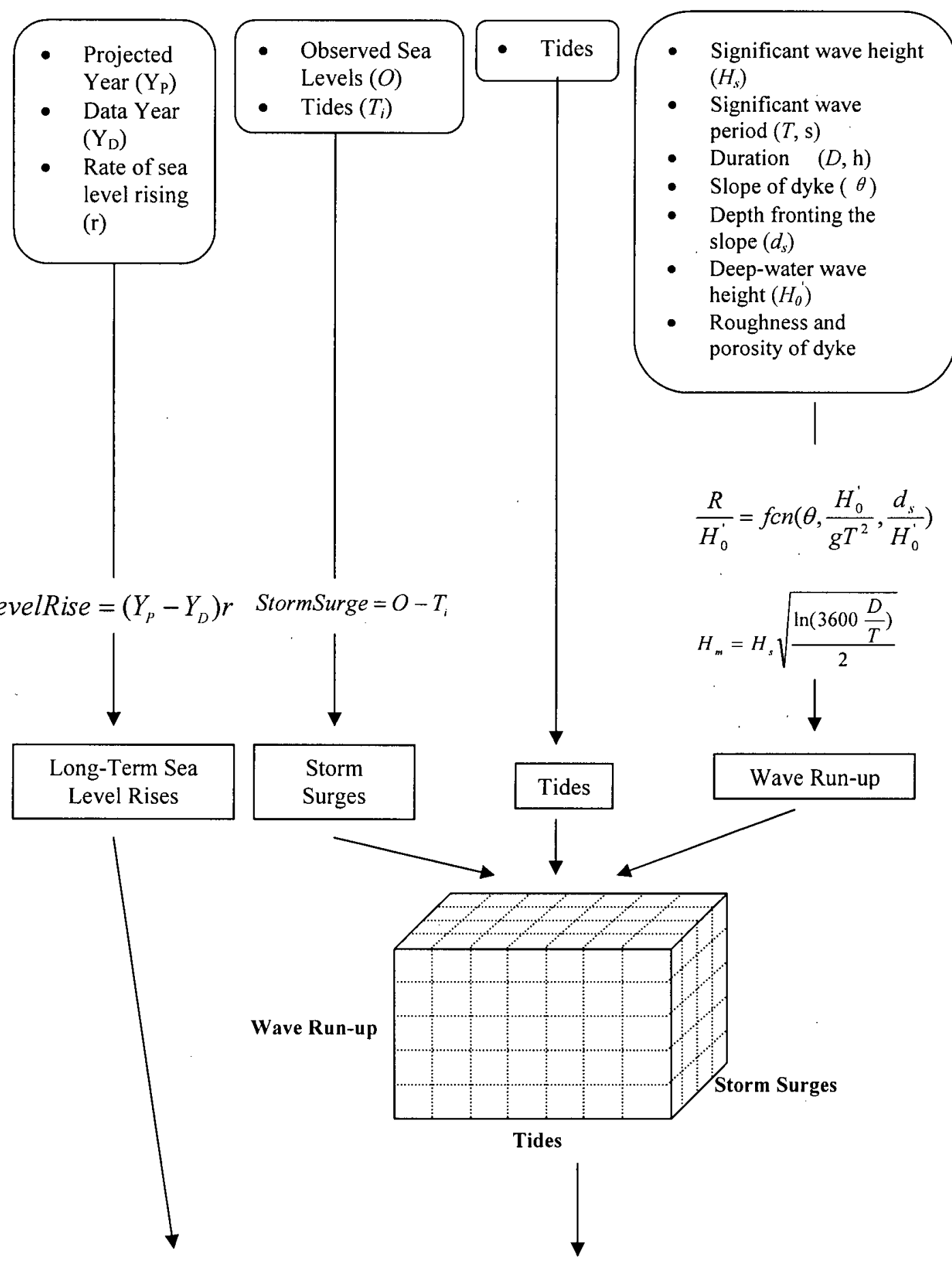

Extreme Sea Levels $=$ Tides + Storm Surges + Wave Run-up + Long-Term Sea Level Rises

Figure 6.5 Flow Diagram of the Hybrid of the DJPM and Simple Addition Method for Combining Tides, Storm Surges, Wave Run-up, and Long-Term Sea Level Rises 


\section{RESULTS AND DISCUSSION}

Sections 7.1 and 7.2 present and discuss the results of tests which assess the efficacy of the DJPM for estimating extreme flood and sea levels for Richmond, B.C., respectively. Section 7.3 concludes this chapter with a discussion of the sources of error for the case study.

\subsection{Assessment of the Direct Joint Probability Method}

The assessment of the DJPM is achieved by comparing the estimates of extreme flood levels for specified return periods using three approaches: the DJPM, Annual Maxima Method, and Simple Addition Method. Extreme flood levels only depend on the components of tides and storm surges, and therefore, all three methods are capable of achieving the flood level estimates. The results using the DJPM, Annual Maxima Method, and Simple Addition Method are presented in Sections 7.1.1, 7.1.2, and 7.1.3, respectively. Section 7.1.4 summaries and discusses these results.

\subsubsection{Estimation of Extreme Flood Levels Using the Direct Joint Probability Method}

The estimation of extreme flood levels is achieved by applying the DJPM and the data of tides and storm surges collected at Point Atkinson from 1972 to 1974 . The DJPM first constructs the two-dimensional histogram using the time series of tides and storm surges as shown in Table 7.1. Here the column and row titles indicate the maximum values of the intervals. The cells in Table 7.1 contain the relative frequencies associated with the 
corresponding tidal and storm surge intervals. The relative frequencies are sorted according to the descending order of flood levels and the annual probability of exceedance associated with each flood level is calculated. The results are summarized in Figure 7.1. Here the smoothed plot drawn represents the relationship between extreme sea level and return period and can be used to estimate the extreme sea levels for specified return periods. When the numbers of intervals used for constructing the histogram increase, the curve representing the relationship between extreme sea level and return period becomes smoother. As indicated in Figure 7.1, the estimated 200year and 1250-year extreme flood levels are approximately $2.25 \mathrm{~m}$ and $2.45 \mathrm{~m}$, respectively.

\subsubsection{Estimation of Extreme Flood Levels Using the Annual Maxima Method}

The section presents the of extreme flood levels estimated by applying the Annual Maxima Method and using the observed sea level data collected at Point Atkinson from 1914 to 1997. The Annual Maxima Method first extracts the annual maxima series. While Table 7.2 presents the annual maxima series, it should be noted that the original data from Point Atkinson for the following years are missing entirely: 1923, 1924, 1925, 1926, 1928, 1929, 1930, 1931, 1934, 1935, 1936, 1937, 1938, 1940, 1941, 1942, 1943, 1945, 1946, 1949, 1959, and 1960. These missing data are defined as a broken record, so the remaining data are used and treated as a continuous record. In addition, a small outlier with the water level of $3.500 \mathrm{~m}$ above the CHAR datum is detected in the year 920. Therefore, 1920 is also removed from the annual maximum series. The annual maxima series is fitted, and the three-parameter Log-Normal Distribution (LN(3)) is determined by both the CFA and RELAN software packages to be the most appropriate distribution type for representing the annual maximum series. The estimated $\mathrm{LN}(3)$ is shown in Figure 7.2 along with the data series, where the theoretical distribution is the 
solid line, and the $95 \%$ confidence intervals are marked by the dashed lines. From Figure 7.2, the 200 year extreme flood level is estimated as $2.60 \mathrm{~m}$ above the GSC datum, and the 1250-year extreme flood level is estimated as $2.68 \mathrm{~m}$ above the GSC datum.

\subsubsection{Estimation of Extreme Flood Levels Using the Simple Addition Method}

The Simple Addition Method is also applied to estimate flood levels by using data for tides and storm surges collected at Point Atkinson from 1914 to 1997 . It first requires the determination of the frequency distributions for tides and storm surges, and a similar procedure as described for the Annual Maxima Method is undertaken for the time series of tides and storm surges. The results of the frequency analyses of tides and storm surges are presented in Figure 7.3, where the estimated frequencies for the time series of tides are plotted on the dashed line and those for storm surges they are plotted on the dotted line. The estimated flood levels are the solid line they are determined by adding the tides and storm surges for the corresponding return periods. The 200-year flood level is estimated to be $3.096 \mathrm{~m}$ above the GSC datum, calculated by adding the 200 -year tide $(2.023 \mathrm{~m})$ and the 200 -year storm surge $(1.073 \mathrm{~m})$. The 1250 -year flood level is $3.196 \mathrm{~m}$ above the GSC datum, obtained by adding the 1250 -year tide $(2.040 \mathrm{~m})$ and the 1250-year storm surge $(1.156 \mathrm{~m})$.

\subsubsection{Assessment of the Direct Joint Probability Method for Estimating Extreme Flood Levels}

The general efficacy of DJPM may be assessed by comparisons of the extreme flood level estimates from applications of the DJPM, Annual Maxima Method, and Simple Addition 
Method. The estimated extreme flood levels resulting from these three methods are summarized in Table 7.3. As expected, the application of the Simple Addition Method produces the highest estimation of extreme flood levels among all approaches due to its conservative nature, and the results obtained for the Simple Addition Method are 23 to $28 \%$ higher than the results obtained for the DJPM, and 19\% higher than those for the Annual Maxima Method. Furthermore, the results obtained for the Annual Maxima Method are closer to the results obtained for the DJPM. The percent difference of the 200-year and 1250-year flood levels estimated by these two methods are $13.46 \%$ and $8.58 \%$, respectively, relative to the DJPM values, with the difference in the number of year of required data being 59 years. The reason for the lower flood level values determined in the application of the DJPM is that the sea levels for the years 1972, 1973, and 1974 are generally low flows years compared with those in the 62 years of data used for the other methods of analysis. The observed sea levels for 1972, 1973, and 1974 rank 44, 37, and 62 in descending order of observed sea levels, for the 62 year history of record used. Therefore, the results of this method are sensitive to the choice in years used for the estimations, because they are largely dominated by the maximum tides and maximum storm surges captured during the years of data used. The DJPM also exhibits the disadvantage of not being able to provide an extreme flood level greater than the data available. Considering the data used in this method, the results demonstrate that the DJPM is able to provide a reasonable estimate of the flood level using data with short periods of record. Under limited data availability, the DJPM can still provide a reasonable estimation of extreme flood levels. It should also be noted that the estimations resulting for the DJPM and Annual Maxima Method are smaller than the current 200-year flood level of $2.8 \mathrm{~m}$ used by Richmond. Thus, the current design flood is well within the estimations computed using all of these approaches. 


\subsection{Estimation of Extreme Sea Levels using the DJPM and Hybrid DJP-Simple Addition Method}

The DJPM and the Hybrid DJP-Simple Addition Method are applied to estimate extreme sea levels for Richmond, because the extreme sea levels for Richmond include the effects of tides, storm surges, wave run-up, and long-term sea level increases. Section 7.2.1 presents the results of the application of the DJPM for estimating extreme sea levels based on data for either a combination of observed sea levels, tides, and waves or a combination of tides, storm surges, and waves. Section 7.2.2 presents the results of the application of the Hybrid DJP-Simple Addition Method for estimating extreme sea levels based on tides, storm surges, wave run-up, and long-term sea level increases. Section 7.2.3 summarizes and discusses the results.

\subsubsection{Estimations of Extreme Sea Levels Using the Direct Joint Probability Method}

Section 7.2.1.1 presents the estimations of extreme sea levels using observed sea levels and wave run-up, and Section 7.2.1.2 presents the estimations of extreme sea levels using tides, storm surges, and wave run-up.

\subsubsection{DJPM Application to Observed Sea Levels and Wave Run-up}

The resulting extreme sea levels, which include the effect of observed sea levels and wave run-up, estimated using the DJPM and data for observed sea levels and waves from 1972 to 1974 are shown in Figure 7.4. Recall that wave run-up is a function of sea levels and wave information, based on Equation 3.16. Figure 7.4 is obtained based on two years of continuous 
data; thus, the plot of results starts from the minimum sea level for the two years of data record. For the purpose of finding extreme sea level values, the focus is on return periods of 100 years or more. The plot shown in Figure 7.4 has a distinct continuity where the wave run-up begins at the minimum sea level of $1.5 \mathrm{~m}$. Wave run-up increases gradually with the increasing sea levels above $1.5 \mathrm{~m}$. The estimated 200- and 1250-year extreme sea.level including wave run-up are $3.25 \mathrm{~m}$ and $3.69 \mathrm{~m}$ above the GSC datum, respectively.

\subsubsection{DJPM Application to Tides, Storm Surges, and Wave Run-up}

The results of the application of the DJPM for the data for tides, storm surges, and waves from 1972 to 1974 are summarized in Figure 7.5. Similar to the observations for Figure 7.4, Figure 7.5 demonstrates that wave run-up is generated at the minimum water depth of $1.5 \mathrm{~m}$. The estimated 200- and 1250-year extreme sea levels are $3.78 \mathrm{~m}$ and $3.90 \mathrm{~m}$ above the GSC datum, respectively.

The effect of the angle of propagation on the estimation of wave run-up and thus the estimation of extreme sea level is summarized in Figure 7.6. As shown in the figure, wave runup decreases as the propagation angle increases. Thus, wave run-up and extreme sea levels are at a maximum when the propagation angle is $0^{\circ}$, and wave run-up and extreme sea levels decrease by $2 \%$ as the wave propagation angle increases to $30^{\circ}$. The 200 - and 1250 -year extreme sea levels with a propagation angle of $30^{\circ}$ are estimated as $3.67 \mathrm{~m}$ and $3.79 \mathrm{~m}$ above the GSC datum, respectively. 


\subsubsection{Hybrid DJP-Simple Addition Method Application to Tides, Storm Surges, Wave Run-up, and Long-term Sea Level Changes}

The Hybrid DJP-Simple Addition Method is applied to the estimation of extreme sea levels for Richmond so as to include the effects of tides, storm surges, wave run-up, and longterm sea level increases. Figure 7.7 shows that the effect of the long-term sea level changes on the extreme sea levels increases as the return period increases. For return periods greater than 200 years, the extreme sea levels predicted increase considerably for the years 2000 and 2010 , because the added affect of long-term sea level rise generates increased wave run-up. The 200year extreme sea levels for the years 1972,2000 , and 2010 are $3.78 \mathrm{~m}, 3.81 \mathrm{~m}$, and $3.82 \mathrm{~m}$ above the GSC datum, respectively. The 1250-year sea levels for the years 1972, 2000, and 2010 are $3.90 \mathrm{~m}, 4.15 \mathrm{~m}$, and $4.16 \mathrm{~m}$ above the GSC datum, respectively.

\subsubsection{Discussion of the Estimations of Extreme Sea Levels for Richmond}

In this thesis, the DJPM is not only applied to estimate the extreme sea levels using different combinations of data that capture the effects of tides, storm surges, and wave run-up, but also to estimate the effect of the angle of propagation on wave run-up and resulting extreme sea levels. The Hybrid DJP-Simple Addition Method demonstrates the effect of long-term sea level increases. The following discussion reviews the results of the estimation of extreme sea levels without the long-term sea level increase, the estimation of extreme sea levels with different angles of propagation, the estimation of extreme sea levels with the long-term sea level increase, and the relevance of these results for Richmond. 
Wave impacts at the contact point of coastal structures are characterized by wave run-up. The extreme sea levels, excluding the long-term sea level changes, are estimated using the DJPM applied for analysing observed sea levels and wave run-up, and tides, storm surges and wave run-up. As shown in Table 7.4, the results obtained for the DJPM application based on only two data types are smaller than those for the DJPM application based on three data types. By breaking down the observed sea levels into tides and storm surges, more combinations of observed sea levels are produced to be used in the estimations of extreme sea levels. This is a definite advantage in the case of short data sets. It also demonstrates that the wave run-up can make a dramatic difference in the extreme sea levels as shown in Figure 7.8, where the two higher-valued plots are for computations including wave run-up.

Analysis of the propagation angle is also undertaken for the case in which extreme sea levels are estimated based on tides, storm surges, and wave run-up. Two propagation angles are examined, $0^{\circ}$ and $30^{\circ}$, and the resulting extreme sea level estimates are summarized in Table 7.5. As shown in the table, the 200- and 1250-year extreme sea levels are both reduced for the $30^{\circ}$ propagation angle relative to the $0^{\circ}$ angle. Thus, the ranges of 200- and 1250-year sea level estimates for Richmond are from 3.78 to $3.67 \mathrm{~m}$ and from 3.90 to $3.79 \mathrm{~m}$ above the GSC datum, respectively.

In addition, the predicted long-term rise in sea levels is included in the estimation of extreme sea levels for different points in time and these estimates are summarized in Table 7.6. The results demonstrate the importance of including the long-term sea level changes in these estimates. For Richmond, where long-term sea rises are prevalent, the extreme sea level estimates with higher return periods show dramatic differences between cases that incorporate long-term sea level change, and those that do not. These results indicate the importance of including wave run-up in the estimation of extreme sea levels for locations where long-term sea level increases are significant. These results also imply that for such cases, the standard 
approach of using short data records that are relatively old in applications of the DJPM, JPM, and RJPM may be misleading because the data may be insufficient to characterize current situations. The degree of impact of the propagation angles is relatively small compared with the degree of impact of the long-term sea level changes.

Comparing the results with the current flood construction level of $3.35 \mathrm{~m}$ for Richmond, the current flood construction is within in the 200 -year estimates resulting from all of the aforementioned methods. Although the effects of vegetation as observed at the west coast of Richmond are not considered in any method, the vegetation can certainly provide a damping effect on waves approaching the shore. However, there is no research or experimental results regarding the effect of vegetation on the propagation of waves. Therefore, the estimations provided here are more conservative than the actual sea level condition, since no adjustment for the damping effect of vegetation is incorporated. Nevertheless, in the long-term, when the sea levels continue to rise, the damping effect may be weakened.

\subsection{Sources of Error for Estimates of Extreme Flood and Sea Levels}

The errors involved in the estimation of extreme flood and sea levels at Richmond, B.C. include the errors that are inherent for the DJPM, and the errors caused by the assumptions due to the lack of data in Richmond. One of the major errors associated with the application of the DJPM is that which can results from the construction of the plots that approximate the relationship between extreme sea level and return period. These plots are used to estimate the sea level for specified return periods, and the smoothness of them depends on the number of data available and the intervals of the histograms developed. However, the data used in this case study are not sufficient for constructing smooth plots, even with a large number of intervals in 
the histogram. Thus, the plots cannot be represented by a simple equation for the relationship between extreme sea level and return period.

The assumptions made due to lack of data in Richmond and the errors that may occur due to these assumptions are summarized as follows:

1. Tides, storm surges, and waves are the governing factors of sea level fluctuations. This assumption is valid for most locations in Richmond, but as previously stated, for two problematic locations in Richmond, other factors that are not analyzed here contribute to extreme sea levels. These factors are the effects of river currents (e.g., near Terra Nova) and the effects of water transport (e.g., near Garry Point). Ignoring these factors could lead to underestimates of sea levels in these locations, but including them would lead to overestimates at most locations along the dyke.

2. The data collected at Point Atkinson represent the data at Richmond. This assumption may be weak for Richmond since the oceanographic characteristics between Point Atkinson and Richmond have the least similarities among all stations considered. There is no evidence supporting or refuting the validity of this assumption, because Richmond does not have any data for comparison.

3. The wave data containing missing data points are treated as continuous. This assumption is weak as the wave data at Point Atkinson exhibit missing data from time to time, and the average frequency of sampling is 2.3 hours. There is no record of an extreme event for the period of data collection, so treating the wave data as a continuous series is considered a standard procedure. The disadvantage of relying on this assumption is that some values of tides and storm surges are excluded in order to accommodate the missing wave data, so some extreme values may be excluded at the same time.

4. The elevation at the toe of the dyke along the coastline is constant at $1.52 \mathrm{~m}$. The elevation at the toe of the dyke is not constant along the whole sea dyke due to shoaling 
and settlement of the dyke structures. Because there is only one record of measurement available at Blundell Road, this assumption is necessary, but is weak. Shoaling increases the sedimentation at the toe of the dyke and increases the elevation at the toe, whereas settlement reduces the elevation at the toe. Various locations can display various degrees of shoaling and settlement, thus the elevations at the toe of the dyke are not only changing with time but are also different at different locations. These elevations are important for the estimation of wave run-up as wave run-up increases with decreases in the toe elevation, see Equation 3.16.

5. The slope of dyke is assumed to be a constant 1:2 throughout the dyke system. As shown in Figure 5.4, the majority of the dyke is not constructed according to the standard design. An actual field survey conducted by the author showed that the slope varies from $1: 2$ to $1: 5$ along the sea dyke.

6. The bottom slope is 1:10. The wave run-up is calculated based on the wave run-up curves for a bottom slope of 1:10, when in fact Richmond has an almost horizontal bottom slope. A quick comparison of the wave run-up calculated using the bottom slope of $1: 10$ and that for the horizontal bottom slope demonstrates that the wave run-up calculated for the 1:10 slope case underestimates the actual wave run-up and therefore the extreme sea levels that include wave run-up estimated in this work likely underestimate the actual extreme sea level.

7. Vegetation does not affect the extreme sea levels. As discussed earlier, the effect of vegetation is not quantified yet, so this assumption is necessary. Until better information is provided, the approach taken in this thesis may be used to provide a conservative extreme sea level.

8. The long-term rise in sea levels at Richmond is at a rate of $1.3 \mathrm{~mm}$ per year. This is an average value obtained from 61 years of data, based on actual data collected at Point 
Atkinson. However, this record is not sufficient for determining a long-term change, which usually requires at least 100 years of data. 


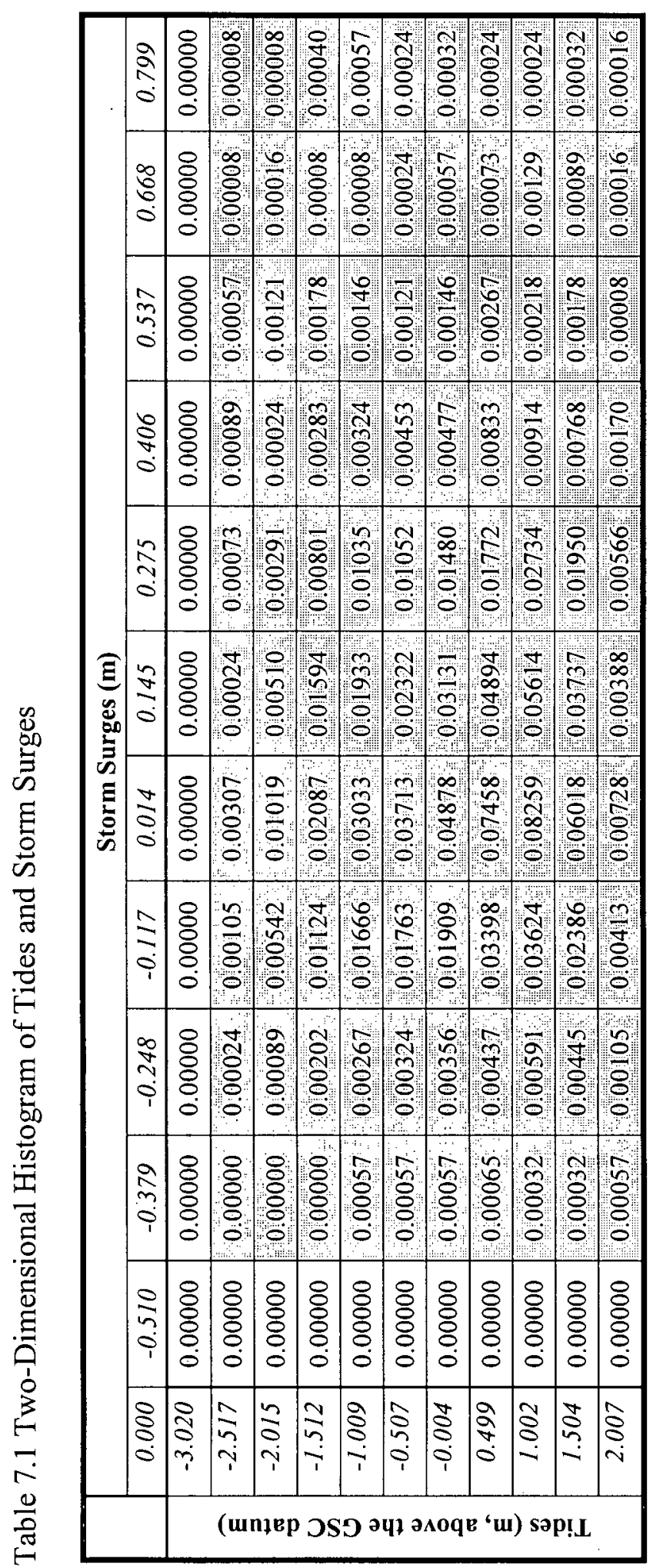


Table 7.2 Screened Annual Maxima Series of Observed Sea Levels

\begin{tabular}{|c|c|c|c|c|c|c|c|c|c|}
\hline Year & Month & Day & Time & $\begin{array}{c}\text { Annual Max } \\
\text { ( } \mathrm{m} \text {, above CHAR datum) }\end{array}$ & Year & Month & Day & Time & $\begin{array}{c}\text { Annual Max } \\
\text { (m, above CHAR datum) }\end{array}$ \\
\hline 1914 & 11 & 22 & 10 & 4.930 & 1968 & 12 & 24 & 10 & 5.440 \\
\hline 1915 & 12 & 8 & 7 & 5.070 & 1969 & 12 & 11 & 8 & 5.310 \\
\hline 1916 & 1 & 6 & 7 & 5.240 & 1970 & 12 & 7 & 12 & 5.350 \\
\hline 1917 & 12 & 31 & 8 & 5.070 & 1971 & 1 & 15 & 9 & 5.210 \\
\hline 1918 & 1 & 14 & 7 & 5.120 & 1972 & 12 & 22 & 8 & 5.330 \\
\hline 1919 & 12 & 24 & 7 & 5.050 & 1973 & 12 & 13 & 9 & 5.280 \\
\hline 1921 & 12 & 21 & 11 & 5.120 & 1974 & 1 & 14 & 10 & 5.380 \\
\hline 1922 & 2 & 16 & 8 & 4.900 & 1975 & 12 & 26 & 11 & 5.220 \\
\hline 1927 & 12 & 12 & 9 & 4.970 & 1976 & 2 & 18 & 7 & 5.060 \\
\hline 1932 & 12 & 22 & 12 & 5.370 & 1977 & 12 & 15 & 10 & 5.450 \\
\hline 1933 & 12 & 19 & 8 & 5.340 & 1978 & 2 & 9 & 7 & 5.460 \\
\hline 1939 & 12 & 14 & 9 & 5.150 & 1979 & 12 & 24 & 10 & 5.320 \\
\hline 1944 & 1 & 1 & 10 & 5.440 & 1980 & 12 & 26 & 9 & 5.220 \\
\hline 1947 & 12 & 18 & 10 & 5.100 & 1981 & 11 & 14 & 8 & 5.280 \\
\hline 1948 & 1 & 1 & 10 & 5.370 & 1982 & 12 & 16 & 7 & 5.600 \\
\hline 1950 & 1 & 10 & 10 & 5.220 & 1983 & 1 & 27 & 5 & 5.490 \\
\hline 1951 & 12 & 1 & 8 & 5.400 & 1984 & 11 & 27 & 10 & 5.230 \\
\hline 1952 & 12 & 30 & 6 & 5.430 & 1985 & 2 & 11 & 10 & 5.040 \\
\hline 1953 & 1 & 20 & 9 & 5.340 & 1986 & 11 & 18 & 8 & 5.050 \\
\hline 1954 & 1 & 7 & 8 & 5.210 & 1987 & 1 & 3 & 9 & 5.520 \\
\hline 1955 & 12 & 6 & 11 & 5.120 & 1988 & 11 & 22 & 15 & 5.200 \\
\hline 1956 & 1 & 5 & 11 & 5.210 & 1989 & 3 & 11 & 7 & 4.970 \\
\hline 1957 & 12 & 24 & 8 & 5.430 & 1990 & 12 & 4 & 8 & 5.250 \\
\hline 1958 & 1 & 10 & 9 & 5.250 & 1991 & 2 & 2 & 8 & 5.250 \\
\hline 1961 & 2 & 15 & 6 & 5.060 & 1992 & 1 & 25 & 9 & 5.280 \\
\hline 1962 & 2 & 8 & 8 & 5.230 & 1993 & 12 & 13 & 6 & 5.240 \\
\hline 1963 & 1 & 1 & 10 & 5.150 & 1994 & 12 & 19 & 7 & 5.200 \\
\hline 1964 & 12 & 22 & 9 & 5.330 & 1995 & 11 & 29 & 11 & 5.240 \\
\hline 1965 & 12 & 28 & 10 & 5.150 & 1996 & 2 & 20 & 7 & 5.340 \\
\hline 1966 & 12 & 4 & 11 & 5.330 & 1997 & 1 & 1 & 10 & 5.240 \\
\hline 1967 & 12 & 5 & 9 & 5.570 & & & & & \\
\hline
\end{tabular}


Table 7.3 Summary of Estimates of Extreme Flood Levels

\begin{tabular}{|c|c|c|}
\hline \multicolumn{3}{|c|}{ Direct Joint Probability Method } \\
\hline Return Period (year) & $\begin{array}{c}\text { Extreme Flood Level } \\
(m, \text { above the GSC datum) }\end{array}$ & $\begin{array}{c}\% \text { Difference } \\
\text { relative to DJPM }\end{array}$ \\
\hline 200 & 2.25 & $0.00 \%$ \\
\hline 1250 & 2.45 & $0.00 \%$ \\
\hline \multicolumn{3}{|c|}{ Annual Maxima Method } \\
\hline Return Period (year) & $\begin{array}{c}\text { Extreme Flood Level } \\
\text { (m, above the GSC datum) }\end{array}$ & $\begin{array}{c}\% \text { Difference } \\
\text { relative to DJPM }\end{array}$ \\
\hline 200 & 2.60 & $13.46 \%$ \\
\hline 1250 & 2.68 & $8.58 \%$ \\
\hline Return Period (year) & $\begin{array}{c}\text { Extreme Flood Level } \\
\text { (m, above the GSC datum) }\end{array}$ & $\begin{array}{c}\% \text { Difference } \\
\text { relative to DJPM }\end{array}$ \\
\hline 200 & 3.10 & $27.42 \%$ \\
\hline 1250 & 3.20 & $23.44 \%$ \\
\hline
\end{tabular}

Table 7.4 Summary of Estimates of Extreme Sea levels

\begin{tabular}{|c|c|}
\hline Joint Probability of Observed Sea Levels and Wave Run-up \\
\hline Return Period (year) & $\begin{array}{c}\text { Extreme Sea Level } \\
\text { (m, above the GSC datum) }\end{array}$ \\
\hline 200 & 3.25 \\
\hline 1250 & 3.69 \\
\hline Joint Probability of Tides, Storm surges, and Wave Run-up \\
\hline Return Period (year) & $\begin{array}{c}\text { Extreme Sea Level } \\
\text { (m, above GSC datum) }\end{array}$ \\
\hline 200 & 3.78 \\
\hline 1250 & 3.90 \\
\hline
\end{tabular}


Table 7.5 Summary of Estimates of Extreme Sea Levels under Different Propagation Angles

\begin{tabular}{|c|c|}
\hline \multicolumn{2}{|c|}{ Propagation Angle $=\mathbf{0}^{\circ}$} \\
\hline Return Period (year) & $\begin{array}{c}\text { Extreme Sea Level } \\
\text { ( } m, \text { above the GSC datum) }\end{array}$ \\
\hline 200 & 3.78 \\
\hline 1250 & 3.90 \\
\hline \multicolumn{2}{|c|}{ Propagation Angle $=\mathbf{3 0 ^ { \circ }}$} \\
\hline Return Period (year) & $\begin{array}{c}\text { Extreme Sea Level } \\
\text { (m, above the GSC datum) }\end{array}$ \\
\hline 200 & 3.67 \\
\hline 1250 & 3.79 \\
\hline
\end{tabular}

Table 7.6 Summary of the Estimates of Extreme Sea Levels Projected for Different Years based on Long-Term Sea Level Changes

\begin{tabular}{|c|c|}
\hline \multicolumn{2}{|c|}{$\mathbf{1 9 7 4}$} \\
\hline Return Period (year) & $\begin{array}{c}\text { Extreme Sea Level } \\
(m, \text { above the GSC datum })\end{array}$ \\
\hline 200 & 3.78 \\
\hline 1250 & 3.90 \\
\hline \multicolumn{2}{|c|}{$\mathbf{2 0 0 0}$} \\
\hline Return Period (year) & $\begin{array}{c}\text { Extreme Sea Level } \\
\text { (m, above the GSC datum) }\end{array}$ \\
\hline 200 & 3.81 \\
\hline 1250 & $\mathbf{2 0 1 0}$ \\
\hline & $\begin{array}{c}\text { Extreme Sea Level } \\
\text { Return Period (year) }\end{array}$ \\
\hline 200 & 3.15 \\
\hline 1250 & 4.17 \\
\hline
\end{tabular}




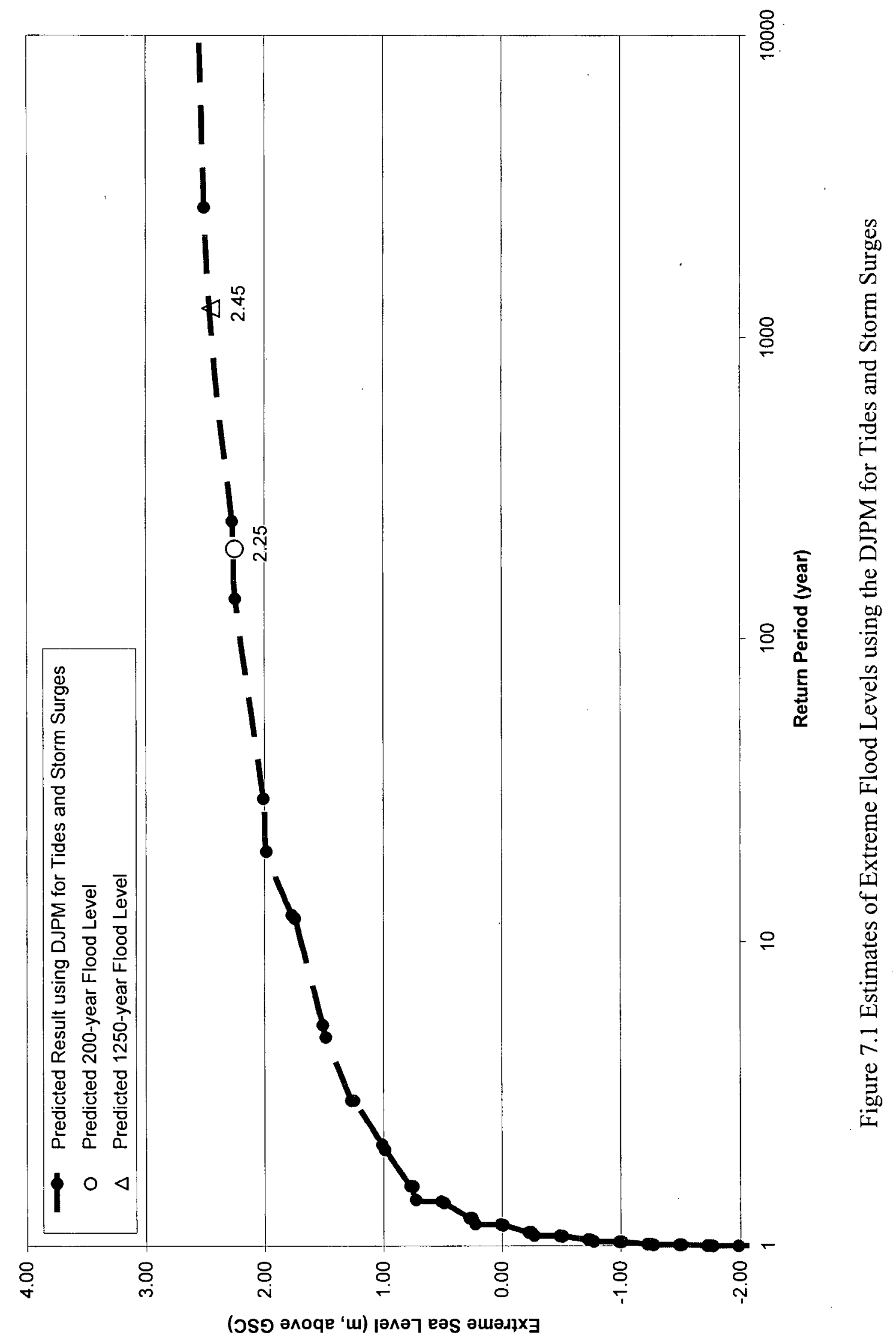




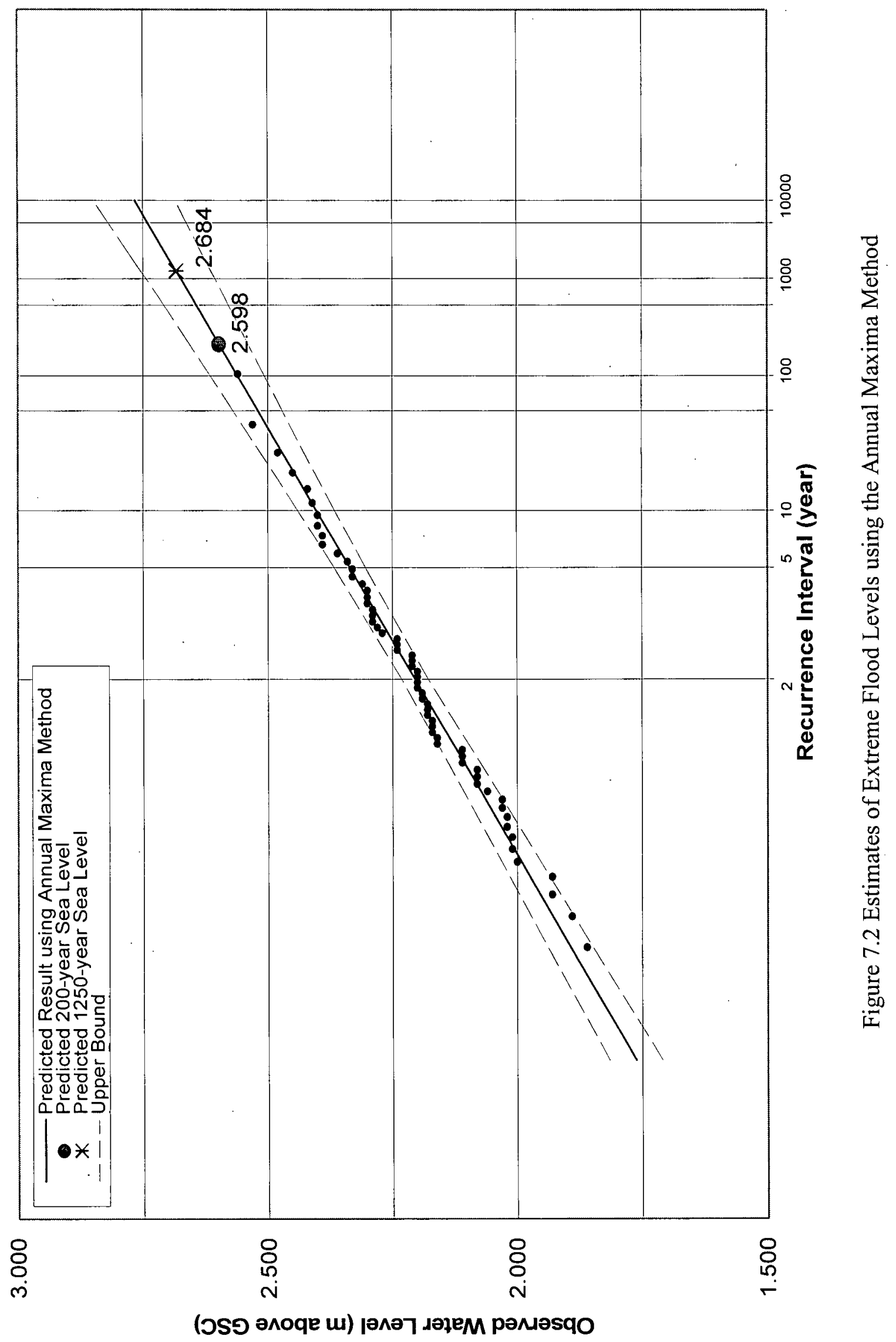




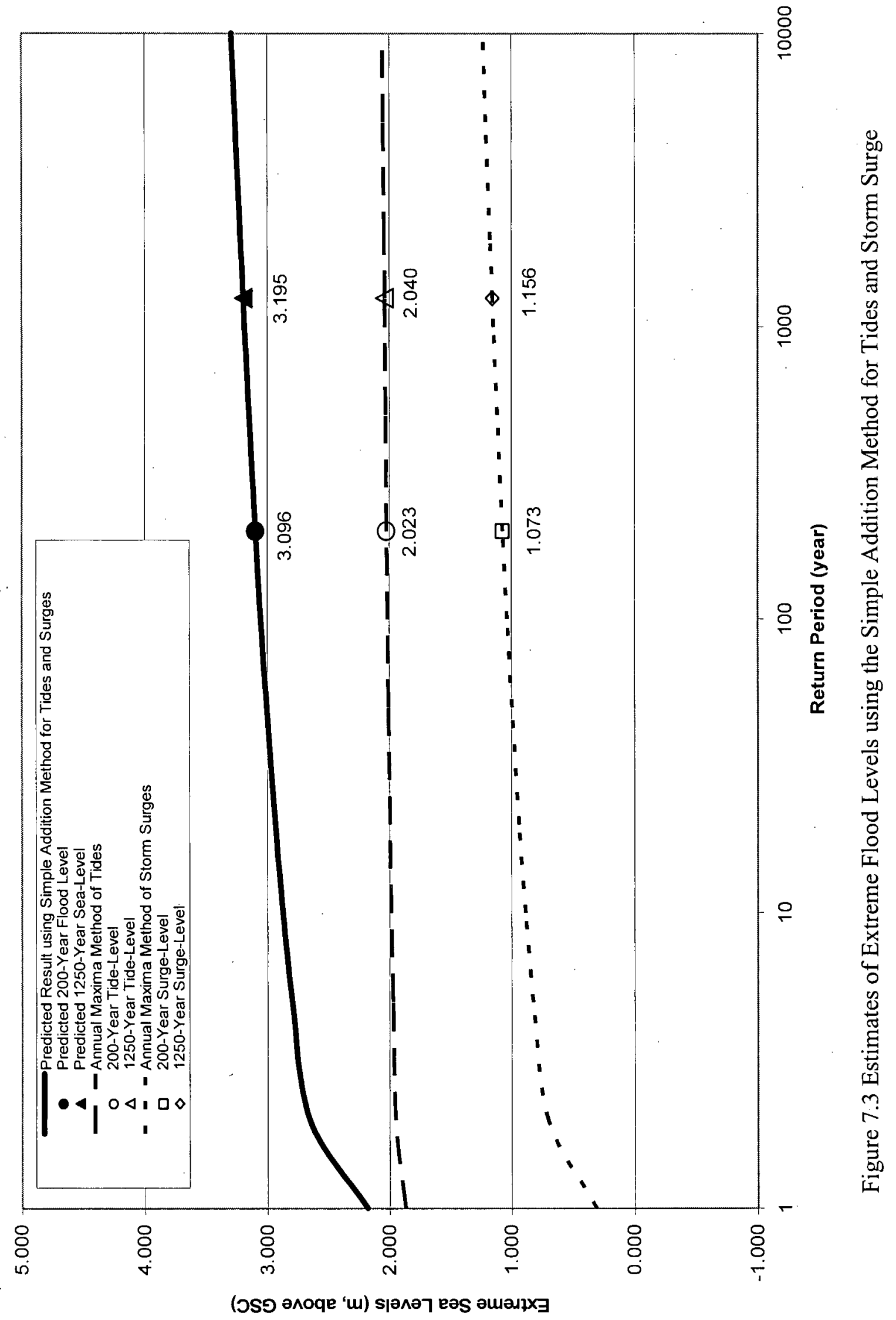




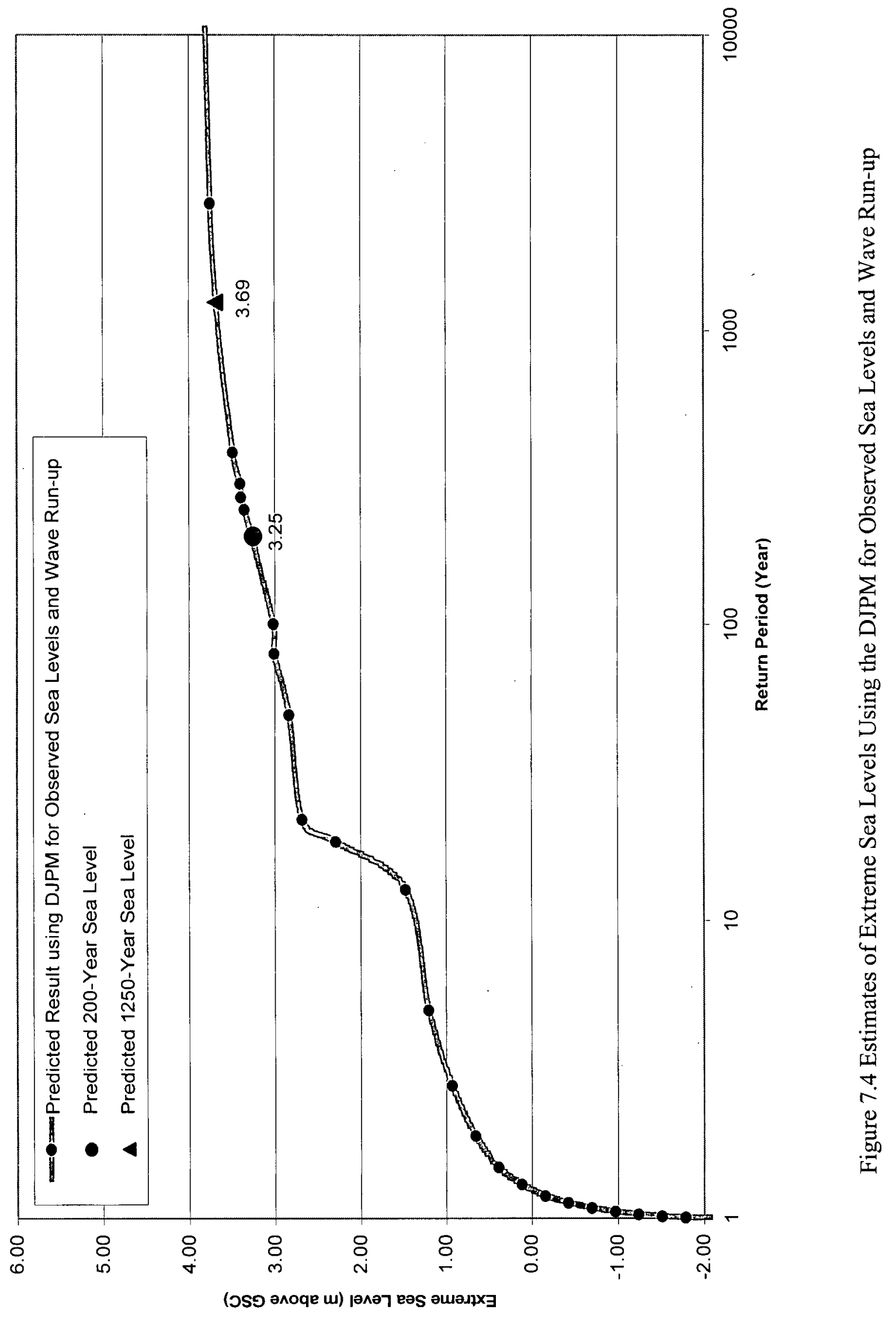




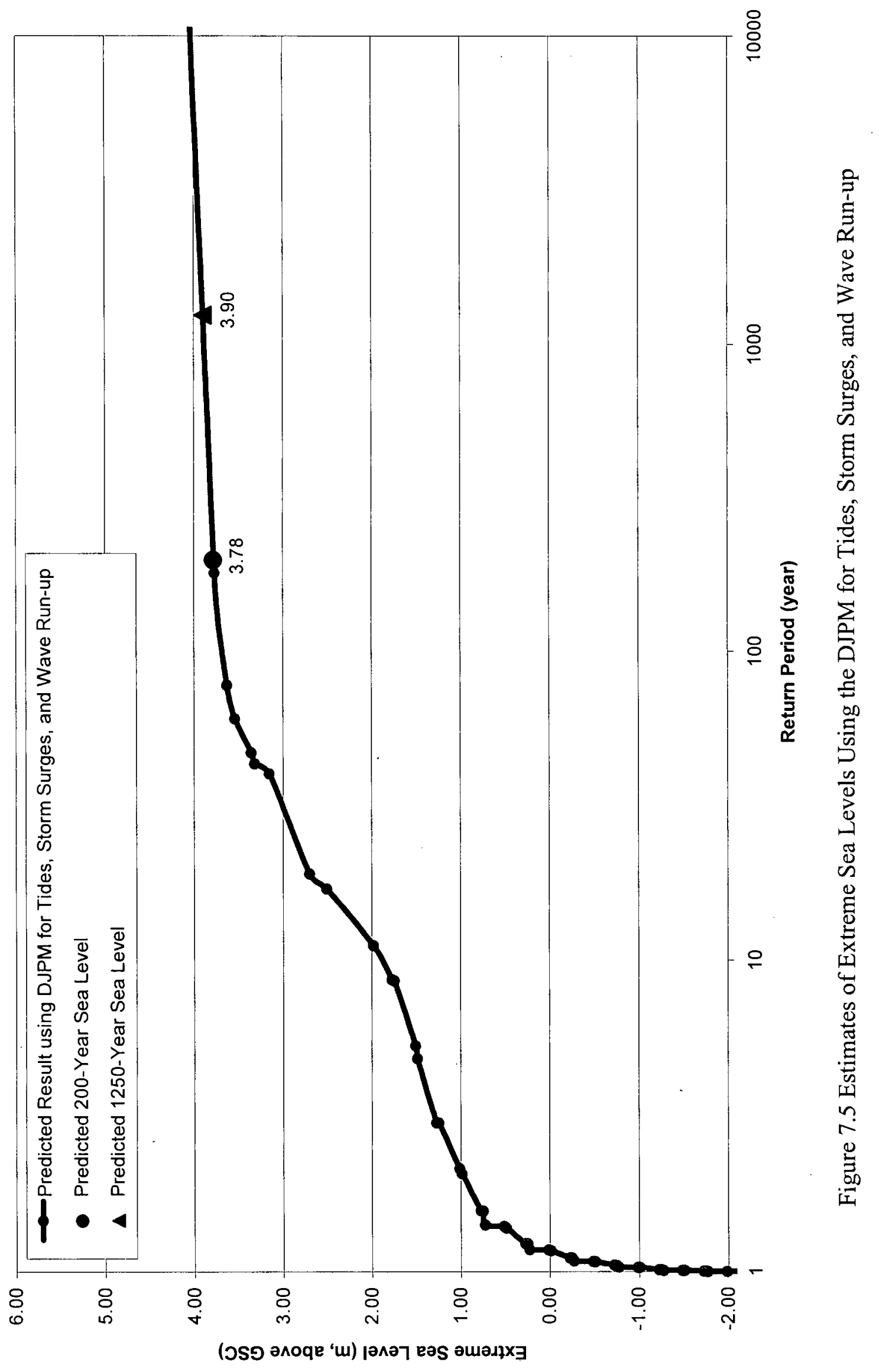




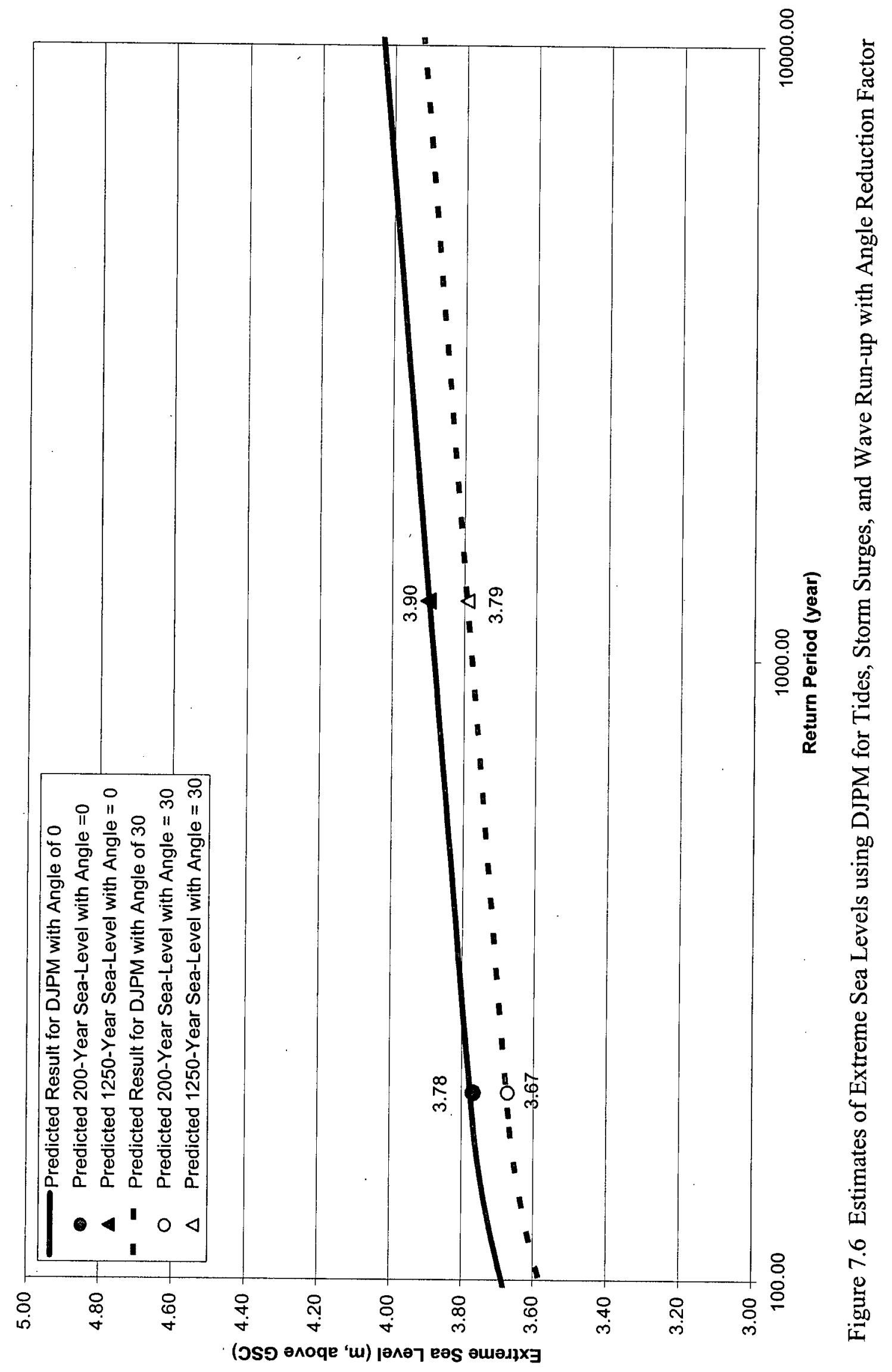




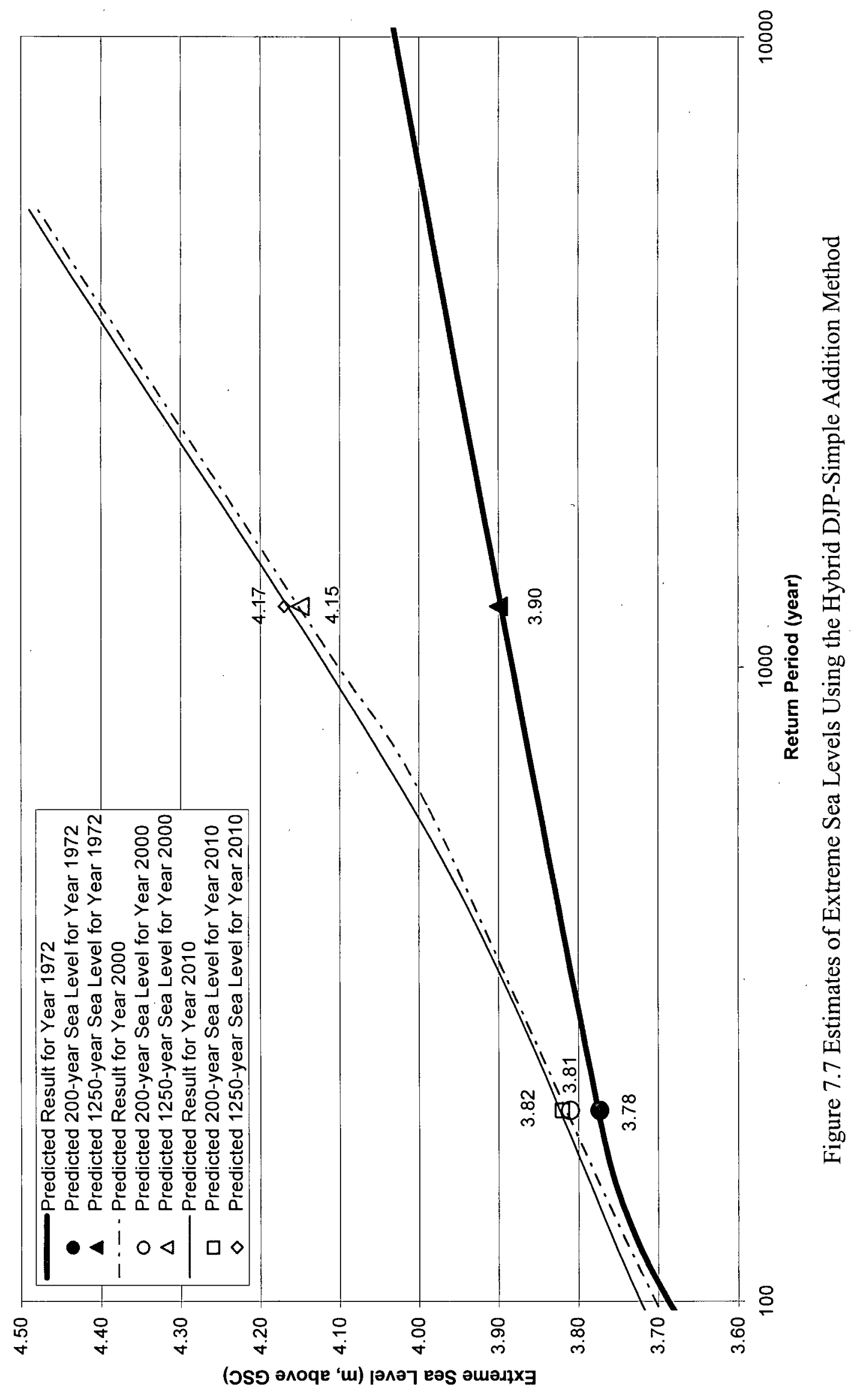




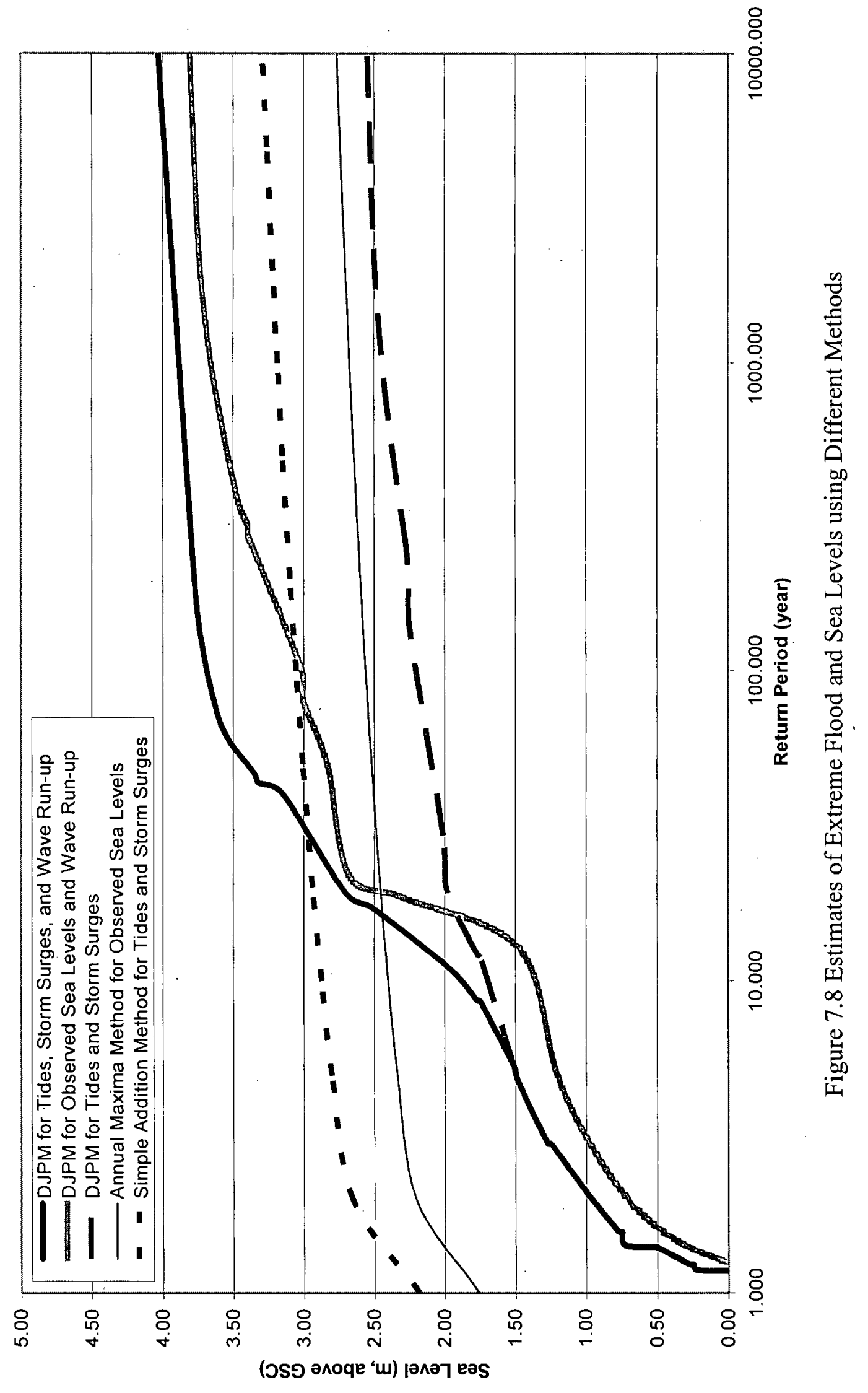




\section{CONCLUSIONS AND RECOMMENDATIONS}

A key element in the design of coastal structures is the crest elevation, and the crest elevation is generally determined by the extreme sea conditions. Estimating extreme sea conditions requires an understanding of oceanographic science and coastal engineering. By determining the local oceanographic environment and employing coastal engineering knowledge, the process of predicting extreme sea conditions is demonstrated for a case study in Richmond, B.C., Canada. This study provides an example of the common problems facing coastal engineers. Several recommendations may be applied to estimate extreme sea conditions for Richmond in the future, and some may be applied in general practice.

While oceanographic science explains numerous factors causing sea level variations, coastal engineering addresses the concerns regarding the functionality of coastal structures and leads to methodologies for predicting extreme sea conditions. The factors contributing to sea level fluctuations include wind waves, storm surges, astronomical tides, tsunami, El Niño, and long-term sea level increases due to climatologic and geologic effects. These components generate different degrees of impact on sea levels at different locations, so the first step in determining extreme sea conditions is to define the critical components causing extreme conditions at the site of interest with the understanding of the failure modes of coastal structures. Failures such as overflowing and overtopping occur when coastal structures have insufficient crest elevations. To prevent overflowing, the crest elevation should be at least at the extreme flood level, which is the sea level without the influence of waves. To minimize overtopping, the crest elevation should be at least at the extreme sea level, which includes the effect of waves. The increase in estimates of extreme sea levels due to the influence of waves may be determined by the wave run-up or wave overtopping discharges. Wave run-up and overtopping discharges are impacts of waves on coastal structures, and they can be computed based on existing empirical 
methods. However, there is no standard regarding the allowable overtopping discharges, so wave run-up is still the governing factor in the estimation of extreme sea levels. Methodologies are then constructed in the second step to combine these components.

Methods for estimating extreme flood levels include the Annual Maxima, $R$-Largest Maxima, Simple Addition Methods, and the JPM and RJPM. These methods are incapable of estimating extreme sea levels due to the deficiencies in each method, such as the inability to represent the different components of extreme sea conditions, to identify the actual joint probability of combining factors, or to estimate the joint probability of any number of dependent factors. In order to overcome these deficiencies and estimate extreme sea levels, the DJPM is developed in this thesis, which is capable of combining any number of dependent variables in the estimation of extreme sea levels. The results of extreme sea levels estimated by the DJPM for Richmond are reasonable based on only two years of data. The DJPM can also accurately portray the relationship between sea levels and wave run-up, in that wave run-up is only generated at sufficient sea levels (e.g., $1.5 \mathrm{~m}$ in the Richmond case), and higher wave run-up is generated with higher sea levels. The Hybrid DJP-Simple Addition Method is also developed to account for the influence of long-term sea level changes on extreme sea levels. The results of the Hybrid Method suggest the importance of including long-term sea level increases and of accounting for data records that are relatively old. The long-term sea level increases amplify the effect of wave run-up, and the estimated extreme sea levels increase dramatically under such conditions. For this reason, old data used in the estimation of extreme sea levels can be misleading when used to represent future conditions.

Although this thesis demonstrates successful applications of the DJPM, more tests should be performed to determine the required length of data for a reasonable estimation of extreme sea levels. Future tests should include a sensitivity analysis regarding how the degree of dependency between variables affects the length of data required. Other tests should include sensitivity 
analysis of variables that may affect the accuracy of the DJPM, such as number of components involved in the estimation of extreme sea levels.

A demonstration of the decision process for estimating extreme sea levels is provided for a case study based on Richmond, B.C., Canada. The results of the case study indicate that the current standard for the Sea Dyke in Richmond is within the range of the 200-year sea levels estimated with all methods. However, as discussed in Chapter 7, there are several limitations involved in the computation due to the poor availability of data and the necessary assumptions. To provide a better estimation of extreme sea levels, recommendations for Richmond include:

1. Collecting data of observed sea levels, tides, and waves at Richmond. According to previous studies and results in Chapter 7, the DJPM, JPM, and RJPM can provide reasonable estimates of design sea levels with short term data sets. Thus, if Richmond starts to collect the observed sea level, tide, and wave data now, in a short time, the City will achieve more representative estimates of design sea levels.

2. Collecting directional wave data. The directional information of waves is important for estimating wave run-up. This thesis makes an assumption that all waves are attacking the shore at angles ranging from $0^{\circ}$ to $30^{\circ}$. The actual data would provide better estimations of wave run-up and extreme sea levels.

3. Conducting a field survey at the toe of the dyke. The assumption of a constant elevation at the toe along the entire dyke is weak because factors, such as shoaling and settlement of the dyke structure, can influence the actual elevation at the toe of the dyke. The value of the elevations at the toe influences the water depth fronting the slope of the dyke and the computation of wave run-up.

4. Including the effects of river current and water transport in the estimation of extreme sea levels at applicable locations. More research should be conducted to estimate extreme sea levels considering the effects of river current and water transport. As mentioned 
earlier, one of the locations in Richmond that has experienced overtopping is at the north end of the Sea Dyke due to the currents caused by the discharges from the Fraser River so river effects certainly play an important role here. Similarly, the disturbance caused by water transport in the Garry Point area of Richmond can also be a potential cause of overtopping.

5. Monitoring long-term sea level changes. This thesis demonstrates that long-term sea level changes increase the amount of wave run-up. Thus, the standard of the crest elevation of the dyke system in Richmond will need to be raised due to the long-term change in sea levels. A monitoring program should be implemented in Richmond to have an accurate annual rate of increasing sea levels.

6. Identifying a standard for allowable overtopping discharges. The controversy regarding the use of wave run-up to estimate the crest elevation is valid, but a standard for allowable overtopping discharges that is suitable for Richmond or the site of interest should be constructed first before applying this approach.

7. Updating the extreme sea levels regularly. The sensitivities of extreme sea levels to the angle of propagation and to long-term sea level increases are demonstrated in this thesis. This indicates that the estimation of extreme sea levels should be updated regularly when any new information becomes available. 


\section{REFERENCES}

Abbott, P. L. (1999). Natural Disaster, WCB/McGraw-Hill, Boston.

Allsop, N. W. H., and McConnell, K. J. (2000). Revetment protection for coastal and shoreline structures exposed to wave attack, in Handbook of Coastal Engineering, Chapter 2, McGrawHill, New York, NY, USA.

Battjes, J. A. (1970). Long-Term Wave Height Distributions at Seven Stations around the British Isles, NIO Report No. 44, National Institute of Oceanography, City of Institute, UK.

Bruun, P. (1989). Port Engineering, Gulf Publishing Co., Houston, TX, USA.

Besley, P. (1999). Overtopping of Seawalls: Design and Assessment Manual, R\&D Technical Report W178, HR Wallingford, UK.

Besley, P. (1999). Wave overtopping of coastal and shoreline structures, in Handbook of Coastal Engineering, Chapter 6, McGraw-Hill, New York, NY, USA.

Camfield, F. E. (1990). Tsunami, in Handbook of Coastal and Ocean Engineering, Chapter 10, Gulf Publishing Co., Houston, TX, USA.

Church, M. (2002). Potential changes in relative sea sevel and implications for sustainability in the Fraser River Delta, Symposium on the Changing Face of the Lower Fraser River Estuary, Fraser Basin Council, Vancouver, B.C., Canada.

City of Richmond Website. <http:// www.city.richmond.bc.ca>

Coastal Engineering Research Center (1984). Shore Protection Manual, U.S. Army Corps of Engineers, Washington, DC, USA.

Coastal Engineering Research Center (1995). Design of Coastal Revetments, Seawalls, and Bulkhead, Engineering Manual 1110-2-1614, U.S. Army Corps of Engineers, Washington, DC, USA. 
Golder Associates Ltd. and Associated Engineering Ltd. (2003). Dike Design and Construction Guide: Best Management Practices for British Columbia, Environment Protection Division, Ministry of Water, Land and Air Protection, BC, Canada.

Goda Y. (1990). Distribution of sea state parameter and data fitting, in Handbook of Coastal and Ocean Engineering, Chapter $7_{2}$ Houston, TX, USA.

Gran, S. (1992). A Course in Ocean Engineering, Elsevier Science Publishers, Amsterdam, the Netherlands.

HAYCO (1989). Flood Management Study. Consulting Report for the Township of Richmond, Vancouver, B.C., Canada.

Headland, J., Smith, W. G., Kotulak, P., and Alfageme, S. (2000). Coastal protection method, in Handbook of Coastal Engineering, Chapter 8, McGraw-Hill, New York, NY, USA.

Herbich, J. B. (1990). Selection of design wave characteristics, in Handbook of Coastal and Ocean Engineering, Chapter 8, Gulf Publishing Co. , Houston, TX, USA.

Hawkes, P. J., Gouldby, B. P., Tawn, J. A., and Owen, M. W. (2002). The joint probability of waves and water levels in coastal engineering design, Journal of Hydraulic Research, 40(3), $241-251$

Hilmi, K., El-Sabh, M., Chanut, J.P., and Murty, T. (2000). Stochastic modeling of short term variations of sea level in eastern Canada, Marine Geodesy, 23(3), 197-218.

Hodgins, D. O. (1985). A Review of Extreme Wave Conditions in the Beaufort Sea, Seaconsult Marine Research Ltd., Vancouver, Canada.

Isaacson, M., and Foschi, R. (2000). On the selection of design wave conditions, International Journal of Offshore and Polar Engineering, 10(2), 99 - 106.

Juszko, B., Brown, R., Boom, B., and Green, D.(1988). A Wave Climate Study of the Northern British Columbia Coast, Canadian Department of Fisheries and Oceans: 175 pp, Sidney, B.C., Canada. 
Ker, Priestman \& Associates Engineering Ltd. (1990). Floodplain Mapping Program. Courtenay, Puntledge and Tsolum Rivers, Inland Waters Directorate, Environment Canada, Canada.

Ker, Priestman \& Associates Engineering Ltd. (1992). Floodplain Mapping of Kincolith 1. R. 14, Indian and Northern Affairs Canada, Environment Canada, Canada.

Ker, Priestman \& Associates Engineering Ltd. (1994). Floodplain Mapping Program. Serpentine and Nicomekl Rivers, Inland Waters Directorate, Environment Canada, Canada.

Lisitzin, E. (1974). Sea Level Changes, Elsevier Scientific Publishing Company, Amsterdam, the Netherlands.

Longuet-Higgins, M. S. (1952). On statistical distribution of the heights of sea waves, Journal of Marine Research, 11(1), 245-266.

Manager, Policy Planning. (2002). City Wide Flood Protection and Management Strategy, Report to Committee, City of Richmond, Richmond, B.C., Canada.

Marine Environment Data Service Website. <http://www.meds-sdmm.dfompo.gc.ca/meds/Home_e.htm>

Ministry of Environment, Lands and Parks (2001). Dyke Operation and Maintenance Manual Template: Dikes and Associated Flood Protection Work), Ministry of Environment, Lands, and Parks, B.C., Canada.

Myers, J. J. (1969). Handbook of Ocean and Underwater Engineering, McGraw -Hill, New York, NY, USA.

Nomitsu, T., and Okamoto, M. (1927). The causes of the annual variation of the mean sea level along the Japanese Coast, Journal of Marine Research, 14(1), 88-155.

North American Lake Management Society Website. <http://www.nalms.org>

Ochi, M. K. (1998). Ocean Waves: the Stochastic Approach, Cambridge University Press, Cambridge, UK. 
Owen, M. W. (1980). Design of sea walls allowing for overtopping, Report EX 924, HR Wallingford, UK.

Pilarczyk, K. W. (2000). Design of dikes and revetments - Dutch practice, in Handbook of Coastal Engineering, Chapter 3, McGraw-Hill, New York, NY, USA.

Pugh, D. T. (1987). Tides, Surges, and Mean Sea-Level, John Wiley \& Sons, Swindon, UK.

Pugh, D. T., and Vassie, J. M. (1980). Applications of the joint probability method for extreme sea level computations, Proceedings of the Institution of Mechanical Engineers, 69, 959-975.

Rao, A. R., and Hamed, K. H. (2000). Flood Frequency Analysis, CRC Press, Boca Raton, FL, USA.

Reid, R.O. (1990). Tides and storm surges, in Handbook of Coastal Engineering, Chapter 9, Gulf Publishing Co., Houston, TX, USA.

Silvester R. (1990). Design of seawalls and groins, in Handbook of Coastal and Ocean Engineering, Chapter 23, Gulf Publishing Co., Houston, TX, USA.

Smith, R. (1986). Extreme value theory based on the $R$ largest annual events, Journal of Hydrology, 86(1), 27-43.

Sorensen, R. B. (1997). Basic Coastal Engineering, Chapman and Hall Publishers, New York, NY, USA.

Subbotina, M. M., Thomson, R. E., and Rabinovich, A. B. (2001). Spectral characteristics of sea sevel variability along the west coast of North America during the 1982-82 and 1997-98 El Niño Events, Progress in Oceanography, 49(1), 353 - 372.

Sverdrup, H. U., and Munk, W. H. (1947). Wind, Sea, and Swell: Theory of Relations for Forecasting, Publication No. 601.,U.S. Navy Hydrographic Office, USA.

Tawn, J. A. (1992). Estimating probabilities of extreme sea-levels, Applied Statistics 41(1), 77 93. 
Tawn, J. A., and Vassie, J. M. (1989). Extreme sea levels: the joint probabilities method revisited and revised, Proceedings of the Institution of Civil Engineers, 87, 429-442.

Tawn, J. A., and Vassie, J. M. (1990). Spatial transfer of extreme sea level data for use in the revised joint probability method, Proceedings of the Institution of Civil Engineers, 89, 433438.

Thomson, R. E. (1981). Oceanography of the British Columbia Coast, Canadian Department of Fisheries and Oceans, Ottawa, ON, Canada.

Tsimplis, M. N., and Blackman, D. (1997). Extreme sea-level distribution and return periods in the Aegean and Ionian Seas, Estuarine, Coastal and Shelf Science, 44(1), 79-89.

Viessman, W., and Lewis, G. L. (1996). Introduction to Hydrology, Harper Collins Publishers, Glenview, IL, USA.

Vincent, C. L., and Resio, D. T. (1990). Wave forecasting and hindcasting in deep and shallow water, in Handbook of Coastal and Ocean Engineering, Chapter 5, Gulf Publishing Co., Houston, TX, USA.

Watt, W. E., Lathem, K. W., Neill, C. R., Richards, T. L., and Rousselle, J. (1989). Hydrology of floods in Canada: a Guide to Planning and Design, National Research Council of Canada, Ottawa, ON, Canada. 
APPENDICES 


\title{
Appendix A: Wave Run-up Curves
}

\author{
A 1. Wave Run-up Curve for $d_{s} / H_{0}^{\prime}=0$ on a 1:10 Bottom Slope from CERC (1984)
}

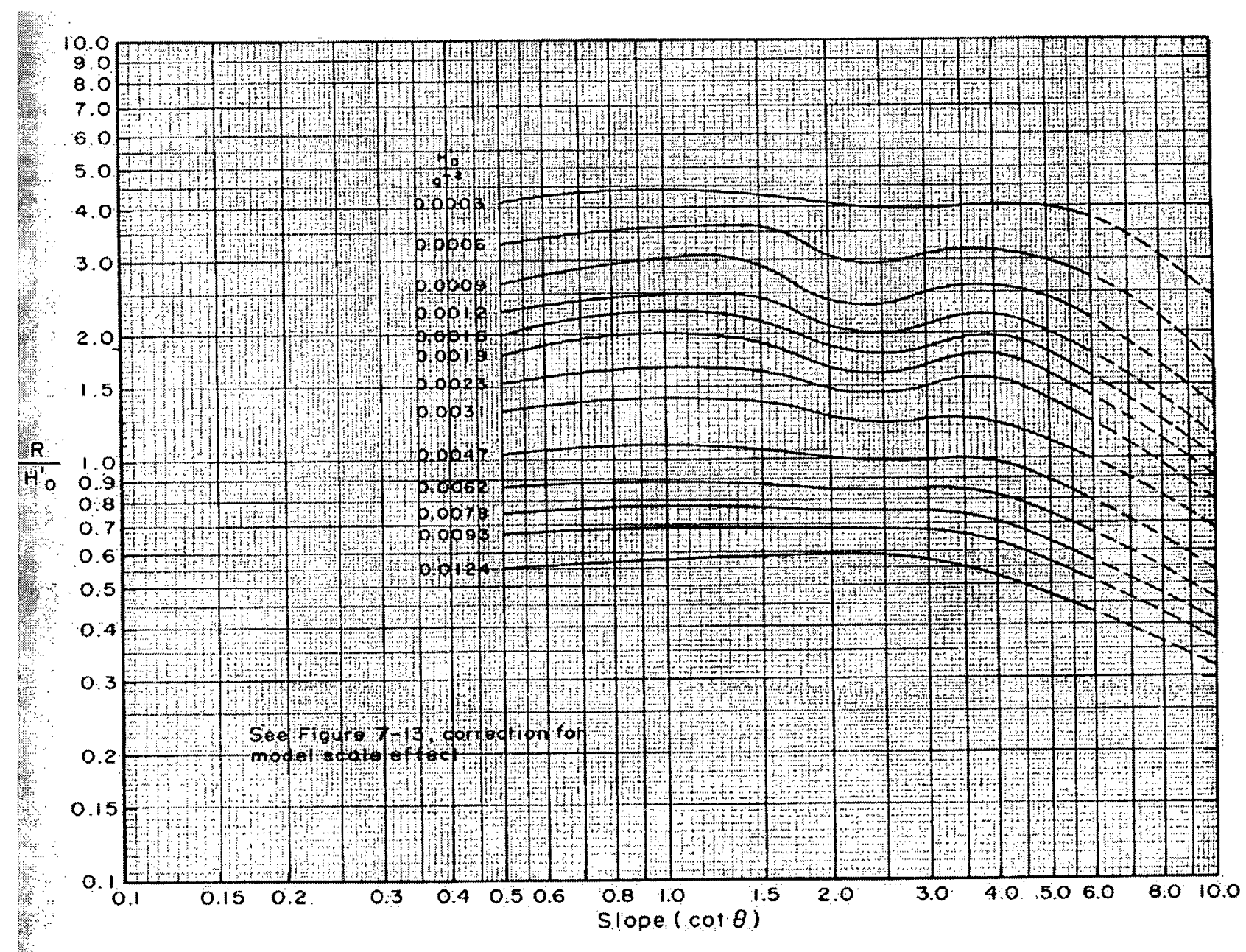


A 2. Wave Run-up Curve for $d_{s} / H_{0}^{\prime} \approx 0.45$ on a 1:10 Bottom Slope from CERC (1984)

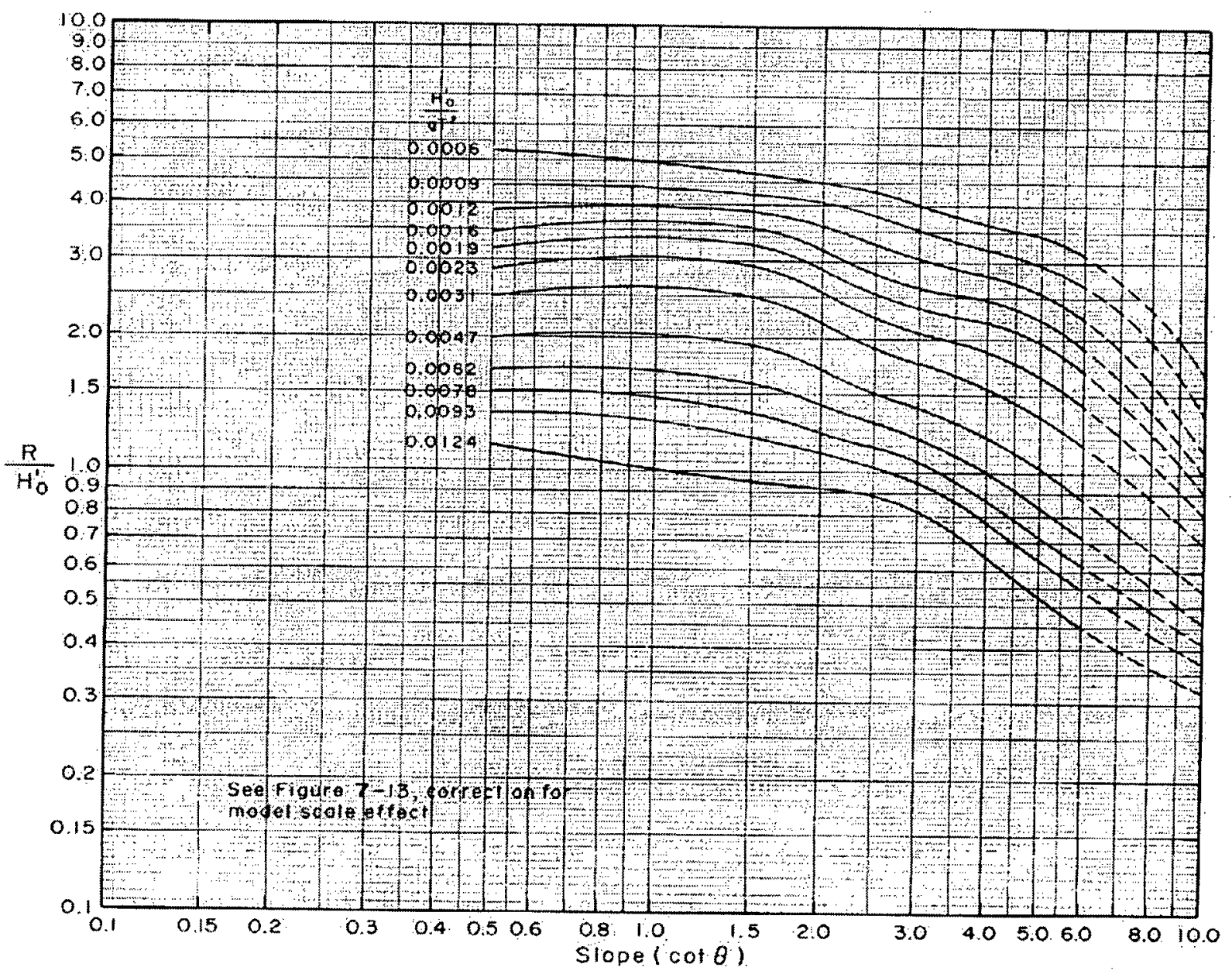


A 3. Wave Run-up Curve for $d_{s} / H_{0}^{\prime} \approx 0.8$ on a 1:10 Bottom Slope from CERC (1984)

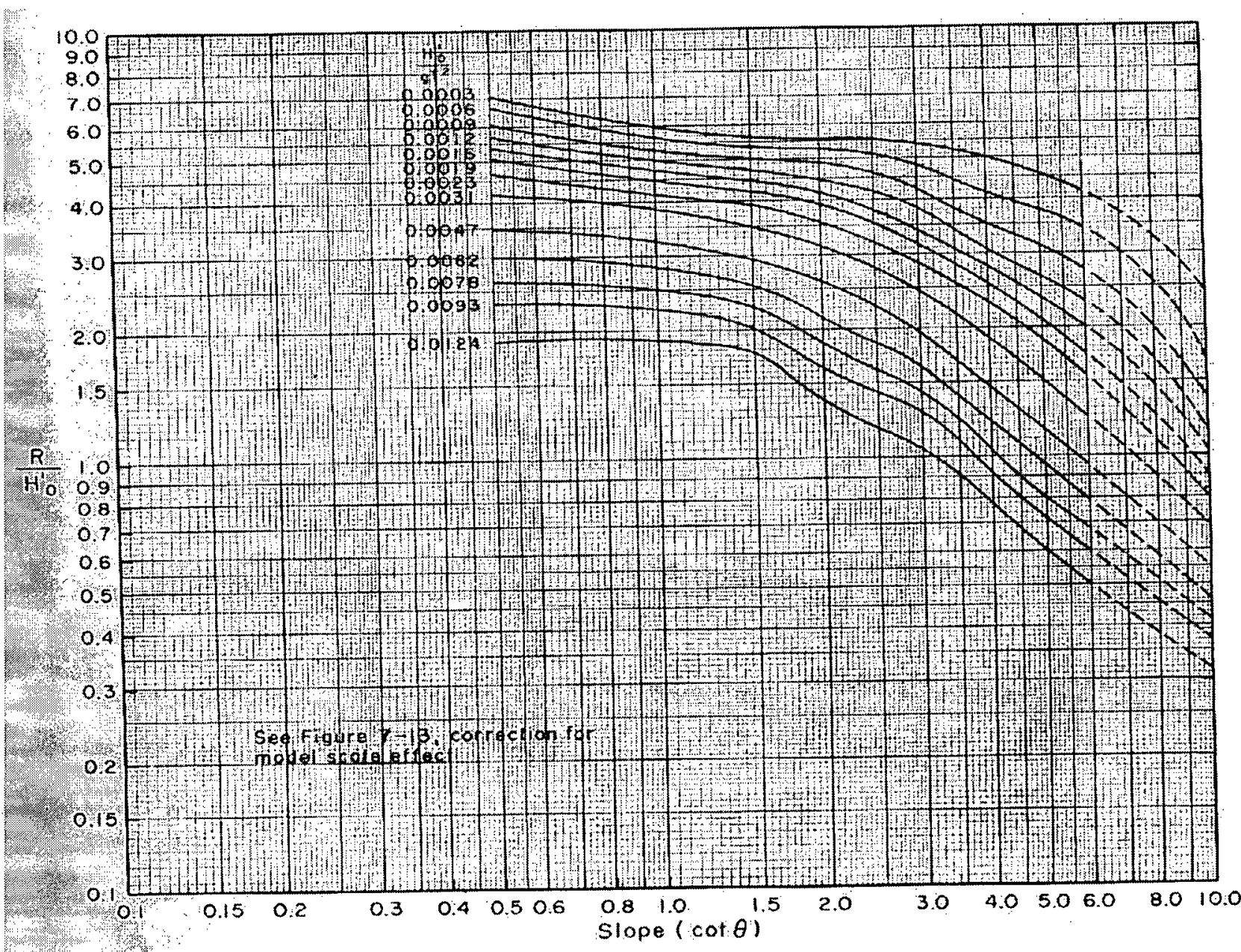


A 4. Wave Run-up Curve for and $d_{s} / H_{0}^{\prime} \geq 3.0$ on a 1:10 Bottom Slope from CERC (1984)

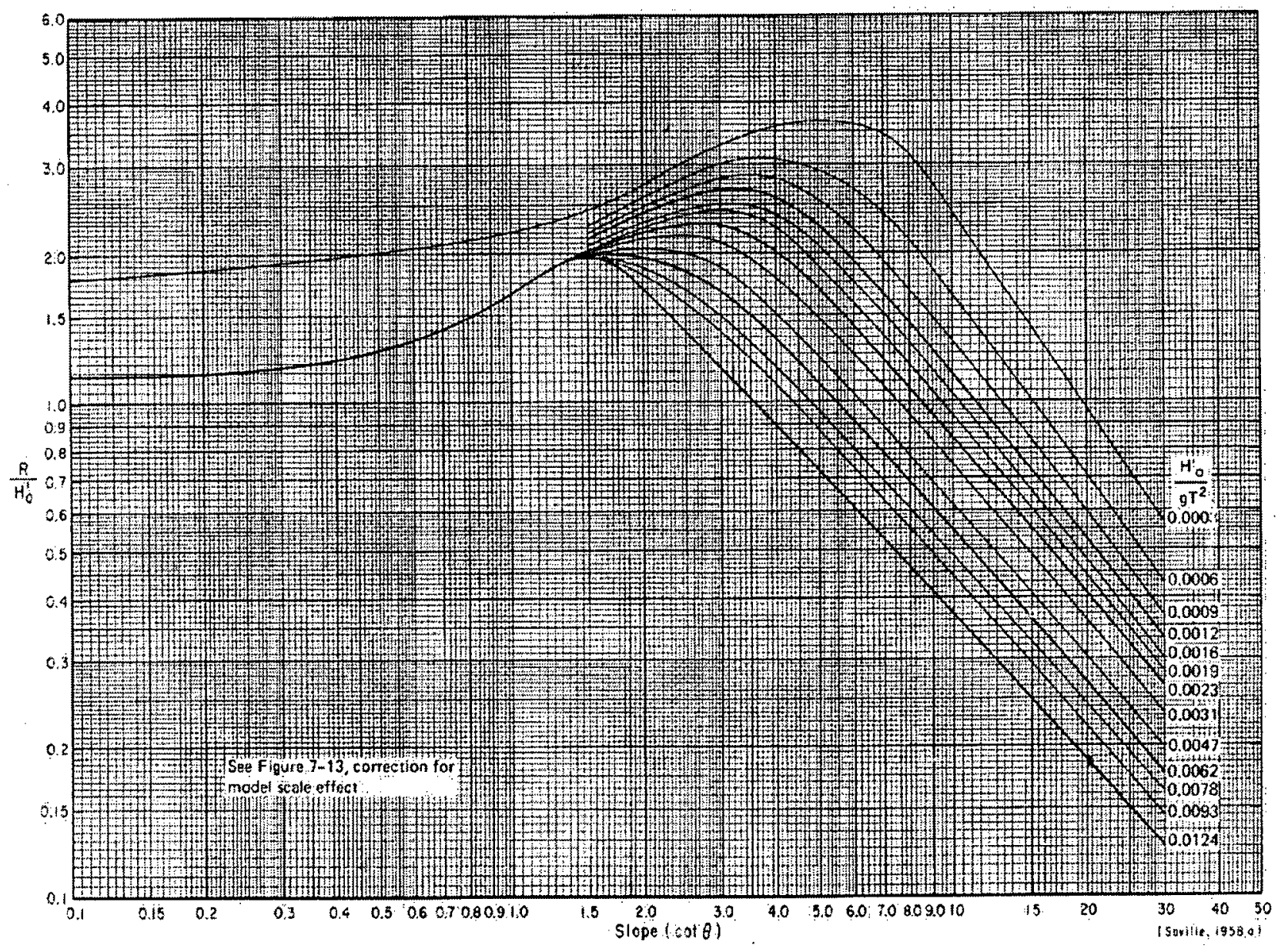


A 5. Wave Run-up Curve for $d_{s} / H_{0}^{\prime}=3$ on a Horizontal Bottom from CERC (1984)

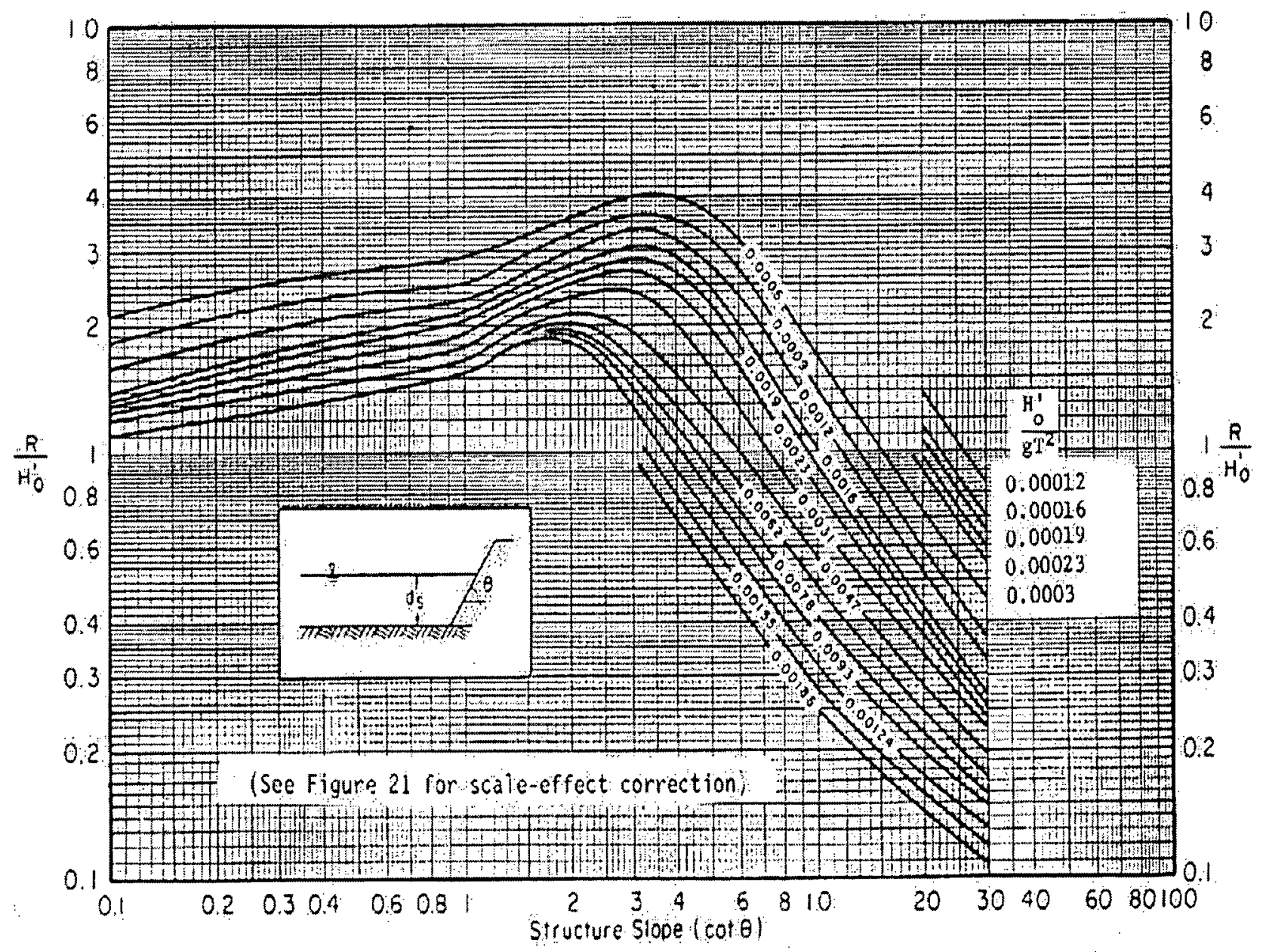


A 6. Wave Run-up Curve of $d_{s} / H_{0}^{\prime}=5$ on a Horizontal Bottom from CERC (1984)

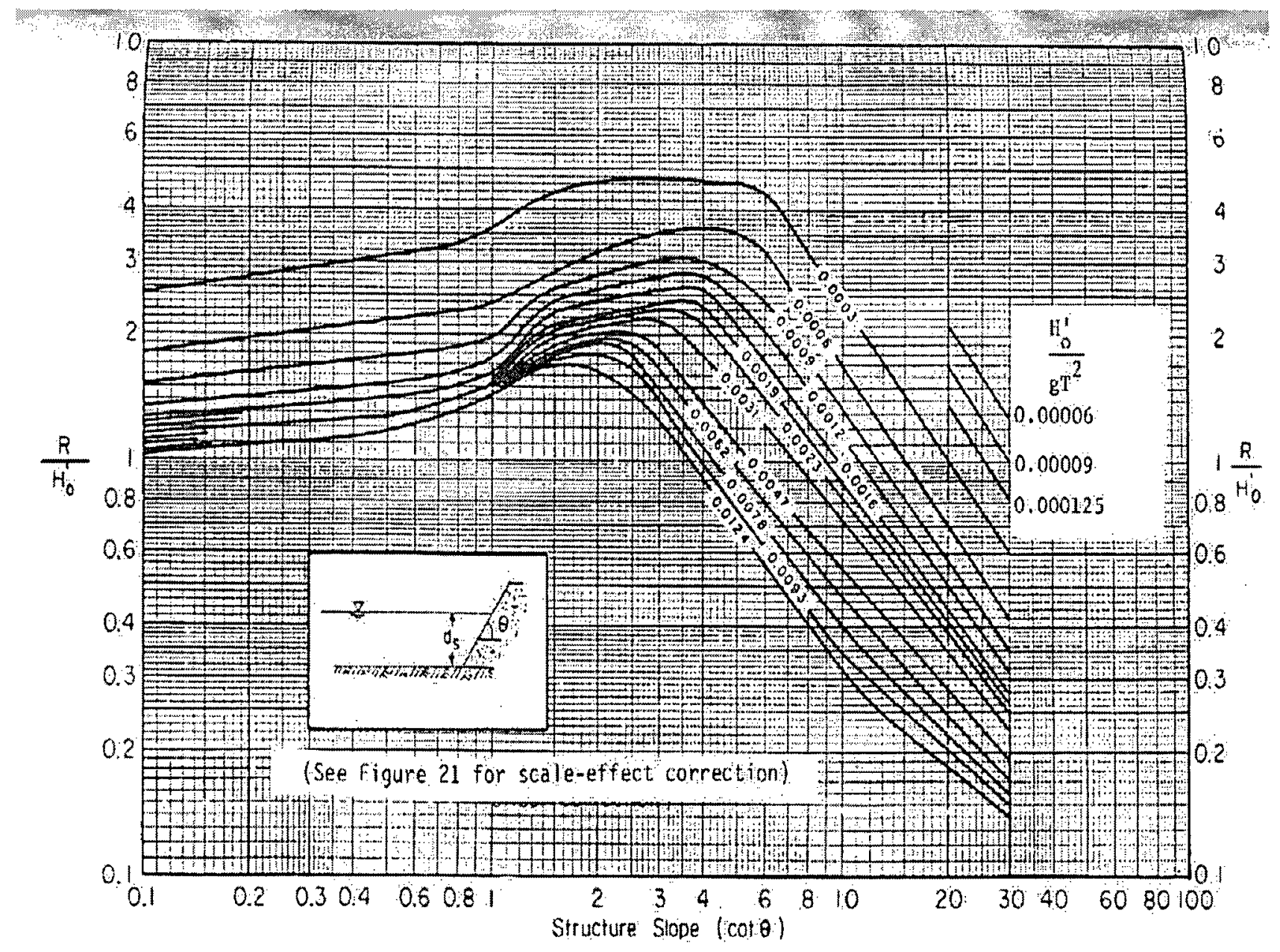


A 7. Wave Run-up Curve for $d_{s} / H_{0}^{\prime}=8$ on a Horizontal Bottom from CERC (1984)

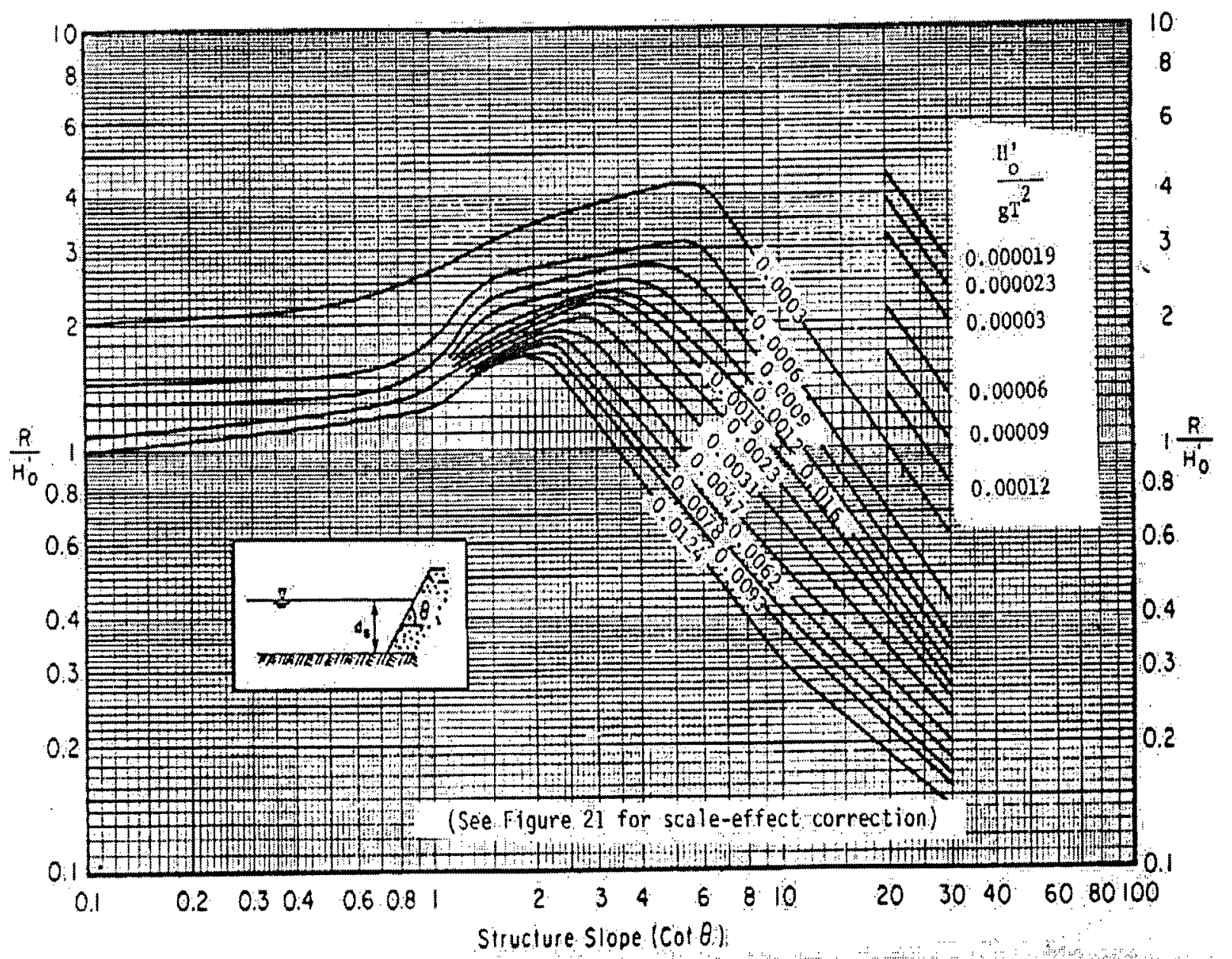




\section{Appendix B: Overtopping Parameters}

B 1. Overtopping Parameters for a Smooth Vertical Wall on a 1:10 Bottom Slope from CERC (1984)

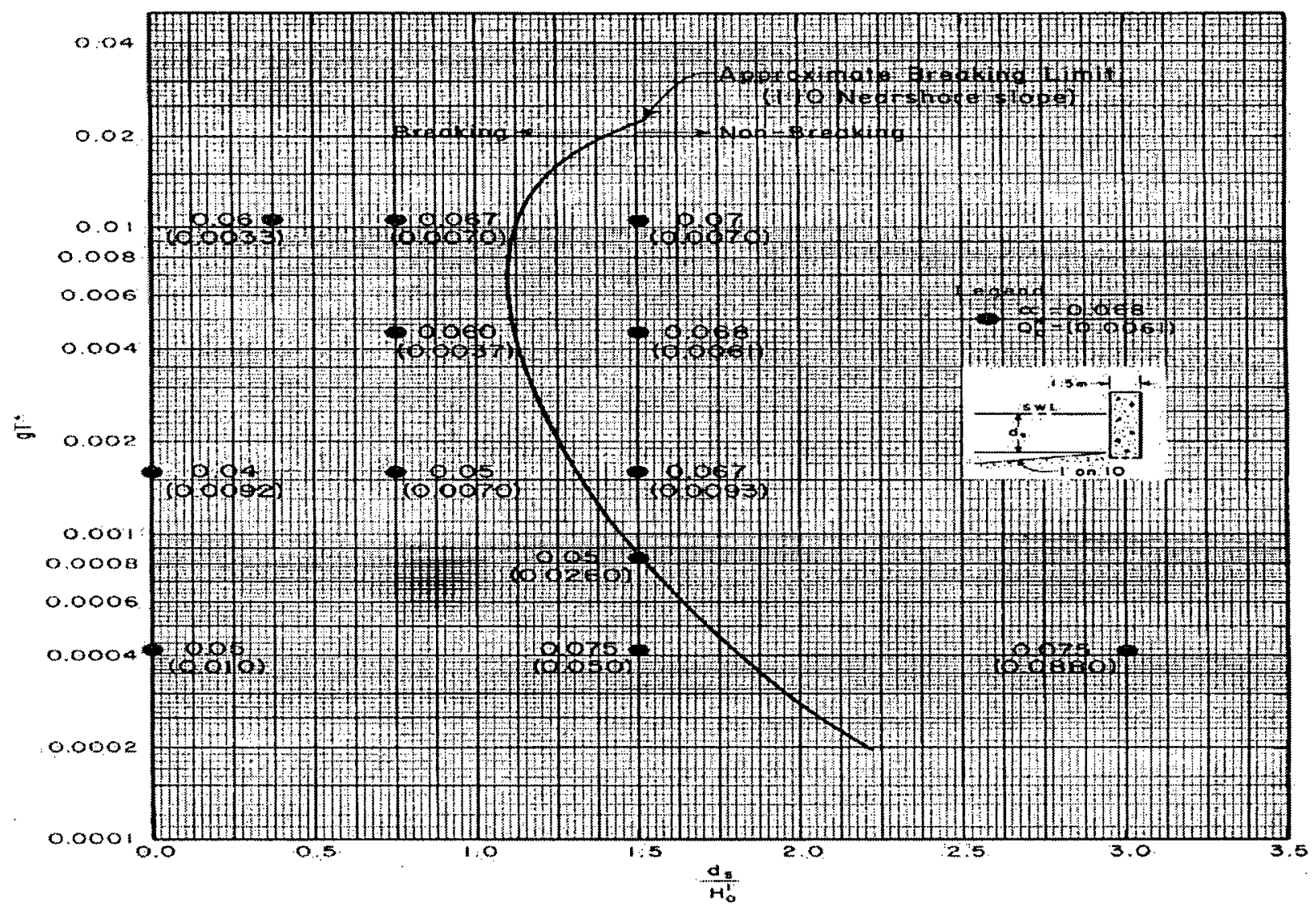


B 2. Overtopping Parameters for a 1:10 Structure Slope on a 1:10 Bottom Slope from CERC (1984)

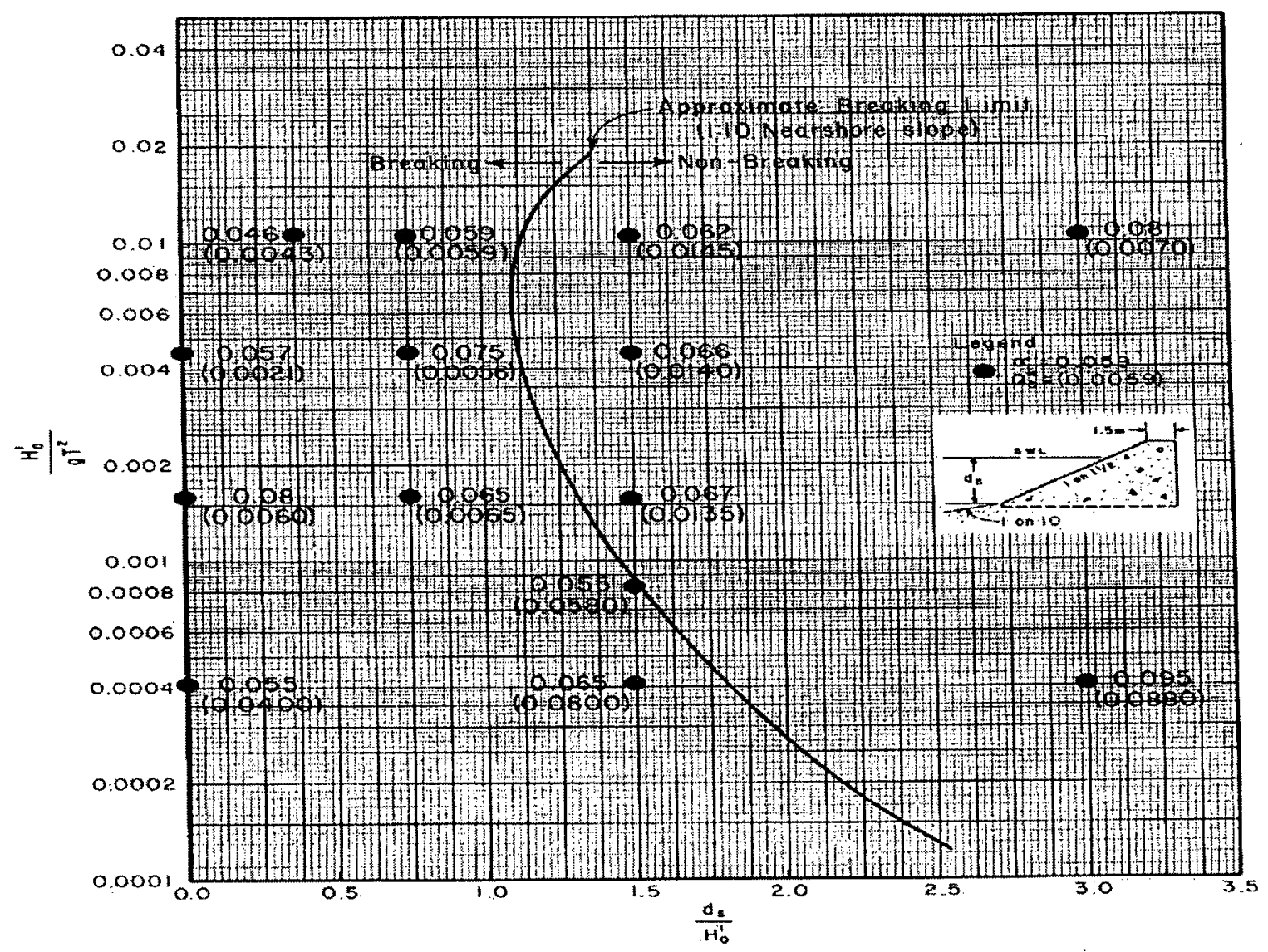




\section{Appendix C: List of Notations}

\begin{tabular}{|c|c|}
\hline Symbol & Description \\
\hline$A$ & Overtopping parameter \\
\hline$A_{i}$ & Amplitude of constituent $i$ \\
\hline$a$ & Wave amplitude \\
\hline$a^{*}$ & Empirical coefficient \\
\hline$B$ & Overtopping parameter \\
\hline$B_{w}$ & Berm width \\
\hline$\beta$ & Angle of the propagation direction \\
\hline$D$ & Total water depth \\
\hline$D$ & Duration \\
\hline$d_{h}$ & Wave depth over the berm \\
\hline$d_{s}$ & Water depth at structure toe \\
\hline$\delta$ & Extremal index \\
\hline$F(x)$ & Cumulative distribution function of $x$ \\
\hline$f$ & Relative frequency \\
\hline$f_{i}$ & Nodal correction of constituent $i$ \\
\hline$f(x)$ & Probability density function of $x$ \\
\hline$f_{T}(y)$ & Probability density function of storm surges \\
\hline$f_{T}(\zeta-y)$ & probability density function of tides \\
\hline$g_{i}$ & Phase lag for constituent $i$ \\
\hline$\gamma_{\beta}$ & Reduction factor for an oblique wave attack \\
\hline$\gamma_{b}$ & Reduction factor for a berm \\
\hline$y_{f}$ & Reduction factor for slope roughness and porosity \\
\hline$\gamma_{h}$ & Reduction factor for a shallow foreshore \\
\hline$\gamma_{s}$ & Adjustment factor for scale effects \\
\hline$H$ & Wave height \\
\hline$H_{0}{ }^{\prime}$ & Incident deep-water wave height \\
\hline$H_{\max }$ & Maximum wave height \\
\hline$H_{r m s}$ & Root mean square height \\
\hline$H_{s}$ & Significant wave height \\
\hline$L$ & Wave lengths \\
\hline$L_{\text {berm }}$ & Berm length \\
\hline$m$ & Number of storm surge intervals \\
\hline$m_{0}$ & Area under the spectral density function \\
\hline$m_{n}$ & Rank \\
\hline$\mu$ & Mean \\
\hline$N$ & Total number of data points \\
\hline$N_{D}$ & Design life \\
\hline$n$ & Number of tide intervals \\
\hline$k$ & Parameter of the distribution \\
\hline$p$ & Probability of exceedance \\
\hline$p_{1}$ & Hourly probability of exceedance \\
\hline$p_{e}$ & Encounter probability \\
\hline$p_{m}$ & Empirical probability of exceedance or plotting position \\
\hline
\end{tabular}




$\begin{array}{ll}p_{N} & \text { Sample probability of exceedance } \\ p_{y} & \text { Annual probability of exceedance } \\ Q & \text { Overtopping rate } \\ Q_{0}{ }^{*} & \text { Empirical coefficient } \\ R & \text { Number of extreme events } \\ R_{b} & \text { Dimensionless crest height } \\ R_{s m o o t h, l a b} & \text { Wave run-up on smooth and impermeable slopes } \\ R_{w} & \text { Wave run-up } \\ R_{u, 2 \%} & \text { Wave run-up level above the still water level which exceeds } 2 \% \\ \sigma_{i} & \text { of the incoming waves } \\ \varsigma & \text { Angular speed of constituent } i \\ T & \text { Standard deviation } \\ T_{p} & \text { Wave period } \\ T_{R} & \text { Peak wave period } \\ \tau & \text { Return period } \\ \theta & \text { Storm length } \\ u_{i} & \text { Bottom slope in front of a structure } \\ V_{i} & \text { Nodal correction for constituent } i \\ u_{i} & \text { Equilibrium tidal phase at } t=0 \text { of constituent } i \\ \xi_{e q} & \text { Nodal correction for constituent } i \\ \xi_{o p} & \text { Equivalent breaker parameter for a slope with a berm. } \\ Y(t) & \text { Breaker parameter } \\ Z_{0}(t) & \text { Meteorologically induced level } \\ z & \text { Mean sea level } \\ \zeta(t) & \text { Extreme sea level } \\ & \text { Sea level }\end{array}$

